\title{
KUNST FÖRDERN
}

Zu den wichtigsten Zielen von Johann Gottlob von Quandt gehörte die Förderung der Künste. Dies tat er als Mäzen, der Kunst ankaufte und Künstler in ihrer Entwicklung unterstützte. Doch nicht nur die Förderung lebender, auch die Erinnerung an vergangene Künstler und Kunstepochen standen bei ihm im Vordergrund. Dementsprechend können seine Aktivitäten für die Alten Meister als Förderung eines Verständnisses für die Künste generell bezeichnet werden. Denn aus der Kenntnis der Vergangenheit wollte Quandt einen Gewinn für die Gegenwart ziehen. Adrian Ludwig Richters Die Überfahrt am Schreckenstein vereint durch seine das Alte und Neue verbindende Metaphorik der Figurengruppe auf dem Lebensboot dieses Verständnis eines tiefen Zusammenhangs aller Zeiten. Das Bild befand sich in Quandts Besitz und Richter gehörte zu denjenigen Künstlern, die Quandt über viele Jahre hinweg förderte (Abb. 10).

Mit den anfangs des 19. Jahrhunderts immer wichtigeren bürgerlichen Vereinen boten sich ihm ganz neue Möglichkeiten der Kunstförderung, denn diese Institutionen hatten Breitenwirkung. Er konnte dadurch seine Ansichten über Kunst besser vermitteln und engagierte sich entsprechend im neu gegründeten Königlichen Altertumsverein und im Kunstverein, dem er mehrere Jahre vorstand. Hier zeichnete sich eine besondere Vorliebe für »höhere Aufgaben« ab.' Besonders die Historienmalerei war hierfür prädestiniert. Doch auch andere Bildgattungen waren, sofern sie seinen Ansprüchen genügten, förderungswürdig. Diesen Aspekten von Quandts Kunstförderung wird im ersten Teil dieser Arbeit nachgegangen. 


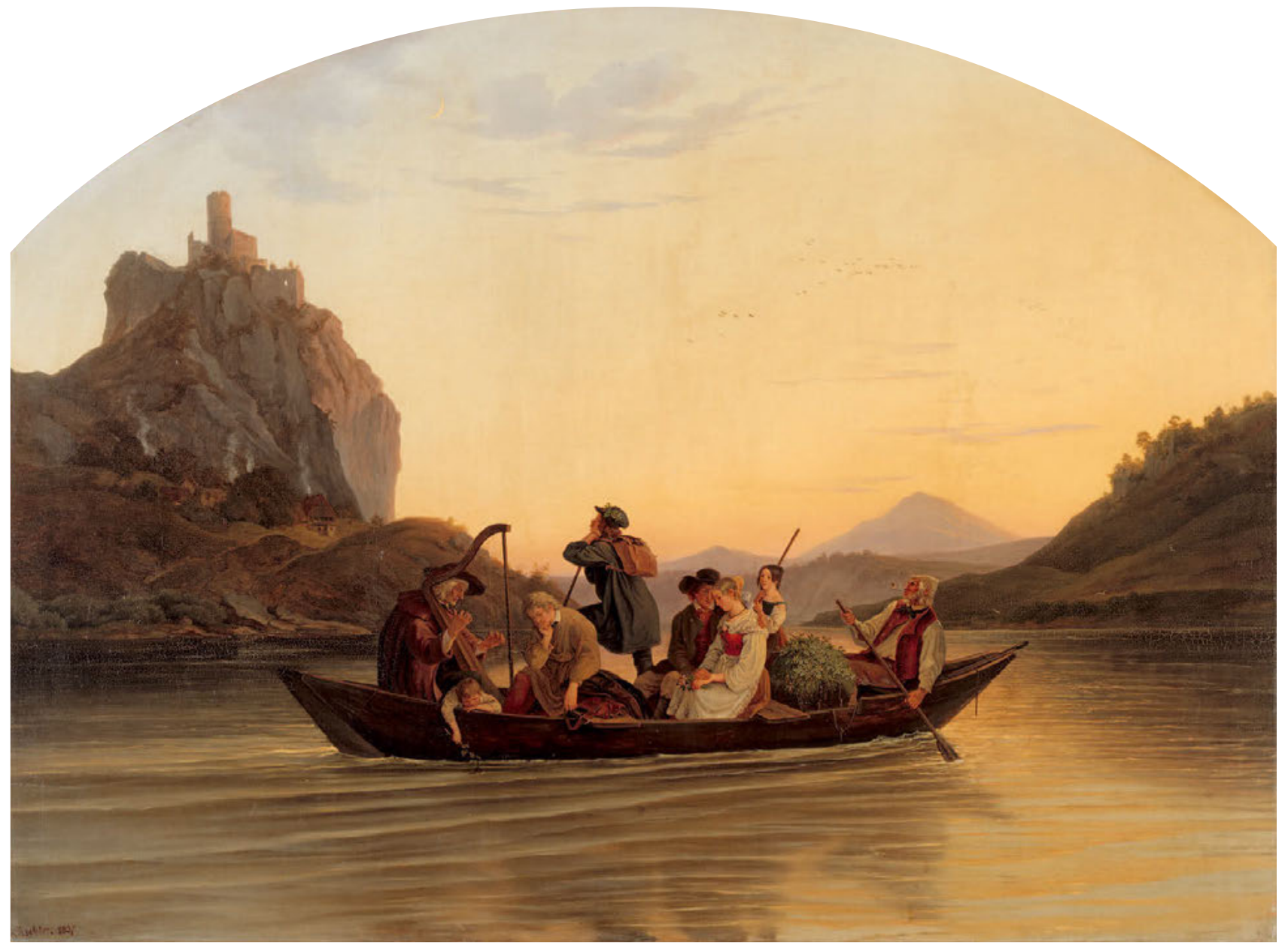

10 Adrian Ludwig Richter, Die Überfahrt am Schreckenstein, 1837, Öl auf Leinwand, 116,5 × 156,5 cm, Dresden, SKD, Albertinum | Galerie Neue Meister, Gal.-Nr. 2229 


\section{NEUE DEUTSCHE MALEREI: Fördern durch Ankäufe}

\section{Die Verantwortung des Kunstfreundes als Staatsbürger}

Johann Gottlob von Quandt sah es als »die Pflicht $[\ldots]$ aller begüterter Landsleute « an, den Künstlern in ihrem Schaffen zur Seite zu stehen - nicht durch Geld, sondern durch Aufträge, »sie durch Bestellungen zu beschäftigen, welche ihren Anlagen angemessen sind (Abb. 11). ${ }^{2}$ Dadurch würde dem Wohl und Erfolg der Gesellschaft gedient. ${ }^{3}$ Diese Haltung entstammt seiner Vorstellung von Gesellschaft, Kunst und Geschichte. Quandt glaubte, dass die zeitgenössische Kunst vom bürgerlichen Alltag abgetrennt war. Er wünschte sich eine Verbindung von Kunst und Arbeit. In der Schrift Über die Stellung der bildenden Künste im Staate, die 1826 als Zusatz zu seinem Entwurf zu einer Geschichte der Kupferstecherkunst erschienen war, beschrieb er sein Ideal. ${ }^{4}$ Nicht Heeresstärke würde dem Staat zum Erfolg verhelfen, sondern die Werktätigkeit des Volkes. Der Auftrag des Staatsmannes sei es, diese zu kanalisieren. In Quandts Augen sollte Bildung die zentrale Rolle spielen. Dadurch würde ein bürgerlicher Kunstsinn erreicht werden, der zum Wohle des Staates gereichen würde: »Da herrscht aber wahre Kunstbildung des Volks, wo der Sinn für Schönheit al- ler Formung allgemein geweckt und verbreitet ist, so daß die Bildung des Geistes werkthätig wird und selbstbildend auftritt, die rohen Stoffe nach Zweck und mit Sinn zu gestalten, jedem Arbeiter nothwendig, ja es ihm unmöglich sein würde etwas Ungestaltetes oder Unzweckmäßiges hervorzubringen.« Dieser politischen Komponente von Kunst als Faktor für die Bildung der Staatsbürger blieb er bis zum Ende seines Lebens treu. ${ }^{5}$

Quandt maß der Kunst eine wichtige pädagogische Rolle in der Gesellschaft zu. Daraus folgerte er, dass Erfolg oder Misserfolg eines jeden politischen Gefüges an der Qualität des künstlerischen Schaffens abgelesen werden könne. Ausgehend von dieser Grundidee legte sich Quandt ein Geschichtskonstrukt zurecht, das von der Kontinuität einer vom menschlichen Geist durchdrungenen, die Zeiten überdauernden Idee ausgeht. »Wahre Geschichtserkenntnis ist nur das Erkennen einer Idee, welche sich in dem Zusammenhang aller und in den einzelnen Begebenheiten ausprägt, zu nennen, nicht aber das Aufzählen einzelner Begebenheiten nach einer Zeitfolge. $\ll^{6}$ Durch den Blick auf die Entwicklung der Kunst versuchte er den Fortlauf der Geschichte zu charakterisieren. Dort, wo er Verfall und Aufstieg der Kunst feststellte, fand auch derselbe Prozess im Staat
1 Jahresbericht des Sächsischen Kunstvereins für das Jahr 1828, in: HStADD, 12509 Sächsischer Kunstverein, Nr. 1, fol. 124V. Köhler 2002, S. 23. S. a. Kovalevski 2010, S. 20, Kat. Nr. B-C 2.

2 Quandt 1826 (1), S. 288-289. S. a. Maaz 1986, S. 31-32.

3 Quandt 1826 (1), S. 309-312. »Das was man Überfluß nennen könnte, wird in die Pulsadern des Gewerbslebens hinüberströmen, und schon darum für den, der mehr Einnahme hat als er zur Befriedigung der gewöhnlichen Lebensbedürfnisse braucht, aufhören Überfluß zu seyn, welcher Mißbilligung und Neid erregen könnte; denn indem er dadurch das geistige Bedürfniß, alles um sich zu verschönern, zu befriedigen sucht und den Besitz von Gegenständen, an welchen der sinnvolle Mensch sich erfreut, zu erlangen strebt, fördert, nährt, bildet er zugleich die nützlichsten Glieder des Staats. « Möglicherweise formuliert Quandt hier dezidiert gegen Passavant 1820, S. 6, der hier schreibt, der Einzelne könne nicht viel bewirken. Beide Autoren sehen ansonsten die gleichen Effekte im Verhältnis von Nation und Kunst. S. a. Schmitz/ Strobel 2001, S. XIII-XIV. Über Kunst als Selbstzweck siehe Quandt 1819, Bd. 1, S. 66-67; Quandt 1830 (1), S. 348-351.

4 Quandt 1826 (1), S. 295-312. Siehe auch Quandt 1854 (1) über den Staat in Anlehnung an Aristoteles.

5 Brief von Quandt an Unbekannt vom 22.2.1859, in: Leipzig, Universitätsbibliothek, Nachlass 261:6, Quandt, fol. 3V-4V: »Ich habe dargethan, daß ohne Erweckung u Entwicklung des Sinnes für das Schöne, welche uns durch Kunstwerke hervorgebracht werden können, das Volk auf einer niedern Stufe der Bildung stehn bleibt u darum die Künste, als Bildungsmittel des Volks, vom Staate gepflegt werden müssen.[...] Als ich jene Abhandlung für die const: Zeitung schrieb, dachte ich mich in die Stelle eines Abgeordneten, dessen Aufgabe es ausschließlich ist, alles auf das Wohl des Volks zu berechnen. Ich mußte die Gedankenfolge so ordnen, daß ich als oberstes Postulat das höchste Wohl des Volkes aufstellte. Das höchste Wohl des Volkes aber ist die geistige Bildung u die höchste Bildung die ästhetische Geistesbildung. Diesem Gedankenzusammenhange nach wird die Kunst an sich nicht als Zweck, sondern als Mittel der Volksbildung u diese zum höchsten Zweck des Staats gemacht.« Quandt bezieht sich hier auf einen Artikel, den er in der Sächsischen Constitutionellen Zeitung geschrieben hatte. Siehe Quandt 1857, S. 1133-1134.

6 Quandt 1826 (1), S. IX. S.a. Quandt 1839 (1), S. 1: »[...] die Geschichte [ist auch nicht mehr] ein bloses Aufzählen von Einzelnheiten, welche an und für sich betrachtet doch nichtig sind, so groß auch die Begebenheit für den Augenblick erscheint, und ihre Berichte über Vor- und Rückschritte in Wissenschaften, Künsten und Sitten sind nicht ein Wetterleuchten, wo Licht und Finsterniß wechseln; vielmehr zeigt sich Alles in einem Lebensverbande, in einem Pulsiren ohne Stillstand, als ein beseeltes Ganze[s], was nach vollem Bewusstseyn und Willen und in Erkenntniß und That sich darzuthun strebt.» 


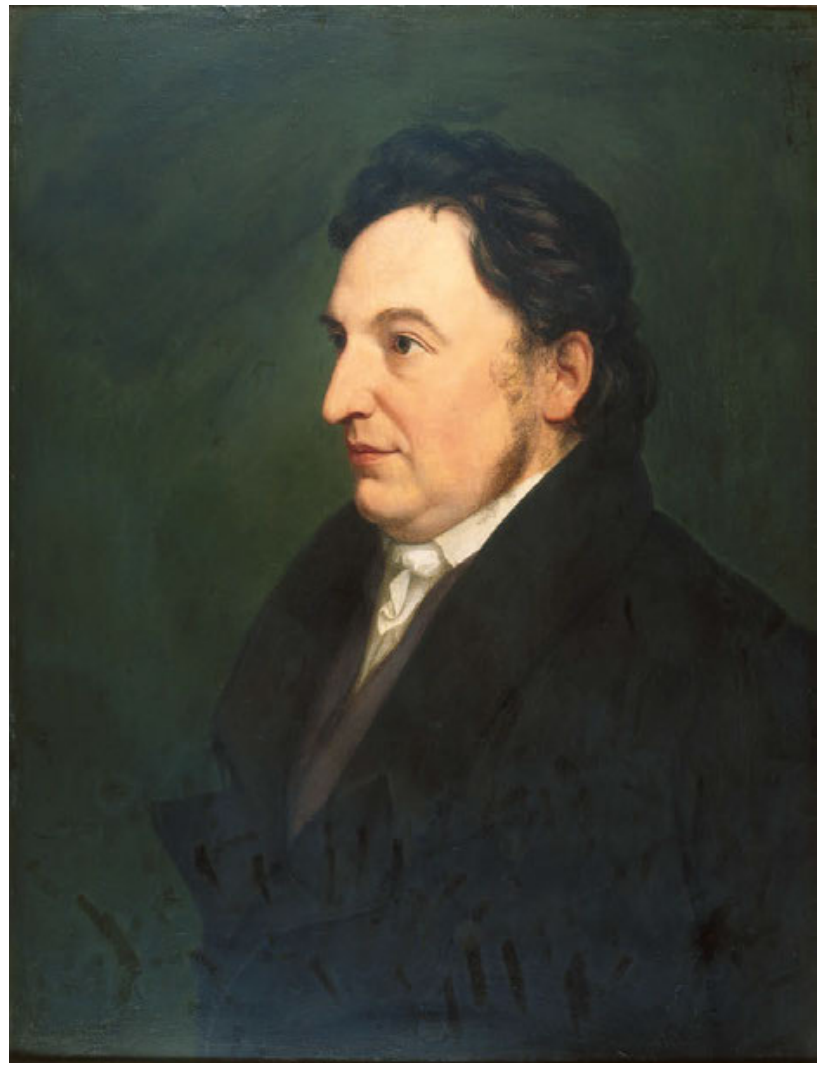

11 Carl Christian Vogel von Vogelstein, Bildnis Johann Gottlob von Quandt, 1824, Öl auf Holz, 63,5×53 cm, Dresden, Städtische Galerie, Inv.-Nr. 1978/k 385

statt. »Blicken wir auf die größten Momente der Geschichte, so sehen wir, daß die weisesten Herrscher dieses Mittels sich bedienten, die Gefahr drohenden Volkskräfte durch und auf eine heilbringende Thätigkeit und Entwickelung des Kunstsinns zu lenken $[. .$.$] Dahingegen ist der Fall der Künste immer dem der$ Staaten vorangegangen, und es ist dies nicht bloß als ein zufälliges Zusammentreffen anzusehen. «7

Dieser Verbindung der parallelen Entwicklung von Kunst und Politik liegt möglicherweise eine Idee zugrunde, die Johann Dominik Fiorillo in seiner Vorrede zur Geschichte der zeichnenden Künste, erschienen ab 1798, formuliert hatte. Der Künstler

7 Quandt 1826 (1), S. 304-306. Verfall und Aufstieg beschrieben in Quandt 1826 (1), ab S. 132 und ab S. 158 (Abhandlung über Deutschland im 17./18. Jh.), ab S. 203 (Abhandlung über die Italiener des 17. Jahrhunderts). S. a. Quandt 1839 (1), S. 1-11. Der Zusammenhang von Kunst und Staat bzw. Politik, wie inn Schiller und Schelling voraussetzten, hat bei diesen beiden Denkern genau die gegenteilige Konsequenz für den Fortgang der Geschichte: Während Schiller in Zeiten der Blüte der Kunst einen Tiefpunkt der Menschheit feststellte, sah Schelling Höhepunkte der Kunst bedingt durch Phasen geistiger Höhepunkte im blühenden Staat. Wenn auch bei den beiden das Resultat einer hohen Kunstepoche diametral entgegengesetzt ist, unterscheidet sich die Begründung vollständig von Quandt: Bei diesem ist Kunst die Bedingung für die Entwicklung eines Staates, bei Schiller und Schelling und Göttinger Professor spielte für die Frühromantiker und auch für Quandt eine wichtige Rolle. Dies zeigt sich im Porträt des Dresdener Kunstfreundes von Ferdinand Hartmann, auf dem der Dargestellte in seiner Bibliothek direkt neben Fiorillos Bänden sitzt (vgl. Abb. 1). In der Einleitung zu seinem umfassenden Werk erklärte der Verfasser in Abgrenzung zu älteren Autoren von Kunstgeschichten nämlich, er beabsichtige die politischen Begebenheiten in seine Betrachtungen mit einzubeziehen. ${ }^{8}$ Während Fiorillo in seinen Ausführungen viel detaillierter auf die einzelnen Künstler und ihre Kontexte eingeht, zeigt sich bei Quandt weniger ein Interesse an den historisch detaillierten Entwicklungslinien als an den Schlüssen, die er daraus für die Gegenwart ziehen kann.

Quandt stellte also fest, dass gute Staaten für Blütezeiten qualitativ gute Kunst benötigten. Er unterschied dabei Kunst, die eine geistige Idee durch die Anschauung vermittle, und Kunst, die allein wegen ihrer ausgefeilten Technik gerühmt werde. Natürlich zielte er auf eine geistig hochstehende Kunst $\mathrm{ab}$, die einer aufstrebenden Kultur dienen würde, während technische Raffinesse allein dem Künstler zu Erfolg verhelfe: »Wenn das wahre Kunstwerk es uns ganz vergessen macht, daß uns davon ein äußerer Raum trennt, daß es nicht ein Gedanke in uns ist, daß wir diesen Gedanken von außen durch Darstellung, durch künstlerische Mittel empfangen, daß Darstellung und Gedanke jedes für sich betrachtet werden kann, so mahnt ein Gemälde, Kupferstich oder anderes künstlerisches Werk, welches kein wahres Kunstwerk [ist], wo der geistige Verstand äußerst gering ist, zuerst an das Verdienst dessen, der es gemacht hat $[. .$.$] .« Nur der große Künstler könne einen guten Gedanken$ in einem Kunstwerk aufgehen lassen, wohingegen der gemeine Künstler sich durch ausgefeilte Technik und Nachahmung anderer Künstler oder der Natur um Verdienst beim Publikum bemühe. Dabei würde die Person, und nicht die Idee, die der Künstler durch das Kunstwerk aufzeige, bewundert. ${ }^{9}$

Hier wird erkennbar, dass Quandts Kunstgeschichte vor allem ein Ziel hatte: Die historische Kontextualisierung sollte aufzeigen, in welchem Verhältnis ein Kunstwerk zu einer geistigen Wahrheit stand, nach welcher sich eine Gesellschaft richten

sind es Staat und Gesellschaft, die die Qualität der Kunst bedingen. Freilich muss diese Kunst bei Quandt vom Staatsmann durch Bildung gefördert werden. Vgl. Schiller 2005, S. 40-41; Schelling 2004, S. 92-93; Passavant 1820, S. 5-6. S. a. Schlink 2002 [1997], S. 8-10; Karge 1998, S. 150-152 zum politischen Verständnis von Kunstgeschichte bei Carl Schnaase und Jacob Burckhardt.

8 Fiorillo 1997 [1798], Bd. 1, Vorrede, S. XII: »Auf die politische Geschichte, die doch einen so wichtigen Einfluß auf die Künste hat, daß zum Beyspiel viele glänzende Kunstepochen von der Regierung eines Fürsten den Namen erhalten haben, wird dabey meistens gar keine Rücksicht genommen.« Ebd., S. XVIII: »Die Rücksicht auf die politische Geschichte habe ich mir immer gegenwärtig erhalten.«

9 Quandt 1826 (1), S.68-69. 
sollte. $^{10}$ Konsequent forderte er deshalb Kunstakademien, die nicht die Nachahmung von Stilidealen propagierten, sondern »bloß das Positive und rein Wissenschaftliche der Kunst « vermittelten. Manier - also die Nachahmung eines Meisters - sei »todte Form«. Die Forderung an die Kunstschulen lautete, nur tatsächlich Erlernbares zu lehren, nicht aber Stil und Geschmack, die sich, je nach Mode und geographischem Gebiet, unterschieden. ${ }^{11}$ Das »Ideelle«, das dem Geist des Künstlers entspränge, dürfe nicht durch die Ausbildung gebremst werden. Im Gegenteil solle »der Lehrer nie auf den Schüler einwirken, sondern bloß aus ihm heraus entwickeln«. Auf dem Fundament einer Basis-Ausbildung solle der Lehrer seinem Schüler nur noch als Ratgeber beistehen. Durch Kenntnis der Geschichte, Mythologie, Logik und Ästhetik würde die Phantasie angeregt. ${ }^{12}$ Damit wäre der angehende Künstler befähigt, die von Quandt geforderte Überführung einer im Verstand geborenen Idee in das sinnlich wahrnehmbare, intellektuell aufgeladene Kunstwerk vorzunehmen. ${ }^{13}$ Der Künstler übernähme so seine zentrale Rolle in der Gesellschaft, wie er es noch wenige Monate vor seinem Tod 1859 formulierte: »Die Künstler müssen sich als Glieder einer Organisation betrachten, in der kein Theil um seiner selbst willen da ist, sondern, wie schon oft gesagt, jeder Einzelne ein integrierender Theil des Ganzen seÿn muß. In diesem Zusammenhange nehmen die Künstler eine sehr ehrenvolle Stellung ein, da sie die Beförder [er] einer hohen Geistesbildung sind. Die Künstler können darin keine Demüthigung finden, daß von ihnen verlangt wird, sie sollen durch ihre Werke zum höchsten Wohl des Volkes beitragen. $\ll^{14}$

So wie Staatsleute und Künstler sollte auch der einzelne Bürger zu dieser Volksbildung beitragen. Gerade als reicher privilegierter Staatsbürger konnte dieser seinem Staat zu Prosperität verhelfen und »die wahre Entwickelung der intellectuellen Kräfte « und damit »wahre Cultur befördern: $:^{15} »$ Der wahrhaft kunstsinnige Reiche wird nichts um des Scheines willen thun, sondern um einen wesentlich geistigen Genuß sich zu verschaffen und den Kunstfleiß zu fördern. $\ll^{16}$ Quandt definierte dem-

10 Kat. Quandt 1853, S. 2; S. a. Quandt 1826 (1), S. 132. S. a. Weddigen 2008 , S. 213-216; Locher 2001, S. 43-44

11 Quandt 1826 (1), S. 266-268, 273-274; Quandt 1824, S. 365. Erstaunlich aufgeschlossen fordert Quandt, dass die Anfänger bei guten Lehrern unterrichtet werden sollten. Ein Anciennitätsprinzip könne bei der Klassenaufteilung eingehalten werden, nicht aber, dass die besten Lehrer nur die ältesten Schüler betreuten; Quandt 1826 (1), S. 278-279. Die Lehrer sollten nicht Änderungen im Stil der Schüler bewerten, sondern nur Fehler; ebd., S. 283. S. a. Marx 2014 (1), S. 103.

12 Quandt 1826 (1), S. 284, 287-288.

13 Quandt 1830 (1), S. 295-301.

14 Brief von Quandt an Unbekannt vom 22.2.1859, in: Leipzig, Universitätsbibliothek, Nachlass 261:6, Quandt, fol. 4V-5r.

15 Quandt 1826 (1), S. 299-304, hier S. 303: »Die wahre Cultur muß so in den Menschen übergegangen seyn, daß man an seinen Werken es erkennt und in seinem Leben es wahrnimmt. Nicht bloß als eine Beimischung, als eine einzelne erlernte Kenntniß, oder erworbene Geschick- entsprechend seine eigene Rolle im Staatsgefüge und rechtfertigte seine eigene Kunstsammlung und Kunstförderung mit der Bildung eines allgemeinen Kunstsinns, der dem Wohl des Landes und seines Volkes diente.

\section{Förderungswürdige Höhepunkte der Kunst}

Welche Kunst Quandt fördern wollte, hing mit seiner spezifischen Vorstellung von Kunstgeschichte zusammen. Dabei handelt es sich um ein zyklisches System einer Entwicklungsgeschichte, das er schon früh formuliert hatte. Dieses erinnert stark an Hegels ab 1817 formulierte Geschichte der Kunst. Der Berliner Philosoph unterschied in seinen Vorlesungen über die Ästhetik Phasen symbolischer, klassischer und romantischer Kunstformen, die er in der Menschheitsgeschichte beobachtete. Quandt schrieb äquivalent: »Wenn der Naturkundige aus Versteinerungen, Gebirgstrümmern und dem Lebenden auf die Bildungsgeschichte der Natur schließt, mehrere wechselnde und wiederkehrende Epochen unterscheidet, welche wie Pulsschläge der Welt anzusehen sind, so schließt der Kunstverständige aus den überlieferten Werken der Vorzeit auf die Geschichte der Menschheit. $\ll^{17}$ Diesem Prinzip blieb er Zeit seines Lebens treu und wiederholte es immer wieder in Aufsätzen, Rezensionen und Briefen: Die Kunstgeschichte wiederspiegelt die Geschichte der Menschheit, vor allem der vernünftig denkenden Menschheit. Zu fördern war also diejenige Kunst, welche die Menschen zu Blütezeiten gebracht hat und weiterhin bringen würde.

In seinem Aufsatz über einen Fund einiger Gemälde Alter Meister in Leipzig im Jahr 1815 formulierte er sein zyklisches Geschichtsbild genauer: ${ }^{18}$ Zu Urzeiten lebten die Urmenschen in einem Zustand »höherer Intuition«. Sie befanden sich in einer Einheit von Göttlichkeit, Natur und Dasein. Die Menschen begannen, die sie umgebende Welt anzuschauen. Hieraus entsprangen die Ideen. Es fand eine Entwicklung vom göttlich-

lichkeit, sondern als wahre Entwickelung der intellectuellen Kräfte erscheint die Kunstbildung des Volkes, und ist dann wahre Cultur.« Das Argument erinnert an Schiller: »Alle Verbesserung im politischen soll von Veredelung des Charakters ausgehen. [...] Man müßte also zu diesem Zwecke ein Werkzeug aufsuchen, welches der Staat nicht hergiebt [...]. Dieses Werkzeug ist die schöne Kunst.« Schiller 2005, S. 33, 90-95. 16 Quandt 1826 (1), S. 309.

17 Quandt 1815, Sp. 961. Der Zusammenhang mit Hegel müsste noch ausgearbeitet werden. Quandt beanspruchte mehrmals, einige zentrale Gedanken von Hegels Ästhetik einige Jahre vor diesem formuliert zu haben; siehe Brief von Quandt an Julius Schnorr vom 2.12.1843, in: SLUB, Mscr. Dresd. n Inv. 15, Bd. 31, fol. 234V. Ebenso Quandt 1844 (1), S. 141. Zur Geschichte der Kunst bei Hegel aktuell Zirfas 2016, S. 131133. S. a. Ernst Müller, »Romantisch/Romantik«, in: ÄGB 2010, Bd. 5 , S. $315-416$, S. 330 .

18 Quandt 1815, Sp. 961-1006. S. a. Quandt 1830-1833, Bd. 3, S. 337-348. Zum Gemäldefund siehe weiter unten. 
allgemeinen zum mannigfaltig-individuellen statt. Das »Ideale« strebte zum »Realen«, die Idee wurde zum Bild, der Wille zur Tat. In der Folge entstand die Sprache als »hörbares Bild« und die Hieroglyphe als »sichtbarer Gedanke« und am Ende dieser Entwicklung die bildende Kunst. Sie wurde zur Vermittlerin zwischen Natur und Begriff. Doch das Betrachten und Erforschen zahlreicher Einzelheiten entfernte die Menschen vor der Anschauung des Göttlichen und Allgemeinen. Die Kunst stellte daher nur äußere Wahrnehmungen der Natur oder der Geschichte dar. Sie war zum Realismus geworden. ${ }^{19}$

Dann »trat Christus unter die Menschen, und es begann eine neue Zeit. « $^{20}$ Der Glaube, die Gewissheit des Göttlichen in der Natur und der Blick in das eigene Innere kehrten zurück. Die frühe christliche Kunst war demnach zuerst Hieroglyphe und Symbol. Erst mit der Zeit und mit den wachsenden Erfahrungen des Christentums entstand Stoff für Geschichten und für »eigentliche Kunstgebilde«. Diese Kunst war von innen geprägt: »Es war die Liebe, der Glaube, die Demuth, das siegende Dulden, das Mitleid, der selige Schmerz und die himmlische Freude, einzelne Tugenden, welche im Bilde sich anzuschauen strebten. $\ll^{21}$ Zuerst wurden Charakterbilder wie die Mater dolorosa oder der Ecce homo, die nicht handelnd waren, erschaffen. ${ }^{22}$ Es war dies nicht ein Mangel an Kunstfertigkeit, sondern innere Überzeugung und Ablehnung der Täuschung durch künstliche Mittel. Das eigentlich Historische, also dargestellte Handlung, welche die Figuren im Bild miteinander in Verbindung brachte, war anfänglich rein zufällig. Erst mit der Darstellung von Verkündigungen, Grablegungen oder Mariengeschichten seien die ersten Historiengemälde gemalt worden. ${ }^{23}$

19 Paraphrase und Zitate nach Quandt 1815, Sp. 961-962.

20 Quandt 1815. Sp. 962-963: „Da der Glaube nicht einzelne Vernunftbegriffe aufstellt, die unendliche Liebe nicht einzelne Objekte umfaßt und die Beschauung des Göttlichen, reales und ideales in einen Akt des Bewußtseyns auflöst, so mußte nothwendig die bildende Kunst ganz verschwinden, da sie nur das Einzelne, Bedingte, darzustellen vermag. Die frühesten Denkmale aus der christlichen Zeit, welche man mir als Einwürfe gegen meine Behauptung anführen könnte, sind nicht als Werke der reinen christlichen Kunst anzusehen, indem bei allen mythologische Ideen eingemischt sind."

21 Quandt 1815, Sp. 963.

22 Quandt 1815, Sp. 963: »Die Kunst stellte diese Personen nicht in Handlung dar, sondern als Anschauungen, nicht als Menschen im bewegten Leben, sondern als Wesen, welche auf jener Höhe stehen, wo der Geist über seinem Daseyn schwebt und in seinen Schmerzen und Freuden sich anschaut."

23 Die ersten von Cimabue in Italien, sehr frühe auch in den Niederlanden. In Deutschland seien es Michel Wolgemut und Martin Schongauer gewesen. Ebd., Sp. 964.

24 Ebd., Sp. 972: »Die rein historischen Bilder entfernten die Kunst immer weiter von den höhern allgemeinen Anschauungen, wurden immer individualisirender und nahten sich immer mehr der Wirklichkeit."

25 Brief von Quandt an Karl August Böttiger vom 12.7.1815, in: SLUB, Mscr. Dresd. H 37, Bd. 151 (40), Nr. 3, abgedruckt in: Kat. Leipzig 1997, S. 157, Dokument 8.
In der Folge habe gegen Ende des Mittelalters erneut eine Entwicklung hin zum Realistischen stattgefunden. ${ }^{24}$ Bei Albrecht Dürer noch in gesundem Maß als Sinn für die Naturschönheiten hätten die Künstler immer häufiger nur noch Naturgegenstände wegen des Reizes nachgebildet. Die Kunst spaltete sich in Gattungen. Mit der Zeit sei sie vor allem »zur Darstellung von äußeren Wahrnehmungen ausgeartet $\ll .25$ So ging die Anschauung des Göttlichen, wie sie bei den Menschen des Mittelalters noch ursprünglich gewesen war, verloren und die Verbindung von Kunst, Religion und Gesellschaft wurde aufgelöst. ${ }^{26}$ Hiermit kritisierte Quandt vor allem die Kunst der Manieristen mit ihren vermeintlich nachahmenden Gemälden der großen Renaissancekünstler und diejenige des Barocks mit ihren naturnahen Stillleben, illusionistischen Perspektiven und genrehaften Szenen. ${ }^{27}$ Aber auch die in seinen Augen kalte Nachahmung der Antike durch die Klassizisten, die deren »Geist« doch nie erreichten, war ihm ein Dorn im Auge. ${ }^{28}$

Im Sinn seines entwicklungsgeschichtlichen Systems der Kunstgeschichte musste Quandt annehmen, dass nach dem Niedergang der Kunst in der Neuzeit ein erneuter Aufstieg zu erwarten war. So formulierte er in dem Aufsatz über die Leipziger Gemälde, es sei zu »erwarten, welche große Weltbegebenheit die Kunst, indem sie das ganze Menschengeschlecht umgestaltet, zur ursprünglichen Würde zurückführen wird, nachdem die Kunst zum zweiten Mal ihrem göttlichen Ursprunge abtrünnig geworden ist. $\ll^{29}$ In seinem Bericht über die erste Italienreise von 1813, der 1819 erschien, hielt er fest, dass sich dieser neuerliche Höhepunkt anbahne. Mit dem napoleonischen Kunstraub in Rom hätten sich die Künstler von der klassizistischen Nach-

26 »Das Interesse an Kunst glich aber nicht mehr dem in der Vorzeit, [...], wo Werke der Kunst noch Gegenstände religiöser und patriotischer Gesinnungen waren.« Quandt 1834 (1), S. IX-X. S. a. Grewe 2017, S. 9697 zum ähnlichen Geschichtsbild von Friedrich Overbeck.

27 Beispielsweise Annibale Caracci: »Heute war ich im Palaste Farnese, um die Gallerie des Annibal Caracci zu sehen. Was Verstand, Kenntniß und Fertigkeit vermag, ist hier geleistet, aber auch recht fühlbar, daß diese nicht ausreichen, um wahre Kunstwerke hervorzubringen. Alle diese Compositionen sind aus Figuren zusammengesetzt, welche in Raphaels, Michel Angelo's und anderer großer Meister Werken vorkommen, allen hier stehen sie ohne Leben und Wärme, es sind entseelte Körper, kalte Nachbildungen. Carach [sic!] konnte nicht glauben, daß der Raub, den er an so berühmten Vorgängern verübte, unbemerkt bleiben würde. Es ist zu vermuthen, daß er sich schmeichelte, jene zu verbessern, und zu übertreffen. « Quandt 1819, Bd. 2, S. 161.

28 Quandt 1819, Bd. 2, S. 164-165: »Zu Folge der Versicherung aller Kenner und Künstler, können wir nur die Antike in der Antike ganz kennen und würdigen lernen. [...] Man hatte vorher in der Kunst nur die Antike nachzuahmen gesucht, und sie doch stets verfehlt, weil der neuere Künstler unter andern Verhältnissen lebt, als die der antiken Welt waren. [...] Es lebte nicht der Geist der antiken Welt in den Nachbildungen."

29 Quandt 1815, Sp. 973. 
ahmung der Antiken abgewendet und den mittelalterlichen und vor-raffaelischen Künstlern des Due- bis Quattrocento zugewendet: »Die Künstler verglichen die Werke [...] des Raphaelischen Mengs, der die Antiken auf das fleißigste studirt hatte, mit denen Alter Meister, und sahen den himmelweiten Unterschied zwischen den altchristlichen und modernantiken Werken ein. Denn jene erschienen wirklich ganz himmlisch und höhere

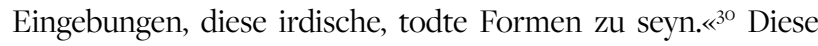
Wiederentdeckung, die zu einer neuen Kunst führen würde, sei von deutschen Künstlern in Italien ausgegangen. Die Kunst sei also auf dem Weg, nicht mehr »lieblose Handwerksmäßigkeit« zu sein, sondern das Produkt »liebevollen Fleißes, in welchen Tiefe und Reichthum der Phantasie und des Gefühls sich ergießt«. Wirklich erfolgreich würde sie dann werden, wenn der »Kunstgeist der ältern Schule« ausgebildet würde. ${ }^{31}$

Mit seiner Entwicklungsgeschichte versuchte Quandt darzulegen, dass die Menschheit und ihre Kunst Phasen des Aufschwungs, der Höhepunkte und des Niedergangs unterworfen seien. ${ }^{2}$ Diese Vorstellung gehörte bereits in Giorgio Vasaris Künstlerviten - einer wichtigen Quelle Quandts - zu den bedeutenden Grundgedanken und war auch bei neueren Kunstgeschichten, wie derjenigen Winckelmanns, Fiorillos oder auch bei Goethe und Meyer in den Propyläen, ein gängiger Topos. ${ }^{33}$ Selbst Johann David Passavant bediente sich in seiner Verteidigungsschrift über die Vorbilder der Nazarener dieses entwicklungsgeschichtlichen Schemas. ${ }^{34}$ Gleichzeitig war es Quandt bewusst, dass die ursprüngliche Wechselbeziehung von Kunst, Religion und Gesellschaft, deren letzten Höhepunkt er im Hoch- und Spätmittelalter verortete, in seiner Zeit nicht reaktiviert werden konnte. ${ }^{5}$ Die Lösung schien ihm in den Zielen der nazarenischen Künstler in Rom zu liegen. Ihre religiösen Motive vermochten Themen wie Ehre, Treue oder Liebe aufzugreifen, die den Betrachter zu weitreichenden Gedanken anregten und somit eine Wendung zum Inneren und zur Gefühlswelt, gleichsam eine gelehrte, aber emphatische Bildbetrachtung befördern würde. ${ }^{36}$ Hier klingt Schellings Diktum an, man solle die christliche Kunst für die philosophische

30 Quandt 1819, Bd. 2, S. 163-175, hier S. 165.

31 Quandt 1819, S. 168.

32 Quandt 1815, Sp. 973: »Wir erkennen hieraus den Kreislauf der Kunst, dies Ausströmen und Zusammenfließen, sich Theilen und Vereinigen, Ebben und Fluthen wo Leben sich kund thut [...]. Nach diesen allgemeinen Bemerkungen über die Bildungsgeschichte der Kunst, wird es leicht Kunstwerke chronologisch zu ordnen und in ein System zu bringen; wir wollen es kürzlich an den in Leipzig aufgefundenen alten Gemälden versuchen.« S. a. Grewe 2006, S. 403.

33 Vgl. Vasari 2004, »Vorrede der Lebensbeschreibungen«, »Vorrede des zweiten Teils« und »Vorrede des dritten Teils«, S. 47-74, 77-90, 91-104 sowie die dazu gehörigen Einleitungen von Matteo Burioni, ebd., S. 43-45, 75-76, 89-90; Winckelmann 1764, S. X; MKL 1999, S. 470-473; Fiorillo 1997 [1798], S. XVI-XVII, XX; Einleitung, in: Meyer/Goethe
Betrachtung in den Blick nehmen, weil sie das Unendliche in sich trage. ${ }^{37}$ Diese Verbindung von Denken und Betrachten, von Kunstgeschichte und Vernunftgeschichte gehörte zu Quandts Lebensthemen. In der Kunst suchte er daher nach allgemeinen Begriffen, die sich in Tugendmotiven wie dem Mitleid oder der Liebe manifestieren konnten. Die Kunst der Lukasbrüder und ihrer Nachfolger in Rom schien hierfür prädestiniert zu sein. Doch weil er nach allgemeinen Begriffen fahndete, lagen auch andere Künstler, Themen und Gattungen immerzu im Bereich seines Interesses.

Quandts Entwicklungsgeschichte atmet in vielen Aspekten das ein, was später mit dem oszillierenden Begriff der Romantik umschrieben wurde und bereits in seiner Zeit zum sinnentleerten Begriff mit zahlreichen Bedeutungen geworden war. Es zeigt sich darin die Rezeption zeitgenössischer Positionen aus Philosophie, Literatur und Kunst. Besonders der Wille zur Vereinheitlichung in sinngemäßen Formulierungen wie der Einheit von Göttlichkeit, Natur und Existenz oder von Kunst, Religion und Gesellschaft, dem Bild als Mittler zwischen Natur und Begriff, dem Blick ins Innere und der Göttlichkeit im Äußerlichen sind typisch für die verschiedenen Denkströmungen, die später unter dem Begriff des Romantischen subsumiert wurden. Dabei ist weniger der literarhistorische Epochenbegriff einer modern-romantischen Literatur im Gegensatz zu einer antikklassischen gemeint, wie ihn Friedrich Schlegel formuliert hat - und der später zum unpassenden Gegensatz zwischen Klassizismus und Romantik aufgebaut wurde. ${ }^{3}$ Vielmehr zeigt sich hier eine ausgleichende »Romantik«, welche die Poesie als eine über die Literatur hinaus in alle Künste eingreifende Kunstform begreift. Friedrich Schlegel schrieb, die romantische Poesie sei »eine progressive Universalpoesie. Ihre Bestimmung ist nicht bloß, alle getrennte Gattungen der Poesie wieder zu vereinigen, und die Poesie mit der Philosophie und Rhetorik in Berührung zu setzen. Sie will, und soll auch Poesie und Prosa, Genialität und Kritik, Kunstpoesie und Naturpoesie bald mischen, bald verschmelzen.«In den Worten seines Bruders August Wilhelm Schlegel war die Poesie »dasselbe, wodurch der menschliche

1798/99, S. XXXI-XXXIII. S.a. Prange 2004, S. 23-25; Locher 2001,

S. 40-41; Gethmann-Siefert 1995, S. 208.

34 Passavant 1820, S. 1-20. S. a. Schröter 1990, S. 345-347; Thimann 2014 S. 48-52; Ders. 2013, S. 314-324. Locher 2010, S. 71 weist das Schema auch in Franz Kuglers Handbuch der Kunstgeschichte nach.

35 Siehe hierzu Quandt 1819, S. 163-180. S. a. Passavant 1820, S. 2-5.

36 »Und da alle Bildung von innen ausgehet, die Nothwendigkeit, einem idealen Ziele sich zu nähern, im Geiste liegt, so ging das Streben nach Vervollkommnung der Kunst aus dem Innern hervor.« Quandt 1819, Bd. 2, S. 171.

37 Gethmann-Siefert 1995, S. 186-187.

38 Ernst Müller, »Romantisch/Romantik«, in: ÄGB 2010, Bd. 5, S. 315-16, 323-332. S. a. Beyer 2011, S. 7-16 
Geist überhaupt zur Besinnung gelangt.« $\ll^{39}$ Quandt betonte dies selber immer wieder und seine Entwicklungsgeschichte der Kunst zeigt, dass sich in den Augen der so genannten Romantiker immer wieder »romantische Zeiten« ereignet haben, mithin Romantik ein »überzeitlicher Begriff ist..$^{40}$ Wie manch anderer auch gehörte Quandt zu denjenigen Zeitgenossen, die nach Verbindungen zwischen Vergangenem und Gegenwärtigem suchten. ${ }^{11}$

In diesem Sinn machte er sich auf, zeitgenössische Kunst zu fördern. Was seinem Denken entsprach, das erwarb er für die Sammlung im Haus an der Klostergasse (Abb. 12). Dort waren die großen Namen der Maler seiner Zeit vertreten. In seinen Briefen und Artikeln lassen sich Begeisterung und Kritik für diese Bilder nachvollziehen. Dass er einer der wenigen konsequenten Mäzene seiner Zeitgenossen war, zeigt sich in einer Notiz an Schnorr vom Januar 1821 über die Leipziger Sammler: »Was die Stimmung unter hiesigen Kunstfreunden anbelangt, so ist diese immer noch die alte u nicht die beste, sie sind geneigt alte Bilder mit großen Kosten zu kaufen, begnügen sich darinn mit Mittelmäßigem u mögen nichts für das Emporkommen der neuern Kunst thun. So hat Carus u auch Speck, jeder seine Sammlung, sehr vermehrt, ohne daß dadurch etwas entschieden Gutes gethan wäre. « ${ }^{2}$ In gewissem Sinn sah sich Quandt mit seinen hehren Idealen selber als Teil dieser Entwicklung, die zu einem neuen Höhepunkt hinstrebte. Die Künstler trugen mit ihren Werken zur erhofften Blütezeit bei, Quandt nahm seine Rolle als Förderer, Mäzen und Käufer wahr.

Die Verbindung von Kunst, Gesellschaft und Religion erinnert in vielerlei Hinsicht an Aussagen, wie sie im Kontext der in Rom tätigen deutschen Künstlergruppe des Lukasbundes und ihrer Entourage, den sogenannten Nazarenern, anzutreffen sind. ${ }^{43}$ Quandts frühe Schriften deuten in eine Richtung, die eine Art Theorie der nazarenischen Kunst erahnen lässt. Sie reihen sich in ein Phänomen einer »Nazarener Kultur« ein, die Cordula Grewe als »eine Kultur der Manifeste« bezeichnet-

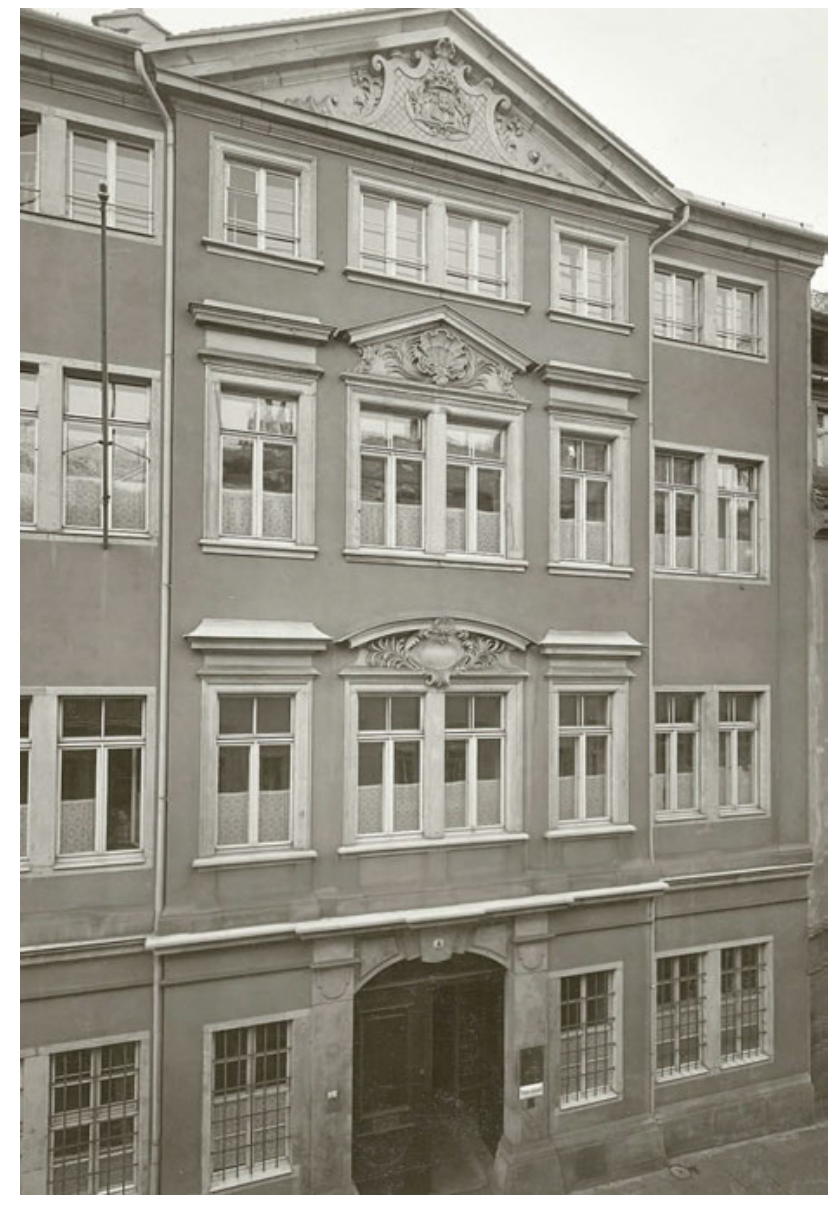

12 Das Haus von Johann Gottlob von Quandt an der Großen Klostergasse 4, Ansicht der Gassenseite, Foto: Walter Möbius, 19.11.1937

Manifeste, die in Briefen und Artikeln, Pamphleten und Kommentaren, vor allem aber in Allegorien und programmatischen Bildern freigesetzt worden seien. ${ }^{44}$ Der Kunstschriftsteller förderte die Nazarener nicht nur schriftlich, sondern gerade auch durch seine Ankäufe ebendieser modernen »Gedankenkunst«.45 Es stellt sich also über seine praktische Kunstförderung hinaus
39 Beide Zitate nach Ernst Müller, »Romantisch/Romantik«, in: ÄGB 2010, Bd. 5, S. 328. S. a. Joachimsthaler 2016, S. 23-36

40 Beyer 2011, S. 11-13, hier S. 11. Genauso wie es »Klassizismen«, also Rückbezüge auf die Antike, immer wieder gab, wenn auch hier nicht im Sinn eines Stil-, sondern eines geistesgeschichtlichen Begriffs. S.a. Wolf 2002, S. 17-19.

41 Hierbei ist explizit mehr gemeint als nur ein Betonen der Gemeinsamkeiten der sich im traditionellen Sinn der Epochenbezeichnung streitenden, sogenannten Klassikern und Romantikern über die Antike. Siehe dazu Beyer 2011, S. 22-23.

42 Brief vom 7.1.1821, in: SLUB, Mscr. Dresd. n Inv. 15, Bd. 31, fol. 57r. Mit »alten Werken« meint Quandt vor allem Niederländer des 17. Jahrhunderts. - Zu Quandts Förderung der Zeitgenossen: Immermann 1833, S. 282: »Imponirt uns in großen Gallerien die Machtfülle der Kunst, so zeigt sie sich dagegen im Privatbesitz vertraulicher mit dem schönen Menschengemüthe zusammenhangend, von dem sie doch immer ausgeht, und wohin sie ewig zurückstrebt. Dieser lebendige individuelle Bezug tritt am klarsten hervor, wenn der Sammler Zeitgenossen über seine Schwelle ladet. v. Quandt hat vorzügliche ältere Stücke, doch wandte er Vermögen und Eifer wenigstens mit gleichem Glücke auf Werke Jetztlebender.« Ebenso Böttiger 1822, S. 61: »Denn seine Gemäldesammlung hat es fast nur mit den gelungenen Leistungen lebender Künstler zu thun [...]. Gewiß, es wäre zu wünschen, daß gerade diese Art von Kunstliebhaberei von den Lieblingen Fortunens, die zugleich der Musenkunst hold sind, weit mehr geübt würde, als es zu geschehen pflegt.«

43 Hierzu kenntnisreich Grewe 2009, S.19-60. Zur begrifflichen Abgrenzung von Lukasbrüdern und Nazarenern siehe Grewe 2015, S. 4.

44 Grewe 2015, S. 24: »Nazarene culture was a culture of manifestoes, unleashed in letters and journal articles, pamphlets and commentaries, and, above all, allegories and programmatic images."

45 Grewe 2015, S. 1-15. Zu den nazarenischen, selbstreflexiven Denkbildern ebd., S. $73-89$. 
die Frage über das engere Verhältnis Quandts zu den Nazarenern. Dieser Frage wird in den nachfolgenden Unterkapiteln nachgegangen.

\section{Il capo dei nazareni: Quandt in Rom}

Schließt man von einigen Passagen in Quandts 1819 gedruckten Streifereien im Gebiete der Kunst, dem Bericht über seine erste Romreise von 1813, auf einen möglichen Startpunkt seiner Auseinandersetzung mit den Nazarenern, so erscheint dieser doch recht früh - nur drei Jahre nach der Ankunft der Lukasbrüder in Rom: »Dahingegen sprachen Raphaels und seiner Vorgänger Werke so eindringend zum Herzen, daß die Lebenden fühlten, daß diese vom Herzen kamen [...]. Die rührende Stimme des Gefühls, welche gleichsam mit dem Odem der Natur aus diesen alten Bildern spricht, belehrte die Künstler, daß es etwas Höheres, Allgemeineres, Ewiges im Menschen und außer ihm gäbe, wovon auch die Antike nur eine Strahlenbrechung sey [...] So gieng von Italien aus ein wiedererwachender Lenz der Kunst, und zwar waren es Deutsche, welche zuerst durch Wort und That die Herrlichkeit einer frühern Kunstperiode [...] verkündeten. $\ll^{46} \mathrm{Si}-$ cherlich hat die lange Redaktionsphase des Reiseberichts zu einigen gedanklichen Setzungen geführt, was das Fehlen von Namen der ersten Lukasbrüder erklären könnte. Gewiss aber zeigen die Streifereien Quandts Beschäftigung und gedankliche Vorbereitung zu seinem folgenden Rombesuch von 1819/20 auf. Hier nämlich trat seine Förderung zeitgenössischer deutscher Künstler und besonders der Nazarener erst in vollem Ausmaß zu Tage.

Als er mit seiner Frau anfangs Oktober 1819, nach einer Reise mit Stationen in München, Wien, Venedig und Florenz, in Rom eintraf, öffnete er sein Haus den deutschen Künstlern. ${ }^{47} \mathrm{Im}$ Tagebuch von Clara Bianca von Quandt ist von Teeabenden die
Rede, vom Weihnachtsfest 1819, von Liedern, die sie gesungen habe, oder vom gemeinsam mit den Künstlern gefeierten Hochzeitstag am 2. Juni 1820.48 Johann Gottlob organisierte Fackelführungen zu den Skulpturen im Vatikan. ${ }^{49}$ Er stellte den Künstlern seinen Wintermantel gegen ein kleines Entgelt für Gewandstudien zur Verfügung. Mit dem Beitrag richtete er einen Fonds ein, mit dem weitere Kleider für Draperiestudien gekauft wurden. ${ }^{5 \circ}$ Julius Schnorr von Carolsfeld äußerte sich mehrfach begeistert über das Kunstverständnis des Mäzens und seiner Frau: »Beide haben sich bei der römisch deutschen Künstlerschaft einen $\mathrm{Na}-$ men gemacht. Besonders wird Quandt, der sich den Künstlern durch seine Persönlichkeit noch mehr als durch seine Bestellungen lieb und wert machte, unvergesslich sein. « ${ }^{1}$

Auch wenn in seinem Gasthaus nicht nur nazarenische Künstler verkehrten, war Quandt in dem Jahr seines Romaufenthalts doch ein Dreh- und Angelpunkt für diese junge Kunstrichtung. ${ }^{22}$ In einer aussagekräftigen Briefpassage zeichnet sich $\mathrm{ab}$, wie er die Nazarener sah und wie er selber in mancher Augen gesehen wurde: »Fast alle jungen u ältern deutschen Künstler versammlen sich Abends beÿ mir u die Gegner der neuen Schule nennen mich scherzhafter Weise; il capo dei nazareni. Doch hat man von dieser Parthey im Ausland einen ganz falschen Begriff. Keines wegs zeichnen sie sich durch eine besondere Kleidung $\mathrm{u}$ in der Kunst durch Nachahmung der Alten aus, was vielleicht sonst mehr der Fall war. Nur ein junger Schwitzer [Schweizer] u Oberbeck (sic!) [Overbeck] tragen noch deutsche Röcke, denen es aber recht gut steht $\mathrm{u}$ vielleicht hat nur Rambou $[\mathrm{x}]$ sich so in Giottos Manier eingearbeitet, daß er davon nicht mehr laßen kann. Die Uebrigen haben von den alten Mustern blos das Beste, den Ernst u die Strenge behalten, und gleichen darinnen jenen vorzüglichen Alten Meistern in der Objectivität des Auffaßens u in der lebendigen, geistreichen u seelenvollen Charakteristik welche sie in ihre Bilder legen.«s3
46 Quandt 1819, Bd. 2, S. 166-167 und der ganze Absatz zum 12. Juli 1813 über einen Ausflug zu den Antiken im Vatikan; ebd., S. 163-180.

47 Zur Reiseroute siehe Quandts Brief an Christian Clodius vom 16.8.1819, in: SLUB, Mscr. Dresd. App. 204, Nr. 94. Zum Netzwerk siehe Brief von Quandt an Gustav Hänel (?) vom 15.1.1820, in: SLUB, Mscr. Dresd. App. 204, Nr. 97.

48 Bemmann 1925, S. 6. Auszüge des Tagebuchs in SLUB, Mscr. Dresd. n Inv. 77 I, 9, 164, 173. Zum Weihnachtsfest der Brief von Julius an Veit Schnorr vom 31.12.1819, in: SLUB, Mscr. Dresd. n Inv. 8, Bd. 1, fol. 161 r. S. a. Schnorr 1886, S. 158; Uhde 1875, S. 288. S. a. Neidhardt 1976, S. 235; Noack 1907, S. 179. Einige Lieder im »Lieder=Schatzkästlein der Frau Clara Bianca«, datiert »Rom. am Weihnachtsabend. 1819«, in: SLUB, Mscr. Dresd. n Inv. 15 Bd. 31, fol. 7-21.

49 Schnorr 1886, S. 170; S. a. Noack 1907, S. 125; Seidler 2003, S. 244: »Unbeschreiblich war der Eindruck, als einst Herr von Quandt nächtlicher Weile die unübersehbare Galerie der plastischen Bildwerke [in den vatikanischen Sammlungen - AR] durch Fackeln beleuchten ließ. Die Statuen schienen Leben zu athmen, so frappant wirkte die düsterrothe Gluth, der hin- und herschwankende Schatten [...].«
50 Brief von Julius an Veit Schnorr vom 22.2.1820, in: SLUB, Mscr. Dresd. $n$ Inv. 8, Bd. 1, fol. $164 \mathrm{~V}$.

51 Zitiert nach Bemmann 1925, S. 6 aus dem Tagebuch Schnorrs.

52 Der Begriff »Nazarener « und vielleicht gar der Spottname des »capo dei nazareni« geht wohl auf den Landschaftsmaler Johann Christian Reinhart zurück, der ebenfalls bei Quandt zu Besuch war. Reinharts Kritikpunkte erinnern an diejenigen, die Quandt widerlegt; Stolzenburg 2012, S. 83-84. S. a. Meyer/Goethe 1817 [1999], S. 116-125. Zur Einordnung der Sezession der Nazarener siehe Grewe 2015, S. 21-35.

53 Brief von Quandt an Gustav Hänel(?) in Leipzig, vom 15.1.1820, in: SLUB, Mscr. Dresd. App. 204, Nr. 97. Zur Einordnung des Zitats im erweiterten Kontext der Lukasbrüder siehe Grewe 2015, S. 213-216. Bei dem im Brief erwähnten Schweizer handelt es sich entweder um den Zürcher Maler und Bekannten von Louise Seidler, Johann Caspar Schinz, der 1825 Quandt in Dresden besuchte, oder um den Kupferstecher Samuel Amsler. Beide verkehrten laut dem Tagebuch von Clara Bianca von Quandt mit dem Ehepaar. Siehe ThULB, HSA, Aut. W. M. v. Goethe, Nr. 1166, J. C. Schinz an Louise Seidler, Dresden, o. Datum [1825], [S. 1-2]. S. a. Quandt 1820 (1), S. 262; Quandt 1817, S. 143. 


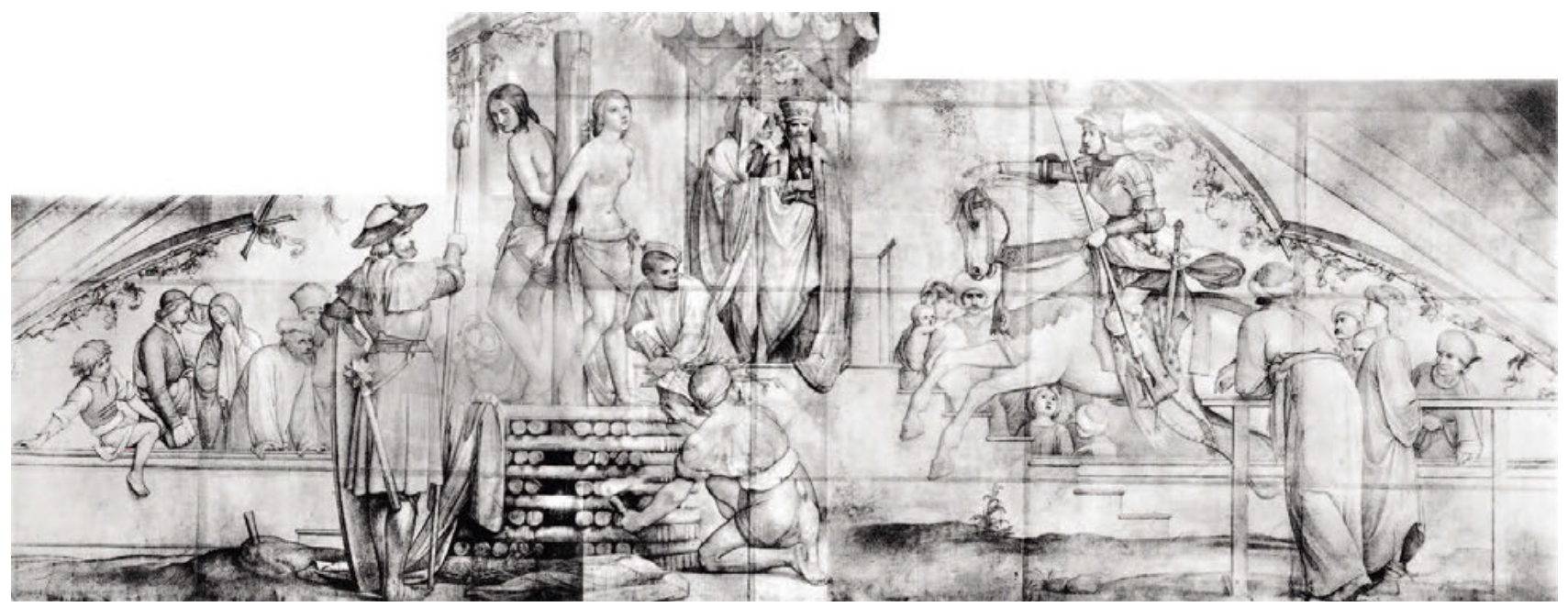

13 Johann Friedrich Overbeck, Sophronia und Olindo auf dem Scheiterhaufen, 1819, Schwarze Kreide, $210 \times 490 \mathrm{~cm}$, Leipzig, Museum der bildenden Künste, Inv.-Nr. KS 119

Quandt wehrte sich gegen das Klischee der unüberlegten Nachahmung Alter Meister bei den Nazarenern. Hiermit trat er nachträglich in die Diskussion über die Ausstellung deutscher Künstler im Römer Palazzo Caffarelli im Jahr 1819 ein, die er selber knapp nicht mehr miterlebt hatte. Der Hoffnungsträger der Nazarener, der österreichische Kaiser Franz I. von Habsburg, hatte Rom besucht und sollte der Förderer einer neuen deutschen Kunst werden. Er gab sich uninteressiert, ja ablehnend, es folgten vehemente Kritiken gegen die neue Kunstrichtung in Deutschland. ${ }^{54}$ Friedrich Schlegel war dagegen angetreten, hatte gegen den Hauptkritikpunkt der »Nachäffung« altitalienischer Meister in einem Aufsatz dezidiert Stellung bezogen, Johann David Passavant ein Büchlein über die Vorbilder der neudeutschen Künstler publiziert.55

Auch Quandt wollte die nazarenischen Bilder richtig und in einem tieferen Sinn verstanden wissen. Technik und Stil dienten in seinen Augen vielmehr der Aneignung der besten Aspekte vergangener Kunstepochen und sollten auch Vorbilder darin sein, Schlechtes zu unterlassen. ${ }^{56}$ Er glaubte, jedes Motiv verlange nach einem eigenen Stil und einer eigenen Technik: »Wir möchten fast behaupten, daß für jeden Gegenstand nicht

54 Grewe 2015, S. 48-49.

55 Quandt 1820 (1), S. 262: »Da dieß Jahr die deutschen Künstler keine gemeinsame Ausstellung ihrer Werke [wie 1819] veranstalteten, indem jene, zu welcher sie patriotische Begeisterung, bey Anwesenheit Sr. Maj. des Kaisers in Rom, vereinigte, zu Parteylichkeiten, ja feindlichen Aeußerungen und Kunstkritiken in deutschen Zeitungen [...] Veranlassung gegeben hatte, so mußte der Kunstfreund die Werkstätten der Künstler einzeln besuchen. «S. a. Passavant 1820, S. 88-92. Friedrich Schlegel, Über die deutsche Kunstausstellung zu Rom im Frühjahr 1819 und über den gegenwärtigen Stand der deutschen Kunst in Rom (1819). Ursprünglich sollte Carl Friedrich von Rumohr die Nazarener verteidigen. Thimann 2014, S. 48-52, 314-324; Ders. 2013, S. 305-312; nur ein passender Styl, sondern auch sogar nur ein bestimmter Vortrag der einzig zweckmäßige sey [...]; und auf diese Weise würde es gar keinen feststehenden Styl geben dürfen, sondern jedes Bild seinen eignen Styl und Vortrag erfordern. « ${ }^{57}$ Mit dieser Argumentation beabsichtigte er die Kritik der Nachahmung abzuschwächen. Zudem verdeutlichte er, dass ihm die künstlerische Auffassung - der »Ernst« und die »Strenge« - der Bildmotive wichtiger war als Technik und Stil. Das Kunstwerk sollte den Betrachter zu Gedanken über die Menschen und ihr Handeln anregen. Diese Verteidigung der neuen Kunstrichtung handelte ihm den spöttischen Ruf des »capo dei nazareni«, des Oberhaupts der Nazarener, ein. Die Eloquenz seiner lobenden Worte, seine gefühlsbetonten Ausführungen über die neudeutsche Kunst und sein konkretes Engagement trugen hierzu bei.

Tatsächlich waren seine Ankäufe und Aufträge zahlreich. Schnorr von Carolsfeld berichtet darüber: »Von den Aufträgen, die Herr Quandt gegeben, und den Ankäufen, die er gemacht hat, will ich nur einige anführen: Näcke ist aufgetragen, eine große Komposition, die heilige Elisabeth, welche Almosen unter den Armen verteilt, vorstellend, in Öl auszuführen; Ph. Veit eine Judith; v. Rohden eine große Landschaft; [...] Von Ankäu-

Schröter 1990, S. 344-353. Einer der vehementesten Nazarener Kritiker war der Landschaftsmaler Johann Christian Reinhart: »Nazarener sind eine eigene Gattung von Menschen [...]. Ihre Hauptbeschäftigung ist, die Kunst in die erste Epoche nach dem Verfall der Künste, also in ihre Kindheit zurückzuführen, weshalb sie auch die Fehler und Schwächen der ältesten Meister verehren und nachahmen, da sie ihnen für Schönheiten gelten. « Zit. nach Stolzenburg 2012, S. 83-84.

56 »Die aus jener frühen Zeit vorhandenen Werke sind allerdings als belehrende Vorbilder zu betrachten, aber nicht blos als Beispiele dessen, was zu thun, sondern auch, was zu vermeiden ist.«Quandt 1819, Bd. 2, S. 174 .

57 Quandt 1820 (1), S. 262. S.a. Locher 2001, S.163-178. 
fen, die Herr Quandt machte, führe ich nur folgende an: einen großen Carton von Overbeck (der nicht Zeit hatte ein Ölbild für Quandt zu malen), einen Christuskopf von Eggers. $\aleph^{8}{ }^{8}$ Lakonisch kommentierte Dorothea Schlegel in einem Brief an ihren Gemahl Friedrich Quandts Unterstützung der römisch-deutschen Künstler: »Quandt [...] macht jetzt hier den Regen und das schöne Wetter bey den Deutschen; er gibt allen zu thun. «9 $^{59}$

Der reiche Kunstförderer erwähnte in seinem Artikel »Wanderung durch die Werkstätten deutscher Künstler in Rom«, der 1820 im viel gelesenen Kunstblatt von Ludwig Schorn erschienen war, alle seine Erwerbungen und Bestellungen gleich selber. Während er andere Kunstkäufer namentlich nennt, spricht er in eigenen Dingen immer von einem »deutschen Kunstfreund oder vom »mehrmals erwähnten Kunstfreund«. Dieser er-

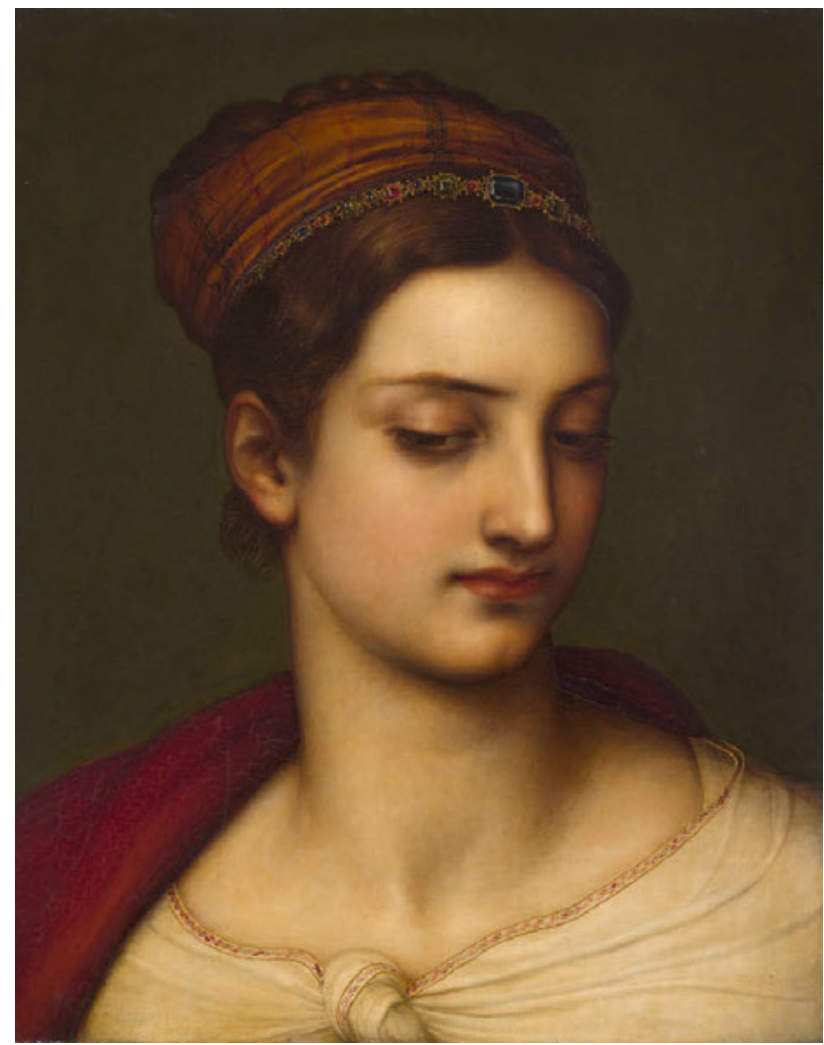

14 Carl Eggers, Heroisches Frauenbildnis (Vittoria Caldoni oder Buti, heute als Bildnis Marianne Rehberg), vor 1824, Öl auf Holz, 47 ×36,5 cm, Leipzig, Museum der bildenden Künste, Inv.-Nr. G 71

58 Brief an den Vater vom 22.2.1820, in: SLUB, Mscr. Dresd. n Inv. 8 Bd. 1, fol. 164v. S. a. Schnorr 1886, S. 169-170. Siehe Rüfenacht 2018, SQ-69 (Rohden), SQ-70 (Eggers), SQ-77 (Veit), SQ-95 (Naeke), SQ-141 (Overbeck).

59 Brief vom 6.11.1819, in: Schlegel 1980, S. 230. Über die Aufträge s.a. ebd., 1980, S. 243-244.

60 Quandt 1820 (1), S. 262-264. Für Details zu den einzelnen Aufträgen siehe die tabellarische Übersicht über Quandts Gemäldesammlung in: Rüfenacht 2018, SQ-64 (Catel), SQ-69 (Rohden), SQ-70, SQ-73

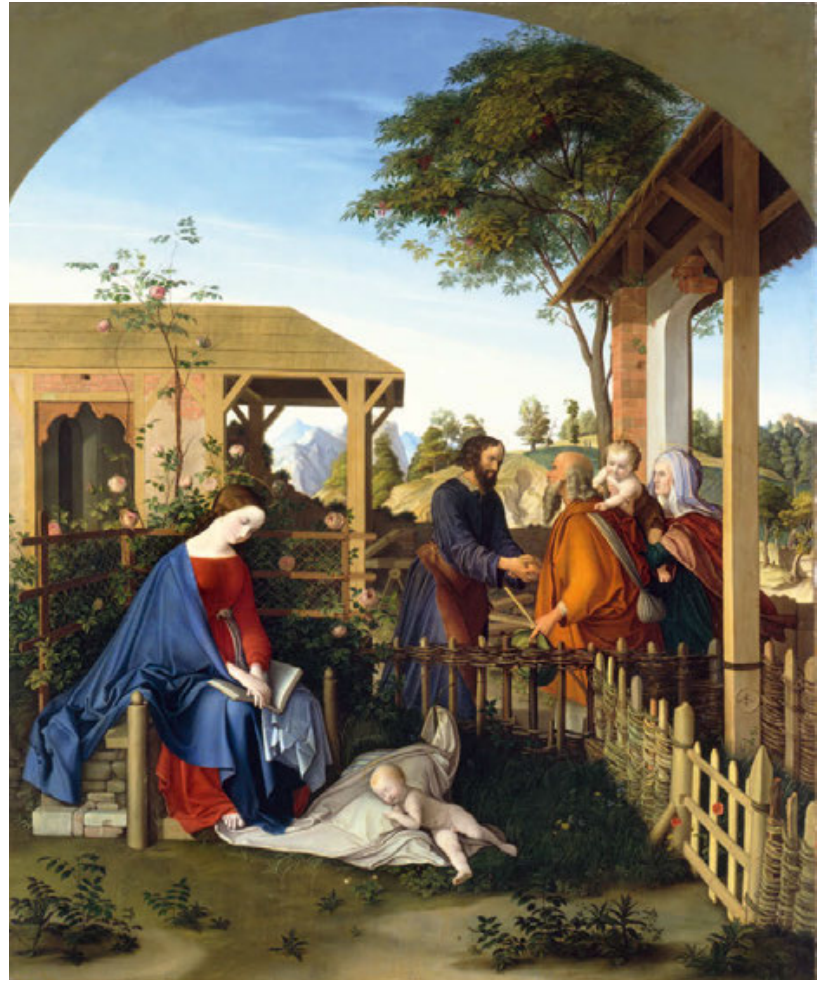

15 Julius Schnorr von Carolsfeld, Die Familie Johannes des Täufers bei der Familie Christi, 1817, Öl auf Leinwand, $123 \times 102,5$ cm, Dresden, SKD, Albertinum | Galerie Neue Meister, Gal.-Nr. 2217

stand dreizehn Kunstwerke: den Karton Sophronia und Olindo auf dem Scheiterhaufen von Friedrich Overbeck (Abb. 13), ein Christusportrait, eine Heilige Katharina und ein Heroisches Frauenbildnis (Abb. 14) von Carl Eggers, Die Familie Johannes des Täufers bei der Familie Christi (Abb. 15) von Julius Schnorr, Die Heilige Elisabeth verteilt Almosen auf der Wartburg von Gustav Heinrich Naeke (Abb. 37), eine Judith von Philipp Veit, überliefert als Kupferstich (Abb. 58), eine Kopie der Madonna di Casa Tempi Raffaels von Louise Seidler (Abb. 59), die er in seiner Sammlung mit der ebenfalls in Rom erworbenen Maria mit dem Kinde (Abb. 6o) von Schnorr präsentierte, die Landschaft mit einem Einsiedler von Johann Martin von Rohden, überliefert in einer Radierung (Abb. 64), Die unglückliche Heimkehr des Fischers von Franz Catel (Abb. 72), schliesslich zwei Genreszenen von Johann Adam Klein. ${ }^{60}$

(Eggers), SQ-74 (Schnorr), SQ-75 (Seidler), SQ-77 (Veit), SQ-86, SQ-90 (Klein), SQ-95 (Naeke). Bei der zweiten sakralen Szene dürfte es sich um Die Familie Johannes des Täufers bei der Familie Christi von 1817 handeln. Ebd., SQ-79. An Schnorr gingen in Rom noch zwei Bildnisaufträge: Porträts von Vittoria Caldoni sowie seiner Frau, Clara Bianca von Quandt; ebd., SQ-88, SQ-142. Zu Veits Judith, zuerst als Loreley gedacht, siehe Quandt 1820 (1), S. 264: »Veit, dem von erwähntem Kunstfreund [Quandt] ein Charakterbild der poetisch-romantischen Person, der zauberischen Loreley, nach einer rheinischen Volkssage, 
Auf diese Römer Ankäufe, die Bernhard Maaz bereits 1986 ausführlich analysiert hat, sei hier nur in zwei Beispielen von Nazarener Künstlern - Overbeck und Eggers - näher eingegangen. ${ }^{61}$ Die Erwerbungen von Julius Schnorr werden in einem nächsten Unterkapitel vertieft analysiert. Gustav Heinrich Naekes Historie Die Heilige Elisabeth verteilt Almosen auf der Wartburg, die Quandt in Rom in Auftrag gegeben hatte und erst 1827 vollendet war, wird im Zusammenhang mit seiner Förderung der Historienmalerei in einem späteren Kapitel behandelt. Louise Seidlers Raffael-Kopie und Johann Martin von Rohdens Landschaft mit Einsiedler als Pendant zu Caspar David Friedrichs Die zertrümmerte Hoffnung werden im Kontext der Ausstellung seiner Privatsammlung vertieft diskutiert.

Mit dem Ankauf eines Werks von Johann Friedrich Overbeck ist eine Anekdote überliefert, welche die unter den Römer Künstlern legendäre Liebenswürdigkeit Quandts verdeutlicht: Overbecks Karton mit der Geschichte von Sophronia und Olindo aus Torquato Tassos Gerusalemme liberata, der während zweier Jahre als Vorlage für ein Fresko des Tasso-Saales im Casino Massimo in Rom entstanden war, wurde in einem Sturm umgeworfen und zerrissen (Abb. 13). Darauf kaufte ihm Quandt die zerstörten Bögen ab. Louise Seidler zitiert den Sammler folgendermaßen: »Als Herr von Quandt dies hörte, sagte er sogleich, den verzweifelnden Künstler liebevoll tröstend: ,Nun, jetzt, da den Carton kein Anderer kaufen wird, nehme ich ihn zu jedem Preise. ${ }^{62}$ Wahrscheinlich handelte Quandt nicht nur aus Mitleid, sondern auch aus Opportunismus, denn er versuchte schon länger Werke dieses führenden Nazareners der ersten Stunde zu erhalten, was aufgrund dessen großer Arbeitsbelastung lange nicht möglich war. ${ }^{63}$

Carl Eggers, sächsischer Nazarener und seit 1813 für den Rest seines Lebens in Rom verbleibend, beherrschte die etwas einseitige Fähigkeit, Köpfe verschiedener mythologischer, christlicher oder lebender Figuren zu malen. Quandt schätzte den künstlerischen Ausdruck Eggers' und erstand die stattliche Anzahl von vier Gemälden für seine Sammlung, auch wenn er meinte, es sei »schade daß Eggers fast immer nur einzelne Köpfe malt u ich würde mich freun einmal eine ganze oder doch wenigstens halbe Figur von ihm zu sehn. $\ll^{64}$ Nebst dem erwähnten Christusportrait erregte das Bildnis der heiligen Katharina besonderes Aufsehen, so dass Maximilian Speck von Sternburg in Leipzig einen Auftrag vergab. Das Produkt löste jedoch große Unzufriedenheit aus, so dass Quandt zur Protektion Eggers das Gemälde - eine heute nicht mehr eruierbare, heilige Dorothea - übernahm und im Schlafzimmer seiner Frau präsentierte. Von einem vierten heroischen Bildnis, später auch als Vittoria Caldoni oder Vittoria Buti interpretiert und heute im Museum der bildenden Künste Leipzig als Bildnis Marianne Rehberg identifiziert, ließ Quandt verlauten, es habe seiner kleinen Sammlung einen »bedeutenden Zuwachs« ermöglicht (Abb. 14) ${ }^{65} \mathrm{Wie}$ hoch Quandt Eggers einschätzte, zeigt sich in seinem Vorsatz, Goethe zum besseren Verständnis der neudeutschen Kunst die heilige Katharina zur Ansicht zuzusenden. ${ }^{66}$

\section{Julius Schnorr von Carolsfeld}

Besondere Förderung erfuhr Julius Schnorr von Carolsfeld. ${ }^{67}$ Seine Familie war schon lange mit Quandt und seinen Eltern befreundet. Bereits 1817 erwarb er Die Familie Johannes des Täufers bei der Familie Christi, weil ihm das »rein Menschliche« und die »frische natürliche Darstellung« imponierte (Abb. 15) ${ }^{68}$ Kaum war Schnorr 1818 nach Italien gereist und in Rom angekommen, versuchte der Kunstmäzen Zeichnungen von Friedrich Overbeck und Peter Cornelius zu erlangen. ${ }^{69}$ Der Nazarener zweiter Generation lieferte ihm hierzu Informationen über die deutschrömischen Künstler und fungierte als Vermittler. zu malen aufgegeben war, malt für diesen Besteller aus eigner Wahl, statt genannter Aufgabe, eine Judith. Alles Widrige, was dieser Gegenstand leicht mit sich bringen kann, wußte Veit zu entfernen, und in seinem Bilde steht sie als eine tragische Heldin da.« S. a. Suhr 1991, S. 66-67, 263, 362; Maaz 1986, S. 40-41; Schlegel 1980, S. 230-231, 238; Schnorr 1886, S. 154; Raczyński 1836-1841, Bd. 3, S. 224.

61 Maaz 1986, S. 28-50.

62 Seidler 2003, S. 196. S. a. Schlegel 1980, S. 239-244.; Gerstenberg/Rave 1934, S. 87-89; Bemmann 1925, S. 14; KB 1820, Jg. 1, Nr. 25, S. 100. Zum Fresko siehe Vignau-Wilberg 2011, S. 75; Kat. Rom 1981, S. 320-322.

63 Erst 1830 konnte er mit der Leinwandwiederholung des Freskos an der Außenseite der Portiuncula-Kapelle in Santa Maria degli Angeli nahe Assisi, dem Gemälde Das Rosenwunder. Die Vision des HI. Franz von Assisi ein Werk Overbecks erwerben. Brief von Overbeck an Quandt vom 25.2.1830, in: München, Bayerische Staatsbibliothek, Autograph Overbeck, Friedrich. Das Gemälde befindet sich heute in Leipzig, MbdK, Inv. Inv. I.170. S. a. Rüfenacht 2018, SQ-85; Rüfenacht 2016, S. 99, Anm. 54.
64 Brief an Schnorr vom 23.2.1823, in: SLUB, Mscr. Dresd. n Inv. 15, Bd. 31, fol 94 r. Quandt 1824, S. 367 und Quandt 1820 (1), S. 263. S. a. Rüfenacht 2018, SQ-70 bis 73; Neidhardt 1993, S. 33; Bemmann 1925, S. 16; Raczyński 1836-1841, Bd. 3, S. 225.

65 Kat. Quandt 1824, [Nr. 15], S. 8. Zur Provenienz und Änderung des Bildtitels siehe Rüfenacht 2018, SQ-72.

66 Brief an Schnorr vom 7.1.1821, in: SLUB, Mscr. Dresd. n Inv. 15 Bd. 31, fol. 58v; s. a. Schmitz/Strobel 2001, S. 21.

67 Brief von Julius an Veit Schnorr vom 20.2.1820, in: SLUB, Mscr. Dresd. n Inv. 8, Bd. 1, fol. 164v.

68 Das Bild war auf der Leipziger Ausstellung der Kunstakademie präsentiert. Kat. Leipzig/Bremen 1994, Nr. 14, S. 192-193. S. a. Bergmann-Gaadt 2015, S. 175-176; Teichmann 2001, S. 72; Maaz 1986, S. 33; Bemmann 1925, S. 13; S. a. Schnorr 1909, S. 35. Zum Verhältnis Schnorrs und Quandts ausführlich Maaz 1986, S. 32-36.

69 Brief von Quandt an Schnorr vom 20.6.1818, in: SLUB, Mscr. Dresd. n Inv. 8, Bd. 1, fol. 104v. 


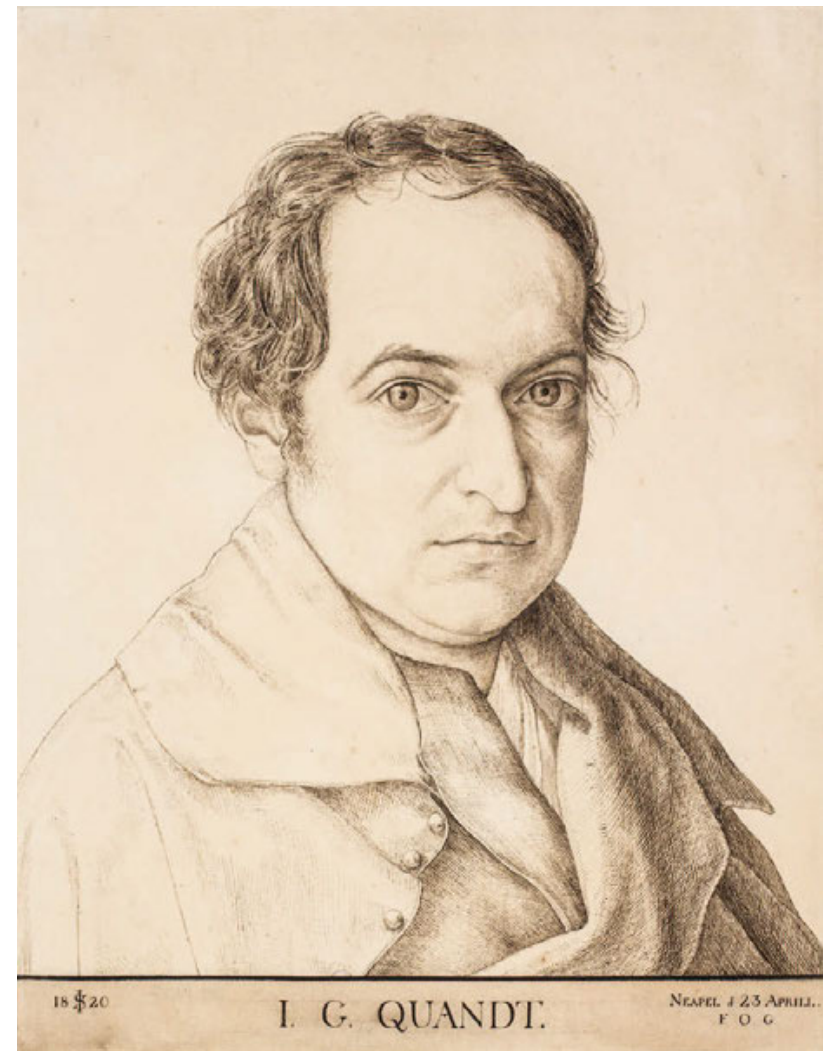

16 Julius Schnorr von Carolsfeld, Bildnis Johann Gottlob von Quandt, 1820, Bleistift und Tusche auf Papier, $263 \times 204$ mm, Wien, Kupferstichkabinett der Akademie der bildenden Künste, Inv.-Nr. HZ 8423

Gleichzeitig unterstützte Quandt den jungen Schnorr in Rom nicht nur mit Briefen, sondern auch finanziell, und glaubte, dieser könne nur in der ewigen Stadt seine Kunst verbessern. Als Julius im Sommer 1818 von finanziellen Sorgen und Heimweh geplagt war und Gedanken äußerte, zurückzukehren, schrieb Quandt seinem Vater Veit Schnorr von Carolsfeld in Leipzig einen langen Brief, in dem sich sein Italienideal manifestiert: »[...] er [Julius - AR] soll Rom nicht eher verlaßen, bis er selbst es für gut findet und sich keine Sorgen machen. Ein so wackrer Künstler wird Gott und kein wahrer Kunstfreund verlaßen, es ist eine heilige Pflicht ihn auf der Bahn die er betreten zu erhalten, nur unter Roms heitern, glühenden Himmel, konnte die Blüte des Geistes vollkommen sich entfalten, ich habe es vorausgesagt. Mit Entzücken las ich in seinen Briefen, wie ihm Raffaels Werke immer verständlicher und lieber werden, das konnte nur so kommen, wenn er nach Rom ging, wenn er Italien kennen lernte, wo die Natur noch am natürlichsten, am wenigsten unter

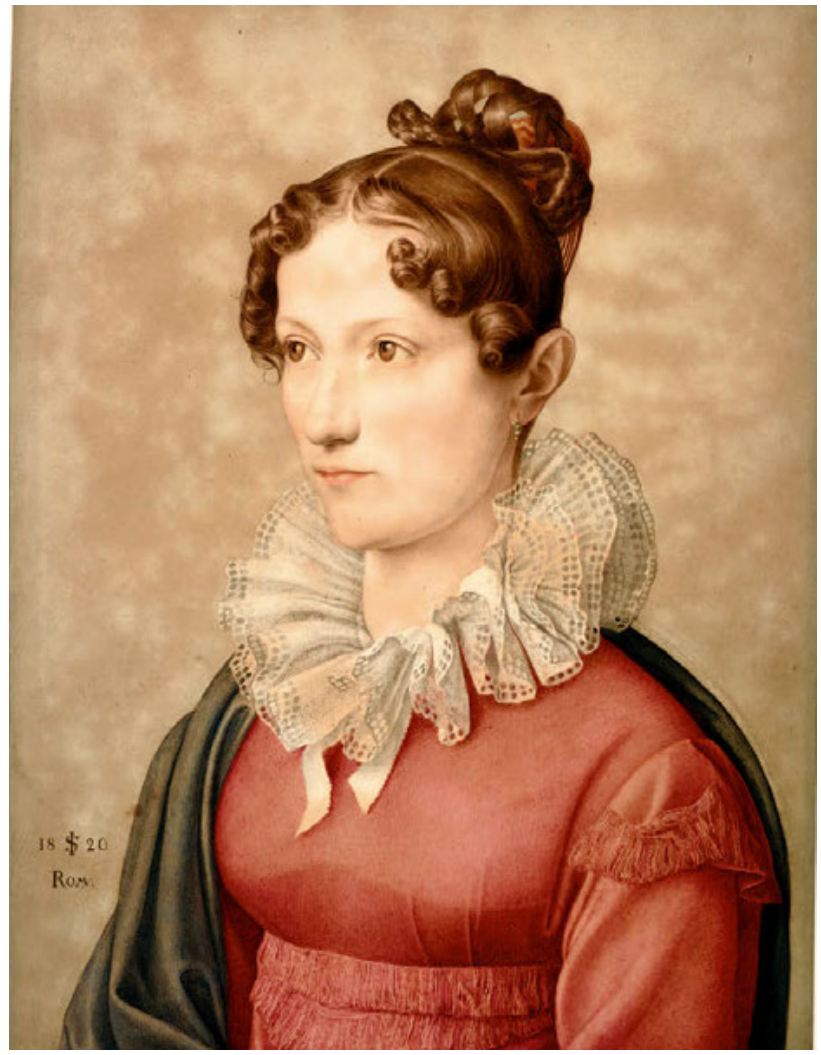

17 Julius Schnorr von Carolsfeld, Bildnis Clara Bianca von Quandt, 1820, Aquarell über Bleistift und Feder, $287 \times 213$ mm, München, Privatbesitz

allen Ländern, beschnitten, entstellt, beengt ist, denn Raffaels Kunstcharakter, ist nur ein Reflex der reinen Naturschönheit. Es wäre ja sehr traurig wenn unser Julius, der die Welt noch mit gar schönen, trefflichen Werken erfreuen kann, so nahe am Ziele der Vervollkommnung umkehren und nur einen Blick in das Paradies gethan haben sollte. Er ist dazu berufen die Kunst von Irrthümern zu reinigen, er selbst wird und kann seinen Geschmak nur in Rom, läutern, er ist eine zu gesunde, kräftige Natur als daß er nicht jeden fremdartigen Anflug ablegen und aus seinem Wesen ausstoßen und in die Arme der ewigen Natur zurückkehren sollte, deren zeitlose Schönheit, die antike, italienische und altdeutsche Schönheit in sich schließt. [...] Wir müßen ihn also in Rom durchaus zu erhalten suchen, wir sind es ihm, uns, der Welt und der Ewigkeit schuldig. « $^{\circ}$

In dieser Briefpassage subsumieren sich mehrere zentrale Aspekte, die für Quandts Kunstanschauung charakteristisch sind. So zeigt sich sein Bedürfnis, die Rangordnung der Kunst-

die Gabe der unermüdlichsten Werkthätigkeit, welche leider den meisten neuern Künstlern fehlt, so daß ihre Talente unfruchtbar bleiben und als Mensch zeichnen ihn die liebens und verehrungswürdigsten Eigenschaften aus.« Ebd., fol. 197r-198v. 


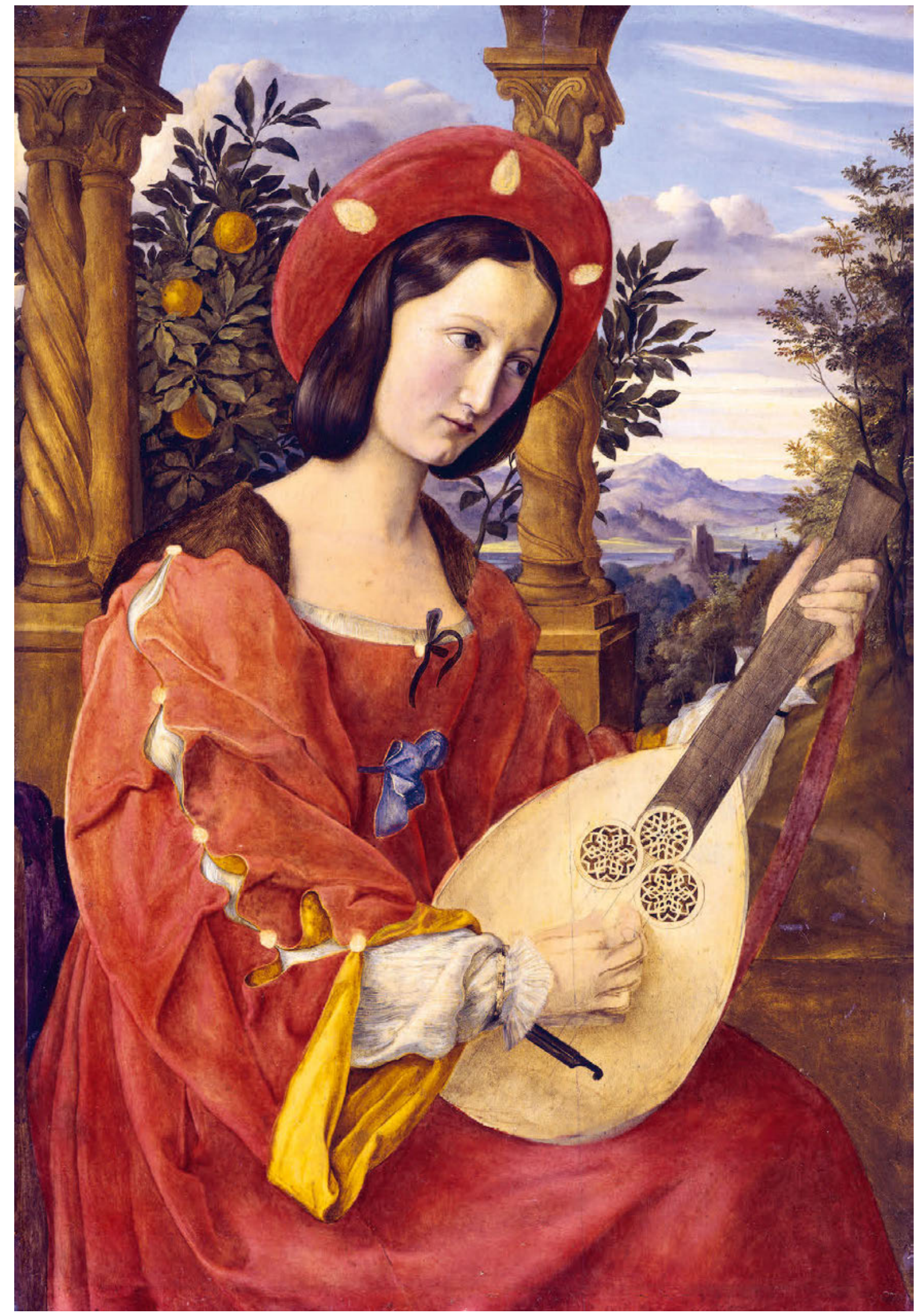

18 Julius Schnorr von Carolsfeld, Bildnis Clara Bianca von Quandt, 1820, Mischtechnik auf Holz, $37 \times 26 \mathrm{~cm}$, Berlin, Alte Nationalgalerie, Inv.-Nr. A || 361 


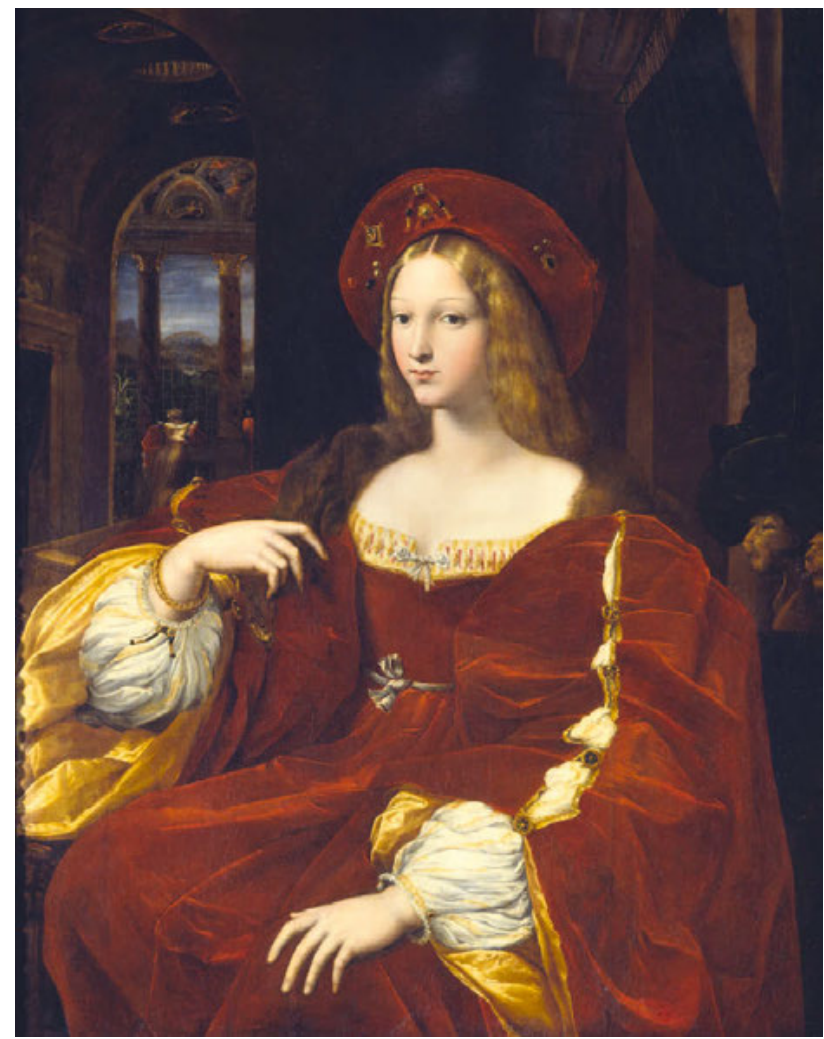

19 Raffaello Santi gen. Raffael und Giulio Pippi gen. Giulio Romano, Porträt der Dona Isabel de Requesens, Vize-Königin von Neapel (früher: Johanna von Aragón), um 1518, Öl auf Holz auf Leinwand übertragen, $120 \times 96 \mathrm{~cm}$, Paris, Musée du Louvre, Inv.-Nr. 612

Nationen auszugleichen, wenn er davon spricht, dass in der $\mathrm{Na}^{-}$ tur gleichzeitig italienische, altdeutsche und antike Schönheit aufzufinden sei. Schönheit als Grundbedingung der Kunst fand sich also gleichberechtigt in den Zeiten und Nationen wieder ein Aspekt, der in seiner eigenen Sammlung mehrfach auftaucht und noch diskutiert werden wird. Des Weiteren entpuppt sich Raffael weniger als ein individuelles Kunst-Genie, denn als ein Naturprodukt, als folgerichtiges Resultat der schönen, italienischen Natur. Dadurch wird Raffael zum Vorbild. Diese Vorbildhaftigkeit einzelner Künstler ist ebenfalls ein roter Faden in

71 »Wirklich habe ich noch keinen Künstler gefunden, der so universell, so wenig einseitig, in seinem Gefühl u Urtheil ist als Julius, $u$ alles Treffliche, mag es heidnisch oder christlich, altitalienisch oder raffaelisch seÿn gleich tief auffaßt u sich aneignet. Denn darin besteht doch die rechte Ausbildung des Künstlers, daß er das beste, wo er es findet, in sich aufnimmt u dadurch so universell, in objectiver Hinsicht, als möglich wird u dabeÿ doch ganz selbstständig bleibt. « Brief von Quandt an Unbekannt vom 26.4.1820, in: Leipzig, Universitätsbibliothek, Mappe 215, Quandt, Johann Gottlob von, fol. [1v]. Zur Rolle der italienischen und deutschen Alten Meister, insbesondere Raffael und Dürer siehe Thimann 2015, S. 9-39.

72 Brief von Julius an Veit Schnorr vom 29.12.1820, in: SLUB, Mscr. Dresd. n Inv. 8, Bd. 1, fol. 193r-194V; Schnorr 1886, S. 202-203; ebenso Quandt an Veit Schnorr am 28.12.1819/1.1.1820, in: SLUB, Mscr. Dresd. n Inv. 8,
Quandts Sammlung. Schließlich zeigen sich Quandts wiederholt formulierte Hoffnungen in die deutschen Künstler in Rom, durch Kenntnis vergangener Kunst eine neue, große Kunst zu erschaffen. Dieses Anliegen teilte er letztlich mit den Nazarenern in Rom, was ihn, den Mäzen, als Teil von ihnen auszeichnete. ${ }^{71}$

Mit Quandts Ankunft in Rom 1819 fand die persönliche Förderung Schnorrs eine intensive Fortsetzung. Die beiden spazierten zusammen durch Rom, um das Mittelalter aufleben zu lassen. Hierbei erstellte Schnorr zumeist an den Teeabenden in der Wohnung des Ehepaars Quandt Zeichnungen von Gärten und Terrassen der Ewigen Stadt - die sogenannten Teeblätter. Sie stellten nicht nur die italienische Natur dar, sondern interpretierten sie als Nachhall des mittelalterlichen Roms. ${ }^{72}$ In diesem Zusammenhang entstand auch das assoziationsreiche Blatt Der Zug der Heiligen Drei Könige, heute im Museum der bildenden Künste in Leipzig (vgl. Abb. 22). Schnorr hatte es Johann Gottlob und Clara Bianca von Quandt als Überraschung und Erinnerung an die gemeinsame Zeit in den Römer Gärten zu Weihnachten 1819 geschenkt und die beiden prominent aus dem Bild blickend neben den reitenden Königen platziert. ${ }^{73}$ Die vielfigurige Historie ist ein besonderes Manifest der Freundschaft zwischen den Quandts und dem Künstler und fügt sich darüber hinaus in die für die Nazarener typischen Freundschaftsbilder ein, hatte der Maler unter einem Bogen am rechten Bildrand doch auch sich selbst mit seinen Künstlerfreunden Theodor Rehbenitz und Friedrich Olivier sowie seine zukünftige Ehefrau Marie Heller als eine der klugen Jungfrauen in der Zeichnung dargestellt. ${ }^{74}$

Diese mannigfaltigen Wechselwirkungen zwischen dargestellter und gelebter romantischer Freundschaft erfuhr im Frühjahr 1820 fruchtbare Weiterentwicklung während einer Reise Schnorrs mit dem Ehepaar Quandt nach Neapel. Quandt glaubte, dass der Aufenthalt für Schnorrs Schaffen bedeutsam war: »Der zwar kurze Aufenthalt in Neapel, war wie ich glaube, von einem wohltätigen Einfluß auf diesen geistreichen Maler. Er lernte den Werth einer heitren, kräftigen Kunst fühlen, welche unter Heilgenbildern u den Werken des Mittelalters verloh-

Bd. 2, fol. 191r-v. S. a. Kuhlmann-Hodick 2000, S. 24-25; Kat. München/ Dresden 2000, S. 302-304, Kat. Nr. 149-152. Schnorr und Quandt reisten zusammen nach Neapel, wo sie unter anderem den Vesuv bestiegen. Ausführlicher Brief Schnorrs an den Vater vom 23.5.1820 über diesen Aufenthalt, in: Schnorr 1886, S. 172-176. S. a. Peter VignauWilberg, »Das Italienerlebnis des jungen Schnorr von Carolsfeld «, in: Vogel 1996, S. 124; Justi 1932, S. 78; Schnorr 1909, S. 11; Schnorr 1886, S. 155 .

73 Zum christlich-moralischen Gehalt der Zeichnung siehe Dehmer/Petri 2018, S. 23-24, 27-28.

74 Dehmer/Petri 2018, S. 26-27. Zur Rolle der Freundschaft und zum Freundschaftsbild in der Romantik siehe Grewe 2009, S: 61-68; Büttner 2002, S. 15-28. 
ren geht. ${ }^{75}$ Zugleich war die Reise Manifest einer tiefen Freundschaft. Schnorr selber beschrieb sie seinem Vater emphatisch: »[...] am wenigsten kann ich es verwinden, mit Quandts in ein und derselben Stadt [zurück in Rom - AR] zu sein und doch getrennt zu leben. Unter einem Dache mit jemand zu hausen, den man lieb hat, hat einen eigenen Reiz; man ist dem andern unverborgener, denn der Gedanke kann sogleich zur Mitteilung werden. Und wie wir nun vollends so oft in dem engen Raum eines Wagens oder eines Schiffchens [auf der Neapelreise - AR] zusammen waren, da wurde so wie jede Regung des Leibes auch so leicht jede Regung des Innern offenbar. [...] Jetzt ist mir, als hätten wir uns nicht mehr so lieb, wenigstens bin ich ihrer Liebe nicht so gewiß. Das macht mich betrübt, darum wünschte ich fast, sie wären schon fort von hier. Eine völlige Trennung wird mir lange nicht so schmerzlich sein als diese halbe. ${ }^{* 6} \mathrm{In}$ der Tat war die Freundschaft so tief, dass der Künstler über Quandt von seinem »Prinzen« sprach und über Clara Bianca von Quandt von seiner »Herrin « - ganz in der Tradition mittelalterlicher Minnedichtung.77 Ein Resultat dieser romantischen Freundschaft war das kleinformatige Ölbild der Frau von Quandt mit Laute. Es handelt sich dabei um das weit herum gerühmte, noch von Ludwig Justi als »wahres Juwel [...], mit einer Liebe und Genauigkeit ausgeführt wie bei den frommen Meistern des fünfzehnten Jahrhunderts« bezeichnete Porträt Clara Bianca von Quandts als Johanna von Aragonien. ${ }^{78}$

Der Entstehung des Ölbildes ging eine einigermaßen komplizierte, doch recht gut aufgearbeitete Werkgenese voran, die einiges über die Bedeutung von Freundschaftsbildnissen in der Romantik kundtut.79 In seinem Römer Porträtbuch hatte Julius Schnorr zahlreiche nahestehende Personen gezeichnet, darunter auch Quandt (Abb. 16). ${ }^{80}$ Eine Zeichnung der Gemahlin folgte. Hiervon wünschte sich Quandt wiederum eine Kopie. Ende 1819 wurde Schnorr, vermittelt von seinem Vater, zudem der Auftrag überbracht, zum Geburtstag der Frau des Dichters Johann Georg Keil in Leipzig, die eng mit Frau von Quandt befreundet war, eine aquarellierte Zeichnung herzustellen (Abb. 17). In einem Brief an eine unbekannte Person schrieb Quandt: »Der Hofrath Keil hat sich von mir meine Frau angebeten, um sie seiner Frau zum Geburtstag zu schenken, versteht sich im Bilde, wie es allemal geschieht wenn man die Leute welche in der Welt herumlaufen, nicht selbst habhaft werden kann.

75 Brief von Quandt an Unbekannt vom 26.4.1820, in: Leipzig, Universitätsbibliothek, Mappe 215, Quandt, Johann Gottlob von, fol. [1v].

76 Brief von Julius an Veit Schnorr vom 23.5.1820, in: SLUB, Mscr. Dresd. n Inv. 8, Bd. 1, fol. 171r. S. a. Schnorr 1886, S. 172-173.

77 Schnorr 1886, S. 164, 417, 439, 447, 456. S. a. Teichmann 2001, S. 113; Kat. Rom 1981, S. 251; Anton Merk, »Zur Bildnismalerei der Nazarener«, in: Kat. Frankfurt 1977, S. 153.

78 Justi 1932, S. 78. S. a. Rüfenacht 2018, SQ-142; Kat. Berlin 2002, S. 381-382.

79 Nachfolgende Ausführungen beziehen sich, wenn nicht anders ver-

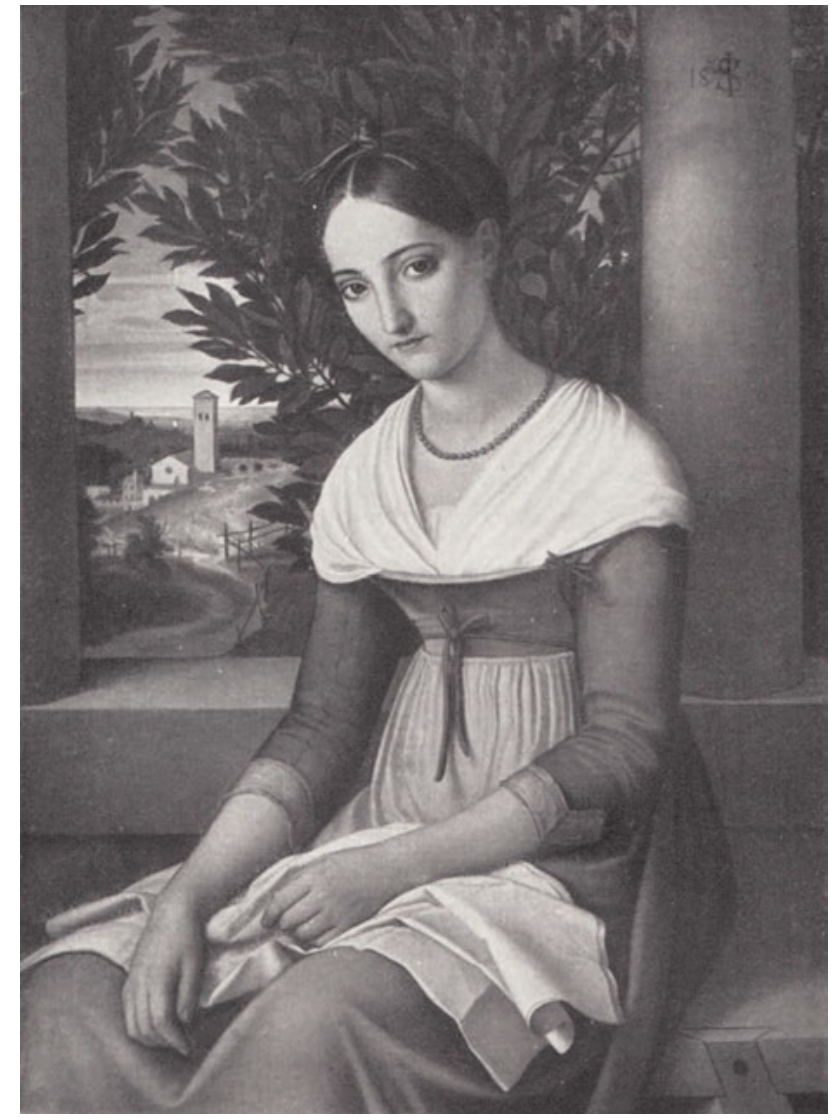

20 Julius Schnorr von Carolsfeld, Vittoria Caldoni, 1823/25, Öl auf Leinwand, ca. $87,3 \times 66 \mathrm{~cm}$, Verbleib unbekannt

Ich vermuthe, daß Keil meine Frau in Gold wird einfaßen laßen u da der Tischler u Vergolder Zeit braucht um den Rahmen zu fertigen, so überschicke ich Ihnen durch dieses Blatt, worauf dieser Brief geschrieben wird, die Größe des Bildes, welches Julius Schnorr zu malen angefangen hat, mit der Bitte dem Hofrath Keil die Größe des Bildes genau anzugeben. Ich vereinige also zweÿ edle Zwecke, jedoch in der eigennützigen Absicht Sie u Keil zum baldigen Schreiben zu veranlaßen. Doct. Hillig u der Papa Schnorr sind ebenfalls in das Geheimniß dieses Briefs eingeweiht $\mathrm{u}$ daher darf ich diese grüßen laßen, aber niemand anderes darf von diesem Brief etwas erfahren. $\ll^{81}$ Mit diesen Freundschaftsaufträgen nahm bei Quandt der Wunsch Gestalt an, Schnorr mit einem Porträt seiner Frau in Öl zu beauftragen

merkt, auf die wegweisenden Aufsätze von Bernhard Maaz und Stefan Seeliger. Die Entwurfszeichnungen befinden sich unter anderem in München, Berlin und Wien. Genaue Angaben hierzu bei Maaz 1998, S. 138-141; Seeliger 1997, S. 34-36.

80 Kat. Leipzig/Bremen 1994, S. 104, Kat. Nr. 31.

81 Brief von Quandt an Unbekannt, vom 15.1.1820, in: SLUB, Mscr. Dresd. App. 204, Nr. 97. S. a. Bertsch 2009, S. 570-571; Maaz 1998, S. 139 vermutet als Empfänger Friedrich Rochlitz. 


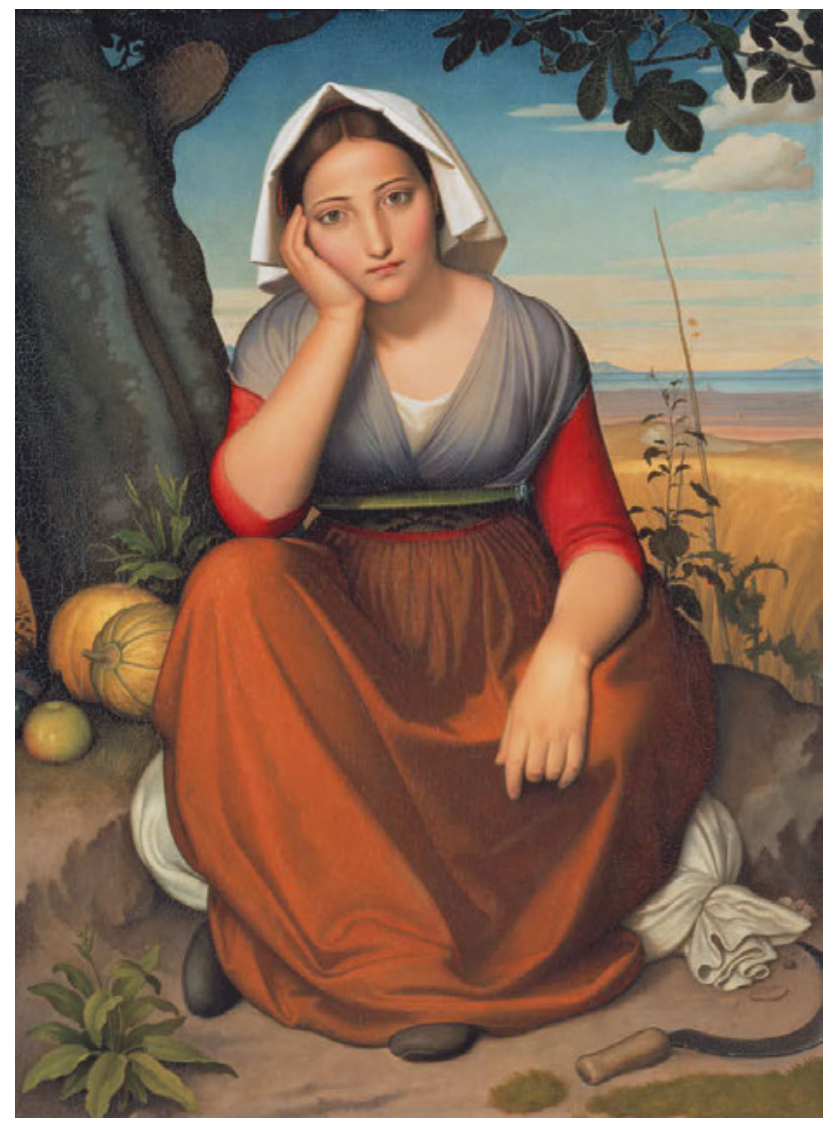

21 Johann Friedrich Overbeck, Vittoria Caldoni, 1821, Öl auf Leinwand, $89 \times 65,8 \mathrm{~cm}$, München, Bayerische Staatsgemäldesammlungen - Neue Pinakothek, Inv.-Nr. WAF 757

(Abb. 18). Auf seinen Wunsch hin sollte sich der Künstler Raffaels Porträt der Dona Isabel de Requesens zum Vorbild nehmen (Abb. 19). Dieses wurde zu seiner Zeit noch als Bildnis der Johanna von Aragonien identifiziert und hing in einer Replik im Palazzo Doria Pamphili. ${ }^{8}$ Wie Bernhard Maaz überzeugend darlegen konnte, vereinigt sich in Schnorrs Gemälde der zeittypische, bei Quandt mehrfach zu beobachtende und in weiteren Kapiteln dieser Arbeit zu diskutierende Wunsch eines Ausgleichs nördlicher deutscher und südlicher italienischer Kunst. ${ }^{83}$ Raffael als großes Vorbild unter den alten Italienern diente dem deutschen Künstler Schnorr als Ideal, womit er -

82 Maaz 1998, S. 141. Das Original befindet sich heute in Paris, Louvre. S. a. Quandt 1826 (2), S. 33-35, 38-39; Brief von Quandt an Veit Schnorr vom 28.12.1819/1.1.1820, in: SLUB, Mscr. Dresd. n Inv. 8, Bd. 2, fol. 192r und der Dankesbrief von Frau Keil an Clara Bianca von Quandt, in: SLUB, Mscr. Dresd. n Inv. 15, Bd. 31, fol. 27r-28v. Vgl. Teichmann 2001, S. 113-117, 292293; Kat. Leipzig/Bremen 1994, S. 202-203; Kat. Rom 1981, S. 251-253.

83 Maaz 1998, S. 141-144.

84 Wackenroder/Tieck 2005, S. 6-11, 19, 55-56; Schlegel 1996, S. 97-106. Für einen Überblick über die literarische Raffael-Rezeption und -Verehrung siehe Ernst Osterkamp, »Der Kulturheiland. Raffael in der deutschen Literatur der Goethezeit«, in: Kat. Göttingen 2015, S. 43-60. wie auch Quandt mit seinem Wunsch einer Anlehnung an ein Raffael-Porträt - an die frühromantische Verehrung des großen Renaissance-Malers anschloss. Verschiedene Autoren hatten, grundgelegt bereits in Aussagen Anton Raphael Mengs' und Johann Joachim Winckelmanns, seit dem späten 18. Jahrhundert die außerordentliche Rolle dieses Künstlers herausgehoben. Gerade im Kontext der Sixtinischen Madonna in der Dresdener Gemäldegalerie und somit im unmittelbaren Wirkkreis Quandts und auch Schnorrs, war diese zunehmende Verehrung zu beobachten und manifestierte sich in verschiedenen Schriften, unter anderen von Wilhelm Wackenroder, Ludwig Tieck oder August Wilhelm Schlegel. ${ }^{84}$ Schnorr vereinte also mit Raffael vor Augen in Komposition, Stil, Kostüm, Landschaft und architektonischem Rahmen geschickt verschiedene Elemente deutscher und italienischer Kunst zu einem einheitlichen Ganzen. Quandt als seit wenigen Monaten adlig gesprochener Auftraggeber konnte sich gleichzeitig an den großen RenaissanceAuftraggebern messen.

Schnorr war mit diesen Aufträgen überglücklich. Seinem Vater schrieb er: »Ich habe die schönsten Aufträge von der Welt. Zunächst führe ich das Porträt der Madame Quandt aus, dann vollende ich das Madonnenbild für sie. $\times^{85}$ Am hier erwähnten Madonnenbild, das ebenfalls in Quandts Römer Zeit fällt, arbeitete er seit Oktober 1819. Diese Maria mit dem Kinde, heute im Wallraff-Richartz-Museum in Köln, war ein Geburtstagsgeschenk von Quandt für seine Frau. Es sollte nach seiner Vollendung in der Präsentationsanordnung im Dresdener Haus eine wichtige Funktion als Rollenbild der fürsorglichen Mutter und Gegenstück zu einer Kopie nach Raffael von Louise Seidler übernehmen, wovon noch ausführlich zu berichten sein wird (vgl. Abb. 59-60). ${ }^{86}$

Schnorrs besondere Förderung setzte sich nach Quandts Rückkehr nach Dresden fort. 1821 beauftragte er ihn mit einem Porträt des bekanntesten Modells seiner Zeit, der Vittoria Caldoni aus Albano (Abb. 2O). Ein paar Monate zuvor hatte er sich noch erhofft, die Variante von Friedrich Overbeck kaufen zu können und erkundigte sich bei Schnorr erfolglos um die Vermittlung des Bildes (Abb. 21) ${ }^{87}$ Der Besitz des Porträts war ihm wichtig, denn mochte sie »nun in antiken oder altitalienischen

S. a. Grewe 2015, S. 98-108; Kat. Dresden 2012, S. 41-42, 89-92, 235; Brückle 2001, S. 128-129.

85 Brief von Julius an Veit Schnorr vom 31.12/1.1.1819, in: SLUB, Mscr. Dresd. n Inv. 8, Bd. 1, fol. 161v. S. a. Schnorr 1886, S. 159; Kat. Berlin 2002, S. 382 .

86 Zum Entstehungsprozess siehe Kat. Leipzig/Bremen 1994, S. 212-213, Kat. Nr.6o. Rüfenacht 2018, SQ-74.

87 Brief an Schnorr vom 31.8.1821, in: SLUB, Mscr. Dresd. n Inv. 15, Bd. 31, fol. $70 v$. Quandt musste die Vorzeichnungen gekannt haben, nicht aber das ausgeführte Gemälde und fragte hier in Konkurrenz zu Kronprinz Ludwig von Bayern, der das Bild beim Künstler in Auftrag gege- 
Styl schön seÿn, schön ist sie doch gewiß und verdient durch die Kunst der Nachwelt aufbewahrt u verewigt zu werden. ${ }^{88} \mathrm{Er}$ überließ dem Künstler die Wahl, nach dem Original oder nach einer eigenhändigen Zeichnung zu malen, da es nicht so sehr auf die »wirkliche Ähnlichkeit«, sondern auf die »Auffassung der Schönheit« ankomme. ${ }^{89}$ Schnorr nahm die Aufgabe eifrig an und beschäftigte sich intensiv mit der Zeichnung. Es entstanden neun Entwürfe. Quandt war zufrieden und wünschte nur wenige Änderungen. ${ }^{\circ \circ}$ Über das Endprodukt, das er 1825 erhielt, schrieb der Sammler diplomatisch: »Ich glaube daß dieses Portrait eine schwierige Aufgabe war, weil dieses Mädchens Schönheit, wie mir scheint, weniger in der vollkommenen Entwicklung u dem Ebenmaas des Organischen, als vielmehr im Ausdruck der sittlichen Schönheit beruht. Daher kommt es, daß man so höchst verschiedenartige Portraits der Vittoria sieht, je nach dem der eine Künstler mehr sich an die äußre Erscheinung gehalten, der andere das Bild der Seele zu geben gestrebt hat. (91 $^{1}$ Quandts Anspruch einer geistigen, inneren Schönheit der Natur, die durch die Kunst hervortritt, manifestiert sich auch hier.

\section{Quandts Verhältnis zu den Nazarenern nach der Romreise}

Die Ankäufe von Werken verschiedener Nazarener Künstler, allen voran von Julius Schnorr von Carolsfeld, und die schriftlichen Quellen zeigen, dass Quandt den jungen deutschen Künstlern in Rom nahestand. Gleichzeitig unterschieden sich seine persönlichen Ansichten in einem zentralen Aspekt erheblich von denen der Lukasbrüder. Deren religiöses Sendungsbewusstsein war ihm fremd..$^{92}$ Latent zeigt sich dies bereits in Schnorrs Zeichnung Der Zug der Heiligen Drei Könige von 1819 (Abb. 22). Schnorr wollte einerseits an die gemeinsamen Spaziergänge durch die römischen Gärten und über alte Terrassen erinnern, während denen Quandt offenbar gern mittelalterliche
Minnegeschichten von Liebe, Verrat und Enttäuschung erzählt hatte. Andererseits legte er Quandt dieses wahrhaft romantische Empfinden als Weltbezogenheit aus: »Als wir zusammen in Rom umherwandelten, wurden (besonders durch die altitalienischen Gärten) die Zeiten des Mittelalters unserm Geiste lebendiger als die früheren, als die Zeiten der Römer [...]. In den Lorbeerbüschen sahen wir Liebespaare, wir hörten die Zither klingen auf der Terrasse vor der Geliebten Fenster. Wir sahen den Verräter lauschen bei der Fontäne, deren Rauschen seine Schritte übertönte. Quandt äußerte nun mehrmals, daß Darstellungen aus diesen Zeiten ihm Vergnügen machen würden, so daß bei mir der Gedanke erregt wurde, eine dergleichen zu unternehmen, da ich ohnehin immer Lust dazu hatte. Doch konnte ich mich nicht lange mit diesem Gedanken beschäftigen, ohne auf die heilige Schrift, auf die ich gern alle meine Gedanken zurückführe, geleitet zu werden, und da kam es denn, daß ich jene Gärten den thörichten Jungfrauen anweisen mußte; denn das romantische rosenfarbige Licht, in welchem jene Zeiten erscheinen, konnte in meinen Augen doch nicht die lebendige Klarheit eines reinen, heiligen Wandels überleuchten. Das verschiedene Thun und Treiben der Menschen wurde also in meinem Geiste in eine gewisse Rangordnung gebracht, welche auszusprechen ich mich um so mehr gedrungen fühlte, als ich glaubte, daß Quandt wirklich etwas mehr als billig an der Welt hing, ihm also eine Darstellung dieser Art sogar erbaulich werden könne. Um der ganzen Idee Haltung zu geben, mußten notwendig die Heilsucher, die heiligen drei Könige, der Mittelpunkt des Bildes werden $\left[\ldots . . \times \times^{93}\right.$

Die drei Könige marschieren im Bild dem Licht entgegen. Rechts daneben widmen sich die fünf klugen Jungfrauen ihren frommen, fürsorglichen und häuslichen Tätigkeiten. Im Mittelgrund links zwischen den Bäumen predigt Johannes der Täufer. Auf einer Terrasse rechts ergeben sich die fünf törichten Jungfrauen Tanz, Untätigkeit und Getändel. Diese Szenerie mit dem jungen Mann unten an der Mauer dürfte genau auf Quandts ben hatte. Koeltz 2010, S. 110-118, 250, 310. Ausführlich zu Overbecks Porträt siehe Davis 2013, S. 1-91.

88 BriefanSchnorrvom26.11.1821, in:SLUB,Mscr.Dresd.nInv.15, Bd. 31, fol. 78 r.

89 Brief an Schnorr vom 4.3.1822, in: SLUB, Mscr. Dresd. n Inv. 15, Bd. 31, fol. 82v. S. a. Davis 2013, S. 15-16; Elke Spickernagel, »Vittoria Caldoni im Kreis der Nazarener«, in: Vogel 1996, S. 114-115. Zum Auftrag Schnorr 1886, S. 254-256, 259.

90 Brief an Schnorr vom 25.4.1822, in: SLUB, Mscr. Dresd. n Inv. 15, Bd. 31, fol. 85v-86v. Zu den Vorarbeiten und der langwierigen Ausführung siehe Schnorr 1886, S. 380-381, 404, 412-416, 429, 434, 442-443, 458-459, 461-462. Ebenso die Briefe von Julius an Veit Schnorr vom 2.9.1822, 23.9.1825 und 7.9.1826, in: SLUB, Mscr. Dresd. n Inv. 8, Bd. 1, fol. 226r-227r, 266r, 278r. S. a. Kat. Hamburg/Paris 2016, S. 148-149; Koeltz 2010, S. 101-110; Teichmann 2001, S. 119-120.

91 Brief an Schnorr vom 24.8.1822, in: SLUB, Mscr. Dresd. n Inv. 15, Bd. 31, fol. 133r. Schnorrs Antwort vom 4.10.1822, in: Schnorr 1886, S. 414
(24.8.1826). Schnorr selber empfand seine Arbeit als misslungen. "Quandt mag mit dem Bilde thun, was er will: es verstecken, verbrennen oder ersäufen; mich wird es nicht kränken, denn diesmal hab ich's verdient." Brief an den Vater vom 2.11.1826, in: Schnorr 1886, S. 317; ebenso negativ im Brief an Quandt am gleichen Tag, in: München, Bayerische Staatsbibliothek, Autograph Schnorr von Carolsfeld, Julius. S. a. Kat. Hamburg/Paris 2016, S. 148; Teichmann 2001, S. 118-123; Kat. Leipzig/Bremen 1994, Nr. 42, S. 204; Bemmann 1925, S. 13. Das Original ist verschollen. Der letzte Besitznachweis mit Abbildung entstammt Sauerlandt 1908, S. VII, S. 10 (Tafel). Das Gemälde ist dort im Besitz eines Major C. Geisberg in dessen Villa in Berlin-Schöneberg verzeichnet, dem heutigen Sitz der kroatischen Botschaft. S. a. Rüfenacht 2018, SQ-88.

92 Zur Religiosität der ersten Nazarener, vor allem Overbeck und Pforr, siehe Grewe 2009, S. 19-25.

93 Schnorr 1886, S. 202-203. 


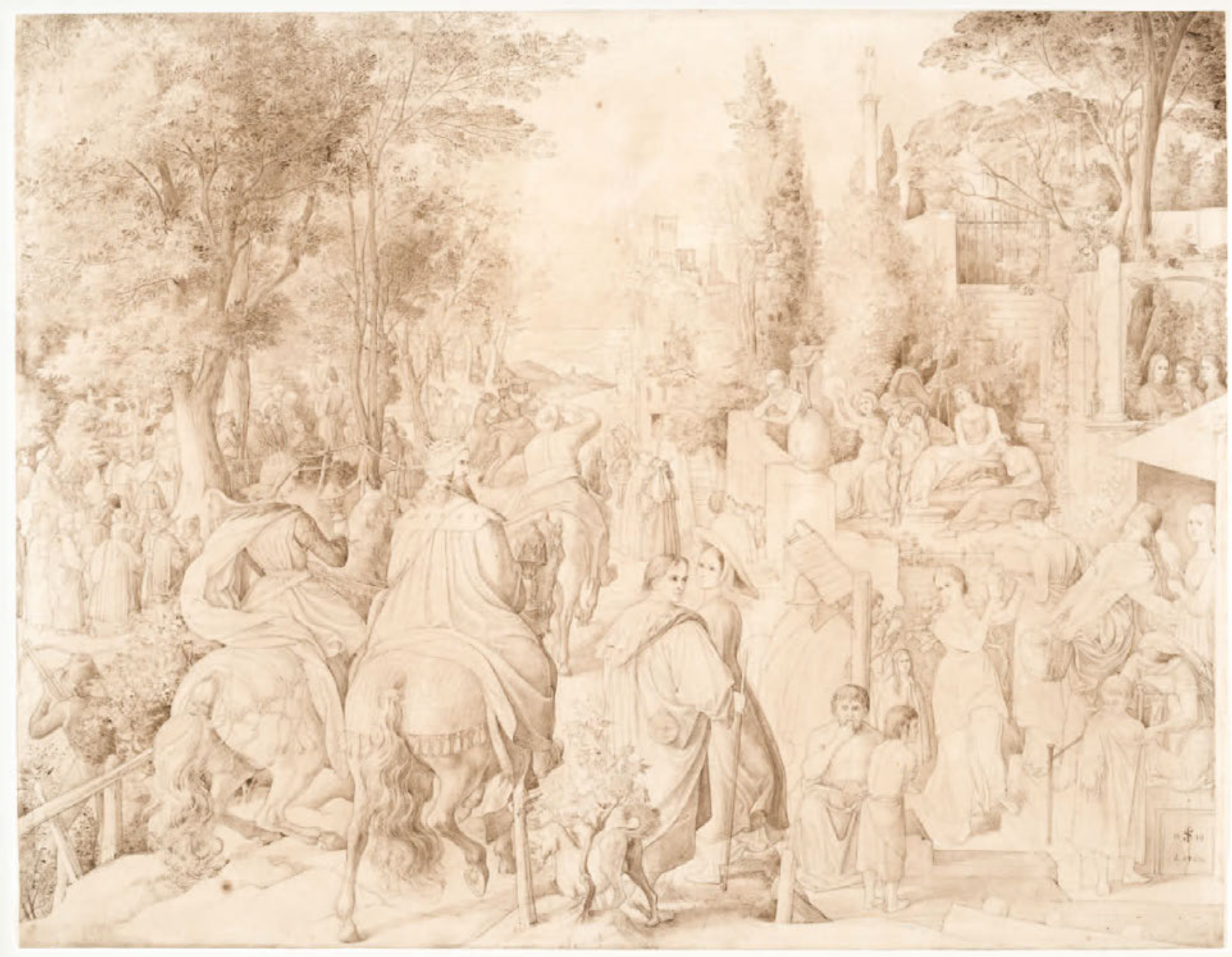

22 Julius Schnorr von Carolsfeld, Der Zug der Heiligen Drei Könige, 1819, Feder und Pinsel in Braun über Bleistift auf Velinpapier, $510 \times 657$ mm, Leipzig, Museum der bildenden Künste, Inv.-Nr. NI. 8457

Geschichten während der Spaziergänge verweisen. Unmittelbar davor geht dieser denn auch, dargestellt als Pilger, mit seiner noblen Ehefrau Clara Bianca zusammen mit den Königen ins Licht und blickt anerkennend zurück.

Schnorrs Zeichnung war also voller christlich-moralischer Assoziationen, was der Künstler in voller Absicht so angelegt hatte: »Du weißt, Quandt deutet gern und sieht manchmal in einer einfachen Darstellung unendliche Anspielungen und Beziehungen. Da wollte ich ihm nun eine Nuß zu knacken geben, ein Rätsel zu lösen, welches ihm sauer werden sollte. «94 Quandt äußerte sich über den Inhalt der Zeichnung nie näher. Einzig in einem Brief an Schnorr hatte er einen Bezug zum Zug der Heiligen Drei Könige von Benozzo Gozzoli im Palazzo Medici in Flo- renz hergestellt. Schnorr habe dessen allegorischen Gedanken des Zuges zur Krippe bestens weiterentwickelt.95

Bedenkt man Quandts andernorts vehement ausgedrückte Kritik der Allegorie und seine Ausführungen über Gozzoli und die vorraphaelischen Künstler in seinen Streifereien im Gebiete der Kunst auf einer Reise von Leipzig nach Italien, die 1819 erschienen waren, so ist nicht davon auszugehen, dass er Schnorrs moralischen Wink mit dem Zaunpfahl nicht verstanden hätte. ${ }^{96}$ So heißt es 1819 in den Streifereien über Gozzoli und seine Zeitgenossen: »Denn so wahr auch der Ausdruck in Mienen und Stellungen ist, so bis zum Erstaunen richtig viele Theile auch gezeichnet sind, [...] so ist doch immer in der Zusammenstellung etwas der Wirklichkeit widerstrebendes in den Bildern
94 Schnorr 1886, S. 203-204. Ausführlich zu den verschiedenen Bedeutungen und Assoziationen im Bild siehe Dehmer/Petri 2018, S. 23-27.

95 Dehmer/Petri 2018, S. 24.
96 Quandt 1830 (1), S. 306-314, hier S. 311-312: »Auch sucht die Allegorie durch Ideenassociation sich zu helfen und ist blos hindeutend." 
dieser alten Maler. Schon, daß wir mehrere Momente zugleich in einem Bilde erblicken, fast lächerliche Nebengruppen in den ernstesten und würdevollsten Darstellungen finden, daß viele Theile so an einander gefügt sind, als wären es Bruchstücke von mehrern Bildern, welche in einen Rahmen hätten sollen gefaßt werden, zeigt offenbar, daß die älteren Künstler in ihren historischen Gemälden, gar keine wirklichen Begebenheiten darstellen wollten. ${ }^{97}$ Dieser Gedanke ließe sich auf Schnorrs gleichzeitig entstandene Zeichnung adaptieren, verband diese doch in der ikonographischen Tradition so verschiedene Darstellungen wie die heiligen drei Könige, die klugen und törichten Jungfrauen oder die Predigt Johannis des Täufers. Es dürfte daher vielmehr an der wertvollen Freundschaft der beiden und am persönlichen Charakter der Zeichnung gelegen haben, dass Quandt Schnorrs allegorisierende Moral schlicht ignoriert hatte, zumal sich seine Frau - und damit sicher auch er selbst dieses Gehalts durchaus bewusst war..$^{9}$

Explizit wurde Quandts Unverständnis gegenüber Frömmelei und missionarischem Eifer der Nazarener schon bald nach seiner Rückkehr nach Deutschland. In einem Brief an Schnorr vom Januar 1821 wird dies deutlich und zugleich eine leise Kritik an Tendenzen der nazarenischen Malerei wahrnehmbar. Quandt kritisierte darin die Streitschrift des Altphilologen Bernhard Joseph Docen, der die zentrale Rolle des Katholizismus als Vorbild für die Künstler hervorgehoben hatte: »Diese Abhandlung hat in Deutschland großes Aufsehn gemacht u viel Anhänger gefunden, obwohl es nicht schwer wäre die Maske davon abzuziehn u das gemeine Pfaffengesicht darhinter zu entdecken. Die Kunst, welche meiner Meinung nach, aus dem ganzen Gebiet des Reinmenschlichen schöpfen, Gegenstände, Ideen und Form

97 Quandt 1819, Bd. 3, S. 150.

98 Eintrag im Tagebuch vom 24.12.1819: „Schnorr hatte eine wunderschöne Zeichnung für Quandt heimlich gemacht. [...] die Bildidee ist: das verschiedene Treiben der Menschen vorzustellen, welche alle nach einem Ziele hinstreben.« Zitiert nach Dehmer/Petri 2018, S. 23.

99 Brief vom 7.1.1821, in: SLUB, Mscr. Dresd. n Inv. 15, Bd. 31, fol. 57v-58r; s. a. Schmitz/Strobel 2001, S. 20. Docens Streitschrift Neudeutsche, religiös-patriotische Kunst. Gegen die Weimarischen Kunstfreunde erschien 1819 und richtet sich gegen den Nazarener-kritischen Aufsatz von Johann Heinrich Meyers und Goethes Neu-deutsche religiospatriotische Kunst von 1817; siehe dazu weiter unten.

100 Quandt 1831 (4), Sp. 99-100. Er pflichtet Carus an vielen Stellen bei, findet aber, dass dieser sich trotz entsprechender Argumente nicht traue, die Kunst als pantheistisch zu bezeichnen: „Der Vf. naht sich oft einer pantheistischen Ansicht der Natur und einer Erklärung wie sie auf das Gemüth wirkt und durch die Kunst aufgefasst werden soll, und spricht von einer schaffenden Natur; allein er bebt mit Schauder immer wieder vor dieser Ansicht zurück, und kann sich nicht entschließen das Lösungswort des Räthsels auszusprechen, welches doch nur durch eine pantheistische Erklärung gelöst werden kann." Quandt selber spricht seine Meinung über Kunst als Pantheismus meines Wissens nur hier in dieser Deutlichkeit aus. Vgl. hierzu auch die Ausführungen zum nazarenischen Landschaftsbild und Sicht der Natur am Beispiel Ferdinand Oliviers in Grewe 2015, S. 149-173. erhalten muß, wird darinn gar nicht berücksichtigt, sondern auf einen Kreis des Positiven beschränkt, so wohl im Felde der Geschichte als auch der Religion [...].«99 Quandt glaubte nicht, dass Religion die Triebfeder der Kunst sei, sondern vielmehr das »Reinmenschliche«. In seiner Rezension von Carl Gustav Carus' Neun Briefe über Landschaftsmalerey postulierte er am deutlichsten: »Allein die Natur ist keine Sprache und die Kunst kein Evangelium, wodurch das Göttliche erst mittelbar dem Menschen offenbart würde, vielmehr ist sie der sich offenbarte Gott unmittelbar selbst [...]. Ueberhaupt ist alle Kunst pantheistisch. ${ }^{100}$ Grundsätzlich verortete er in Zeiten wie dem Mittelalter eine starke Verbindung von Religion und Gesellschaft, die fruchtbar für die Kunst war, weil hier die menschlichen Ideale mit der Realität vereint zu sein schienen. ${ }^{101}$ Dennoch ist in dieser Vorstellungsweise die Religion nur Ausdruck des Menschen, sein Inneres und sein Denken zur Anschauung zu bringen. Dieser Akt ist nicht von einer Religion bestimmt, sondern von der Natur, welcher der Mensch angehört. ${ }^{102}$

Seine Skepsis gegenüber pietistischen Selbstverständlichkeiten äußerte sich in einem Streit mit dem äußerst frommen Schnorr. Die differenten Ansichten brachen im Zusammenhang mit zwei gleichzeitigen Berufungen des Künstlers nach Düsseldorf und München im Jahr 1826 zutage. Schnorr wollte nicht selber entscheiden und schrieb Quandt, er überlasse die Wahl seinem Gott. Der Kunstförderer sah darin eine »gefährliche, scheinbar fromme Eitelkeit«. Julius und dessen Vater Veit warfen ihm in der Folge Befangenheit gegenüber der Religion vor und die Unfähigkeit, Frömmlerei von rechtschaffenem Glauben zu unterscheiden. ${ }^{103}$ Nachdem Quandt Ende 1827 bei einem Sturz vom Gerüst einer Baustelle beide Beine gebrochen hatte,

101 Quandt 1819, Bd. 2, S. 169-171: »Daß eine Uebereinstimmung der subjectiven Anschauung und der Darstellung in höherem Grade bey den ältern Kunstwerken statt findet, als bey den neuen, ist gar nicht zu läugnen, und aus der Geschichte zu deduciren. [...] Und da alle Bildung von innen ausgehet, die Nothwendigkeit, einem idealen Ziele sich zu nähern, im Geiste liegt, so ging das Streben nach Vervollkommnung der Kunst aus dem Innern hervor. Da aber die Vollkommenheit in der Kunst in der Uebereinstimmung eines Idealen und Realen besteht, welches zu Einem Seyn im Kunstwerke, zu einem Anschauen des Idealen in einem Realen wird, beides aber nur die Betrachtung sondert, so entstanden nothwendig mit klarern, bewußtern, subjectiven Anschauungen auch bestimmtere, ausdrucksvollere, entsprechendere Bilder.«

102 Quandt 1819, Bd. 2, S. 179-180: »Der Himmel gebe, daß der Verlust der Antiken auf die Kunst heilsam wirke, und die Künstler belehre, daß die Naturschönheit die älteste und reinste Antike, und so alt wie Welt und Geist jedes wahre Kunstwerk aber, sey es heidnisch oder christlich, nur ein Abglanz von ihr ist. « Quandt 1831 (4), Sp. 98-101. Zur Verortung von Quandts Religionsverständnis in der Zeit siehe Bergmann-Gaadt 2015, S. 130-133.

103 Brief an Schnorr vom 14.4.1826, in: SLUB, Mscr. Dresd. n Inv. 15, Bd. 31, fol. 129v-130r. Die Stellungnahmen Schnorrs, in: Schnorr 1886, S. 306308, 510-518. Brief von Vater Veit an Sohn Julius Schnorr vom 6.5.1825, in: SLUB, Mscr. Dresd. n, Inv. 8, Bd. 1, fol. 274V: »Q. liebt dich wirklich ungemein; aber er ist in vorgefaßten Meinungen befangen und ver- 
zeigte sich erneut der Unterschied zwischen der frommen Schicksalsgläubigkeit Schnorrs und Quandts weltbejahendem, naturverbundenen, ja pantheistischen Gottesbild. ${ }^{104}$

Quandts Nähe zu den Nazarenern verlor sich bereits in den 1820er Jahren zunehmend, wie in seinen Schriften bemerkbar wird. Dies hängt damit zusammen, dass sich sein Interesse vermehrt der philosophischen Ästhetik zuwandte, wie verschiedentlich noch zu zeigen sein wird. Diese ließ sich aber nur schlecht einer neuen Kunst-Schule zuordnen, war sie doch in ihren philosophischen Zielen selber mit divergierenden Problemen beschäftigt, die eine eigentliche Ausbildung einer »romantischen Schule« gar nicht recht ermöglichte. ${ }^{105}$ Zudem fehlen gänzlich Hinweise, dass seine Abhandlungen für die deutschen Künstler in Rom relevant gewesen wären.

Nachträglich sah Quandt seine Beziehung zu den Nazarenern kritisch: »Damals war ich von all dem Neuen, von dem Großen berauscht [...]. Der künstlerische Gedanke wurde über die Darstellung gestellt, und darum wurden die vorraphaelischen Werke überschätzt, die späteren herabgewürdigt, oft bloß, weil sie in der Darstellung vollkommener waren. Die Wahrheit liegt hier in der Mitte zweier irriger Meinungen, denn nur wenn der Gedanke und Darstellung ganz eins und gleich vollkommen sind, ist es auch das Kunstwerk. « ${ }^{106}$ Quandts selbstkritische Verortung betrifft hier die alte Frage der querelle des anciens et des modernes. Besonders die Lukasbrüder hatten als Kritik an der akademischen Ausbildung die Rolle der antiken Kunst für die Zeitgenossen radikal hinterfragt und in der Hinwendung zur Kunst des Quattrocento und der Frührenaissance eine Wende zu einer sehr selbstreflexiven Gedanken-Kunst vollzogen. ${ }^{107}$ In jungen Jahren hatte dieser Perspektivenwechsel den jungen Dresdener Kunstfreund interessiert, doch war der in Kants Philosophie Geschulte letztlich nie von seinen Grundmaximen abgekommen, Poesie und Vernunft als wahren Motor der bildenden Künste zu verstehen. Gerade sein wiederholtes Betonen,

mag nicht sich eine Idee von einem rein religiösen und christlichen Gemüth u. Karacter ohne Uiberspannung u Frömmlerei zu machen, der alle Tugenden der schöneren Humanität in sich faßt, und zu einem Glaube an Gottes Walten u Führung in eines frommen Geistes Seele zu erheben, so schöner u edler Handlungen er auch fähig ist." 104 Zum Glaubensverständnis Quandts siehe die Briefe an Schnorr vom 20.7. und 12.8.1828, in denen er Schnorrs alttestamentarisches Urteil über die Gründe seines schweren Unfalls, bei dem er beide Beine brach, zurückwies; SLUB, Mscr. Dresd. n Inv. 15 Bd. 31, fol. 149r-155r. Die religiös-elitäre Härte von Vater und Sohn Schnorr - Quandt habe durch Leiden Würde erhalten, müsse Demut lernen, das Unglück würde zum Besten führen, etc. - ersichtlich in den Briefen der beiden vom 4.1., 13.1., 16.2. und 12.9.1828, in: SLUB, Mscr. Dresd. n Inv. 8, Bd. 1, fol. 342r-343v, 363v-364r. S. a. Maaz 1986, S. 7-8; Justi 1932, S. 80; Bemmann 1925, S. 43-44.

105 Ernst Müller, »Romantisch/Romantik«, in: ÄGB 2010, Bd. 5, S. 324 : »Der Begriff romantisch ist [...] selbst nicht geeignet, den theoretischen Kern dieser Richtung zu bestimmen.« wie wichtig die Übereinstimmung von Gedanke und Kunstwerk sei, ist weiterreichenden Diskussionen der romantischen Philosophie verpflichtet als der letztlich kleinlichen Frage, ob die antike oder mittelalterliche Kunst nun vorbildhafter für die Gegenwart sei. Dies zeigte sich schon 1819: »Zu Folge der Versicherung aller Kenner und Künstler, können wir nur die Antike in der Antike ganz kennen und würdigen lernen. [...] Man hatte vorher in der Kunst nur die Antike nachzuahmen gesucht, und sie doch stets verfehlt, weil der neuere Künstler unter andern Verhältnissen lebt, als die der antiken Welt waren. [...] Es lebte nicht der Geist der antiken Welt in den Nachbildungen. $\ll^{108} \mathrm{Ge}-$ nauso historisierte er die Kunst des Mittelalters und der Renaissance, war er sich doch bewusst, dass deren religiöse Aufgaben in seiner Zeit nicht mehr wiederholbar waren. ${ }^{109}$ Vielmehr ging es ihm um den »Geist « in der Kunst. Antike und Mittelalter dienten als ideelles Vorbild, als gleichberechtigte Referenzpunkte in der Vergangenheit für die Erschaffung von etwas Neuem.

Darin zeigt sich die Verbindung zwischen so genannten Klassizisten und Romantikern, die in der Zeit um 1800 viel wichtiger war als deren Unterschiede. Diese wurden vor allem auf dem Papier formuliert - und dies meist polemisch: Goethe wehrte sich, ebenso wie Quandt in seinem Positionsbezug gegen die Frömmelei Schnorrs, gegen religiöse Schwärmerei und weniger gegen das Mittelalter-Interesse der jungen Künstlergeneration, worauf noch zurückzukommen ist. ${ }^{110}$ Umgekehrt warfen die jungen Künstler Goethe und seinen Anhängern schwärmerische Antikenverehrung vor. ${ }^{111}$ Dennoch bezogen sich die »Romantiker« auf den Begründer der Antikenverehrung, Johann Joachim Winckelmann, der einerseits mit Nachahmung der Alten deren Idealisierung und Anpassung an die eigene Zeit und nicht deren unreflektierte Kopie meinte, vor allem aber historisierte er mit einer gänzlich neuen, als poetisch empfundenen Sprache der Kunstbeschreibung die griechische Kunst, wobei gerade ihre analytische Seite für die Kunstwissenschaft

106 Zitiert nach Bemmann 1925, S. 7, ohne Nachweis. Die Stelle konnte nicht eruiert werden. S. a. Schmitz/Strobel 2001, S. XXXIX.

$107 \mathrm{Vgl}$. Grewe 2015, S. 73-89.

108 Quandt 1819, Bd. 2, S. 164-165.

109 In gewissem Sinn steckt darin auch der rasche Niedergang nazarenischer Kunst, denn in der selbstreflexiven Einbindung der eigenen Werke in die Kunstgeschichte wurden sie selber fast von Beginn weg historisiert. Siehe dazu Grewe 2015, S. 83 am Beispiel von Peter von Cornelius' Fresken in der Loggia der Alten Pinakothek: »The Pinakothek opened to the public in 1836, but it would be another four years before the loggia decoration was finished, more than a decade after its inception in 1827. By then, the social, political, and intellectual climate had changed and the ,museum age' had dawned. When finally unveiled, Cornelius's cycle was already itself a historical document, a testimony to the spritit of a bygone era."

110 S. u. Kap. Künstler der Innerlichkeit. Zur Konkurrenz auf dem Papier siehe Joachimsthaler 2016, S. 35.

111 Siehe Beyer 2011, S. 27. 
und damit auch für Quandt und seine Zeitgenossen hoch bedeutsam war: »Keiner [kann] die höchsten Meisterwerke ohne dichterische Begeisterung verstehn und ein Kunstkenner werden. Der wahre Dichter ist der geborne Kunstkenner.«"12

Schließlich ist nicht zu unterschätzen, dass gerade die Lukasbrüder und ihre Zugewandten, mittelbar durch ihre RaffaelVerehrung, unmittelbar durch ihre künstlerische Sozialisierung an den alten Akademien und ihren Lehrern, in ihrer Kunst von antiken Vorbildern geprägt waren. Wie Cordula Grewe es beschrieben hat, benötigten sie durch ihren Willen, eine neue christliche Kunst zu machen, idealisierte künstlerische Mittel, um die biblischen Geschichten geschichtlich und zugleich allzeit gültig darzustellen: Der Winckelmann'sche Neoklassizismus bot hierfür weiterhin nützliche Möglichkeiten. Trotz aller geistigen Unterschiede liegt auch hier eine die Generationen verbindende Vorstellung eines zeitlosen Ideals, das der Vergangenheit wie auch der Gegenwart verständlich bleiben sollte. ${ }^{113}$

Für die Beurteilung von Quandts Verhältnis zu den nazarenischen Künstlern wäre ein Vergleich seiner Texte mit Wackenroder, Tieck, Novalis oder den Gebrüdern Schlegel nötig. Sie waren die zentralen Ideengeber der Lukasbrüder in Rom. ${ }^{114}$ Es muss hier genügen, ihre wichtige Rolle vorauszusetzen und abschließend nur noch auf einige Äußerungen und Netzwerke einzugehen. Quandt gehörte zu der Generation, die mit diesen Texten aufgewachsen war. Jedenfalls war ihm die prägende Rolle von Wilhelm Wackenroders und Ludwig Tiecks Herzensergießungen eines kunstliebenden Klosterbruders von 1797 bewusst, wie er in einem Brief an Schnorr feststellte. ${ }^{115} 1826$ hob er in Erwiderung auf eine Schmähschrift von einigen deutschen Künstlern in Rom, darunter Bertel Thorvaldsen, Philipp Veit und Joseph Anton Koch, noch einmal die Rolle dieser und weiterer Autoren hervor: »Ferner sollten diese Künstler doch nicht vergessen, was sie den Schriften des Fernow, Wackenröder,

112 Quandt 1844 (3), Sp. 1192. S.a. Joachimsthaler 2016, S. 31-36; Beyer 2011, S. 17-23.

113 Grewe 2015, S. 113-127, v. a. S. 116, 124-127. S. a. Bergmann-Gaadt 2015, S. 128-129, 305-306

114 Dies wurde schon früh festgestellt: Meyer/Goethe 1817 [1999], S. 124-125; Carl Friedrich von Rumohr, »Über den Einfluss der Litteratur auf die neueren Kunstbestrebungen der Deutschen«, in: Raczyński 1836-1841, S. 375. S. a. Thimann 2014, S. 42-48; Thimann 2013, S. 319322; Grewe 2007, S. 90-100; Scholl 2007, S. 139-144; Prange 2004, S. 59-60, 99-107; Locher 2001, S. 156-163, Schröter 1990, S. 340-341; Kultermann 1966, S. 145-156.

115 Brief von Quandt an Julius Schnorr vom 17.5.1818, in: Mscr Dresd. n, Inv. 15, Bd. 31, fol. 4r-v. Zitiert im Kap. Die Alten Meister. Nachstreben statt Nachahmen, Anm. 25.

116 Undatierter Brief von Quandt an Schnorr [März/August 1826], in: SLUB, Mscr. Dresd. n Inv. 15, Bd. 31, fol. 132r. Bei der Schmähschrift handelt es sich um die Betrachtungen und Meynungen über die jezt in Deutschland herrschende Kunstschreiberei des Architekten Adolf Weissenburg von 1826. Sie wurde von Ludwig Catel, Joseph Anton
Tiek, Spät [Balthasar Speth - AR] u Schorn schuldig sind, denn ohne diese u ohne dass Philosophen u Dichter die Welt durch ihre Werke zum Genuß der Kunst vorbereiteten, hätten diese Künstler schwerlich Eingang gefunden, da durch die Wissenschaft der Kunst die Lantze gebrochen wird. $\ll^{116}$

Darüber hinaus sind wohlwollende Bekundungen zwischen Quandt, Tieck und Schlegel nachweisbar, die auf überschneidende Wirkungskreise schließen lassen. Friedrich Schlegel schrieb im Dezember 1819 an seine Gemahlin Dorothea: »Quandt grüße herzlich von mir; das sind die rechten Leute, die Ihr eigentlich braucht, die doch auch in ihrer Weise etwas Rechtes von der Kunst verstehen oder es wenigstens recht meynen damit. «177 Der Kulturphilosoph und Philologe hatte Quandts Streifereien im Gebiete der Kunst auf einer Reise von Leipzig nach Italien gelesen, die 1819 erschienen waren und von dessen Förderung der neuen Kunstrichtung Zeugnis gaben.

Mit Ludwig Tieck war Quandt durch Mitgliedschaft in dessen literarischem Kreis in Dresden bekannt. Der Schriftsteller widmete den dreizehnten Band seiner Werke, die 1829 bei Reimer in Berlin erschienen waren, »dem Herrn von Quandt in Dresden«. Tieck schrieb, »wie sehr ich Sie, verehrter Freund, hochachte und wie nahe ich mich Ihnen, durch Ihren schönen und gebildeten Sinn für Kunst und Poesie, verbunden fühle [...]. Ein ächter reiner Sinn, ein Enthusiasmus für unsern vaterländischen Goethe, so wie für die Muster alter Skulptur, ein Verständniß des Rafael, eine Liebe, die unbeschränkt sich alles Edle aneignen will, wird nicht häufig gefunden: noch seltner mit so vielen Kenntnissen und dem Eifer, der Kunst selbst fortzuhelfen, vereinigt. « ${ }^{118}$ Quandt war begeistert von der Widmung und dankte in einem Antwortbrief, dass er ihn damit für die Nachwelt in Erinnerung behalte. In den Worten Tiecks entfaltet sich das Wohlwollen, das Quandt in seinen frühen Dresdener Jahren seitens der deutschen Künstler entgegenkam. ${ }^{19}$

Koch, Johannes und Franz Riepenhausen, Johann Martin von Rohden, Bertel Thorvaldsen, Johann Christian Reinhart und Philipp Veit unterzeichnet. S. a. Stolzenburg 2012, S. 84; Kat. Hamburg/München 2012, Kat. Nr. 245

117 Friedrich an Dorothea Schlegel am 23.11.1819: »/ch lese seine Reise [die Streifereien von 1819 - AR] mit dem größten Vergnügen, wegen der ungezwungenen, klaren, leichten, lebendigen und doch gefühlvollen Art und Denkart und Schreibart.« Schlegel 1980, S. 262, 247. S.a. Schmitz/Strobel 2001, S. XXXV. Quandt wurde gegen Ende seines Lebens Schlegels Ansichten gegenüber kritisch und schrieb 1856, dieser habe vor allem Kunstansichten entwickelt, um »außerordentliche Meinungen« wiederzugeben. Quandt 1856, S. 5 .

118 Tieck 1829, [s. p.]. Zu Tiecks literarischem Kreis siehe Richter/Strobel 2001, S. 129-139; Klecker 1997, S. 243

119 Quandt an Tieck am 12.10.1829, in: Tieck 1864, S. 82: „Durch dieses öffentliche Zeugniß Ihres Wohlwollens haben Sie die Mitwelt mir befreundet und mein Andenken für die Nachwelt aufbewahrt und mich ohne Mühe und Verdienst, zum berühmten Manne gemacht, also für mich gethan, was ich nicht zu erreichen vermocht hätte.« 
Wenn Quandt auch nicht als Theoretiker der Nazarener bezeichnet werden kann, so war er für die deutschen Künstler in Rom eine bedeutende Persönlichkeit. Womöglich lag dies in seiner handfesten Art, Taten auf seine vielen lobenden Worte in Artikeln und Büchern folgen zu lassen. Indem er Aufträge vergab und Ankäufe tätigte, förderte er zahlreiche Künstler. Louise Seidler schrieb rückblickend: »[...] Herr von Quandt war sich gleich geblieben; er hatte gethan, was Tausende mit ihrem Gelde nicht thun würden, wenn sie auch noch so sehr mit ihrem Mäcenatenthum prunken. Fürsten leuchtete er als Muster eines Kunstbeschützers voran, und wenn sein Beispiel viele Nachahmung weckte, so stünde manches besser!«120 Wie sich sein Verhältnis zu der neudeutschen, nazarenischen Kunst in den Jahren nach seinem Römer Aufenthalt entwickelt hatte, wird im Kontext seiner Arbeit im Sächsischen Kunstverein und seiner Korrespondenz mit Goethe noch einmal differenziert aufgegriffen.

\section{Künstlerförderung an der Großen Klostergasse in Dresden}

Mit der Rückkehr aus Rom im Sommer 1820 fand die Förderung zeitgenössischer Künstler in Dresden ihre Fortsetzung. ${ }^{121}$ Quandt hatte in der Zeit seiner Abwesenheit zwei Häuser an der Neustädter Großen Klostergasse gekauft und bis 1824 großzügig umbauen lassen. ${ }^{122}$ Das Dresdener Heim wurde zum Treffpunkt der Kunstschaffenden. Adrian Ludwig Richter erinnerte sich:»Den bedeutendsten Einfluß auf Kunst und Künstler übte zu jener Zeit in Dresden der Baron von Quandt. [...] Sein angenehm gelegenes Haus mit der vorzüglichen Gemäldesammlung neuerer deutscher und mehrerer Alter Meister bildete öfters den Sammelplatz von Künstlern und Kunstfreunden. [...] Zu allen Zeiten haben Männer, welche, durch Vermögen begünstigt, eine unabhängige Stellung einnahmen und mit lebhaftem Geist, Verständnis und warmer Überzeugung eine bestimmte

120 Seidler 2003, S. 291. Ähnlich Schnorr 1886, S. 180: „So zieht denn auf einmal fort, was in dem letzten halben Jahre mächtig helfend in die Speichen des Kunstrades eingegriffen hat.« S. a. Schlegel 1980, S. 243244; Pecht 1877, S. 62-63.

121 Die Reiseroute verlief via Florenz, Mailand, Genf, Bern, Zürich, Basel, Straßburg, Paris und einer Zwischenstation bei Goethe in Weimar. Siehe die Briefe von Quandt an Veit Schnorr vom 9.7.1820 und an Julius Schnorr vom 25.9.1820, in: SLUB, Mscr. Dresd. n Inv. 8, Bd. 2, fol. $196 \mathrm{v}$ und Inv. 15, Bd. 31, fol. 4Or. S. a. Kat. Dresden 2017, S. 21.

122 Zum Hausbau und den zugehörigen Projekten siehe weiter unten.

123 Richter 1909, S. 325. S. a. Pecht 1877, S. 63; Böttiger 1822, S. 61.

124 Beim von Richter erwähnten Bild Götzloffs muss es sich um den Uttewalder Grund handeln, eines von sehr wenigen Gemälden einer sächsischen Landschaft dieses Künstlers in der Tradition Caspar David Friedrichs, jedoch ohne inhaltliche Überhöhung. Götzloff weilte ab 1821 in Rom und malte danach nur noch italienische Veduten. Von diesen besaß Quandt keine; Kat. Lübeck/Koblenz 2014, S. 9-13. Zu
Richtung verfolgten, wohltätig fördernd auf die verwandten Elemente eingewirkt, indem sie für das Zerstreute einen Sammelpunkt bildeten, von dem aus das Leben sich erhöhte und in weitere Kreise verbreitete. So war es hier bei Quandt. $\ll^{123}$ Richter schrieb einigen Landschaftsgemälden in Quandts Sammlung eine wichtige Rolle für seine künstlerische Entwicklung zu. So schrieb der junge Künstler im Jahr 1822, die Landschaften von Carl Wilhelm Götzloff, Adam Klein und Franz Catel, insbesondere aber die in Rom angekaufte südliche Landschaft Johann Martin von Rohdens hätten ihn für den Umgang mit den Eigenheiten der Natur im Gemälde sensibilisiert (vgl. Abb. 64). ${ }^{124} \mathrm{Er}$ empfand deren unakademische Kunst als »höchst liebevolles Anschließen an die Natur, geadelt durch ein gewisses Stilgefühl, welches sie den ältesten Meistern abgelernt hatten«. Genau dies war Quandts Anliegen, als er seine Sammlung einrichtete. ${ }^{125}$

Nachfolgend werden zwei besonders begünstigte Landschaftsmaler beispielhaft herausgegriffen. ${ }^{126}$ Richter war wohl derjenige Künstler, der Quandts kontinuierlichste Unterstützung erfuhr. Dies begann mit einer Rezension der Dresdener Akademieausstellung im Herbst 1824, fand eine Fortsetzung in verschiedenen Ankaufsempfehlungen, als Quandt Präsident des Komitees des Sächsischen Kunstvereins war und schlug sich noch 1848 in einem rühmenden Bericht nieder. ${ }^{127}$ Zudem kaufte ihm der Dresdener Mäzen vier Landschaften ab. Drei dieser Gemälde - die Abendandacht (Abb. 23) sowie die beiden Pendants Ariccia (Der Morgen) und Civitella (Der Abend) (vgl. Abb. 56-57) - werden im Rahmen ihrer prominenten Präsentation in Quandts Sammlung noch ausführlicher diskutiert. Der vierte Ankauf war die Überfahrt über die Elbe am Schreckenstein (vgl. Abb. 10). Nachdem Carl Friedrich von Rumohr Richter kritisiert hatte, das Italienische liege ihm nicht, wurde dem Künstler die Zuwendung zur deutschen Landschaftsdarstellung allgemein attestiert. ${ }^{128}$ Quandt bezeichnete Richters Fähigkeiten als »mehr auf die hohen, nordischen Gebirgsländer von seiner Natur hingewiesen [...] als auf südliche, heiter und groß-

den Werken der hier erwähnten Künstler in Quandts Sammlung siehe Rüfenacht 2018, SQ-64, SQ-80 (Catel), SQ-81, SQ-86, SQ-90 (Klein), SQ-138 (Götzloff).

125 Zur Rolle der Alten Meister in Quandts Sammlung siehe unten. Richter 1909, S. 111. S. a. Neidhardt 1976, S. 248; Bemmann 1925, S. 21 .

126 Weitere Ankäufe werden in nachfolgenden Kapiteln diskutiert. Für einen Überblick über die Neuen Meister in seiner Sammlung siehe Rüfenacht 2018, S. 6-45.

127 Quandt 1824, S. 366. Richter im Tagebuch zum 3.12.1824: »Mein Bild war darin [im Kunstblatt - AR] gewaltig gelobt, und so wenig ich auch von allen Rezensionen halte, so that es mir doch sehr wohl, und die Eitelkeit regte sich gewaltig.« Zitiert nach: Kat. Dresden/München 2003, S. 126, 166, 170. Quandts Empfehlungen fanden nicht immer Anklang, so dass zum Leidwesen Richters mehrere Bilder abgelehnt wurden; Richter 1909, S. 348-349; Quandt 1848, S. 239-240. S. a. Spitzer 2007, S. 6-7.

128 Kat. Dresden/München 2003, Kat. Nr. 26, S. 200-206. Zu Rumohrs Kritik ebd., S. 110, 179 


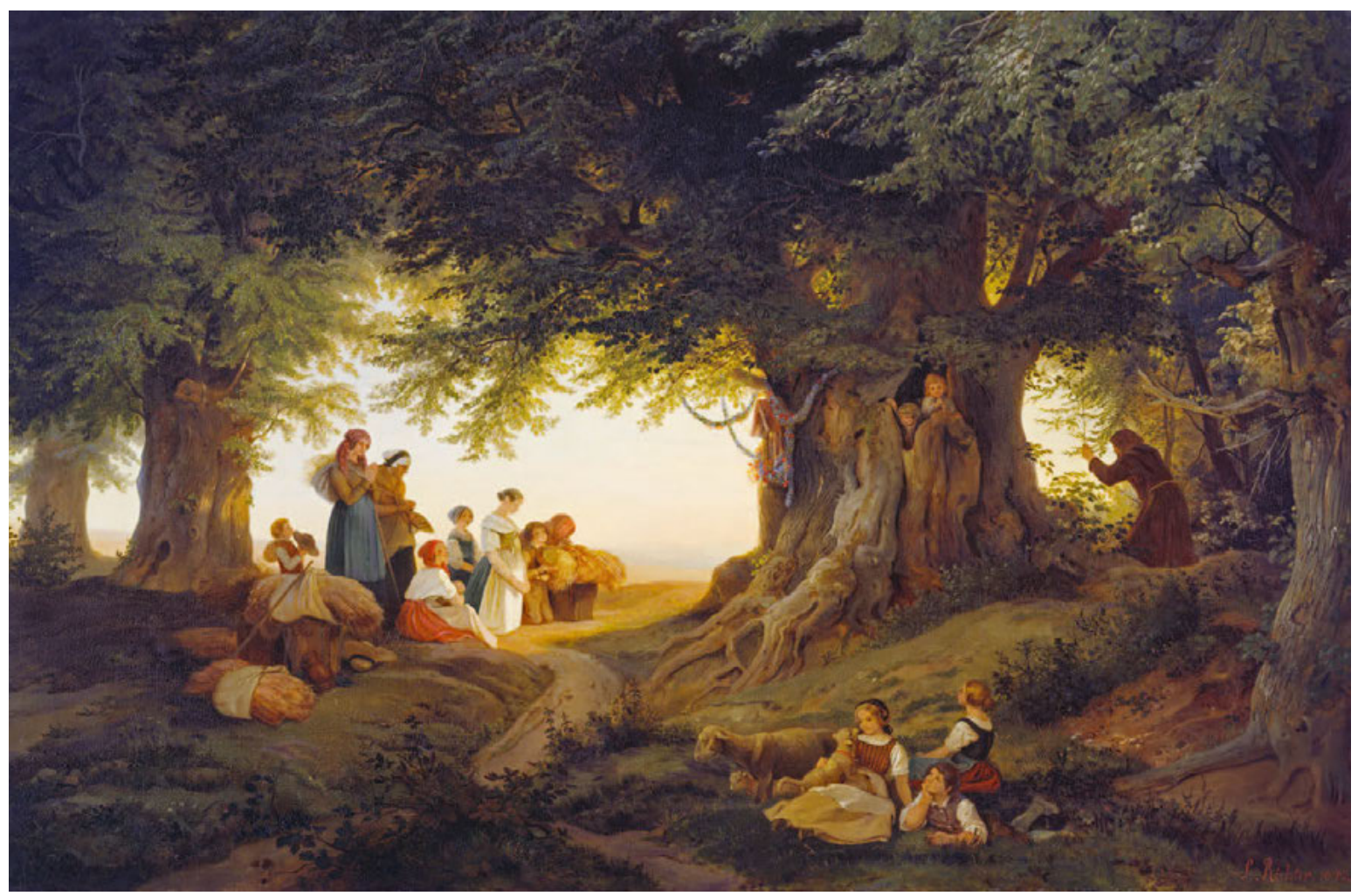

23 Adrian Ludwig Richter, Abendandacht (Abendläuten), 1842, Öl auf Leinwand, $70 \times 105$ cm, Leipzig, Museum der bildenden Künste, Inv.-Nr. G 201

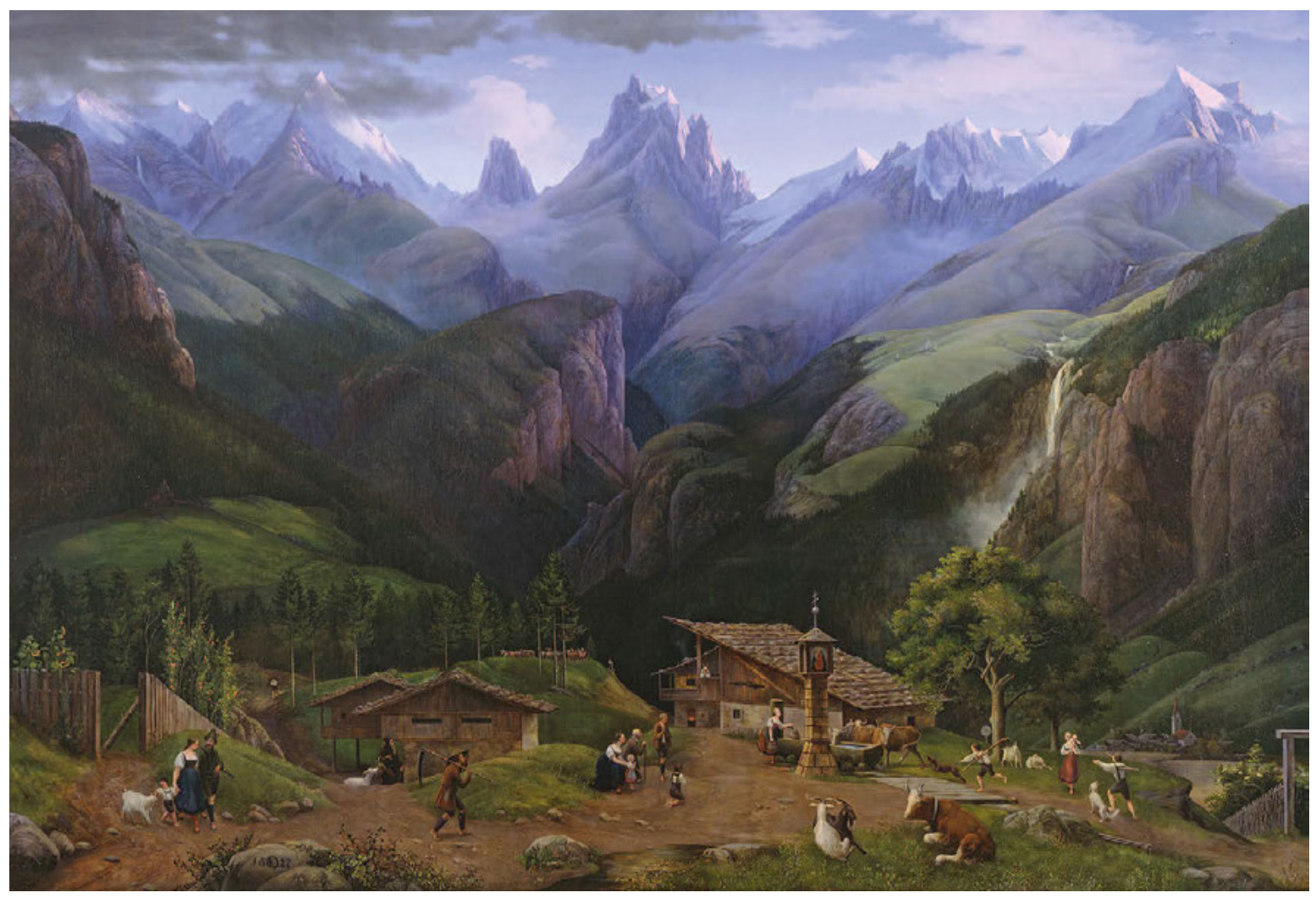

24 Ernst Ferdinand Oehme, Ave Maria. Abend in den Tiroler Alpen, 1827, Öl auf Leinwand, $114 \times 170 \mathrm{~cm}$, Berlin, SMB, Alte Nationalgalerie, Inv.-Nr. A III 494 
artig sich ausbreitende Gegenden. $\ll^{129}$ Die Überfahrt erwuchs zur Ikone der deutschen Spätromantik.130 Zusammen mit der Abendandacht erfuhr sie vor allem wegen ihrer stimmigen Darstellung der Natur und dem Fokus auf die Figuren besondere Anerkennung. ${ }^{131}$ In dem Motiv des abendlichen Gebets am knorrigen Baum sei, so Quandt, »alles Gottesdienst, sowohl das Naturleben in Bäumen, Gräsern u Sonnenlicht, als auch in den Betenden u dem Kinderspiele. Leis pulsirendes, athmendes Leben durchdringt das Ganze $\mathrm{u}$ eine Ruhe $\mathrm{u}$ Seligkeit haucht mich wie eine kühlende Abendluft nach heißem Tage aus diesem Bilde an. Es ist dies Bild ein recht eigentlicher Feierabend. $\ll^{132}$

Für Richters Freund Ernst Ferdinand Oehme setzte sich Quandt mit dem Kauf von fünf Gemälden ein. Wie Richter beherrschte Oehme in seiner Malerei die nördliche Landschaft besser als die südliche. Seine Vorlagen zum Bergbild Ave Maria. Abend in den Tiroler Alpen von 1827 (Abb. 24) waren auf gutem Weg und Quandt bemerkte: »Oehme schien große Lust z $[\mathrm{u}]$ haben, dies Bild in Oel zu malen, u ich habe ihm Gelegenheit dazu gegeben, in dem ich ihm das Bild im Großen auszuführen auftrug.« Schließlich lobte der Mäzen das vollendete Gemälde: »Hoch über den Wäldern u Gebirgen leuchten die Gipfel der Eishöhen im Glanz der Sonne, welche schon für die Thalbewohner verschwunden ist. In der That spricht sich ein heiliger Ernst in diesem Bilde aus, eine Gebetsstimmung, weshalb es mit Recht ein Ave Maria heißen kann.«쪼 In weiteren Artikeln äußerte er sich positiv zu seinen Landschaften und schätzte an ihnen ihre »beseelte $[\mathrm{n}]$ Anschauungen der Natur «.134 Mit dem Gemälde Dittersbacher Grund, das Oehme auf Quandts Rittergut gemalt hatte, entstand zudem ein Bild, das im Hängungssystem des Sammlers mit einer Landschaft des niederländischen Meisters des 17. Jahrhunderts Jacob van Ruisdael ein erstaunliches Gegenüber erhielt. Dieses Pendant wird in einem nachfolgenden Kapitel ausführlich kontextualisiert (vgl. Abb. 62-63).

Quandts Methode, Künstler durch Ankäufe zu unterstützen, war vor allem in den 1820er und 1830er Jahren wichtig. Seine Interessen und seine Teilnahme am internationalen, deutschen und lokalen Kunstleben ermöglichten ihm in diesen Jahren eine umfassende Künstlerförderung, deren weitere Ausprägungen in

129 Quandt 1824, S. 366

130 Die Einbindung markanter Figuren, die mit dem Historiengemälde vergleichbar sind, spielen in der Rezeption des Werks eine wichtige Rolle; Rüfenacht 2018, SQ-78. Kat. Dresden/München 2003, S. 28-29. S. a. Spitzer 2007, S. 42; Hans Joachim Neidhardt, »Bildhauerkunst und Malerei«, in: Gross et al. 2005/06, S. 705-711.

131 Kat. Dresden/München 2003, S. 18, 26-31. Zur Abendandacht siehe ebd., Kat. Nr. 32, S. 225-228; Rüfenacht 2018, SQ-65. Zu den Entwicklungsschritten Richters in Italien s. a. Neidhardt 1976, S. 273.

132 Brief an Georg Schöler vom 29.11.1845, in: München, Bayerische Staatsbibliothek, Autograph Quandt, Johann Gottlob von. S. a. Grossmann 1925-1928, S. 140; Bemmann 1925, S. 22f. Eine weitere Beschreibung in Quandt 1848, S. 240. den nachfolgenden Kapiteln noch ausführlich thematisiert werden. Bernhard Maaz konnte in seiner akribischen Analyse von Quandts Aufträgen und Ankäufen feststellen, dass sein Wirkungskreis in diesen Jahren wesentlich weiter gefasst war als in seinen letzten beiden Lebensjahrzehnten. In den 1840er Jahren wich die breite Ankaufspolitik Aufträgen an Freunde: So ist Adrian Ludwig Richter wohl eher aus diesem Grund und weniger wegen seiner spätromantischen Malerei unterstützt worden, denn andere Spätromantiker nahm der Mäzen, soweit es in den Quellen ersichtlich wird, kaum mehr wahr. ${ }^{135}$ Zugleich war er sich auch selber bewusst, dass er je länger je weniger Einfluss auf das Kunstleben nehmen konnte. Am Beispiel Richters zeigt sich eine Enttäuschung über die Anerkennung seiner gezielten Förderung von Künstlern durch Rezensionen und Ankäufe: »[...] sehr wohl fühle ich, daß [...] das, was ich über Richter gesagt habe, ein Nichts sey. [...] da aber unser Künstler weder zu einer Gegenseitigenruhmversicherungsgesellschaft noch Tadelhagelentschädigungsassekuranzanstalt gehört, so ist er nicht nach Verdienst bekannt genug. Daß ich ihn nicht zum berühmten Manne stempeln konnte, versteht sich von selbst, da, was ich auch über ihn [...] sagte, Leute von Kunstkennermetier gewiß nicht beachtet haben. $\ll^{36}$ Wenn Richter als romantischer Landschaftsmaler bis heute hinlänglich bekannt ist, zeigen sich doch hier gewisse Zweifel über seine eigene Anerkennung. Tatsächlich kümmerte er sich im fortgeschrittenen Alter immer weniger um die künstlerischen Tagesaktualitäten. So fragte er 1855 bei Richter nach, wie es um die jungen Künstler stehe: »Da mir nun aber die jüngeren Künstler sonst sämmtlich aus den Augen gekommen sind, so ersuche ich Sie mir mitzutheilen welche Schüler sich vorzüglich ausgezeichnet. Daß mir die jüngeren Künstler sämmtlich unbekannt geblieben sind, beweist daß ich veraltet bin, denn junge Männer schließen sich nicht leicht an Greise an. « $^{137}$ Sein Lebensziel, die Kunst und die Künstler durch Ankäufe und tatkräftige Unterstützung zu fördern und dadurch selber Teil einer großen gesellschaftlichen Entwicklung zu sein, war damit gegen Ende seines Lebens etwas undeutlich geworden. Dennoch hat die Politik seiner Ankäufe gezeigt, dass Quandt in den meisten Fällen nach einem übergeordneten Kunstideal strebte.

133 Beide Zitate im Brief an Schnorr vom 5.12.1825, in: SLUB, Mscr. Dresd. n Inv. 15, Bd. 31, fol. 125V. Rüfenacht 2018, SQ-50.

134 Brief von Schnorr an Quandt vom 22.7.1825, in: Schnorr 1886, S. 490; Quandt über das Alpenglühen im Brief an Schnorr vom 5.12.1825, in: SLUB, Mscr. Dresd. n Inv. 15, Bd. 31, fol. 125v. S. a. Kat. Dresden/Lübeck 1997, S. 14-15, 19-20, 212-213.

135 Maaz 1986, S. 18-65, hier S. 59.

136 Quandt 1848, S. 239.

137 Brief von Quandt an Adrian Ludwig Richter vom 24.2.1855, in: München, Bayerische Staatsbibliothek, Autograph Quandt, Johann Gottlob von. 


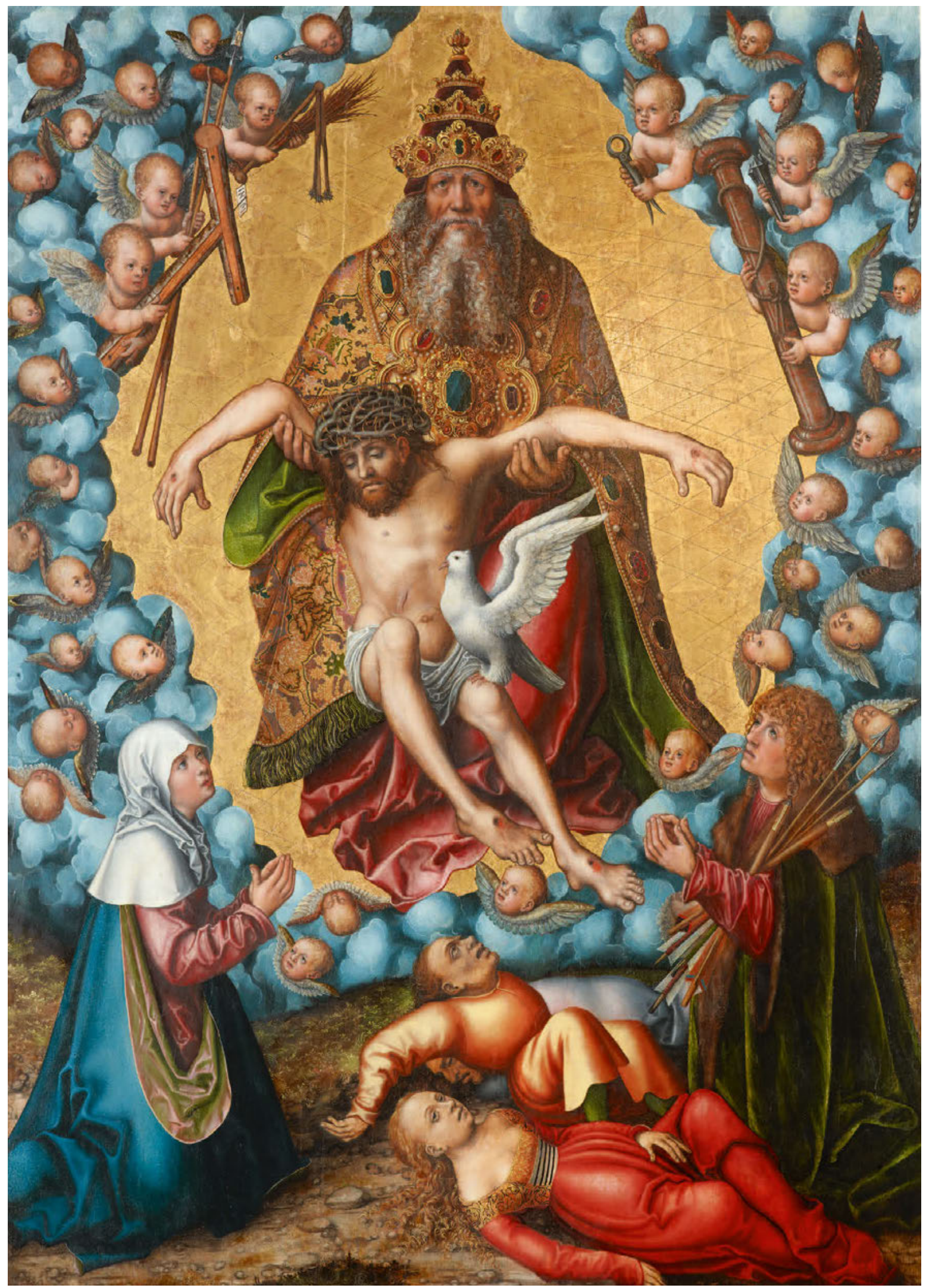

25 Lucas Cranach der Ältere, Die heilige Dreifaltigkeit, um 1515, Öl auf Holz, 142,5 × 102 cm, Leipzig, Museum der bildenden Künste, Inv.-Nr. G 248 


\section{DIE ALTEN MEISTER: Nachstreben statt Nachahmen}

Durch seine Ankäufe versuchte Quandt, zeitgenössische Künstler zu fördern und ihnen die Herstellung von Kunstwerken zu ermöglichen, denn er setzte große Hoffnungen in das deutsche Kunstschaffen seiner Zeit. Um die Qualität dieser Kunst zu verbessern, glaubte er die Kenntnis vergangener Kunstepochen verbreiten zu müssen. Er war überzeugt, dass die Werke Alter Meister vorbildlich für eine neue Malerei seien. Damit wurde deren Studium und die Förderung der Kenntnis dieser Werke für ihn sehr wichtig. Besonders die altdeutschen Gemälde des Spätmittelalters spielten bereits in Quandts jungen Jahren eine wichtige Rolle. Dank ihnen schaffte er den Eintritt in den Kreis der anerkannten Kunstschriftsteller und entwickelte über die Jahre eine große Kennerschaft.

\section{Erlebnisse, Entdeckungen, Erläuterungen}

In seiner Autobiographie beschreibt Quandt ein Schlüsselerlebnis, das ihm die altdeutsche Kunst nahegebracht habe: Auf einer Reise mit seinem Vater nach Annaberg im sächsischen Erzgebirge ließ er sich während der Reparatur der Kutsche die Annenkirche aufschließen. »Wie war er aber ergriffen und überrascht, als er zum erstenmal in seinem Leben Werke eines sinnvollen Meisters des 16ten Jahrhunderts erblickte [...]. Werke der Malerei an dem Orte ihrer Bestimmung [machen] doch immer eine ergreifendere Wirkung, als wenn sie in Gallerien versetzt worden sind. $\ll^{1}$ Es handelte sich um altdeutsche Gemälde, darunter solche nach Martin Schongauer und Albrecht Dürer, aber auch nach Hans Memling. Dieses Erlebnis regte Quandt zu vertieften kunsthistorischen Studien, besonders der Alten Meister, an und führte 1811 zu seinem ersten Aufsatz in der Zeitung für die elegante Welt. Triebfeder war dem

1 Quandt 1828 (2), S. 137.

2 Quandt 1811, Sp. 1593-1598; Quandt 1812, Sp. 85-86. Zur Rolle der Franzosen bei der Wiederentdeckung deutscher Alter Meister s. a. Savoy 2011, S. 143-145.

3 Quandt besuchte die Sammlung der Gebrüder Boisserée mehrmals und stand mit Sulpiz auch in brieflichem Kontakt. Siehe Brief von Sulpiz Boisserée an Quandt, nicht datiert [Poststempel: Stuttgart, 16.5.1827], in: Krakau, Biblioteka Jagiellonska, Autographen Sammlung, Boisserée [vor 1945 Sammlung Autographa der Preußischen Staatsbibliothek Berlin]. Zu einem Besuch der Sammlung Boisserée siehe den jungen Kunstfreund seine patriotische Liebe, die als Folge von Napoleons Eroberungen in bildungsbürgerlichen Kreisen weit verbreitet war: »Wer ein Freund teutscher Kunst und teutschen Sinnes ist, dem werden solche Werke die größte Freude gewähren, in welchen beides in einem verklärten Lichte erscheinet. [...] Einen Schatz dieser Art besitzt Annaberg in Sachsen, und so viel ich weiß, ist der Kunstreichthum dieser Stadt fast völlig unbekannt. $\ll^{2}$ Der Artikel stieß auf viel Wohlwollen, so dass er weitere Texte schreiben konnte. Das Interesse an deutscher, mittelalterlicher Kunst war groß, so dass Quandt mit seinen Entdeckungen und Aufsätzen hier nur anzuknüpfen brauchte. Dies zeigt sich auch darin, dass der Göttinger Philosophieprofessor und Maler Johann Dominicus Fiorillo in den gleichen Jahren die Bände zur deutschen und niederländischen Malerei in seiner Geschichte der zeichnenden Künste veröffentlichte. Ähnlich den Gebrüdern Boisserée erwarb sich Quandt nach und nach den Ruf eines Kenners altdeutscher Kunst und begann, wie die beiden Kölner, eine eigene Sammlung aufzubauen. ${ }^{3}$

Ein weiteres Schlüsselereignis für Quandt war die Auffindung altdeutscher Bilder auf dem Dachboden der Nikolaikirche in Leipzig. Der Fund bildet bis heute einen bedeutenden Grundbestand spätmittelalterlicher Malerei des Museums der bildenden Künste. ${ }^{4}$ Das Leipziger Ratsmitglied Christian Gottlob Frege beauftragte den Kunstkenner anfangs 1815, in der Thomaskirche einige alte Gemälde zu begutachten. Sie waren im Rahmen der Untersuchungen aller Leipziger Kirchen auf Schäden nach der Völkerschlacht zum Vorschein gekommen. Hieraus erhoffte sich Quandt weitere Funde in der Nikolaikirche. Tatsächlich entdeckte er auf dem Dachboden mehrere Tafeln, von denen er vier Lucas Cranach d. Ä. zuschrieb. Diese sakralen Kunstwerke waren bei der Umgestaltung der Kirche

Brief von Quandt an Christian August Heinrich Clodius, nicht datiert [1819], in: SLUB, Mscr. Dresd. App. 204, Nr. 92. S. a. Quandt 1826 (1), S. 273. Zu Fiorillos Bänden über Deutschland und die Niederlanden in seiner Geschichte der zeichnenden Künste, die zwischen 1815 und 1820 erschienen, siehe Niehr 1997, S. 292-305; Schrapel 1997, S. 306-327. Quandt besaß Fiorillos Werk in seiner Bibliothek, siehe Kat. Quandt 1860 (1), S. 155. Zum aufkommenden Interesse an der altdeutschen Kunst siehe Locher 2001, S. 128-132.

4 Siebter Bericht des Leipziger Kunstvereins, Leipzig 1850, S. 3. Siehe Rüfenacht 2016, S. 88-91. 
1785 dort verstaut worden. ${ }^{5}$ Er veröffentlichte daraufhin in der »Zeitung für die elegante Welt« einen langen Artikel. Dem Geschmack der Zeit und dem neuen Interesse an altdeutscher Kunst entsprechend, berichtete er positiv über die aufgefundenen Tafeln, vor allem über diejenigen mit Cranachs Monogramm. Die Restaurierung einer Auswahl der besten Tafeln beaufsichtigte er. So wurde die von Würmern zernagte Tafel von Cranachs Die heilige Dreifaltigkeit (Abb. 25), die er noch dem jungen Albrecht Dürer zuschreiben wollte, auf Leinwand und neues Holz übertragen. ${ }^{6}$ In wenigen Fällen äußerte er sich negativ, beispielsweise über die Kreuzigung von Georg Lemberger, der Deckelinnenseite des so genannten Schmidburg-Epitaphs (Abb. 26). Er empfand sie als »Zerrbild «? Ein Teil der aufgefundenen Gemälde wurde in der Ratsbibliothek des Gewandhauses ausgestellt, die als weniger wichtig empfundenen Tafeln wie Lembergers Kreuzigung gleichenorts eingelagert. Quandt erinnerte sich noch Jahre später an dieses »merkwürdige Bild«, als es darum ging, Bestände für das neu zu gründende Leipziger Museum zu finden. ${ }^{8} 1848$ wurde der gesamte Bestand durch das neue Museum aufgenommen und vom Gewandhaus an seinen Standort in der Bürgerschule überführt.

Quandts Fund auf den Leipziger Kirchendachböden stieß auf viel Resonanz. Selbst Goethe publizierte schon kurz nach der Entdeckung im Morgenblatt für gebildete Stände einen Artikel und schrieb den Fund dem jungen Leipziger Kunstfreund zu. ${ }^{9}$ Wenn auch nicht restlos geklärt ist, ob der Weimarer Dichter selbst den Text oder nur die kurze Einleitung verfasst, ob Quandt persönlich die Erläuterungen über die Gemälde vorformuliert oder ein Goethe-Freund aus dem Leipziger oder Weimarer Netzwerk die entsprechenden Passagen geliefert hat, so wurde der Aufsatz doch 1830 in die von Goethe noch persönlich beaufsichtigte Werkausgabe aufgenommen und somit mit seinem Namen beglaubigt. ${ }^{10}$ Quandt übersandte aus Dankbarkeit die Umrissstiche einiger Köpfe auf den Gemälden an den Dichterfürsten."

5 Susanne Heiland hat in einem Aufsatz 1997 die Zuschreibung des Fundes an Quandt hinterfragt. Ihre Argumente sind zurückzuweisen, da Quandt nachweisbar noch Jahre später akribische Kenntnisse über den Verbleib der Bilder hatte, so dass seine herausragende Rolle nicht geringgeschätzt werden kann. Zu der Diskussion der Argumente mit neuen Quellen siehe Rüfenacht 2016, S. 88-91; Heiland 1997, S. 10-18. S. a. Schölzel 2012, S. 140; Reindl 2006, S. 200; Schmitz/Strobel 2001, S. 3-17; Kat. Leipzig 1997, S. 154-163; Magirius 1989, S. 50; Neidhardt 1976, S. 236f.; Bemmann 1925, S. 4; Kneschke 1867, S. 367; Quandt 1831 (1), S. 35; Meyer/Goethe 1817 [1999], S. 127. Der Fund legte nicht den Grundstein für Quandts Gemäldesammlung, wie Klecker 1997, S. 243 meint.

6 Quandt 1815, Nr. 123, Sp. 979.

7 Quandt 1815, Nrn. 121-126, Sp. 961-1006; Das »Zerrbild« Lembergers war wohl tatsächlich eines, war es doch in Untersicht ausgeführt und zu Quandts Zeit wohl zu tief gehängt; siehe dazu Reindl 2006, S. 200-203.

8 Brief von Johann Gottlob von Quandt an das Komitee des Leipziger

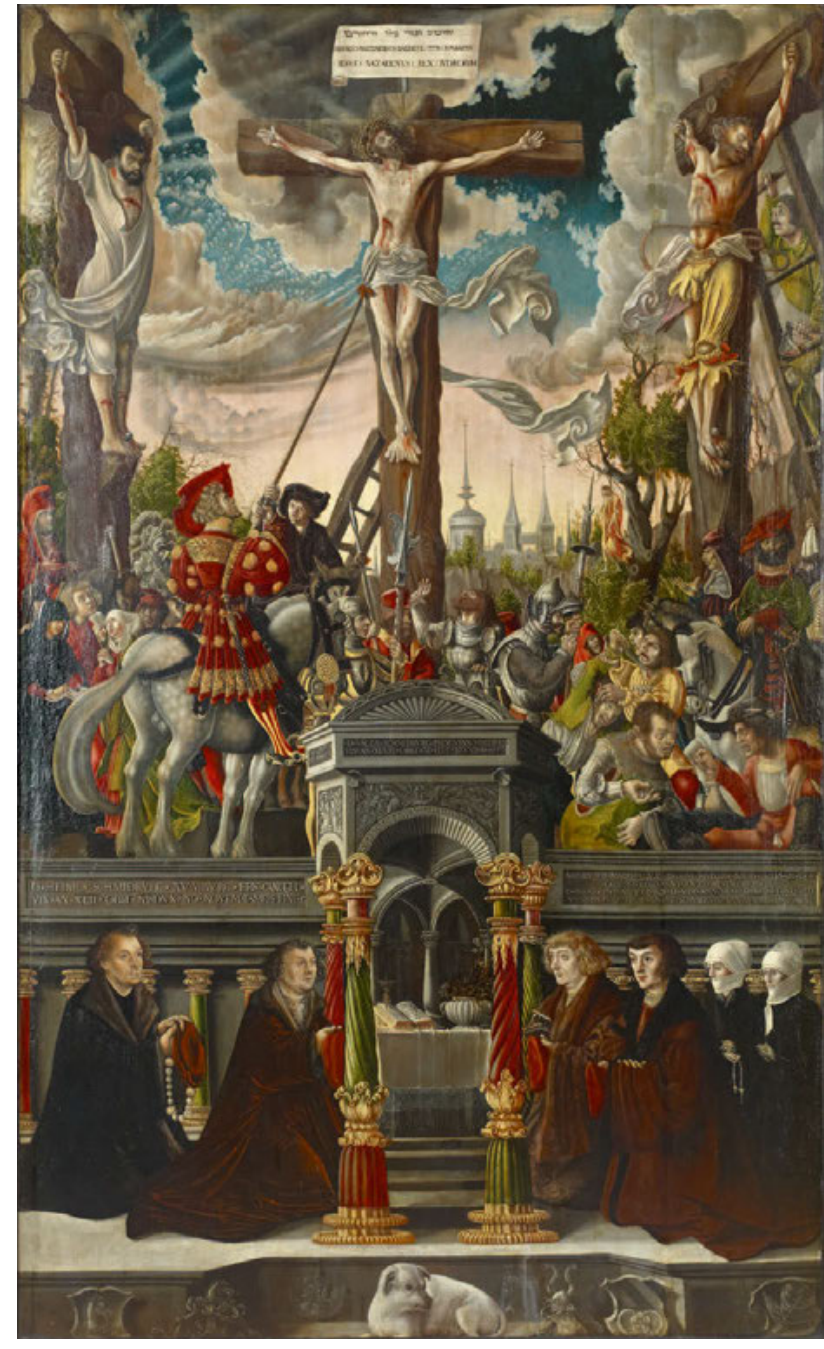

26 Georg Lemberger, Kreuzigung Christi mit Stiftern, 1522, Öl auf Holz, $142,7 \times 84,5$ cm, Leipzig, Museum der bildenden Künste, Inv.-Nr. G 609

Spätestens mit dem Attest der Weimarer Kunstfreunde und Goethes zeigte sich die Bedeutung von Quandts Fund. Er bot dem jungen Leipziger einerseits die Schaffung eines Netz-

Kunstvereines, 24.3.1837, in: MbdK, Kunst Nr. 8, wie Anm. 1, Kunst Nr. 4d, fol. 28v; Rüfenacht 2016, S. 90-91.

9 Nachricht von altdeutschen in Leipzig entdeckten Kunstschätzen: Anonym [Goethe] 1815, S. 273-274: »Die Entdeckung dieser bedeutenden Schätze sind wir Hrn. Quandt schuldig, einem jungen Handelsmann, der mit Enthusiasmus für die Kunst schöne Kenntnisse derselben verbindet, auch Geschmack und Einsichten auf Reisen geläutert hat."

10 Goethe 1827-1842, Bd. 39, S. 273-278; MA 1994, Bd. 11.2, S. 299-302. S. a. Beyer/Osterkamp 2011, S. 465; Heiland 1997, S. 10, 14.

11 Brief von Quandt an Johann Heinrich Meyer vom 14.6.1815, in: Schmitz/ Strobel 2001, S. 4. Es handelte sich dabei nicht um die ersten Stiche. Bereits im Winter 1815 hatte er solche nach Weimar geschickt; siehe Brief von Meyer an Christian Ludwig Stieglitz vom 5.3.1815, in: Berlin, SMB, Zentralarchiv, Autographensammlung, Mappe 940/2. Für Hinweis und Transkription danke ich Johannes Rössler, Bern/Passau. 
werkes, das von einigen Kunstfreunden seiner Geburtsstadt über Carl August Böttiger in Dresden und Johann Heinrich Meyer in Weimar schließlich zur persönlichen Bekanntschaft mit Johann Wolfgang von Goethe führen sollte. ${ }^{12}$ Andererseits diente ihm der Bilderfund als Gelegenheit, seine Vorstellung einer Entwicklungsgeschichte der Kunst von einer urtümlichen Anschauung des Göttlichen als Grundlage aller Kunst herzuleiten und diese einem breiteren Publikum bekannt zu machen. ${ }^{13}$ Gegenüber Böttiger formulierte er in einem Brief: »Der Gegenstand ist zu wichtig und zu anziehend [...], ja ich bin so schwärmerisch für meine alten Meister eingenommen, daß ich das Höchste zu behaupten wage $[. .$.$] . Daß die Anschau-$ ung des Göttlichen der Kunst voranging, die Kunst selbst aber die in der Materie ungebohrene Idee ist, $[. .$.$] ist wohl nicht \mathrm{zu}$ bezweifeln, eben so glaube ich ist es historisch nachzuweisen, daß die Kunst sich immer mehr von diesem idealen Ursprung entfernte und zur Darstellung von äußeren Wahrnehmungen ausartete. $\ll^{14}$ In den Leipziger Gemälden glaubte er diese Verbindung von Kunst und Göttlichkeit oder die in der Kunst inkarnierte göttliche Vernunft wiedergefunden zu haben. Wie er in der Einleitung zu seinem Artikel über die Tafeln ausführte, war die menschliche Vernunft befähigt, diese göttliche »Idee« in der Kunst zu erkennen. Die Alten Meister sollten daher als Vorbilder für eine neue Kunst dienen. ${ }^{15}$ In der Folge steigerte sich seine Publikationstätigkeit deutlich.

\section{Künstler der Innerlichkeit}

Quandts frühe Aufsätze waren noch weniger kennerschaftlichen Fragen gewidmet. Vielmehr handelte es sich um Lebensbeschreibungen älterer Künstler und spekulative Entwicklungsgeschichten der Kunst und der Menschen, die auf älterer Kunstliteratur wie Vasaris Viten oder Sandrarts Teutsche Academie basierten. Seine 1816 im Tübinger Kunstblatt publizierte Biographie von Fra Angelico verstand er dementsprechend in einem größeren Kontext, wie der Titel des Aufsatzes Ueber Guido von Fiesole, in Beziehung auf Kunst im Allgemeinen zeigt. Er verortete den florentinischen Künstler, ganz Vasari folgend,

12 Siehe hierzu die edierte Korrespondenz zwischen Meyer und Quandt zum Leipziger Gemäldefund, in: Schmitz/Strobel 2001, S. 3-17.

13 Paraphrase im Kapitel Förderungswürdige Höhepunkte der Kunst, siehe oben. S. a. Scholl 2007, S. 54-59.

14 Brief von Quandt an Carl August Böttiger vom 12.7.1815, in der SLUB, Mscr. Dresd. h 37, Bd. 151 (40), Nr. 3, abgedruckt in: Kat. Leipzig 1997, S. 157 .

15 Quandt 1815, Sp. 973.

16 Quandt 1816 (2), S.66-67. Zum Niedergang der Künste, wie er ihn ein Jahr vor dem Fiesole-Aufsatz dargestellt hatte, siehe Quandt 1815, Sp. 961-973 oder Quandt 1839 (1), S. 5: »Die Darstellung des Wirklichen in einer aufsteigenden Phase der Kunstentwicklung. Der malende Mönch sei als Mensch eine Einheit von Sein und Erscheinung gewesen. Seine Bilder hätten sich mit dem Göttlichen vereinigt und das Göttliche überall in der Natur entdeckt.

Im Unterschied zu Vasari zielte Quandts Aufsatz auf eine Aufwertung des Florentiner Klostermalers ab. Wenn Vasari seine Künstlerviten auf die beiden Höhepunkte Raffael und Michelangelo hinstreben ließ, versuchte Quandt ihre Biographien einzuordnen und auszugleichen. Im Gegensatz zu Fra Angelico hätten Raffael und Michelangelo sich von einer fraglosen Liebe zu Gott und von der göttlichen Vollkommenheit abgewendet, um in äußeren Erscheinungen das »Urbild der Schönheit « zu suchen. Diese Hinwendung zum Realen habe bereits den Niedergang der Kunst in sich getragen. ${ }^{16}$ Damit wurde Fra Angelico für Quandts Vorstellung italienischer Kunstgeschichte eigenständig und den großen Künstlern der Renaissance ebenbürtig zur Seite gestellt. So schreibt Quandt: »Viele beeiferten sich im Leben und in der Kunst ihm ähnlich zu werden. Unter seinen Schülern zeichneten sich Benozzo Fiorentino, Zanobio Strozzi, Domenico di Michelino und Gentile da Fabriano aus. Durch letztern pflanzte sich Fiesole's Gefühl für Natürlichkeit, Schönheit der Farbe auf Jacopo Bellini von diesem auf Giovanni Bellini und Giorgioni (sic!) fort und durch Titian wurde vollendet, was Fiesole begonnen, die Trefflichkeit des Kolorits. $\ll^{17}$ Der Kunstkenner verband Fra Angelicos Biographie mit der Kunstgeschichte, um einerseits seine Rolle für die Entwicklung der Künste aufzuwerten. Andererseits ermöglichte ihm dieses Verfahren, seine eigenen Kunstansichten anhand von Künstlerbeispielen schildern zu können. Damit wollte er die Kunst der Alten Meister neu beurteilen.

Mit einem rezensionsartigen Aufsatz über eine Neuauflage von Kupferstichen einer Passions- und Auferstehungsserie des Niederländers Hendrik Goltzius versuchte Quandt das Wesen der altdeutschen Kunst zu erklären. ${ }^{18}$ Wie im Fiesole-Aufsatz nutzte er auch hier das Werk eines Künstlers, um allgemeine Aussagen über die Kunstgeschichte machen zu können. Die Vorzeichen standen hier jedoch anders. Goltzius diente ihm in diesem Fall eben gerade nicht als positives Beispiel und war nicht mehr eigentlicher Alter Meister. Quandt warf dem Künst-

an sich, worin Albrecht Dürer, Wohlgemuth's Schüler die höchste Bewunderung verdient, wodurch er aber von seinem Meister abgefallen war, leitete auf Abwege, und zwar zu einer Natürlichkeit, die in Niedrigkeit ausartete.« S. a. Scholl 2007, S. 270-280.

17 Quandt 1816 (2), S. 71

18 Es handelt sich um die Auflage Das Leiden, Sterben und Auferstehung unseres Herrn Jesu Christi. Zwölf Bilder, zu Ende des 16ten Jahrhunderts gezeichnet und in Kupfer gestochen von Heinrich Golzius, hrsg. v. Ferdinand Adolph Krummenacher, Berlin: Haßelbach, 1818. S. a. Quandt 1853, S. 125, Nr. 899 
ler vor, Nachahmer ebendieser zu sein: »Dies ist der Fall mit Heinrich Golzius, einem Mann vo[n] großer Kunstfertigkeit, der alle Eigenschaften eines ausgezeichneten Kupferstechers und Copisten besaß [...]; denn da seine Hand mit Leichtigkeit Alles nachahmen konnte, so bildete er sich ein, jeden großen Meister erreichen zu können, und in wie fern ihm dies gelungen ist, davon zeigen seine sechs großen Blätter, in welchen er es L. v. Leyden, Dürer, ja Raphael selbst gleich zu thun glaubte. [...] Es scheint mir also sehr bedenklich, Heinrich Golzius als ein Muster altdeutscher Kunst aufzustellen, $[. .$.$] den Nachahmer eines$ alten Meisters, der doch selbst nicht mehr von dem wahren und reinen göttlichen Funken beseelt und beseeligt war $[. ..] \times \ll^{19}$

Quandts Artikel steht im Zusammenhang mit dem Vorwurf, den Johann Heinrich Meyer in seinem Aufsatz Neu-deutsche religios-patriotische Kunst ein Jahr zuvor postuliert hatte. Darin stellte der Weimarer Kunstschriftsteller fest, dass einige neue deutsche Künstler - vornehmlich die Nazarener - die Wertschätzung der Alten Meister etwas übertrieben hätten und sich der Gefahr aussetzten, Nachahmer »alterthümlicher Einfalt « zu werden. ${ }^{20}$ Der Artikel erschien im zweiten Heft von Goethes Zeitschrift Ueber Kunst und Alterthum in den Rheinund Mayn-Gegenden im Namen der Weimarer Kunstfreunde. Er stieß im Umkreis der kritisierten Künstler und Schriftsteller auf großen Unmut und erzeugte zahlreiche Reaktionen. Obschon Meyer der Autor war, schrieben die Kritisierten die Streitschrift Goethe zu, der inhaltlich tatsächlich großen Anteil daran hatte. ${ }^{21}$ So auch Quandt: »Gewiß hat Göthe, den wir hier nennen, nicht jenen falschen Jüngern das Wort geredet, so wenig, als diejenigen kränken wollen, welche auf eignem Wege die Wahrheit in der Kunst suchen, und daher notwendig den alten Meistern begegnen [...]. $\ll^{22}$

Die beiden Weimarer Gelehrten kritisierten verschiedene Maler wie Philipp Otto Runge, Caspar David Friedrich, Fried-

19 Quandt 1818 (2), S. 273. S. a. Quandt 1853, S. 124: »Sein hauptsächliches Verdienst ist, dass er den Grund zur Ausbildung der Grabstichelarbeit legte. Ein geregeltes Schraffir, was er, wie man sagen möchte, erfand, tritt in seinen Werken oft zu auffallend hervor; das Mittel zum Zweck erhoben, sind seine Stiche mehr Kunststücke, als Kunstwerke.»

20 Meyer/Goethe 1817 [1999], S. 114, 123. Siehe dazu Apel/Greif 1997, S. $627-630$.

21 Meyer/Goethe 1817 [1999], S. 116-125. Adressat der Schrift war Friedrich Schlegel, der in den Augen Goethes und Meyers Ideengeber und Leitstern der Nazarener war; Grewe 2015, S. 62. S. a. Kommentar von Hendrik Birus, in: ebd., S. 818-828; Thimann 2013, S. 301-305; Tauber 2011, S. 419-420; Locher 2001, S. 156.

22 Quandt 1818 (2), S. 265-266:

23 Meyer/Goethe 1817 [1999], S. 114-115: »Weil aber das anziehend Einfache, die rührende Unschuld in den alten Gemälden nicht absichtlicher Kunst und besondern Zwecken vielmehr der Gesinnung der Meister und der Zeit, worin sie lebten angehört, so konnte die Nachahmung nicht gelingen.« S. a. Thimann 2013, S. 304-305; Tauber 2011, S. 419; Heckmann 2003, S. 126-129; Locher 2001, S. 158-163. rich Overbeck und die Gebrüder Riepenhausen, hoben aber auch Positives hervor. Sie bemerkten in der Aneignung der Alten Meister einen versteckten Patriotismus und das Bedürfnis nach religiöser Harmonie, glaubten aber, dass solches nicht mehr erreichbar sei. Vaterlandsliebe und Frömmigkeit würden anhand mittelalterlicher Bilder auf eine für immer vergangene Zeit projiziert. Die Einfachheit und Unschuld dieser Alten Meister gehöre zu einer vergangenen Gesinnung. Somit sei ihre Kunst nicht nachahmbar. ${ }^{23}$

Goethe und Meyer wertschätzten zwar aus kulturellem Interesse die mittelalterliche Kunst, die durch die Kirchen- und Klosteraufhebungen im Zuge der Französischen Revolution zutage gefördert worden war. ${ }^{24}$ Sie bestimmten aber nicht genauer, was sie unter alter oder altdeutscher Kunst genau verstanden. Zentrales Anliegen ihres Textes war es vielmehr, die Vorbildhaftigkeit bestimmter Kunstepochen hervorzuheben. Mit ihrem Text wollten sie zeitlos anerkannte Kunstregeln propagieren. Goethe und Meyer waren überzeugt, dass in der Entwicklungsgeschichte der Kunst nur wenige, allgemeingültige Regeln tradiert würden. Stile oder Charakteristika hingegen würden nicht überliefert, da diese mit den Individuen, die sie hervorgebracht hatten, untergingen, wie eben die Einfachheit und Unschuld der mittelalterlichen Meister. Für die Ausbildung der Künstler stelle die griechische Kunst die sichersten, allgemeinen Werte zur Verfügung. Diese nachzuahmen, lohne sich daher. ${ }^{25}$

Genau dieser ausschließliche Fokus auf die griechische Kunst verstand nun Quandt als Verteidiger der kritisierten Freunde Alter Meister überhaupt nicht. In einem im Jahr nach Erscheinen von Meyers und Goethes Streitschrift geschriebenen Brief an Julius Schnorr von Carolsfeld fragte er sich, warum Goethe »ausschließlich die griechische Kunst als die einzig heilbringende betrachten [würde]? Wo die Vorzüge dieser

24 Meyer/Goethe 1817 [1999], S. 126-128: »Schließlich aber wollen wir der erwachten Neigung zum Alterthümlichen auch ein billiges Lob nicht entziehen und bekennen, daß man derselben, vornehmlich in Deutschland, die Erhaltung einer unzähligen Menge von Kunstmerkwürdigkeiten verdankt.« S. a. Heckmann 2003, S. 72-77.

25 Meyer/Goethe 1817 [1999], S. 125-126: »Da sich überdieß von den Künstlern nur etwa die äußere Form und allgemeine Regeln fortpflanzen, herübernehmen lassen; so folgt, daß je vollkommener diese sind, desto ergiebiger, nützlicher auch das Studium derselben, und desto glücklicher die Nachahmung der mit solcher Freyheit studirten Kunstwerke seyn wird. [...] Hieraus geht nun hervor daß es in Bezug auf die Kunst am sichersten und vernünftigsten ist, sich ausschließlich mit dem Studium der alten Griechischen Kunst, und was in neuerer Zeit sich an dieselbe anschloß, zu befassen; hingegen immer gefährlich und vom rechten Weg ableitend andere Muster zu suchen. « S. a. Tauber 2011, S. 416-417. 
vor jener bestehn? Ob es nicht auch Nachäffung seÿ, die alten Griechen zum Muster zu wählen? Ob es nicht eine zeitlose Schönheit gebe? «26 Nicht ganz zu Unrecht stellte er fest, dass weniger die geistlose Nachahmung der Alten Meister in Meyers und Goethes Argumentation das Problem war, sondern die Frage, welche Kunstform vorbildlich für die Gegenwart sei. In seinem Aufsatz über die altdeutsche Kunst von 1818 führte er seine Beweisführung daher auf eine übergeordnete Ebene. Er hielt zuerst fest, dass um 1500 in Deutschland und den Niederlanden ein Prinzip von Meister und Schüler geherrscht habe. Dadurch sei eine Kontinuität in der Kunst tradiert worden. Bedingt durch die von der christlichen Religion durchdrungene Gesellschaft habe »eine Gleichheit der Gesinnung« bestanden. Diese Frömmigkeit und Liebe zu einem göttlichen Prinzip sei individuell ausgeprägt gewesen. Daher hätten die Künstler trotz tradierter Kunstformen durchaus eigene Sichtweisen entwickelt. Ihre Kunst sei Darstellung der eigenen Innerlichkeit und des persönlichen Seelenlebens gewesen. Die Maler des 15. Jahrhunderts hätten also einzig und allein danach gestrebt, den »Zustand des Gemüths « künstlerisch umzusetzen. Mit den Errungenschaften wissenschaftlicher Erkenntnis zum Beginn der Neuzeit sei aber die »Sicherheit des Gefühls« in der Kunst verloren gegangen und die Künstler hätten sich vermehrt auf Regeln verlassen. ${ }^{27}$

Quandt verstand die Werke Alter Meister also nicht als Werke, die nach den Regeln der Schönheit komponiert waren, sondern als solche, die sich nach der Natur richteten. Ihr künstlerischer Ausdruck hatte etwas »Treffendes, Ursprüngliches, Naives«. Der Künstler als Individuum hatte als frommer Mensch, der in der Einheit mit seiner göttlichen Umwelt lebte,

26 »Göthe hat kürzlich wieder ein Bändchen herausgegeben unter dem Titel: Ueber Kunst u Alterthum. Es ist aus einer Stelle dieses Buchs zu erkennen, daß Göthe über den Aufsatz welcher, Ueber die alterthümelnde, christelnde Kunst, überschrieben war zur Rede gesetzt worden ist. Junge Kunstgenoßen, wie Göthe sich ausdrückt, haben die Frage aufgeworfen: ob denn die weimarischen Kunstfreunde, im Jahre 1797, als der Klosterbruder [Wilhelm Heinrich Wackenroder und Ludwig Tieck, Herzensergießungen eines kunstliebenden Klosterbruders - AR] herausgegeben ward, schon derselben Meinung gewesen, ob sie schon damals die neue Richtung der deutschen Kunst mißbilligt? Daß Göthe hier auf, Ja! antworten würde, war vorauszusehen. Viel mehr hätte man ihn fragen sollen, warum denn die weimarschen K[un]stfr[eun]d[e], ausschließlich die griechische Kunst als die einzig heilbringende betrachten? Wo die Vorzüge dieser vor jener bestehn? Ob es nicht auch Nachäffung seÿ, die alten Griechen zum Muster zu wählen? Ob es nicht eine zeitlose Schönheit gebe? « Brief von Quandt an Schnorr vom 17.5.1818, in: SLUB, Mscr. Dresd. n Inv., Bd. 31, fol. 4r-v. Quandt bezieht sich hier auf Goethes kurzen Artikel »Deutsche Sprache« im dritten Heft der Zeitschrift Ueber Kunst und Alterthum von 1817, abgedruckt in: FA 1999, Bd. 20, S. 212. S. a. den Kommentar von Hendrik Birus, in: FA 1999, Bd. 20, S. 971.

27 Quandt 1818 (2), S. 269-270: »In Deutschland und den Niederlanden hatte sich bis zu Dürers Zeit die Kunst von Vater auf Sohn, von Meister auf Schüler, wie eine Tradition fortgepflanzt. [...] doch zu dem sein Inneres in die Bilder gebracht. ${ }^{28}$ Diese harmonische Vereinigung des verinnerlichten Individuums mit der göttlichen Natur, wie es sich in den mittelalterlichen Kunstwerken zeigte, müsse vorbildhaft für die neue Kunst sein: »Es scheint nun eben an der Zeit zu seyn, daß die Welt, nach einem weiten, durchwanderten Kreise und einem langen Umherirren im Gebiete des Wissens und Genießens äußerer Dinge, zu dem Ewigen, Gewissen und Innern, zurückkehrte; - und durch keine Gewalt ist ihr Lauf aufzuhalten. [...] Wenn nun unter zwei Menschen, gleich viel, ob der eine ein halbes Jahrtausend früher lebte, als der andere, eine innere Uebereinstimmung statt findet, muß da nicht auch nothwendig eine Aehnlichkeit ihrer Werke wahrnehmbar seyn? Und sind wir dann nicht viel mehr aufgefordert, aus dieser Gleichheit in der Wahl der Gegenstände und ihrer Ausführung, auf eine Uebereinstimmung der Gesinnung zu schließen, als befugt, ihr Streben für eine Alterthümelei zu erklären [...]? Nur dann sind wir zu einem solchen Urtheil berechtigt, wenn diese Aehnlichkeit bloß auf Zufälligkeiten beruht, nicht auf dem Wesentlichen, Geistigen. Denn so gewiß, als nichts Neues unter der Sonne geschieht, und das Alte sich nur erneut, so gewiß kehrt auch kein abgeschiedener Schatten mit dem Staube und Moder des Grabes zurück; es gibt keine Gespenster, aber eine Auferstehung, die sich durch inneres Leben verkündet. $\ll^{29}$

Mit seiner Überzeugung, dass die Werke der Alten Meister vorbildhaft seien, griff Quandt ein Argument auf, wie es Friedrich Schlegel 1805 in seiner Zeitschrift Europa postuliert hatte. Schlegel hatte hier auf einer Reise von Paris über Brüssel nach Köln verschiedene Städte besucht und altdeutsche Kunst beschrieben. ${ }^{30}$ Er stellte fest, dass es »das religiöse Gefühl, Andacht und Liebe, und die innigste stille Begeisterung« seien, die diese

Erlernten fügte ein jeder das Seinige hinzu, und daher mag es wohl kommen, das zwar in den Werken mehrerer aufeinander folgender Jahrhunderte ein allgemeiner Typus herrscht, allein doch jedes einzelne Kunstwerk einen ganz individuellen Charakter erhielt [...]. Die Maler bis in das fünfzehnte Jahrhundert [bestrebten sich einzig und allein] den Zustand des Gemüths auszudrücken [...]. Der Geist der Untersuchung, des Theoretisirens brach [danach] auch in die stillen Schranken der Kunst ein [...], die wissenschaftlichen Kenntnisse sollten überall in Anwendung gebracht werden, obschon sie nicht überall ausreichten, und so ging die Sicherheit des Gefühls auch in der Kunst verloren. « Zum Gemüt in der Romantik siehe Scholl 2007, S. 64-84.

28 »Daher überrascht uns so viel Treffendes, Ursprüngliches, Naives in den alten Bildern, das[s], wenn es auch nicht nach unsern Begriffen malerisch, doch äußerst wahr, und so sprechend und bezeichnend ist, daß, wenn man etwas daran veränderte, auch der Ausdruck durchaus entkräftet würde. So ist die Zeichnung in jenen alten Gemälden, wenn auch nicht immer den Regeln der Schönheit, doch fast stets dem Gegenstande gemäß und in einzelnen Theilen der Natur treu nachgebildet.« Quandt 1818 (2), S. 270.

29 Quandt 1818 (2), S. 274.

30 Schlegel 1805, S. 130-145 über Köln. Der Reisebericht über altdeutsche Kunst zieht sich über mehrere Ausgaben hinweg. S. a. Prange 2004, S. 99-100; Niehr 1999, S. 108-110. 
Werke charakterisierten. Im Gegensatz zu Quandt gut ein Jahrzehnt später wog sich der Autor noch im Ungewissen, ob die deutschen Künstler als Ersatz für die nicht mehr vorhandene Frömmigkeit genug ernste Begeisterung aufzubringen vermochten, um eine neue deutsche Kunst zu erschaffen. Schlegel erkannte in der religiösen Kunst des Mittelalters sinnbildhafte Hieroglyphen, die für ein Höheres standen. Zugleich fragte er sich, ob seine Zeitgenossen eigene Sinnbilder zu entwickeln vermochten. Ihm schien dieser Weg, den Philipp Otto Runge mit seinen bedeutungsschweren Arabesken der vier Tageszeiten 1803 beschritten hatte und die ihm bei dieser kritischen Vermutung vielleicht vorschwebten, jedoch risikoreich. So schlug er vor, dass die jungen Maler die altdeutschen Künstler nachahmen sollten, um zu einer »andern Natur « zu kommen. ${ }^{31}$ Freilich ging es Schlegel nicht um eine Nachahmung von Stil, sondern um einen bestimmten Charakter altdeutscher Kunst, der vorbildhaft sein konnte. ${ }^{32}$

Zwar kann eine Kenntnis von Schlegels Artikel nicht direkt nachgewiesen werden. Dennoch ähneln Quandts Äußerungen diesen Passagen. Quandt glaubte an eine Kontinuität der Gesinnungen. Diese würden sich nur den neuen Umständen anpassen. Dadurch entstehe Ähnlichkeit, nicht aber Nachahmung. Für die Künstler seiner Zeit hieß dies, dass sie den Alten Meistern nachstreben, sie aber nicht nachahmen sollten. Bei diesem Nachstreben ging es nicht um künstlerische Stile und Techniken, sondern um Gesinnung und Charakter. Das Erstrebenswerte der altdeutschen Kunst war dem Autor zufolge ein »liebevolle $[\mathrm{s}]$ Sichhingeben an die Natur, das Auffassen ihrer

31 Schlegel 1805, S. 143-145: »Hätte ein [Talent] erst den richtigen Begriff von der Kunst wiedergefunden [...], so würde er vielleicht merkwürdige Werke ganz neuer Art hervorbringen; [...] Eine Hieroglyphe, ein göttliches Sinnbild soll jedes wahrhaft so zu nennende Gemählde seyn; die Frage ist aber nur, ob der Mahler seine Allegorie sich selbst schaffen, oder aber sich an die alten Sinnbilder anschließen soll, die durch Tradition gegeben und geheiligt sind, und die, recht verstanden, wohl tief und zureichend genug seyn möchten? - Der erste Weg ist gewiß der gefährlichere und der Erfolg läßt sich ungefähr voraussehen [...]. Sichrer aber bliebe es, ganz und gar den alten Mahlern zu folgen, besonders den ältesten, und das einzig Rechte und Naive so lange treulich nachzubilden, bis es dem Aug und Geiste zur andern Natur geworden wäre. Wählte man dabei besonders mehr den Styl der altdeutschen Schule zum Vorbilde, so würde beides gewissermaßen vereinigt seyn, der sichre Weg der alten Wahrheit und das Hieroglyphische, worauf, als auf das Wesen der Kunst, selbst da, wo die Kenntniß derselben verlohren war, wahre Poesie und Mystik zuerst wieder führen muß, und selbst unabhängig von aller Anschauung, als auf die bloße erste Idee der Kunst und Mahlerei führen kann.« S. a. Grewe 2015, S. 129-133; Grewe 2006, S. 402; Schrapel 1997, S. 308.

32 S. a. Grewe 2015, S. 214-216.

33 Quandt 1818 (2), S. 274. S. a. Quandt 1816 (3), S. 562-563: „Wo aber, als in den Werken der älteren Kunst, finden wir diese Erfüllung (plenitudo) des Daseyns, diese Gesammtheit des innersten Lebens? Im Leben selbst ist diese Harmonie selten erreichbar [...]. Und so will es auch den neuen Künstlern nicht gelingen, den Menschen so aufzufassen tiefen göttlichen Schönheit, nicht bloß mit dem Verstande, sondern mit dem Gemüthe, und, abgesehen, ob die Regeln der Kunst diese Schönheiten constituiren, das Fixiren des Gegenstandes mit dem innern Auge « ${ }^{33}$ Mit diesem Fokus auf das Innere und das Gemüt nahm Quandt ein wichtiges Motiv der romantischen Künstler und insbesondere der Lukasbrüder auf, wie Christian Scholl und Cordula Grewe in ihren Studien aufgezeigt haben. Demnach zeigt sich im Inneren des Künstlers und des Betrachters eine Ahnung des Göttlichen. Diesem galt es nachzustreben. Der subjektive Charakter der Kunst und ihrer Betrachtung war demnach ein typisches Leitmotiv der Epoche. ${ }^{34}$

Quandts Argumentation ging vom Künstlerindividuum aus, dessen »Inneres« er in seinen Gemälden zu sehen glaubte. Dabei handelt es sich um einen rein spekulativen Zugang, der auf der Phantasie des Betrachters basierte. Grundsätzlich war die Gesinnung eines toten Malers natürlich nicht mehr nachvollziehbar und musste in sein künstlerisches Werk hineininterpretiert werden..$^{35}$ Demgegenüber stellten Goethe und Meyer in ihrem Aufsatz das Kunstwerk an den Anfang. Wenn die beiden Weimarer vom »Gemüt« sprachen, meinten sie eine bestimmte Wirkung eines Kunstwerks auf den Betrachter. Dieses »Gemüthliche« sei nicht nur den Werken der deutschen und italienischen Alten Meister eigen, sondern auch eine Wirkung, die griechische Künstler hervorzubringen vermochten. Dadurch sei der Unterschied zwischen der antik-griechischen und der mittelalterlich-europäischen Kunst eigentlich gar nicht so »schreiend $\ll .{ }^{36}$ Die beiden Weimarer Kunstgelehrten waren sich

und ihn in dieser Vollendung und Fülle darzustellen, als es die Alten vermochten. Immer sind die Darstellungen der Neueren charakteristisch und individualisirend einseitig.« S. a. Quandt 1819, Bd. 1, S. 27, 130-131.

34 Scholl 2007, S. 64-84. Grewe 2015, S. 181-185 versteht die »Appropriation« der Alten Meister durch die Lukasbrüder als unerreichbares, aber umso zentraleres Ziel, um göttliche Vollendung anzustreben. In der diesbezüglich besonderen Befähigung der Künstler um 1500 erklärt sich die Rückwendung der Nazarener. Diese muss aber immer »Bruchstück« bleiben. Dieses Phänomen der Aneignung bezeichnet sie als »Epigonalität«; ebd., S. 21209-225. S. a. Thimann 2015, S. 23; Rössler 2013, S. 286-288.

35 Siehe dazu Niehr 1997, S. 294-295.

36 »Das Wort Gemüth wird im rechten Sinne alsdann gebraucht, wenn mehrere schätzenswerthe Eigenschaften des Menschen vereinigt zur Erscheinung kommen, und, indem sie ihren Werth offenbaren, zugleich einen angenehmen, lieblichen Eindruck auf uns bewirken. In diesem Sinne schreiben wir einem Künstler, einem Kunstwerk Gemüth zu. Nun ist keine Frage daß, wenn Ergebenheit in den göttlichen Willen, Duldung eigener Leiden, Theilnahme an fremden, sich in Gesichtsbildung, Gebärden und Handlungen offenbart, alsdann die Frömmigkeit eines solchen Gemüths eindringlich, ja hinreißend auf uns wirken muß. Allein das fromme Gemüth ist nicht das Einzige: denn das rein Gemüthliche kann sich im Heitern, Großen, ja Erhabenen offenbaren, und in diesem Sinne war die griechische Kunst höchst gemüthvoll. [...] Hält man dieses recht fest im Auge, so erscheint auch der Widerstreit 
also des Schlüsselbegriffs »Gemüt« und damit der Metaebenealso der Suche der neudeutschen Maler nach der wahren Gesinnung altmeisterlicher Kunst - sehr bewusst. Dies hat auch Quandt erkannt. Es ging, wenn dies auch der zentrale Vorwurf der Weimarer Kunstfreunde war, nicht eigentlich um die Nachahmung, sondern um die Frage, welche Kunst vorbildhaft sei.

Interessant ist nun, dass Goethe und Meyer hier letztlich eher in eine theoretische Sackgasse gerieten als Quandt. Sie stellten zwar bei den neudeutschen Künstlern zu Recht fest, dass die Frage der Gesinnung eines Künstlers spekulativer Natur sein musste und der Wesenszug einer vergangenen Zeit nicht wiederherstellbar war. Dadurch lief eine solche Kunst tendenziell Gefahr nachzuahmen. Gleichzeitig führten sie ihre allgemein gültigen Kunstregeln genauso spekulativ auf die griechische Kunst zurück und akzeptieren mittelalterliche und neue Kunst nur im Vergleich mit diesem ästhetischen Regulativ als ein historisch und kulturell »merk-würdiges« Kulturgut, weniger aber als schöne Kunst. Umgekehrt ermöglicht Quandts auf die Gesinnung der Künstler abzielende Argumentation, festgefahrene Kunstregeln zu lösen - mithin ein »modernes« Anliegen, wie es Cordula Grewe in Bezug auf die »Appropriation « Alter Meister durch die Lukasbrüder dargelegt hat. ${ }^{37}$ Schönheit ist demnach nicht allein der griechischen Kunst immanent, sondern auch der mittelalterlichen und damit potenziell auch der neuen deutschen Kunst. Übergeordneter gemeinsamer Nenner dieser unterschiedlichen Kunstepochen und Stile ist die Natur. Der Künstler durchdringt diese mit seiner Vernunft und erschafft dadurch Schönes.

In einem Brief an den Leipziger Philosophieprofessoren Christian August Heinrich Clodius schrieb Quandt im August 1819 über diese inneren Zusammenhänge der Kunstepochen: »Nun muß ich Ihnen noch einiges über die neuen in München lebenden Maler sagen. Sie zerfallen, wie jetzt überall in Academisten u Naturalisten, letztere Benennung scheint mir paßender zu seÿn, als das zum Schimpfwort gewordene Altdeutsche. Erstere schließen sich an Director [Robert von] Langer an, der in allen Fächern der Kunst, in Zeichnung u Malereÿ, Beleuchtung u Gruppierung ein tüchtiger Mann ist. Die Naturalisten wie ich sie nennen will, bekümmern sich weniger um die Regeln der Schule u halten sich ganz an die Natur. Ihre einzige Rücksicht ist, ob alles Natur u der Gegenstand ihrer Darstellung gemäß ist. [...] Dadurch werden ihre Werke allerdings oft denen der alten Meister ähnlich, aber man thut ihnen sehr unrecht,

zwischen alter und neuer Kunst, zwischen christlicher und hellenischer keineswegs so schreiend als er manchmal ausgesprochen wird." Meyer/Goethe 1817 [1999], S. 125-126. S. a. Scholl 2007, S. 84.

37 S. a. Grewe 2015, S. 175-185.

38 Brief von Quandt an Clodius vom 16.8.1819, in: SLUB, Mscr. Dresd. App. 204, Nr. 94. S. a. Quandt 1817, S. 147. wenn man dieser Uebereinstimmung wegen, sie der Nachahmung der Alten beschuldigt, denn dies ist ihre Absicht $\mathrm{u}$ ihr Bestreben nicht, sondern blos eine unvermeidliche Aehnlichkeit, weil die Alten u diese Neuen einen Weg gehn u daher diese oft in jener Fußstapfen treten, wie zweÿ Wanderer auf einem Pfade. $\ll^{8}$ Durch diese, auf seiner Kunsttheorie basierten Sichtweise zeigt sich bei Quandt eine Offenheit für verschiedenartigste Kunstwerke, wie seine Sammlung beweist. Er besaß antike Werke genauso wie altdeutsche, Renaissance-Gemälde und unterschiedlichste Bilder seiner Zeitgenossen. Abgesehen von einer generellen Kritik an Manierismus und Barock zielen seine Urteile in erster Linie auf einzelne Kunstwerke und Künstler, weniger aber auf ganze Schulen oder Epochen ab. ${ }^{39}$

\section{Aufwertung altdeutscher Kunst}

Mit den Jahren vertiefter Erfahrungen wurden Quandts Artikel über Alte Meister zunehmend fundierter. Während er als junger Autor oft Künstlerbeispiele zum Anlass nahm, um generalisierend über Entwicklungsphasen der Kunst zu referieren, so wichen diese spekulativen Erörterungen immer häufiger ausführlichen stilkritischen, literatur- und quellenbasierten Untersuchungen. Seiner Grundhaltung über die wellenförmigen Phasen der Kunstgeschichte als Teil der Menschheitsgeschichte blieb er zwar treu, doch begründete er diese nicht mehr beispielhaft und anekdotisch, sondern extrapolierte den universalgeschichtlichen Argumentationsstrang aus fundierten Untersuchungen..$^{\circ}$

$\mathrm{Zu}$ den Künstlern, die Quandt besonders interessierten, zählten die altdeutschen Maler Michael Wolgemut und Martin Schongauer. Auf zahlreichen Reisen eignete er sich ein kennerschaftliches Wissen über sie an. Als er 1819 nach Rom aufbrach, legte er viele Stationen ein, um ihre Gemälde in München und weiteren Orten Bayerns und Schwabens, aber auch in Wien im Original zu betrachten. Dabei stellte er zahlreiche Unstimmigkeiten in den Zuschreibungen fest. Mit der Zeit legte er sich seine eigene Methode zurecht. Sie basierte auf der akribischen Betrachtung der Werke und der Suche nach Signaturen: »Beÿ meinen Kunstforschungen nehme ich mich sehr in acht, daß ich nicht durch Gallerien irre geführt werde, $u$ halte mich daher um Meister erkennen zu lernen u ihren Typus mir einzuprägen, blos an Werke, welche in öffentlichen Gebäuden, wie z. B.

39 Quandt 1839 (1), S. 4: »jedoch schneidet sich keine Epoche von der andern so scharf ab, als wir sie vermittelst der Urtheilskraft unterscheiden. An der Grenze jeder Epoche finden wir Uebergangsbildungen.« S. a. Quandt 1844 (1), S. 78-82.

40 Zum Begriff der Universalgeschichte als Kulturgeschichte siehe Zwenger 2003, [s. p.]; Nipperdey 1976, S. 45 
Rathäusern u Kirchen aufgestellt sind, $\mathrm{u}$ an solche, welche echte Monogramme führen. Aber wie mit Schäuflein [Hans Schäufelein-AR $]$ hier, so geht es in München mit Dürer, diesem wird alles zugeschrieben, was auch nur nach seinen Zeichnungen, von seinen Schülern ausgeführt wurde. $\ll^{41}$ Auf diese Weise verinnerlichte er sich über die Jahre zahlreiche Bilder und legte sich ein beachtliches Wissen über altdeutsche Kunst, ergänzt durch die Lektüre der älteren und neusten Kunstliteratur und unterstützt durch seine umfangreiche Kupferstich- und Zeichnungssammlung, zu. Reisen zu Originalen unternahm er immer wieder.

Einen beispielhaften Artikel über seine Kenntnis altdeutscher Kunst veröffentlichte Quandt 1840. Darin beschrieb er die Ergebnisse einer Reise nach Colmar, wo er sich mit Werken Schongauers auseinandersetzte. Den Aufsatz bezeichnete Franz Kugler in seinem Handbuch der Kunstgeschichte als eine der aktuellsten, »kritischen Forschungen« über diesen Maler.42 In seiner Untersuchung befasste sich der Dresdener Kenner mit der neuesten Forschung sowie stilkritischen und technischen Fragestellungen. Ziel seines Aufsatzes war es, eine niederländische Schulung Schongauers nachzuweisen und eine Verbindung zu Jan van Eyck herzustellen. So erkannte er an den Originalen in Colmar, dass Schongauer, wie van Eyck, in Öl gemalt hatte. Zugleich band er ihn anhand stilkritischer Merkmale in den Kontext niederländischer Malerei ein und analysierte die Lebensdaten, um wenigstens eine theoretische Bekanntschaft zwischen dem Niederländer und dem Deutschen postulieren zu können. ${ }^{43}$ Schließlich kam er zu einem Ergebnis: »Martin Schongauer ist unbezweifelt unter den deutschen der erste, welcher auf gleiche Weise wie Johann van Eyck malte. Dieser Schule verdankt er nicht allein die Erlernung einer neuen Technik [der Ölmalerei - AR], sondern auch die Erweckung des Sinnes für physiognomische Schönheit, die keinem Deutschen vor ihm in solchem Grade aufgegangen war, und durch ihn trat zuerst inneres Leben in die Gesichtszüge deutscher Bilder. «44 In der Anbindung eines deutschen Malers an die großen Namen der niederländischen Malerei kommt eine Aufwertung deutscher Kunst zum Ausdruck. Die durch technische, stilkritische und biographisch-historische Überlegungen gewonnene Erkenntnis, dass Schongauer als Bindeglied zwischen der hochstehenden altniederländischen Malerei und der altdeutschen Schule fungierte, ermöglichte es ihm, die altdeutsche Kunst in

41 Brief von Quandt an Clodius vom 16.8.1819 aus Wien, in: SLUB, Mscr. Dresd. App. 204, Nr. 94.

42 Kugler 1842, S. 755: „Über das, was in Deutschland von seiner Hand herrührt, hat man erst in jüngster Zeit einige kritische Forschungen begonnen.« Dazu Anm. 1: »Bes. Herr v. Quandt«, bezogen auf Quandt $1840(2)$.

43 Quandt 1840 (2), S. 318-319, 325, 330; Quandt 1839 (1), S. 4.

44 Quandt 1840 (2), S. 331. eine kontinuierlich verlaufende Kunstgeschichte auf hohem Niveau einzuordnen.

Bereits in seinen frühen Schriften war diese Motivation einer Gleichbewertung verschiedener Kunstschulen explizit zum Ausdruck gekommen: In seiner 1819 erschienenen Publikation über die erste Italienreise charakterisierte er die Bedeutung altdeutscher Künstler und versuchte zu begründen, warum sie auf der gleichen Ebene standen wie die italienischen Maler. Dabei hob er nicht in erster Linie die künstlerischen Fähigkeiten hervor, sondern die Gesinnungen der damaligen Menschen: »Wir müssen des Characters unsrer Vorfahren gedenken. Bey ihnen ward die Kunst durch Religion und Selbstbeschauung geweckt und geleitet. Kunst und Religion standen in wohlthätiger Wechselwirkung [...], durch die Kunst wurde die Religion innigst mit dem Leben verflochten. Bey keinem Volke der neuern Zeit war die bildende Kunst so ausschließlich auf Religionsgegenstände und Zwecke hingeleitet als bey den Deutschen im Mittelalter [...]. Bey den Italienern, dem kunstgeübtesten Volke erlitt die Kunst vielseitige Einflüsse; sie kam zu ihnen aus Griechenland; bey ihrem Feuer schmolz Alles in ein mächtiges Lebensgefühl zusammen, welches strebt, sein Daseyn kund zu thun und auf das Daseyn Anderer einzuwirken. Ganz anders war es bey dem sinnigen Deutschen. [... Das tiefe Gefühl stellte mit schöpferischem Bewußtseyn sich im Bilde dar, und je deutlicher diese innern Bilder wurden, desto bewußter, inniger fühlte sich selbst das Gemüth, desto klarer wurden zugleich die Kunstformen; und in der innern Wahrnehmung verschmolz dieß Alles so in eins, daß Phantasie und Gefühl unzertrennlich wirksam waren. [...] So tragen denn die altdeutschen Kunstwerke den Idealcharacter der Deutschen Nation. «45 Quandt charakterisierte die deutsche Kunst als eine Kunst der Innerlichkeit und des Gefühls. Damit war sie in seinen Augen anders geprägt als die extrovertierte, italienische Kunst. Diese war der Ausdruck säkularisierter Frömmigkeit. ${ }^{6}$

Das spezifisch Germanische der Kunst beschäftigte Quandt noch vor einem anderen Hintergrund. Er stellte sich immer wieder die Frage, auf wen die Erfindung der gotischen Architektur zurückging. Auch hier lag sein Hauptinteresse darin, dem eigenen Volk seinen Verdienst attestieren zu können. Dies lässt sich anhand einer Rezension über ein Buch zur Baukunst des Mittelalters aus dem Jahr 1850 darlegen. Quandt versuchte dort

45 Quandt 1819, Bd. 1, S. 130-131.

46 Niehr 1997, S. 297: »Der neue ästhetische Begriff `Vaterland , mit dem auf die vermeintlich nationale Spezialität des Schönen in einem Werk reagiert wird, darf als Ausdruck säkularisierter Form eines religiösen Umgangs mit den Werken gelten. « Zur Ausgleichung italienischer und deutscher Kunst siehe Grewe 2015, S. 176-179; Thimann 2015, S. 22-38; Grewe 2006, S. 404-424; Heckmann 2003, S. 123-126; Schrapel 1997, S. $309-315$ 
eine Definition des Begriffs »gothische Baukunst «. ${ }^{47}$ Er verwendete hierfür aber nicht einzelne Bauelemente wie den Spitzbogen oder das Maßwerk, sondern verstand den spezifischen Charakter, das »innere Wesen« eines Kirchenraumes als das signifikante Merkmal, das ein Bauwerk als gotisch bestimmte. Zugleich merkte er an, dass er gar nicht an eine eigentliche »Erfindung« glaube, die aus dem Nichts entstehe. Vielmehr gehe es um einen bestimmten Moment, in dem Kultur, Gesellschaft und Zeitumstände sich so verdichteten, dass eine Idee zum Vorschein trete und sich zum Beispiel in einem Bauwerk manifestiere. ${ }^{8}$ Hierfür bediente er sich eines ähnlichen Vokabulars wie bei der altdeutschen Malerei. »Innerlichkeit«, was er als typisch deutsch bezeichnete, entdeckte er auch in der mittelalterlichen Architektur. Dementsprechend war die gotische Baukunst himmelwärts strebend und ohne jegliche Schwere..$^{49}$

Interessanterweise bestritt Quandt nicht direkt, dass der Spitzbogen als typisches Merkmal gotischer Baukunst in Frankreich, vor allem in Saint-Denis bei Paris, sehr früh angewendet worden war. Allein die Verwendung des Spitzbogens machte für ihn ein Bauwerk noch nicht zum gotischen Bau. Vielmehr war das Raumempfinden das eigentliche Charakteristikum für die Bestimmung einer Architektur. In Quandts Augen war der »gotische« Raumcharakter erst in Deutschland zur Vollendung gekommen. Als Hauptargument diente ihm der Kölner Dom, wobei er sich auf die aktuellste Forschung von

47 Quandt 1850 (3), S. 253, wobei ihn der Begriff >gothisch selber gar nicht interessierte: »Der Versuch, aus dem Adjectiv >gothisch die Bedeutung herzuleiten, muß aufgegeben werden. Gothisch bedeutet nichts als alterthümlich und ist ein sehr vager Ausdruck.« S. a. Quandt 1846 (2), S. 303-307.

48 »Was versteht man unter dem Worte Erfindung? Es ist eine während Jahrhunderten gleichsam im Schlummer dem Dasein entgegengebildete Idee, welche nun in einem großen Geist zum Bewußtsein kommt und von ihm verwirklicht wird. Keine Erfindung ist eine Schöpfung aus dem Nichts und am wenigsten die Baukunst.« Quandt 1850 (3), S. 255. S. a. Niehr 1999, S. 95-98.

49 »Wenn wir nun hauptsächlich auf die Verbindung der Theile achten, abgesehen von den Verhältnissen, so wird man verleitet den constructiv wichtigsten Theil des Baues, den Spitzbogen, für das wesentliche Merkmal des gothischen Styls, folglich den Erfinder des Spitzbogens auch für den Schöpfer der gothischen Baukunst zu halten. Wäre es möglich den Erfinder des Spitzbogens zu entdecken, so bliebe doch unsre Frage unentschieden, denn dieser Bogen allein für sich drückt keinem Gebäude den Stempel des sogenannt gothischen Styls auf. [...] Das innere Wesen der gothischen Baukunst ist es, worauf es ankommt, daß ein Bau das sei, was man unter gothisch versteht. Der Sieg über die Schwere ist, wie mir scheint, das Wesen und der daraus hervorgehende Typus der sogenannt gothischen Baukunst. [...] Durch den Styl aber, der gothisch genannt wird, fühlen wir uns von der irdischen Schwere erlöst, in diesem Bauen erhebt sich alles vom Grund bis zum Schlußstein mit heitrer Stätigkeit [...] Aus diesen der Andacht geweihten Räumen ist alles verwiesen was an die irdische Schwere erinnert. "Quandt 1850 (3), S. 253-254. S. a. Niehr 1999, S. 75.

50 »Wie wir die Wörter goth. Baukunst und Erfindung verstehn, so ist der, welcher den Plan zum Cölner Dom, diesem Triumph über die
Sulpiz Boisserée, der über die Kathedrale geschrieben hatte, berief: Der Baubeginn der Kathedrale datiere im Jahr 1248. Die Kirche sei dadurch älter als alle hochgotischen französischen Kirchen. Im Kölner Dom sei die Vollendung des schwerelosen Raumes zu ihrem Höhepunkt gelangt. ${ }^{\circ}$ Daraus deduzierte er, die Charakteristik der gotischen Baukunst sei im eigentlichen Sinne deutsch. ${ }^{1}$

Mit dieser Argumentation schloss sich Quandt der schon lange diskutierten Neubewertung der Gotik an, wie Goethes Aufsätze über den Straßburger und den Kölner Dom, Schlegels bereits erwähnter Reisebericht von Paris nach Köln und Boisserées Forschungsarbeit zur Kölner Kathedrale bestätigen. Sein Fokus auf den Raum als Charakteristikum des Gotischen greift dabei ein zentrales Element der frühen Gotikrezeption auf, das Klaus Niehr in seiner Studie erörtert hat. ${ }^{22}$ Es sei nur am Rand angemerkt, dass zu Quandts Lebzeiten vom mittelalterlichen Kölner Dom allein der Chor und Teile der Westseite standen, somit eine »gotische Raumwirkung am Original nur eingeschränkt feststellbar war. Den Beginn seiner Vollendung erlebte er zwar von Dresden aus noch. Fertig wurde der gewaltige Kirchenbau aber erst 1880. Quandt schwebten also weniger originale als ideale Architekturräume vor Augen, wie er sie in Boisserées Geschichte und Beschreibung des Doms von Köln von 1823 in schönen, die Fertigstellung antizipierenden Ansichten studieren konnte (Abb. 27).53

irdische Last, entwarf, der Erfinder der sogenannt goth. Baukunst, die Kugler sehr richtig die Germanische nennt, denn erst durch den Abt des Cölner Doms trat die Idee der Erlösung von der irdischen Schwere architektonisch ins Dasein. Kein französisches Gebäude, ausgenommen die Kirche St. Ouen in Rouen, zu welcher jedoch erst 1318 Abt Marcdargent den Grundstein legte, hat die Aufgabe, mit Hülfe des Spitzbogens die Schwere zu besiegen, eigentlich gelöst.«Quandt 1850 (3), S. 255-256; Quandt 1845, S. 563-564; Quandt 1843 (3), Sp. 419, $427-428$.

51 In diesem Sinn lehnte er auch die in der zeitgenössischen Forschung kursierende These über den Ursprung des Spitzbogens in der maurischen Kunst vehement ab. Quandt bezeichnete die orientalisch-arabische Baukunst als »Zeltbaukunst«, die dem ursprünglichen Nomadentum dieser Völker verpflichtet sei; Quandt 1850 (1), S. 111-112: »Wenn nun der Charakter der arabischen Baukunst der völliger Leichtigkeit und einer Freiheit ist, die bis zur Gesetzlosigkeit und Verneinung aller constructiven Regeln geht, wie sollte ein solches Volk, welches nur in Zelten leben wollte und in der Periode seiner höchsten Blüthe seine ursprüngliche nomadische Natur nicht verleugnete, den festesten aller Träger, den Spitzbogen erfunden haben? - Es ist dies ganz undenkbar und dennoch oft behauptet und diese Behauptung gar zum geheiligten Dogma von einigen Kunstdoctoren erhoben worden. Wenn Araber irgend wo den Spitzbogen anwendeten, so geschah es nur aus Nachahmung oder bedeutungsloser Verzierungssucht. «S. a. Börner 2015, S. 85-86.

52 Niehr 1999, S. 65-84. S. a. Rössler 2013, S. 292-299; Locher 2001, S. 147155; Apel/Greif 1997, S. 624, Kat. Wien 1996, S. 113-125.

53 Sulpiz Boisserée, Geschichte und Beschreibung des Doms von Köln, 2 Bde., Stuttgart: Cotta, 1823, S. 35 (Textband). In Quandts Bibliothek zusammen mit mehreren Büchern über die mittelalterliche Architek- 


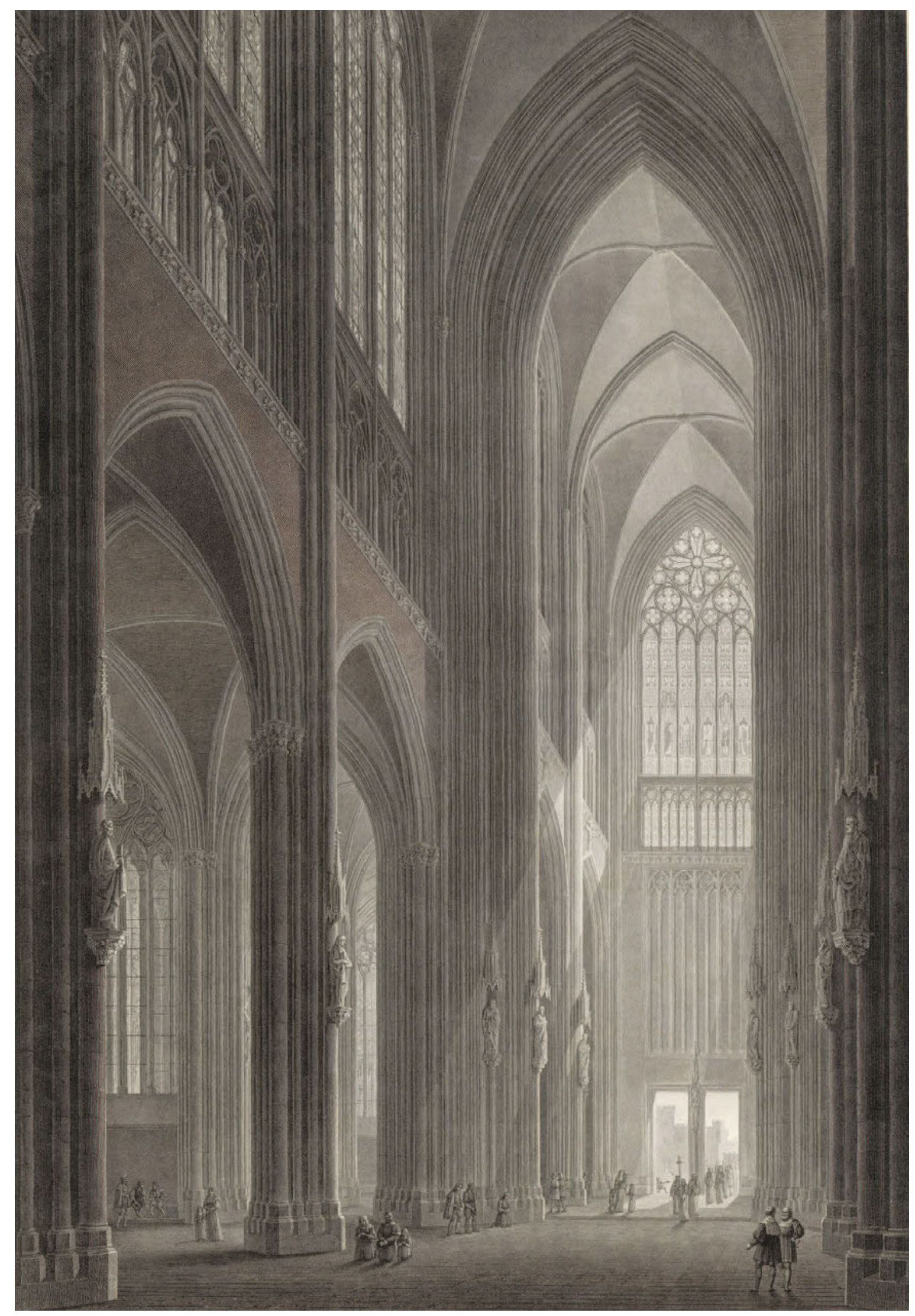

27 »Innere Ansicht der Vorhalle«, in: Sulpiz Boisserée, Ansichten, Risse und einzelne Teile des Doms zu Köln mit Ergänzungen nach dem Entwurf des Meisters (...) (Geschichte und Beschreibung des Doms von Köln, Bd. 2: Tafeln), Stuttgart 1823, Tafel XVI 
Quandt schloss seine Rezension mit dem Satz: »Es ist zu hoffen, daß [der Autor] sein Werk fortsetzen und sowohl den Charakter der französischen, als auch den der deutschen Kirchenbaue bestimmt bezeichnen und dadurch jeder von beiden Nationen ihr geistiges Erbtheil zuweisen wird. $\aleph^{54}$ Darin wird deutlich, dass es Quandt in erster Linie um einen Ausgleich der Nationen ging. Er suchte nach dem Charakteristischen einer jeden einzelnen und konsultierte hierfür zahlreiche wissenschaftliche Publikationen. Dies hing mit seinem genuinen Verständnis von Kultur zusammen. Gesellschaft und Kunst bedingten sich gegenseitig. So nahm er auf seinen Reisen durch Deutschland, Frankreich, Spanien oder Schweden immer beides in den Blickpunkt seiner Betrachtungen. Entsprechend heißen mehrere seiner Reiseberichte »Beobachtungen und Phantasien über Menschen, Natur und Kunst «.55
Die Nationenfrage spielte bei Quandt je länger je weniger eine Rolle und trat nur noch gelegentlich zum Vorschein. Seine Interessen richteten sich spätestens ab den 1830er Jahren hauptsächlich auf die ästhetische Theorie und die Frage, wie Kunst auf den Betrachter wirke. Dies zeigt auch die Weiterentwicklung einzelner Hängungen in seiner Sammlung, in welchen die Gegenüberstellung deutscher und italienischer Kunst wirkungsästhetischen Fragestellungen wich. Dennoch blieb die Aufwertung altdeutscher Kunst wichtig. Indem er sie auf das gleiche Niveau wie die italienischen Vorbilder hob, erhielt er die Möglichkeit, seine Kriterien für Kunst vergleichend anzuwenden. Durch die Gleichbehandlung der Alten Meister des Südens und des Nordens konnte die altdeutsche Kunst ihre Vorbildrolle für die zeitgenössische Kunst wahrnehmen. tur vorhanden: Kat. Quandt 1860 (1), S. 164-168, Nr. 2567. Boisserée hatte mittelalterliche Risse des Domes gefunden und die Bauteile exakt vermessen. Diese Resultate flossen in seine Rekonstruktionen ein. Zu Goethes Gotikrezeption siehe Niehr 1999, S. 23-46, zu Schlegel ebd., S. 107-127, zu Boisserée ebd., S. 159-176.
54 Quandt 1850 (3), S. 256.

55 Frankreich- und Spanienreise; Quandt 1853; Quandt 1850 (1); Quandt 1846 (2). S. a. Börner 2015, S. 121-136. 


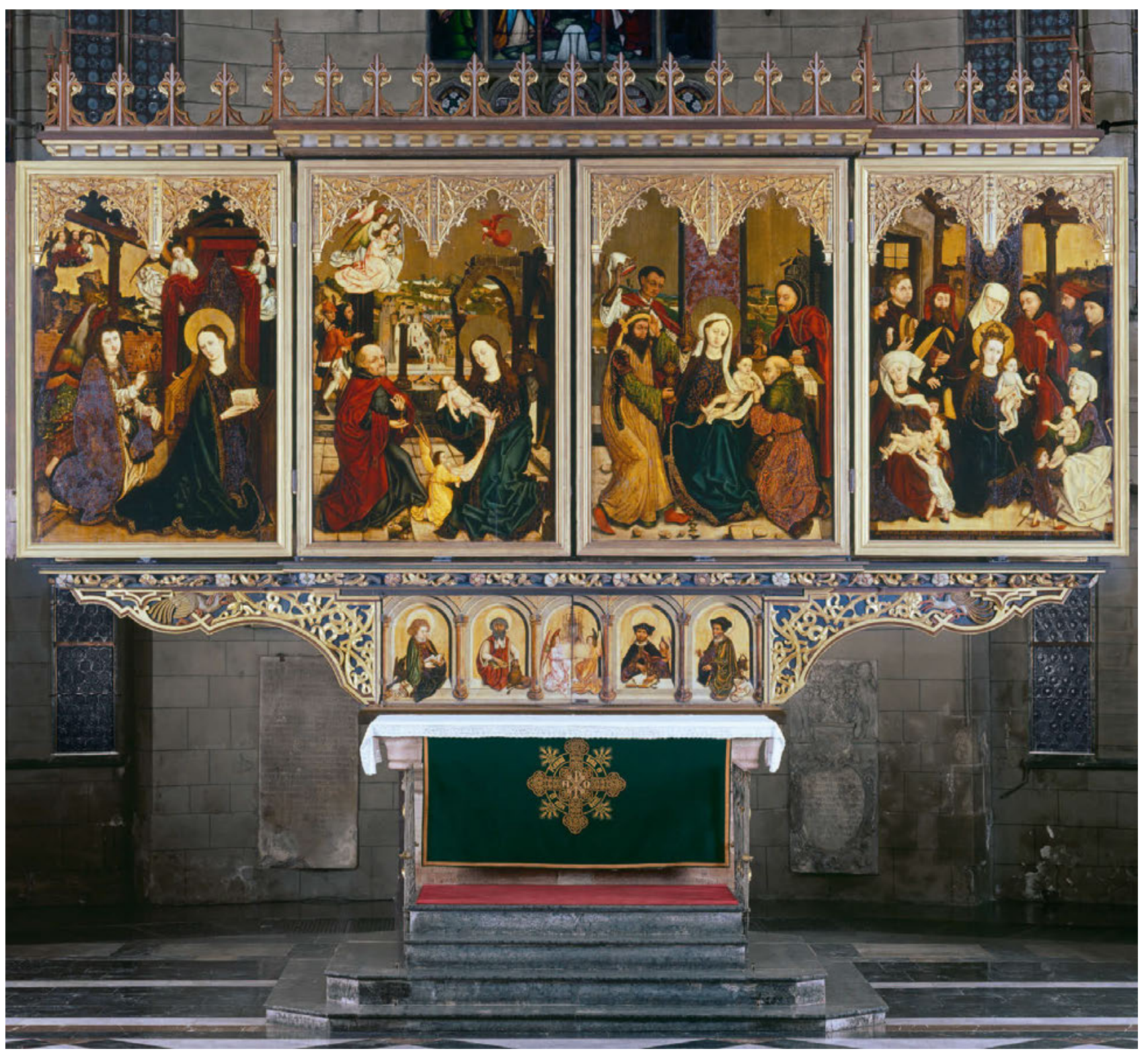

28 Michael Wolgemut, Verkündigung, Geburt Christi, Anbetung, Heilige Sippe (Erste Wandlung des Zwickauer Marienaltars), 1479, Öl auf Holz, $250 \times 700 \mathrm{~cm}$, Zwickau, Marienkirche 


\section{VATERLÄNDISCHES KULTURGUT: Der Königlich-Sächsische Altertumsverein}

Die Alten Meister als Vorbilder für die junge Kunst und die Gesellschaft seiner Zeit blieb Quandts lebenslange Überzeugung. Über seine ganz persönliche Beschäftigung mit altdeutscher Kunst und die daraus resultierenden Aufsätze in Zeitschriften und die Ankäufe für die eigene Sammlung hinaus stellt sich die Frage nach der Wirksamkeit seines Anliegens, diese Überzeugung und damit die Kenntnis der alten Meister einem breiten Publikum zugänglich zu machen. Eine erste Möglichkeit bot sich ihm im Aufbau des Königlich-Sächsischen Altertumsvereins ab 1824, an dem er von Anfang an beteiligt war. Die Gründung der sächsischen Vereinigung unter dem Schutz des Königs gesellte sich zu einem Phänomen, das sich vielerorts auf deutschem Gebiet auszuprägen begann: Grundgelegt in den Errungenschaften der Aufklärung und befördert durch ein historisch-vaterländisches Interesse im Zuge der napoleonischen Eroberungen bildeten sich Vereine, die in den Kulturgütern ihrer Heimat etwas Schutzwürdiges sahen. ${ }^{1}$ Damit erhielt die Sache der altdeutschen Kunst gleichsam ein öffentliches Fundament. Im KöniglichSächsischen Altertumsverein erhoffte sich Quandt seine Ansichten und Kennerschaft einbringen zu können, vaterländische Kulturgüter vor allem des Spätmittelalters bekannt zu machen und sich für ihren Erhalt einzusetzen. Der Zwickauer Marienaltar, der auf Anraten des Altertumsvereins restauriert wurde, gehört zu den herausragenden Beispielen seines Engagements (Abb. 28).

\section{Vereinsgründung, Scheintod und Reaktivierung}

Mit seiner Übersiedlung nach Dresden zu Beginn der 1820er Jahre begann Quandt über die Kunstförderung in seinem Haus hinaus in Vereinen Kunst zu unterstützen. Ein erster Schritt

1 Savoy 2011, S. 246-247; Falser 2008, S. 22; Huse 2006, S. 62; Magirius 1989, S. 52-53.

2 Tagebucheintrag von Ernst Förster vom 29.9.1821, in: Förster 1846, S. 223: "Quandt [...] hat die gute Idee, eine Sammlung von Zeichnungen nach altdeutschen, in vaterländischen Kirchen sich findenden, Gemälden zu veranstalten. Meißen, Naumburg, Görlitz, Zittau und andere Orte, werden die Originalien dazu in hinreichender Zahl liefern. Es sollen in einigen Sächsischen Kirchen Bilder von Wohlgemuth vorhanden sein.« S. a. Heinrich 2002, S. 7; Briel 2002, S. 12; Heiland 1997, S. 15; Magirius 1989, S. 50; Maaz 1986, S. 7-11. Zu den Gründungen patriotischer Vereine siehe Schmitz 2001, S. 32-35. war seine Beteiligung an der Gründung des Königlich-Sächsischen Altertumsvereins. Biographisch gesehen handelt es sich dabei um eine Konsequenz aus seiner bisherigen Beschäftigung mit Werken Alter Meister, die er auf Reisen durch Sachsen besucht und in Artikeln behandelt hatte. Sein Fund von altdeutschen Gemälden auf den Dachböden der Nikolai- und Thomaskirche in Leipzig im Jahr 1815 und die daraus erfolgten Bemühungen um Konservierung, Restaurierung und Ausstellung der Gemälde sind ganz besonders als Motivator für die Erhaltung sächsischer Altertümer zu zählen. Zudem beabsichtigte er im Zuge dieser Wiederentdeckung eine Sammlung an Zeichnungen nach altdeutschen Gemälden in sächsischen Kirchen zu publizieren. Diese Idee, Kunstwerke einer Region zu sichten, aufzulisten und zu dokumentieren, blieb zwar unausgeführt. Sie trug jedoch einen denkmalpflegerischen Gedanken in sich, der mit der Gründung des Königlich-Sächsischen Altertumsvereins neun Jahre später wieder aufgenommen werden sollte. ${ }^{2}$

Bereits 1819 hatte der Altertumsforscher Carl August Böttiger in der Dresdener Abendzeitung einen Artikel veröffentlicht, der die Gründung eines Sächsischen Altertumsvereins forderte. ${ }^{3}$ Nach dem Verkauf der mittelalterlichen Glasmalereien der Marienkirche in Zwickau, der für große Empörung unter Kunstfreunden gesorgt hatte, schrieb Böttiger im April 1824 eine Denkschrift, welche erneut die Gründung eines Vereins forderte. Dieser sollte sich mit der Erforschung, Erhaltung und Aufbewahrung sächsischer Kulturgüter beschäftigten. ${ }^{4}$ Als Beispiel diente ihm Quandt: »Wie der eifrige Förderer aller Kunstforschung, Hr. v. Quandt mehre[re] altdeutsche Gemälde und selbst einige Cranachs in Leipzig dem Staube und Moder entriß und ihre Ausstellung an achtbarstem Orte bewirkte [...], « so solle sich der Altertumsverein für die Rettung von Kunstwer-

3 Magirius 1989, S. 52-53; Ermisch 1900, S. 3-4. Vorbild war der Thüringisch-Sächsische Verein für Erforschung des vaterländischen Alterthums und Erhaltung seiner Denkmale in Naumburg-Halle.

4 Böttiger stellte 21 Punkte zusammen. Das Manuskript »Verein für Erforschung des bildlichen Alterthums im Königreiche Sachsen « von Carl August Böttiger vom 15.4.1824, in: HStADD, 12508 Sächsischer Altertumsverein, Nr. 3 (neu: 755) Statuten 1824-26 »Acta des Königlich Sächsischen Alterthums=Vereins «. S. a. Schmidt-Funke 2006, S. 62; Magirius 1989, S. 53; Ermisch 1900, S. 4-6. 
ken vor ihrer Zerstörung einsetzen. ${ }^{5}$ Er forderte, dass Künstler und Architekten Zeichnungen und Abbildungen erschaffen sollten, »um so zuerst über den gegenwärtigen Zustand, Verstümmelung, Hinfälligkeit derselben eine anschauliche Ansicht zu erhalten. $\varkappa^{6}$ Im ganzen Land wollte er Leute gewinnen, die bei der Inventarisierung helfen und Informationen an den Verein in Dresden senden würden. Gegebenenfalls sollten vor Ort und auf Kosten des Vereins archäologische Grabungen vorgenommen, Urkunden auf Hinweise auf Kunstwerke erforscht und das Umfeld dokumentiert werden. Böttiger verlangte also die umfassende Dokumentation vorhandener und neu aufgefundener Kulturgüter. Die gewonnenen Erkenntnisse sollten in Jahresberichten in Text und Bild publiziert werden. Über seine Idee informierte der Initiator auch Quandt. Dieser antwortete in einem Brief vom 12. April 1824, er unterstütze ihn und hoffe, ein solcher Verein würde den Sinn für die vaterländische Kunst befördern. ${ }^{7}$

In einem Antrag an den König wurde im Sommer 1824 die Gründung eines solchen Altertumsvereins unter königlicher Trägerschaft angeregt. Zu den Unterzeichnern gehörten nebst Böttiger auch Johann Gottlob von Quandt und eine Reihe sächsischer Politiker - darunter der enge Vertraute des Königs, mächtige Kabinettsminister und Direktor der Kunstsammlungen Detlev Graf von Einsiedel. ${ }^{8}$ Bereits im November 1824 wurde ein Fonds von 400 Talern gutgeheißen. ${ }^{9}$ Im Januar 1825 wurde eine gedruckte Bekanntmachung der Vereinsgründung veröffentlicht, die ebenfalls die Statuten und ein Verzeichnis erhaltenswerter Altertümer enthielt. Quandt gehörte selbstredend weiterhin zu den Signierenden. In der Einleitung hieß es: »Von mehreren Alterthumsforschern und Vaterlandsfreunden in Sachsen, ist der Wunsch ausgesprochen worden; die zerstreuten Denkmale der Vorzeit, welche für Kunst und Wissenschaft, und besonders für die Geschichte des Vaterlandes, von Wichtigkeit sind, der Verborgenheit zu entziehen, gegen das
Verderben zu schützen und durch Beschreibung und Abbildung zur allgemeinen Kenntniß zu bringen. Dieses Unternehmen hat bald Freunde gefunden, die sich verbunden haben, um durch gemeinschaftliches Zusammenwirken das zu erreichen, was den Bestrebungen Einzelner nicht gelingen möchte. So hat sich der Verein zu Erforschung und Erhaltung vaterländischer Alterthümer im Königreiche Sachsen gebildet. $\ll^{10} \mathrm{Im}$ Brühlschen Palais, später in einem Palais im Zwinger, fanden die Zusammenkünfte statt, die Prinzen und späteren Könige Friedrich August und Johann übernahmen Direktorium und Vizedirektorium. ." Bis zur Wahl eines Vorstands wurde Quandt mit den Sekretariatsarbeiten beauftragt. Er war zudem als Vorsitzender vorgesehen, was er aber ablehnte. Das Sekretariat übernahm schliesslich der Bibliothekar Friedrich Adolf Ebert ${ }^{12}$

Im Juni 1825 fand eine erste Versammlung statt, in der sechs spezialisierte Sektionen bestimmt wurden. Die erste Sektion für Archäologie übernahm Böttiger, die zweite beschäftigte sich mit Urkunden und Inschriften, die dritte, deren Leitung Quandt übernahm, mit Malerei und Plastik. Die weiteren Sektionen waren für Architektur, Numismatik und Handschriften zuständig. ${ }^{13}$ Die Vereinsmitglieder zahlten für ihre Teilnahme einen freien Betrag, mindestens aber einen Taler. Quandt war besonders großzügig. Während die meisten Mitglieder zwei bis drei, maximal fünf Taler einlegten, zahlte er mit zehn Talern doppelt so viel. Damit blieb der potente Bürger und Kunstförderer wohl vor allem aus Anstand unter den Zahlungen der beiden Direktoren aus der königlichen Familie, die mit zwanzig Talern subskribierten. Quandts generöse Einlage ist wohl Unterstützung der Sache und Selbstdarstellung zugleich. Dies lässt sich auch in seinen Aktien des Sächsischen Kunstvereins beobachten, wo er ebenfalls bis zu doppelt so viele zeichnete wie normale Mitglieder. ${ }^{14}$

In den Jahren nach der Gründung scheint der Altertumsverein und seine Sektionen entgegen der hehren Ziele kaum aktiv

5 Zitiert nach Punkt 10, in: Carl August Böttiger, »Verein für Erforschung des bildlichen Alterthums im Königreiche Sachsen«, 15.4.1824, in: HStADD, 12508 Sächsischer Altertumsverein, Nr. 3 (neu: 755) Statuten 1824-26 »Acta des Königlich Sächsischen Alterthums=Vereins«, [s. p.].

6 Zitiert nach Punkt 12, in: ebd., [s. p.].

7 »Denn so betriebsam und kunstfleissig sie [die Mitbürger - AR] auch sind, so fehlt es ihnen doch an Kunstsinn, der jedoch durch einen solchen Verein geweckt werden könnte.« Zit. nach Ermisch 1900, S. 6.

8 Entwurf zu einem Brief mit Antrag an den König vom 16.7.1824, in: HStADD, 12508 Sächsischer Altertumsverein, Nr.3 (neu: 755) Statuten 1824-26. Zu den weiteren Unterzeichnern siehe Klemm 1835, S. III-IV.

9 Entwurf zu einem Gesetz für einen Vereinsfonds von 400 Talern vom 3.11.1824, in: HStADD, 12508 Sächsischer Altertumsverein, Nr.3 (neu: 755) Statuten 1824-26.

10 Bekanntmachung des Königl. Sächsischen Vereins zu Erforschung und Erhaltung vaterländischer Alterthümer, Dresden: Carl Gottlob Gärtner, 1825, S. 3, datiert am 19.1.1825. Die Statuten ebd., S.7-12, das

Verzeichnis der Altertümer ebd., S. 13-14. HStADD, 12508 Sächsischer Altertumsverein, Nr. 3 (neu: 755) Statuten 1824-26. Abgedruckt in: Magirius 1989, S. 193-194; Klemm 1835, S. V-VII.

11 Bekanntmachung, S. 4; zur Rolle der Prinzen siehe John 2001, S. 471.

12 Bekanntmachung, S. 5: »Die Correspondenz des Vereins wird, bis zur Wahl eines Sekretairs, der mitunterzeichnete von Quandt, unter Mitwirkung des Hofrath Böttiger, besorgen.« S. a. Schmidt-Funke 2006, S. 63; Magirius 1989, S. 53; Ermisch 1900, S. 6-8; Klemm 1835, S. VIII.

13 Magirius 1989, S. 53. S. a. Briel 2002, S. 15-16; Marburg 2001, S. 57-61; Schmitz/Strobel 2001, S. XVII; Maaz 1986, S. 8-9; Briel 1984, S. 15-16.

14 Subskriptionsliste für die Periode von 1826/27, in: HStADD, 12508 Sächsischer Altertumsverein, Nr. 43, Acta des Königl. Sächsischen Alterthumsvereins. Verfassungsacten Fasc. III. Mitglieder=Verzeichnisse Subscriptions=Listen Diplom=Absendungen etc. Scheine von 1824 bis 1826. Mitgliederbeiträge geregelt in den Statuten $\S 9$; s. a. Ermisch 1900, S. 9; Klemm 1835, S. VI. Zum Kunstverein siehe nachfolgendes Kapitel. 
gewesen zu sein, was möglicherweise daran lag, dass es sich um einen von der Regierung eingesetzten Verein handelte. Zwar wurden Materialien aus den Bezirken Sachsens eingesandt, doch wurden sie kaum bearbeitet. Es wurden keine Jahresberichte publiziert und keine Versammlungen abgehalten. Zudem schränkten wohl zwischenmenschliche Probleme die Tätigkeit ein. Sie drehten sich um die Arbeit des Vereinssekretärs Friedrich Adolf Ebert, der offenbar seine Akten und Korrespondenzen unter Verschluss hielt. ${ }^{15}$ Ende 1828 beschloss der Vorstand, private Versammlungen, die auch Nicht-Mitgliedern geöffnet werden sollten, zu organisieren, »um nun die Theilnahme an dem Verein zu steigern [...]. $\ll^{16}$ Diese Zusammenkünfte sollten auf vier Themengruppen aufgeteilt werden, die sich mit Geschichte, Plastik, Münzkunde und Malerei beschäftigten. Die Leitung der ersten Gruppe übernahm Ebert, diejenige für die Malerei Quandt. Als einzige Sektion trat die historische, wenn auch nur bis 1830, zusammen. Die anderen wurden nie aktiv oder zumindest nicht aktenkundig. ${ }^{17}$ Ebenfalls 1828 stellte der Altertumsverein beim König den Antrag, für die Erhaltung der Kulturgüter im sächsischen Staat ein Gesetz auszuarbeiten. Prinz Johann als Direktor des Vereins legte höchstpersönlich einen gut begründeten Entwurf vor. Dieser scheiterte schließlich an den Eigentumsrechten, die nicht beschnitten werden sollten. ${ }^{18}$

1830 rief Direktor Johann erneut zur Gründung von Untersektionen auf. Es sollten nur noch zwei sein: eine historische und eine artistische. ${ }^{19}$ Die Leitung der zweiten Sektion für die bildenden Künste übernahm Quandt zusammen mit Ferdinand Hartmann, das Sekretariat der Archäologe Heinrich Hase. In einem Brief äußerte sich Quandt dazu. Darin zeigt sich seine Enttäuschung über die bisherige Vereinstätigkeit: »[...] der fast vergessene Königl: sächs: Alterthumsverein, [soll $]$ wieder in Anregung u wo möglich in Thätigkeit gesetzt werden [...]. Ich gebe zwar zu, daß es leichter seÿ ein neues junges Leben hervorzurufen, als einen Verstorbenen wieder zu erwecken, allein vielleicht war der Königl: sächs: Alterthumsverein nur ein

15 Magirius 2001, S. 479; Magirius 1989, S. 53-54; Ermisch 1900, S. 10-14 Zu den eingesandten Materialien der ersten Jahre siehe Klemm 1835, S. VIII-XIV. S. a. Quandt 1831 (1), S. 3.

16 Klemm 1835, S. XIV; Ermisch 1900, S. 12-13. Zur Gründung der Privatversammlungen der historischen Sektion siehe die Dokumente vom 1.11. und 8.12.1828 sowie die Sitzungsprotokolle ab März 1829 im Konvolut »Historische Zusammenkünfte auf der königlichen Bibliothek«, in: HStADD, 12508 Sächsischer Altertumsverein, Nr. 9 (neu: 763), Historische Zusammenkünfte in der Königlichen Bibliothek: Protokolle, Vorträge, Notizen 1828-1832.

17 Ermisch 1900, S. 13; Klemm 1835, S. XV-XVI.

18 Prinz Johanns Antrag paraphrasiert in: Ermisch 1900, S. 14-15; Magirius 1989, S. 53-54; Magirius 2001, S. 479-480. S. a. John 2001, S. 472.

19 Quandt 1831 (1), S. 3; Klemm 1835, S. XIV-XV.

20 Brief von Quandt an Unbekannt vom 26.10.1831, in: Berlin, SMB, Zent-
Scheintoder (sic!) u so wäre doch wenigstens ein Versuch mit ihm zu machen. [...] Se. Königl: Hoheit der Prinz Johann, welcher die oberste Leitung des königl: Alterthumsverein gegenwärtig allein übernommen hat, geruhten Versammlungen von artistischen Alterthumsfreunden anzuordnen u einen Comite einzusetzen, welcher sich mit Kunstalterthümern beschäfftigen sollte. Diese zweÿte Abtheilung des Alterthumsvereins u was hier einschlägt, wurde mir, Prof: Hartmann u Hofrath Hase anvertraut. $\ll^{20}$

Trotz Quandts Enttäuschung über die Arbeit des Altertumsvereins muss gefragt werden, warum er selber, wie die erhaltenen Akten des Vereins andeuten, anfangs wenig aktiv war, obschon er sich sonst gerne für Kunstprojekte begeistern ließ und diese auch tatkräftig unterstützte. Ein Grund mochte sein, dass er seit 1828 von seiner Arbeit als Vorstand des neu gegründeten Sächsischen Kunstvereins absorbiert war. Da der Altertumsverein eher träge zu sein schien, ließ er sich wohl von jenem Projekt stärker vereinnahmen. Zudem konnte er sich dort für die Entwicklung der neuesten Kunst einsetzen. Auch schien der kränkliche Sekretär des Altertumsvereins, Friedrich Adolf Ebert, kürzer zu treten. Er hatte anscheinend für viele Unstimmigkeiten gesorgt. Quandt schrieb über ihn, er habe »in stiller Thätigkeit sich mit urkundlich geschichtlichen Forschungen beschäftigt « - nicht mit den Kunstwerken selbst. ${ }^{21}$ Ebert schien die Vorstandsmitglieder tatsächlich nur wenig über seine Arbeit informiert und den Austausch mit Altertumsfreunden in Sachsen weitgehend unter Verschluss gehalten zu haben. Gustav Klemm - sein Nachfolger ab 1834, im Vorstand der ersten, historischen Sektion aber schon länger tätig - schrieb, Eberts geistige Kraft sei durch Krankheit gelähmt gewesen. Der Ausschuss habe ihn daher beauftragt, die Schriften des Vereins herauszurücken, was dieser aber nie tat. ${ }^{22} \mathrm{Hie}-$ raus kann abgeleitet werden, dass es um die Diskussionskultur nach der Vereinsgründung nicht gut gestanden hatte, worauf die verschiedenen Versuche wechselnder Diskussionsgruppen hinweisen mögen.

ralarchiv, Autographensammlung, Mappe 1133, Quandt, Johann Gottlob von, fol. 9 r-10r.

21 Quandt 1831 (1, S. 3. Ähnlich im Brief an Unbekannt vom 26.10.1831: »Wirklich haben sich unter der Leitung des Hofrath Ebert einige Freunde literarischer Alterthümer in stiller Thätigkeit mit Untersuchungen $u$ Abhandlungen beschäfftigt $u$ es sind von ihnen gewiß schätzbare Aufschlüße ihrer vaterländischen Geschichte zu hoffen.» Berlin, SMB, Zentralarchiv, Autographensammlung, Mappe 1133, Quandt, Johann Gottlob von, fol. 9v. Zu den zwischenmenschlichen Problemen s. a. Magirius 1989, S. 53-54; Ermisch 1900, S. 10-14.

22 Klemm 1835, S. XVII: »Eberts geistige Kraft [war] durch die langsam sich ausbildende Krankheit, der er gar bald ganz erliegen sollte, so gelähmt, daß er wohl an eine ihm vom Ausschuß aufgetragene Herausgabe der Schriften des Vereins öfter dachte, allein sie nicht ausführen konnte.« 


\section{Mit gutem Beispiel voran: Quandts artistische} Sektion

Die neue, künstlerische Sektion des Altertumsvereins unter Quandts und Hartmanns Leitung schritt 1830 proaktiv zur Sache und bestimmte zuerst genauer ihre Organisation: Die drei auf zwei Jahre verpflichteten Vorstandsmitglieder sollten sich um Erforschung, Bekanntmachung und Erhaltung von Denkmälern und Altertümern der Kunst und deren Geschichte kümmern. Der Sekretär schrieb die Protokolle und Mitteilungen und führte Korrespondenz. Die Leiter der Sektion organisierten mindestens zwölf Versammlungen pro Jahr, luden dazu im Namen aller in das Vereinslokal ein und erstatteten danach anhand des Protokolls dem Komitee des Gesamtvereins Bericht. Zudem mussten alle Zeichnungen, Berichte, Projektvorschläge dem königlichen Direktor vorgelegt werden. ${ }^{23}$ Quandt formulierte Grundsätze:

», daß nicht blos ein Sammeln u Aufzeichnen der im Lande zerstreuten Alterthümer der nächste Zweck, sondern die Erhaltung derer, welche dem Verderben entgegen gehen, das hauptsächlichste Bestreben seÿn müsste.

2, daß man nicht eher Beÿträge zu den Zwecken der Alterthümer wird einsammeln können, bis dieser durch die That sein Daseÿn verkündet u seine Nützlichkeit bewährt hat.

3, daß man überhaupt keine jährlichen Beiträge einsammlen u eine Verbindlichkeit zur Mitgliedschaft jemand antragen solle, sondern daß der Comite der künstlerischen Abtheilung des Alterthumsvereins, jeden zur Ausführung eines nützlichen Unternehmens für Erhaltung eines Kunstdenkmals auffordern dürfe, wer dazu sich geschickt u willfährig zeigt u daß nur Beÿträge zu bestimmten Zwecken, eingesammlet werden sollen, von solchen, welche freÿwillig, so viel oder so wenig als es auch seÿ, dazu aus Liebe zum Vaterlande u zur Kunst gern beÿtragen wollen.

4, daß die Namen derer, welche zur Erhaltung eines Kunstwerks edelmüthig beÿgetragen haben, dankbar öffentlich bekannt gemacht werden.

5, Eine Hauptsache ist, daß man bald zum Werke schreitet. $\ll^{24}$

23 »Zwei Entwürfe zur Organisation der mit dem künstlerischen Theile beauftragten zweiten Section des Königl. Sächs. Alterthums=Vereins." [1830], in: HStADD, 12508 Sächsischer Altertumsverein, Nr. 12 (neu: 781), Akten der II. Sektion, Entwurf zur Organisation und Protokolle 1831-33. Weitere Punkte betreffen die Regelung von Stellvertretungen und die Legislatur der drei leitenden Mitglieder der II. Sektion, die sich auf zwei Jahre verpflichten. Zu den zwei Sektionen siehe Klemm 1835, S. XI-X. S. a. Quandt 1831 (1), S. 3-4; Ermisch 1900, S. $15-16$.

24 Quandt an Unbekannt vom 26.10.1831, in: Berlin, SMB, Zentralarchiv, Autographensammlung, Mappe 1133, Quandt, Johann Gottlob von, fol. 10r-10v.

25 Protokoll der Sitzung der 2. Sektion des Sächsischen Altertumsvereins
Zwar handelt es sich hier nicht um ein offizielles Dokument, sondern nur um einen Brief, doch zeigt sich darin, wie Quandt vorzugehen beabsichtigte. Ähnlich wie im Kunstverein wurde er als Privatperson aktiv, trat aber im Namen des Vereins auf. Diese Vermischung der Kompetenzen, die im Fall des Kunstvereins zum Rücktritt führen sollte, war im Altertumsverein sehr erfolgreich. Gemäß seinem letzten Punkt schritt der Kunstfreund tatsächlich zur Tat. Ab 1831 traf sich seine Sektion zu gesamthaft zehn Sitzungen und erreichte Beachtliches. Hierüber geben die Protokolle im Sächsischen Hauptstaatsarchiv Auskunft. In der ersten Zusammenkunft, die Quandt im Oktober 1831 einberufen hatte, erläuterte er Kulturgüter in Freiberg, Chemnitz und Annaberg, die er auf einer Reise durch Sachsen gesehen und als erhaltenswert eingestuft hatte. Er wollte sich um Kunstinteressierte bemühen, die deren Konservierung finanziell unterstützen würden, so wie er es in seinen Grundsätzen formuliert hatte. ${ }^{25}$

Wie so oft trieb Quandt mit den Möglichkeiten seines Reichtums die Dinge selbstständig voran. Noch im gleichen Jahr veröffentlichte er die Hinweisungen auf Kunstwerke aus der Vorzeit, die er den Altertumsfreunden in Sachsen widmete, und in denen er sich mit ebendieser Reise zu den erhaltenswerten Kulturgütern Sachsens beschäftigte. Den Ertrag aus dem Verkauf spendete er dem Königlich-Sächsischen Altertumsverein. ${ }^{26}$ Die Schrift verdeutlicht zweierlei: einerseits erläuterte Quandt einleitend, was er von einem Altertumsverein erwartete, andererseits lässt sich zwischen den Zeilen deutlich lesen, dass er die bisherige Arbeit als wenig wirksam einschätzte. Der Autor schrieb, er habe schon im Gründungsjahr 1825 eine Reise durch Sachsen vorgenommen, über die er im Verein Rechenschaft abgelegt habe. Diese hatte keine Resultate zur Folge gehabt, so dass er den Zweck der Hinweisungen folgendermaßen umschrieb: »[...] nachdem ich sie [die Schrift] durch Nachträge vermehrte, und unlängst wieder kleine Reisen zu meiner Belehrung unternahm, [...] so ist sie vielleicht als ein Leitfaden für künftige Wirksamkeit des Vereins nicht ganz unnütz, und wie aus einem Saamenkorn ein mächtiger Baum erwächst, so kann eine kleine Veranlassung die bedeutendsten, heilsamsten

vom 25.10.1831, in: HStADD, 12508 Sächsischer Altertumsverein, Nr. 12 (neu: 781), Akten der II. Sektion, Entwurf zur Organisation und Protokolle 1831-33, fol. 4-5. Hartmann bezweifelte, dass Quandt mit seiner Finanzierungsidee Erfolg haben würde.

26 Quandt 1831 (1), Titelblatt: »Den Alterthumsfreunden in Sachsen gewidmet von Quandt. Der Brutto-Ertrag ist für Zwecke des Alterthumsvereins bestimmt. «S. a. Protokoll der Sitzung der 2. Sektion des Sächsischen Altertumsvereins vom 10.12.1831, in: in: HStADD, 12508 Sächsischer Altertumsverein, Nr. 12 (neu: 781), Akten der II. Sektion, Entwurf zur Organisation und Protokolle 1831-33, fol. 8-9; Ermisch 1900, S. 12. 
Folgen haben. [...] blos den ersten Anknüpfungspunkt fernerer Thätigkeit zu geben, ist meine anspruchslose Absicht. $\ll^{27}$ Sechs Jahre nach der Vereinsgründung glaubte Quandt, den Verein überhaupt erst zu Aktivität anregen zu müssen.

Deutlich wird in der Einleitung auch, dass der Altertumsfreund die vaterländischen Kulturgüter vor allem an ihrem ursprünglichen Ort erhalten wollte. Dieser denkmalpflegerische Wesenszug seiner Absichten verdeutlicht die Erwartungen, die an diese vielerorts gegründeten Altertumsvereine geknüpft wurden. Dabei ging es nicht nur um die Konservierung von Kunstwerken, sondern um die Erhaltung der Heimat und die Förderung einer patriotischen Liebe, die sich in diesen Altertümern manifestierte. Schwärmerisch schrieb er: »Das Gemüth bedarf immer eines Symbols, und so knüpfte sich an die alten Wahrzeichen der Städte, an die bemoosten Thürme, die wir als Kinder schon in Morgenlicht und Abendschein erglühn gesehn, an Bildern in Kirchen und Rathhäusern, die wir bei feierlichen Gelegenheiten betrachtet, die Vaterlandsliebe fester an, als an den todten Buchstaben der Geschichte. Diese uns liebgewordenen, ehrwürdigen Gegenstände verwachsen mit dem Heimathsgefühle und mit allen Erinnerungen unsers Lebens, deren scenischen Hintergrund sie bilden $[\ldots] \cdot \mathrm{k}^{28}$ Es sollte bei der Arbeit des Altertumsvereins also nicht allein um ein historisches oder kulturelles Interesse an der Erhaltung von Kulturgütern gehen. Vielmehr waren diese Kunstwerke Kulisse der Heimat und der Vaterlandsliebe. Wenn Quandt vom »todten Buchstaben der Geschichte« spricht, zeigt sich darin nicht nur eine Kritik an dem Bibliothekar und Vereinssekretär Ebert, der im stillen Kämmerlein an seinen Urkunden gearbeitet hatte, sondern auch an einer grundsätzlichen Skepsis gegenüber der quellenkritischen Geschichte. Wie in einem nachfolgenden Kapitel zu seiner Haltung zur Historienmalerei noch ausführlicher dargelegt werden wird, war Quandt überzeugt, dass Geschichte in der Gegenwart lebendig war und Kunst nicht allein als Tor zur Vergangenheit dienen durfte. Sein Ziel war es, aus der Geschichte zu lernen und als gegenwärtiger Mensch nachhaltig in die Zukunft zu wirken. Alte Kunstwerke waren hierfür Vorbild, denn sie waren mit der Gesellschaft eng verbunden. Die kunstvollen Rathäuser als Horte der Politik und die Kirchen als Häuser der Religion waren ihm Beispiele und Ideale zugleich. Kunst, Gesellschaft und Religion waren früher eine Einheit. Durch die Erhaltung von Altertümern und seine Hoffnungen in die neuen Errungenschaften der deutschen Kunst, wie sie die Nazarener mit ihren Freskenprojekten in Rom, München oder Berlin ausführen konnten, glaubte er diese Einheit wieder herstellen zu können. Indem alte und neue Kunstwerke an den Orten, wo die Menschen lebten, zu sehen waren, konnten sie den Kunstsinn fördern. Die Vereine und Kunstfreunde spielten hierfür eine wichtige Rolle: »Eine von allem Eigennutz und fremdartigem Interesse, dieses sey an sich noch so edel, freie, völlig reine Liebe zu Kunstdenkmalen und ein aus Liebe zum Vaterland entspringender Eifer, diese Denkmale zu erhalten, wo auch sich solche finden mögen, ist gewiß in Vielen lebendig, und diese Gesinnungen zu wecken und zur That aufzufordern, ist der ächte Zweck eines regsamen Alterthums-Verein. $\ll^{29}$

Dieses denkmalpflegerische Interesse an Kulturgütern der sächsischen Vergangenheit fügt sich in ein seit dem späten 18. Jahrhundert europaweit immer weiter verbreitetes Bewusstsein für Geschichte, Volk und Nation ein. Bauten wurden als Denkmale einer vergangenen Zeit wahrgenommen, sie waren Teil einer vaterländischen Kunst und vermittelten daher vertiefte Kenntnisse über die Kultur des eigenen Volkes. Den nötigen Schub, sich auch praktisch um den Schutz historischer Bauten zu kümmern, erhielten solch frühe denkmalpflegerische Ideen schließlich nach der Befreiung von der napoleonischen Besatzung. Bereits die Enteignungen kirchlicher Institutionen und geistlicher Fürstentümer im Frankreich der Revolutionsjahre hatte vielerorts zu massiven Zerstörungen alter Bauten, insbesondere von Kirchen und Klöstern, geführt. Dieser revolutionäre Vandalismus bestärkte die Franzosen in der Erkenntnis, dass historische Bausubstanz schutzbedürftig sei, wozu sie erst erschlossen und inventarisiert werden musste. In der Folge wurden viele Kulturgüter zentral gesammelt und auf Museen, Bibliotheken und Archive verteilt, womit ein Zeichen gegen den kirchlichen und absolutistischen »Despotismus« und für die Französische Republik gesetzt werden sollte. ${ }^{30}$ Die französische Erkenntnis der Notwendigkeit eines Kulturgüterschutzes griff zwanzig Jahre später in wesentlich politischerer Form auf Deutschland über: Nach Napoleons Niederlage von 1814 forderten die Deutschen ihre von Frankreich zwischen 1794 und 1809 in mehreren Aktionen konfiszierten Kunstwerke zurück. Die anfangs erfolglosen Restitutionsbemühungen führten dazu, dass die Ablehnung des französischen Kunstraubs mit einem patriotischen Bewusstsein für das eigene Kulturerbe und der damit einhergehenden Verantwortung der Gemeinschaft für dieses vaterländische Erbe verwuchs. ${ }^{31}$ Der sächsische Altertumsverein und besonders Quandts Initiative, ihn endlich nachhaltig zu aktivieren, steht in dieser Tradition. Seine Reisen durch das Land und die Analysen, was geschützt, gesichert und konserviert werden 
sollte, war in den Anfängen des sächsischen Kulturgüterschutzes beispielhaft, wie seine Hinweisungen nachvollziehen lassen.

Seine Reise führte ihn zuerst ins Erzgebirge, danach nach Leipzig, weiteren Kulturgütern entlang nach Meißen, danach in die Sächsische Schweiz und schließlich in die Oberlausitz..$^{32}$ Der Kunstkenner beschrieb Bauten, Plastiken und Gemälde fast wie ein Cicerone für Altertumsfreunde. Spezifisch ausgerichtet auf konkrete Aktivitäten des Altertumsvereins wies er auf verschiedenste Maßnahmen hin: So forderte er beispielsweise von der goldenen Pforte und der Tulpenkanzel des Freiberger Domes genaue Zeichnungen und schlug vor, die Figuren einer alten Kanzel, die in einer Turmkammer abgestellt war, gesondert aufzubewahren. Für einige Gemälde und Epitaphien in der Annenkirche von Annaberg schlug er Restaurierungsmaßnahmen wie Reinigungen, Firnisauffrischungen und Retuschen vor. Um auf optimale Mittel und gute Fachleute zurückgreifen zu können, sollten diese Bilder nach Dresden transferiert werden. In der Thomaskirche Leipzig verlangte er die bessere Präsentation eines plastischen Meisterwerks. Zudem schlug er den Historikern des Altertumsvereins vor, sich aufgrund eines angeblich florentinischen Gemäldes der Verkündigung Mariä mit der Frage zu beschäftigen, wie der transalpine Austausch zwischen Leipzig und Florenz denn vonstatten gegangen sei. Für den Meißner Dom regte er die Herausgabe einer durch den Altertumsverein finanzierten bauhistorischen Schrift an. Eine Altardecke mit Stickereien in Pirna sollte fachgerecht aufbewahrt werden. ${ }^{33}$ Quandts Hinweisungen beinhalteten zahlreiche Vorschläge zur Dokumentation, Konservierung, Erforschung und Präsentation von Kulturgütern.

\section{Restaurierungsinitiativen in Zwickau und Annaberg}

Gehäuft treten Vorschläge für Restaurierungsmaßnahmen vor. Fast in jedem der besichtigten Orte schlug Quandt Maßnahmen vor. Er brachte auch entsprechende Kenntnisse mit. In den 1820er Jahren hatte er sich für Restaurierungsfragen in der Gemäldegalerie in Dresden eingesetzt und die Berufung des berühmten Restaurators Pietro Palmaroli für die Erneuerung von Raffaels Sixtinischer Madonna durchgesetzt. ${ }^{3+}$ Tatsächlich erwuchs dank dieses Engagements die öffentlichkeitswirksamste Aktion des Altertumsvereins, die von Quandts artistischer Sektion initiiert wurde. Dabei handelte es sich um die Restaurierung des Altars von Michael Wolgemut in der Marienkirche in Zwickau (Abb. 28). Auf die Notwendigkeit dieser Arbeit hatte er in seiner Schrift von 1831 hingewiesen: »In der Kirche zu unser Lieben Frauen werden Kunstwerke von der höchsten Wichtigkeit für die Kunstgeschichte aufbewahrt. [...] Es sind dieß die einzigen Werke des Michael Wohlgemuth, deren Aechtheit nachgewiesen werden kann, und schon darum, abgesehen von ihrer eigenthümlichen Schönheit, welche im Ausdruck der Physiognomien ruht, höchst wichtig, zumal da dieser Meister der Gründer der Nürnberger Schule, und Dürers Lehrer war. [... Diese trefflichen Gemälde befinden sich in einem üblen $\mathrm{Zu}-$ stande, und bedürfen sehr der Reinigung, weil sie von Staub und Rauch ganz bedeckt sind. « ${ }^{55}$ Bereits im Sommer des auf die Publikation der Hinweisungen folgenden Jahres 1832 wurden die Altartafeln nach Dresden überführt. ${ }^{36}$ Der Galerieinspektor Johann August Renner nahm die Restaurierung vor, die Quandt persönlich beaufsichtigte. Danach wurden die Tafeln während zweier Tage in der Gewehrgalerie im Residenzschloss Dresden öffentlich ausgestellt. Die Restaurierung stieß auf viel positive Resonanz. ${ }^{37}$ Prinz Johann, Direktor des Altertumsvereins, beauftragte nach seiner Besichtigung der Bilder Quandt, eine Publikation mit lithographierten Abbildungen vorzubereiten. ${ }^{38}$ Der Kunstfreund fühlte sich in seinen Hoffnungen bestätigt, den Altertumsverein zu erneuter Arbeit angeregt zu haben. So schrieb er an Goethe nach der Restaurierung des WolgemutAltars: »[...] allein ich habe doch schon die Wiederherstellung der Bilder von Wohlgemuth in Zwickau ausgewirkt u wo ein Anfang ist, kann ein Fortgang gehofft werden. «39 $^{39}$
32 Die Stationen der Reise waren Freiberg, Augustusburg, Chemnitz, Annaberg, Schneeberg, Zwickau, Leipzig, Rochlitz, Kloster-Zelle (Altzella), Meißen, Pirna, Stolpen, Budissin (Bautzen), Zittau; Quandt 1831 (1), S. 10-48.

33 Quandt 1831 (1), S. 11-12 (Freiberg), S. 20-26 (Annaberg), S. 35-38 (Leipzig), S. 41-42 (Meißen), S. 42-43 (Pirna).

34 Siehe Kap. Ordnung und Konservierung: Die Königlich-Sächsische Gemäldesammlung.

35 Quandt 1831 (1), S. 28-29.

36 Siehe die Protokolle vom 22.6., 31.7. und 8.8.1832, in: HStADD, 12508 Sächsischer Altertumsverein, Nr. 12 (neu: 781), Akten der II. Sektion, Entwurf zur Organisation und Protokolle 1831-33; Quandt 1839 (1), S. 1; Klemm 1835, S. XVII-XVIII; Magirius 1989, S. 53-54; Ermisch 1900 S. 16-17. Schölzel 2012, S. 195-196, 364-368 hat die Restaurierung des Altars anhand der Quellen genau aufgearbeitet. Die Überführung nach Dresden hätte eigentlich schon Ende 1831 stattfinden sollen, stieß aber auf Widerstand einiger Zwickauer. Trotz mehrerer Briefe Quandts ermöglichte erst die Vermittlung des Prinzen Johann die Restaurierung in Dresden.

37 Die Präsentation fand am 5./6.10.1832 statt. Protokoll vom 4.11.1832 in: HStADD, 12508 Sächsischer Altertumsverein, Nr. 12 (neu: 781), Akten der II. Sektion, Entwurf zur Organisation und Protokolle 1831-33. Carl August Böttiger schrieb dem Bildhauer Christian Daniel Rauch in Berlin über die Bedeutung der Restaurierung. Brief vom 8.10.1832, in: Berlin, SMB, Zentralarchiv, Nachlass Rauch XI.3. Briefe von: Böttiger, 1822-1832.

38 Protokolle vom 4.11.1832 und 9.1.1833, in: HStADD, 12508 Sächsischer Altertumsverein, Nr. 12 (neu: 781), Akten der II. Sektion, Entwurf zur Organisation und Protokolle 1831-33. Angeblich hat Prinz Johann die Restaurierung aus eigenen Mitteln mitfinanziert. Siehe John 2001, S. 472 .

39 Brief von Quandt an Goethe vom 8.12.1831, in: Schmitz/Strobel 2001, S. 150. 
Der Erfolg der Restaurierung des Zwickauer WolgemutAltars durch den Altertumsverein bleibt bis heute mit Quandts beharrlichem Engagement verbunden. Eine vergessene, für die lokale Kunstgeschichte aber nicht weniger interessante Aktion fand zeitgleich statt. Sie gibt tiefen Einblick in Quandts Umgang mit Dingen, die ihm wichtig waren. Ende Oktober 1831 schrieb er an einen namentlich nicht bekannten Mann, möglicherweise einen Pfarrer der Annenkirche in Annaberg. Darin fragte er, ob ein zerbrochenes Flachrelief-Medaillon mit einer Christusdarstellung zur Reparatur und ein kleiner Flügelaltar, der in der Sakristei aufbewahrt würde, zur Reinigung und Auffrischung nach Dresden gesandt werden könnten. Quandt mutmaßte, dass es sich bei dem Altar um ein importiertes, niederländisches Kunstwerk aus der Schule des Jan van Eyck handelte. Er beabsichtigte, die Kosten für Transport und Restaurierung zu übernehmen, wollte die Aktion aber als Auftrag des Altertumsvereins verstanden wissen. Zugleich bot er an, selber eine Kaution zu hinterlegen, sollten die Zuständigen der Annenkirche dem Angebot kritisch gegenüberstehen. ${ }^{40}$

Quandts Anfrage war erfolgreich. Der Altar wurde nach Dresden geschickt und gereinigt. Vier Monate später, am 13. Februar 1832, stand er wieder am alten Standort in Annaberg. Darüber informierte Quandt seinen Korrespondenten: »Ew. Hochwürden habe die Ehre beÿgehend durch den gewöhnlichen Annaberger Boten, den kleinen Flügelaltar, welcher der Kirche zu Annaberg gehört, zurück zu schicken. Nach glücklichem Empfange, dieses schätzbaren Alterthums, ersuche ich Ew. Hochwürden, mir eine kleine Bescheinigung gütigst zu geben, daß ich dieses Kunstwerk richtig wieder abgeliefert habe. Es ist mit diesem Gemälde nur das Nöthige vorgenommen worden, denn eine zu weit getriebene Reinigung alter Bilder, ist nicht ohne Gefahr u raubt ihnen immer den eigenthümlichen

40 »[...] Um nun einen Anfang zu machen, so würde ich ganz ergebenst bitten, die Bruststücke jener Medaillons an mich einzusenden, welches vor Jahr u Tag der Küster der Hauptkirche zu Annaberg fallen ließ, wobeÿ es zerbrach. Es war in Erz gegossen u stellte einen Kranz vor, in dessen Mitte Christus in Basrelief abgebildet war. In dem Kranze waren die Bilder der Evangelisten eingeflochten. Diese Bruststücke sollen hier sorgfältig zusammen gesetzt u dies schöne Kunstwerk der Kirche in bestmöglichem Stande, von dem Alterthumsverein zurück gegeben werden. Ferner befindet sich in der Sacristey der Hauptkirche zu Annaberg ein kleiner Hausaltar mit zweÿ Flügelthüren, auf welchem die Geburt Christi u einige Heilige dargestellt sind. Er ist aus der Eÿkschen Schule u ein sehr kostbares Kunstwerk, welches sehr erblindet ist u einer sorgfältigen Reinigung bedarf. Auch diesen will ich auf meine Kosten, jedoch in Namen des Alterthumsvereins, sorgfältig reinigen laßen u die Kirche soll inn wieder erhalten. Sollten die Kirchenvorsteher Bedenken tragen, dem Alterthumsverein diese Kunstwerke anzuvertrauen, so bin ich erböthig eine dem Werthe dieser Gegenstände angemessene Caution in baarem Gelde zu stellen. Ew Hochwürden wage ich daher um baldige Auswirkung der Einsendung dieser Gegenstände und um baldige Zusendung selbst, ergebenst zu bitten. Nur muß ich bemerken, daß der kleine Altar in ein besonders
Schmalz der Farben, den ihnen die Zeit giebt. Zu gegenwärtigem Zustande ist doch nun alles wieder an diesem Bilde zu erkennen u wird sich viele Jahrhunderte erhalten, wenn es nicht muthwillig oder unvorsichtig zerstört wird. « ${ }^{41}$

Bei dem Flügelaltar handelt es sich um ein Hausaltärchen mit der Nachtdarstellung der Geburt Christi im Hauptbild und einer Verkündigungsszene auf den Flügelinnenseiten sowie zwei Heiligen auf den Außenflügeln (Abb. 29). Es befindet sich noch heute in der Annaberger Stadtkirche. Das nächtliche Geburtsmotiv wird gemeinhin auf eine verschollene Darstellung des Hugo van der Goes zurückgeführt. Es war sehr beliebt und wurde vielfach wiederholt. Seit der Mitte des 20. Jahrhunderts wurde es dem estnisch-flämischen Maler Michiel Sittow zugeschrieben. Dies wurde jüngst durch Matthias Weniger abgelehnt. In seiner Studie mutmaßt er, dass die Geburt Christi als Nachtmotiv wohl nicht von einem Künstler alleine erfunden worden sei, da es auch bei Hans Memling ähnliche Interpretationen gebe. Da die Darstellung aber weit verbreitet war, ordnet er das Kunstwerk aus stilistischen Gründen einer nicht näher definierten nordwestdeutschen Schule zu..$^{42}$ So reiht sich der kleine Annaberger Flügelaltar, den Quandt 1831/32 in Dresden restaurieren ließ, in eine Tradition nächtlicher Darstellungen der Geburt Christi ein und ist, wenn auch in der Zuschreibung unsicher, zeitlich dem frühen 16. Jahrhundert zuzuordnen.

Von Interesse ist nun, dass der Kunstkenner den Altar grundsätzlich korrekt einordnete. ${ }^{43}$ Quandt nannte in seinem zweiten Brief nicht mehr Jan van Eyck als mögliches Vorbild, sondern Hans Memling: »Wenn man es nicht gerade zu streng mit der Angabe des Meisters nimmt, so könnte man dieses Gemälde wohl dem Memling zuschreiben, welcher in dieser Art und Weise malte. «4 Damit lag er zwar nicht richtig, wie er ja selber ironisch-zweifelnd formulierte, dennoch aber auf der rich-

Kistchen eingepackt werden muß, weil wenn er mit den Metallstücken der Medaillons zusammengepackt würde, eines das andere leicht noch mehr beschädigen könnte. Ew Hochwürden verzeihe gewiß um der guten Sache willen, die Mühe die ich demselben verursache, welche von dem königlichen Alterthumsverein auf das dankbarste anerkannt wird $u$ in dem ich auf eine baldige geneigte Antwort hoffe verharre mit größter Verehrung Ew Hochwürden aller ergebenster Diener Johann Gottlob von Quandt.« Brief von Quandt an Unbekannt vom 26.10.1831, in: Berlin, SMB, Zentralarchiv, Autographensammlung Mappe 1133, Quandt, Johann Gottlob von, fol. 11r-12r.

41 Brief von Quandt an Unbekannt vom 13.2.1832, in: Berlin, SMB, Zentralarchiv, Autographensammlung, Mappe 1133, Quandt, Johann Gottlob von, fol. 13r-13v.

42 Weniger 2011, S. 121-124, Kat. N35.

43 Weniger 2011, S. 121. Dies ein Jahrzehnt früher als der Berliner Kunsthistoriker Gustav Friedrich Waagen, der laut Weniger 1843 über das Altärchen berichtete.

44 Brief von Quandt an Unbekannt vom 13.2.1832, in: Berlin, SMB, Zentralarchiv, Autographensammlung, Mappe 1133, Quandt, Johann Gottlob von, fol. 14 r. 


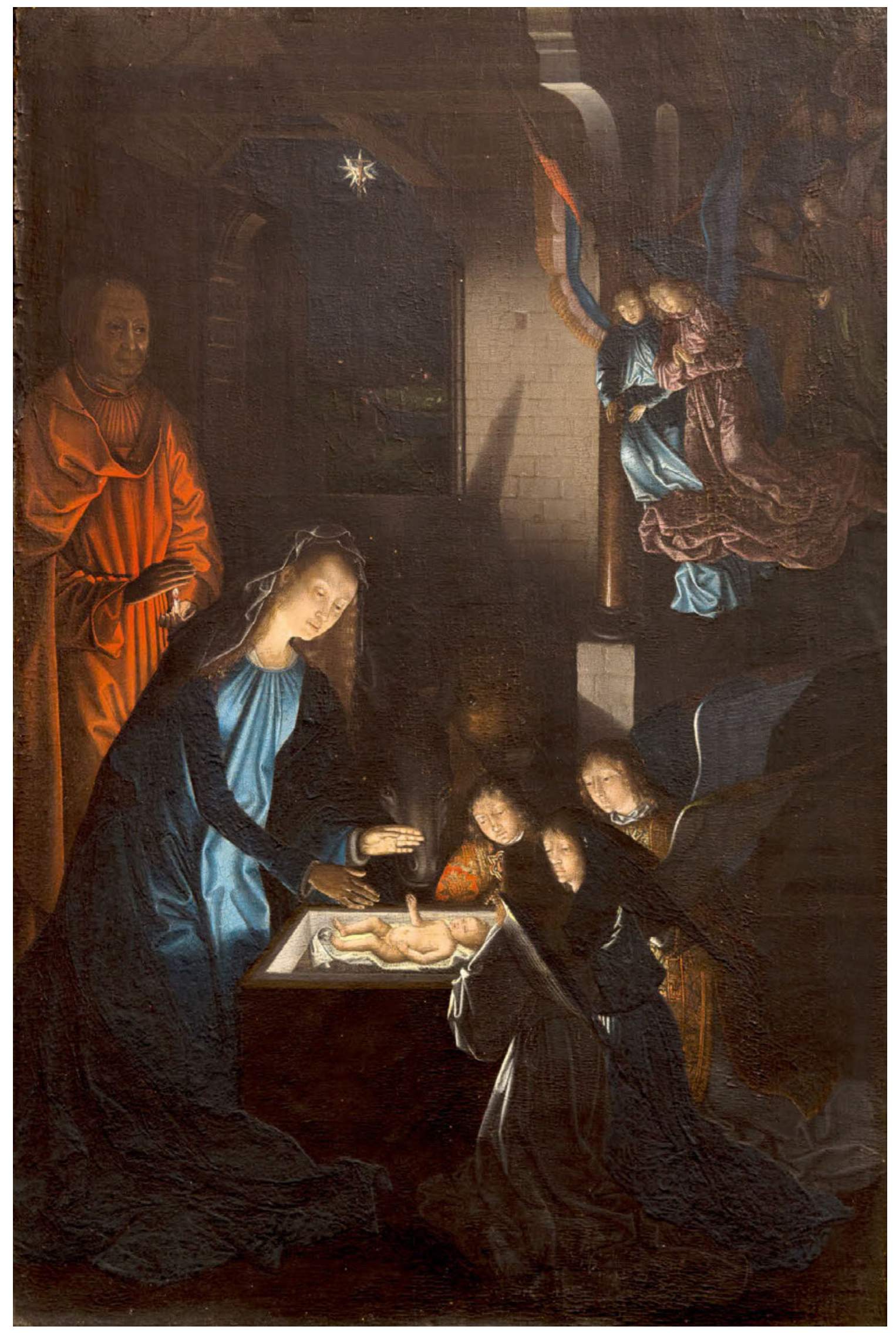

29 Nordwestdeutsch, Anbetung des Kindes bei Nacht, 1. Hf. 16. Jh., Annaberg, Evangelisch-lutherische Kirchengemeinde St. Annen 
tigen Spur, wie die heutige Forschungsdiskussion zeigt. Quandt als Kenner der frühneuzeitlichen Malerei des Nordens ist damit nicht zu unterschätzen, wie auch seine Jahre vor Aloys Hirt vorgeschlagene Zuschreibung des Flügelaltärchens in der Dresdener Gemäldegalerie an Jan van Eyck gezeigt hat - nur dass er hinter den bekannteren Namen eines Hirt oder Waagen etwas in Vergessenheit geraten ist. ${ }^{45}$

Entgegen Quandts Hoffnungen brachte der Sächsische Altertumsverein nach der Annaberger und Zwickauer Restaurierungsaktion vorerst nicht mehr viel zustande. 1834 wurde wegen Kündigung der Zwinger-Räume die Sammlung des Vereins auf die Königliche Bibliothek, die Porzellansammlung, das Historische Museum, das Grüne Gewölbe und das Staatsarchiv verteilt. Damit schien der Verein kurz vor der Auflösung zu stehen. Im selben Jahr konstituierte sich ein bürgerlicher »Verein der sächsischen Alterthümer«. Diese Initiative gab der königlichen Institution erneut etwas Aufwind. 1835 schrieb der neue Sekretär Gustav Klemm das erste Heft der Mittheilungen des Königl. Sächs. Vereins für Erforschung und Erhaltung der vaterländischen Alterthümer. Darin erwähnte er eine erneute Anregung zur Reorganisation und Aktivierung des Altertumsvereins durch Prinz Johann. Es sollten Lokalvereine gebildet werden, um die Untersuchung und Erhaltung der Altertümer besser koordinieren zu können. Zwar war dieser Idee kein Erfolg be- schieden, doch führte sie zu regelmäßigen Versammlungen. 1837 schließlich wurde die bürgerliche Initiative mit dem königlichen Verein zusammengeführt. Von da an ging es aufwärts. ${ }^{46}$

Doch für diese wechselvollen Jahre fehlen Hinweise auf eine Mitarbeit Quandts. Weder im neu gegründeten bürgerlichen noch im königlichen Altertumsverein schien er sich nach 1833 noch betätigt zu haben. Ein indirektes Resultat seiner Tätigkeit scheint es noch gewesen zu sein, ab 1832 die Reorganisation der Rüstkammer unter Einbindung der aufgelösten Kunstkammer in einem der Zwingerpalais vorzunehmen. Ganz im Sinne der Erhaltung sächsischer Altertümer benannte er es neu »Historisches Museum« und verstand es in gewissem Sinn als Museum für das Vaterland und als Bildungsinstitution. Zwar wurde 1839 noch sein Kommentar zu den Lithographien der Zwickauer Altartafeln veröffentlicht. ${ }^{47}$ Dazwischen gibt es jedoch keine Quellen über weitere Aktivitäten. Warum er letztlich nichts mehr zum Verein beitrug, kann nicht nachvollzogen werden. Der Kauf des Rittergutes in Dittersbach 1830 , der ihm viele verwalterische, künstlerische und bauliche Arbeiten auferlegte, mochte einer der Gründe gewesen sein. Seine Erfahrungen im Sächsischen Kunstverein, den er 1828 bis 1833 leitete, und die träge Arbeit im Altertumsverein, die trotz seiner wohlgemeinten Hinweisungen und den Erfolgen in Zwickau und Annaberg unmittelbar nicht besser wurde, waren wohl weitere Faktoren.
45 Quandt schrieb den Dresdener Flügelaltar bereits 1816 van Eyck zu, immerhin im beliebten Journal des Luxus und der Moden; siehe Quandt 1816 (1), S. 836. Offiziell wird die Erstzuschreibung heute Aloys Hirt im Jahr 1830 attestiert. S. a. Neidhardt 2017, S. 351-352.
46 Magirius 2001, S. 480; Magirius 1989, S. 54-55; Ermisch 1900, S. 18-20; Klemm 1835, S. XIX-XXIV.

47 Quandt 1839 (1), S. 1-14. 


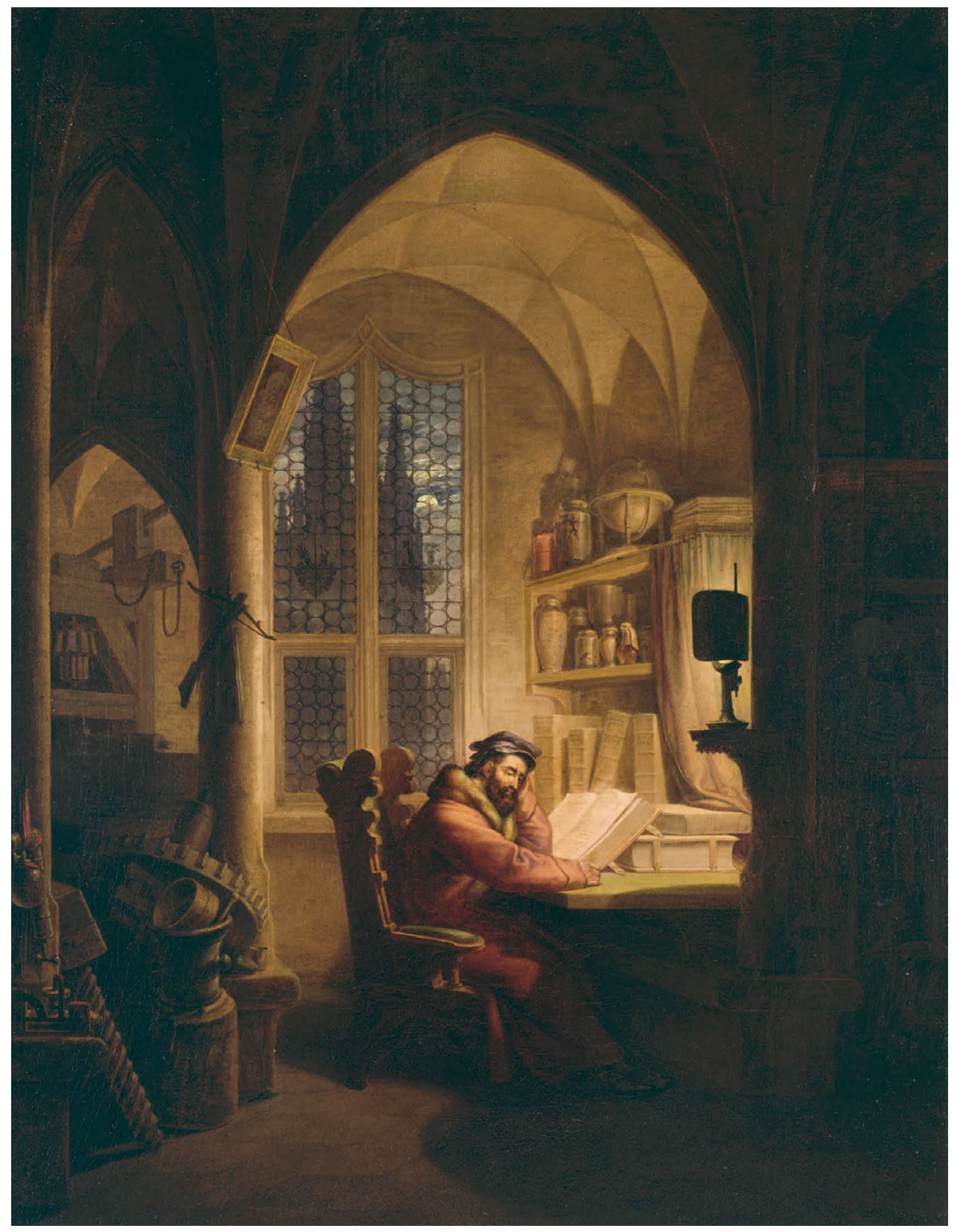

30 Georg Friedrich Kersting, Faust im Studierzimmer, 1829, Öl auf Leinwand, $68 \times 53 \mathrm{~cm}$, Berlin, Privatbesitz 


\section{HÖHERE AUFGABEN: Der Sächsische Kunstverein}

Nur wenige Jahre nach der Gründung des Königlich-Sächsischen Altertumsvereins war Johann Gottlob von Quandt maßgeblich am Aufbau des Sächsischen Kunstvereins beteiligt, dessen erster Vorsitzender er von 1828 bis 1833 war. Ein wichtiger Faktor für die Kunstvereinsgründungen in Deutschland waren oftmals private Initiativen gebildeter Bürger, die sich bei privaten Zusammenkünften zu Gesprächen über Kunst trafen. ${ }^{1}$ Solche hatte auch Quandt in seinem Haus organisiert. Hier ging es in erster Linie um die Betrachtung von Kupferstichen nach Werken Alter Meister. Gleichzeitig wurden aktuelle Fragen der Kunst diskutiert. ${ }^{2}$ Wie schon im Altertumsverein engagierte sich Quandt schon früh bei neuen Initiativen. Er erhoffte sich dadurch eine positive Ausstrahlung der Künste auf die Gesellschaft. Dabei setzte er besondere Hoffnungen in die zeitgenössische Historienmalerei, die er gezielt zu stärken suchte (Abb. 30). Der Kunstverein sollte ihm dabei helfen.

\section{Die Gründung des Sächsischen Kunstvereins}

Erste Ideen zu einem sächsischen Kunstverein waren von Leipzig ausgegangen. ${ }^{3}$ Ein Zirkel von Kunstfreunden, zu denen auch der in Leipzig geborene Quandt gehörte, versuchte dort zwischen 1824 und 1826 einen Kunstverein zu gründen. Es han-

1 Bertsch 2009, S. 565-572; Hempel 2008, S. 55-68, bes. S. 66; Schmitz 2001, S. 30-38.

2 Quandt 1826 (1), S. V-VI: »Mehrere Kunstfreunde sammelten sich allwöchentlich an einem bestimmten Tage. Gemeinsame Neigung machte Angelegenheiten der Kunst gewöhnlich zu den vorherrschenden Gegenständen des Gesprächs [...]. So fand sich Stoff zu schriftlicher Entwickelung in ruhigen, einsamen Stunden; denn erst durch das Niederschreiben wird man sich seiner Gedanken recht klar bewußt. Auf diese Weise sind folgende kleine Abhandlungen über Verbesserungen von Kunstakademien, über die Stellung der bildenden Künste zum Staate und mehrere andere hier noch nicht mitgetheilte entstanden [...].« S. a. Bertsch 2009, S. 568-572; Bemmann 1925, S. 36.

3 Rüfenacht 2016, S. 92. Zu den Bemühungen um einen Leipziger Kunstverein und Quandts Unterstützung bei der Gründung eines solchen vgl. ebd., S. 91-98.

4 Quandt verwies auf die organisatorischen Schwierigkeiten, einen »doppelten Verein« zu bilden. In der Folge fokussierte man auf Leipzig als Vereinsort. Protokoll vom 22.10.1824 über die Gründung eines sächsischen Kunstvereins in Leipzig, in: Leipzig, MdbK, Kunst-1. Die Bildung eines Vereins der Kunstfreunde in Leipzig [betr.] (Kunstverein Sonnabend-Gesellschaft), 1824-1826, fol. 16r. S. a. Hommel 2000, S. 119. delte sich dabei um die erste bürgerliche Initiative für einen sächsischen Kunstverein. Quandt lebte zwar schon seit einigen Jahren in Dresden, verkehrte aber noch gelegentlich in Leipzig und ging verschiedenen Geschäften nach. Dazu gehörten die Sitzungen der Kunstfreunde. Diese forderten Statuten aus München und Berlin an, entwarfen nach diesen Vorbildern ein Reglement und schlugen vor, dass gleichberechtigte Ableger in Leipzig und Dresden geschaffen würden. ${ }^{4}$ Danach suchte man die Unterstützung des Königs und der entsprechenden Behörden in Dresden. Quandt war Mitunterzeichner dieses Anliegens. 5

Der Gründungsversuch fiel in Dresden durch. Wahrscheinlich war man sich am Ort der königlichen Regierung, der königlichen Akademie der bildenden Künste und der königlichen Sammlungen bewusst, dass ein Kunstverein nicht in der Provinz entstehen konnte. ${ }^{6}$ Der Generaldirektor der Kunstakademie, Heinrich Vitzthum von Eckstätt, trieb ab 1826 die Gründung eines sächsischen Kunstvereins in Dresden voran. Er sammelte die Statuten bereits gegründeter Vereine und trat dem Preussischen Kunstverein in Berlin bei. Vorbild für seine Entwürfe waren die Berliner Statuten. Dementsprechend standen sie der Akademie nahe, aus deren Ausstellungen die Kunstwerke für den Verein hauptsächlich gewonnen werden sollten. ${ }^{7}$ In einer ersten Einladung zur Gründung des Kunstvereins formulierte

5 Brief von Veit Schnorr von Carolsfeld, Direktor der Leipziger Kunstakademie und Mitinitiator des Leipziger Vereins, an Heinrich Vitzthum von Eckstätt vom 3.2.1826 und »Einladung zur Theilnahme an einem Vereine der Freunde der bildenden Kunst in Leipzig zur Förderung dieser Kunst im sächsischen Vaterlande durch lebende, zunächst sächsische Künstler«, in: HStADD, 11126 Kunstakademie, Nr. 96, fol. 5r-10v. Die Entwürfe zu der Einladung, in: MdbK, Kunst - 1. Die Bildung eines Vereines der Kunstfreunde in Leipzig [betr.] (Kunstverein - SonnabendGesellschaft), 1824-1826, fol. 30r-45V. S. a. Bertsch 2009, S. 572; Briel 1987 (1), S. 16

6 Anonym, »Plan zu einer immerwährenden Kunstausstellung « mit Statutenentwurf, in: KB 1826, Nr. 18, S. 71: »Ein solcher verunglückter Plan ist der für einen gewissen Ort entworfene nachfolgende, der sich der freundlichen Billigung der höchsten Behörden erfreute, aber an Ort und Stelle, da er den gewöhnlichen Geschäftsgang nehmen mußte, scheiterte."

7 In den Akten zur Gründung des Kunstvereins liegen die Statuten des Leipziger Vereinsentwurfs, in: KB 1826, Nr. 18, S. 71-72 sowie die Statuten des Hamburger, Münchner und Preussischen Kunstvereins in Berlin. HStADD, 11126 Kunstakademie, Nr. 96, fol. 16r-19v. S. a. Briel 1987 (2), S. 14-15. 
Vitzthum die Ziele. Der Verein sollte zu mehr Bestellungen führen und den Künstlern die Möglichkeit bieten, größere Kunstwerke zu vollenden, damit sie ihr Talent und ihre Phantasie entfalten konnten. ${ }^{8}$

Spätestens ab August 1827 nahm Quandt an den vorbereitenden Sitzungen teil. Die Statutenentwürfe sahen Kunstfreunde und Künstler im Vereinsvorstand vor. ${ }^{9}$ Dass das Dresdener Bürgertum die Initiative unterstützte, zeigt sich am so genannten Gründungstag des Sächsischen Kunstvereins. Zum 300. Todestag Albrecht Dürers am 7. April 1828, der, inspiriert vom Nürnberger Jubelfest, in Dresden von zahlreichen Bürgern feierlich begangen wurde, rief Carl August Böttiger im Namen der Kunstfreunde zur Stiftung des Vereins auf. ${ }^{10}$ Zum Künstlerfest hatten zahlreiche Leute Beiträge geleistet und 116 Personen saßen in der Gaststätte »Stadt Wien«, direkt neben Quandts Haus an der Klostergasse in Dresden-Neustadt. Carl Vogel von Vogelstein hatte Porträts von Dürer gemalt, der Architekt Joseph Thürmer eine Ansicht Nürnbergs, Ranken und Verzierungen für den Festsaal entworfen. In Kästen und an den Wänden wurden originale Handschriften, Zeichnungen und Gemälde Dürers aus den königlichen Sammlungen präsentiert. Quandt hatte 104 gerahmte Kupferstiche ausgeliehen, die ebenfalls präsentiert wurden. Den denkwürdigen Anlass beging man mit zahlreichen Reden, Gesängen und Versen, die im Spruch- und Liederkranz zum Albrecht Dürer's-Feste publiziert wurden." Während der Feier trat Carl August Böttiger zweimal auf und sprach über den Kunstverein. Danach wurden Unterschriftenlisten herumgereicht, die von 76 Teilnehmern unterzeichnet wurden. Gleichzeitig wurde Quandt als Vorsitzender des Vereins aufgestellt, was mit großem Applaus quittiert wurde. Er selber war wegen des doppelten Beinbruchs, den er sich Ende 1827 nach einem Sturz über zwei Stockwerke auf einer Baustelle in Leipzig zugezogen hatte, nicht anwesend. Die Nachricht seiner Wahl zum Vorstand überbrachte ihm eine Delegation von Kunstfreunden und Künstlern direkt vom Fest in sein benachbartes Wohnhaus. Darauf sprach man zu Ehren des Abwesenden drei Gedichte und prostete ihm zu. ${ }^{12}$

8 Heinrich Vitzthum von Eckstätt, Einladung zum Beÿtritt zu einem zu errichtenden Verein der Freunde bildender Künste in Sachsen, 1826: „Selbst den ausgezeichnetern Künstlern fehlt es nicht selten an Bestellungen für größere Arbeiten, und sie werden alsdann vielleicht zu lange auf solche beschränkt, welche ihnen und ihrem Streben die eigentliche Befriedigung nicht gewähren, und welche, anstatt das Talent und die Phantasie zu immer neuer Thätigkeit anzuregen, beÿdes vielmehr, zum Nachtheil der Kunst einschläfern. «HStADD, 11126 Kunstakademie, Nr. 96, fol. 61r-v, ebenso die Einladung vom 19.3.1827, ebd., fol. 109v.

9 Einladung zu einer Besprechung, u. a. an Quandt vom 10.8.1827, in: HStADD, 11126 Kunstakademie, Nr. 96, fol. 101r-v. S. a. Briel 1987 (2), S. 27, Anm. 20.

10 Kovalevski 2010, S. 4; Schmidt-Funke 2006, S. 63; Schmitz/Strobel 2001,
Quandt blieb dem Projekt gegenüber erst skeptisch und glaubte nicht richtig, dass der Verein auf Interesse stoßen würde. »Meine Ernennung zum Vorstand des Vereins, welche mehr das Werk einer augenblicklichen günstigen Stimmung als der Ueberlegung mir zu seyn schien, wollte ich ersterer nicht verdanken «, schrieb er seinem Freund Friedrich Rochlitz in Leipzig. Er berief die Mitglieder zu einer Versammlung zusammen, die seine Wahl formell bestätigte. Daraufhin wurden die endgültigen Statuten festgelegt. Quandt setzte sich für das erste Jahr noch bescheidene Ziele. Er wollte so viele Mitglieder gewinnen, dass zwei bis drei Kunstwerke angekauft werden könnten: »Was für jetzt die Hauptsache mir scheint, ist; daß junge Künstler aufgemuntert und Kunstfreunde auf talentvolle Jünglinge aufmerksam gemacht werden. Die Welt urtheilt nun einmal nach Schein u nach Vorurtheilen u daher verschafft es einem Künstler einen rühmlichern Namen wenn es von ihm heißt, daß sein Werk ein Kunstverein kaufte, als wenn er es an einen Privatmann verkauft hat u wäre dieser auch der größte Kunstkenner. « ${ }^{33}$

Die Entwicklung lief indes sehr erfreulich und die Mitgliederzahlen stiegen rasant an. Quandt vermutete, dass die Umstände ideal waren: »Wie [der Kunstverein] sich auf einmal, gleichsam wie ein Meteor in der Luft, erzeugt hat, nachdem mehrere überlegte Plane dieser Art unausgeführt geblieben sind, wahrscheinlich weil die frühern Veranstaltungen in der Absicht Einzelner lag, diesmal aber die Elemente in vielen lagen, welche nur einer Erregung bedurften und eines Mittelpunkts um als Glieder sich aneinander anzuschließen und wie das wuchs, ist wirklich wunderbar und überraschend. Es ist erstaunlich daß in einem Lande, in welchem zur Erweckung des Kunstsinns von Seiten des Königs während einer langen Regierung nicht eben viel gethan worden war, in kurzer Zeit [...] 180 Personen beytragen, bey welchen man wahre Theilnahme an der Sache selbst voraussetzen darf, weil dieser Verein kein von oben herab eingesetzter, sondern freiwill[ig] gebildeter ist. $\ll^{14}$ Tatsächlich beteiligte sich auch König Anton, der den 1827 verstorbenen und von Quandt kritisierten Friedrich August I. abgelöst hatte, mit einem jährlichen Beitrag über 500 Taler zur

S. XVIII-XIX; Briel 1987 (2), S. 15. Zu den öfters begangenen deutschen Dürer-Festen siehe Thimann 2015, S. 24-27.

11 Dürerfest 1828, S. 1-3. »Der treffliche Kunstfreund Hr. v. Quandt hatte 104 in 20 großen Bildrahmen verständig zusammengeordnete echte Kupferstiche Dürers beigesteuert, also fast alles, was die genauesten Verzeichnisse unter Dürers Monogramm aufzuführen vermögen, in erwählten Abdrücken.«

12 Dürerfest 1828, S. 32-39; Zur Wahl während seiner Genesung siehe Brief von Quandt an Friedrich Rochlitz vom 4.6.1828, in: Schmitz/Strobel 2001, S. 26-28. S.a Schmidt-Funke 2006, S. 63-64.

13 Brief von Quandt an Rochlitz, vom 4.6.1828, in: Schmitz/Strobel 2001 S. $27-28$.

14 Brief von Quandt an Johann Heinrich Meyer vom 28.10.1828, in: Schmitz/Strobel 2001, S. 32. 
finanziellen Stabilisierung des jungen Vereins. ${ }^{15}$ Mit viel Verve verschrieb sich der Verein der Förderung sächsischer Kunst und Künstler, wie es das erste Statut verlangte. ${ }^{16}$ Vorsitzender und Komitee trugen hierfür eine große Verantwortung, da nur sie die Ankäufe steuerten. Die Mitglieder erhielten je nach Anzahl gezeichneter Aktien zu fünf Taler Lose für die jährliche Verteilung der angekauften Kunstwerke und wählten das Komitee an einer der zwei um Weihnachten und Ostern anberaumten Generalversammlungen. ${ }^{17}$

Unter der Förderung der Künstler verstand Quandt explizit nicht die materielle Förderung in dem Sinn, als Künstler durch Verkäufe an den Verein ihren Lebensunterhalt besser finanzieren konnten. Vielmehr wollte der Vorsitzende sie zu gehaltvollen und großen Werken anregen, die keinen guten Absatz fanden, wie er immer wieder betonte. Dies waren vor allem Historiengemälde. Entsprechend zog er über das erste Jahr Bilanz: »Wir hätten gewünscht, im historischen Fache der Malerei, Gemälde von höherem Werth zu finden, allein es bot sich hierzu keine Gelegenheit dar, und wir müssen hoffen, daß die Künstler durch den Verein zu höheren Aufgaben ermuthigt werden. Auch können wir die Bemerkung nicht verbergen, daß die Bilder von historischen Gegenständen, welche sich etwa noch fanden, nur kleine Figuren enthielten, an welchen sich weder der Zeichner bewähren, noch die innere geistige Bildungskraft in ihrer ganzen Fülle entfalten und verkünden kann: denn es erfordert eine Figur von etwa zwei Drittheil Lebensgröße eine weit vollständigere Kenntnis der Formen, als eine kaum einen Fuß große, und es kann sich der Künstler durch eine Composition von nur wenig größern Figuren mehr, als durch ein Bild von vielen kleinen Figuren beurkunden.« Das Fazit des Gründungsjahres war also durchzogen. Einerseits war Quandt von den Motivinhalten nicht überzeugt, andererseits machte er technische Probleme aus. ${ }^{18}$

15 Die Zusage des Königs erfolgte am 15.10.1828, in: HStADD, 11126 Kunstakademie, Nr. 96, fol. 140r.

16 Erste Statuten vom 14.5.1828, in: HStADD, 11126 Kunstakademie, Nr. 96, fol. 133 r-134V

17 Zusammenfassung der Statuten bei Kovalevski 2010, S. 5-6. Zur Organisationsstruktur der Kunstvereine und Verlosungen siehe Schmitz 2001, S. 52-57, 272-288.

18 Unter den acht verlosten Ankäufen des Jahres 1828 befand sich nur eine kleine Historie von Carl Gottlieb Peschel, Rebecca und Elieser. Jahresbericht des Sächsischen Kunstvereins für das Jahr 1828, in: HStADD, 12509 Sächsischer Kunstverein, Nr. 1, fol. 124V. Köhler 2002, S. 23. S. a. Kovalevski 2010, S. 20, Kat. Nr. B-C 2.

19 Siehe dazu den Brief von Quandt an Johann Heinrich Meyer vom 28.10.1828, in: Schmitz/Strobel 2001, S. 33: »Noch erlauben Sie mir eine Erklärung darüber zu geben, warum in den Statuten des Kunstvereins keine Preisaufgaben erwähnt werden [...]. Unsere Gründe sind aber diese; daß wir auf keine Weise den Strebungen der Künstler durch Aufgaben eine Richtung geben, sondern eines jeden Anlagen und Neigungen wollten frey walten laßen. [...] Daher suchen wir ebenso sehr ja fast mehr noch auf das Publicum als auf die Künstler zu wir-

\section{Streitfragen: Preisaufgaben und Vereinsaufträge}

Da bereits nach dem ersten Jahr ein Überschuss in der Kasse blieb, entbrannte eine Diskussion um die Frage, ob der Verein Preisaufgaben ausschreiben sollte. Diese waren bis dahin nicht vorgesehen. ${ }^{19}$ In Wettbewerben sollten Künstler zu einem vorgegebenen Bildgegenstand Entwürfe einreichen. Der Sieger erhielt einen Preis. Vorbild waren die Preisaufgaben Goethes und Johann Heinrich Meyers zu Themen der griechischen Mythologie in Weimar zwischen 1799 und 1805, deren Eingaben in den Propyläen öffentlich diskutiert worden waren, sowie neuere Versuche in verschiedenen deutschen Städten. ${ }^{20}$ Antreiber der Diskussion war der Archäologe und Mitglied des Vereinskomitees Carl August Böttiger. Er kannte die Weimarer Preisaufgaben noch aus eigener Erfahrung, stand aber gar nicht in der Gunst Goethes, weil er als boshafter Rezensent eines GoetheTheaters und der Ergebnisse der Preisaufgaben von 1802 galt. Letztere hatten einen handfesten Skandal hervorgerufen. ${ }^{21}$ Umso pikanter ist es, dass Quandt, der wissen musste, dass Böttiger aufgrund seiner Missgunst Weimar verlassen hatte, Goethe auf die Preisaufgaben ansprach und um einen Erfahrungsbericht bat. ${ }^{22}$ Goethe, erst wenige Wochen zuvor als Vermittler der Weimarer Kunstfreunde dem Sächsischen Kunstverein als Mitglied beigetreten und mit Quandt in Kontakt, erbat sich etwas Zeit für eine ausführliche Antwort. Er betonte, man solle vorsichtig sein und im Jahr 1829 damit noch zuwarten.23

Die Diskussionen im Verein kamen vorerst zu keinem Ergebnis, so dass Quandt einen Aufsatz druckte und an die Mitglieder verteilte, worin er sich gegen eine Einführung von Preisaufgaben aussprach. ${ }^{24}$ Er glaubte, dadurch die Eigenständigkeit künstlerischer Ideen zu unterlaufen. Vielmehr wollte er die Künstler anregen, sich zu bilden. Der Kunstverein sollte ihnen

ken, indem wir uns bestreben jenem Liebe $u$ Theilnahme zur Kunst einzuflößen.«

20 Klauss 2001, S. 187-200. S. a. Briel 1987b, S. 22-23.

21 Schmidt-Funke 2006, S. 150-152. Über Böttigers Unbeliebtheit in Weimar siehe ebd., S. 78-84; Klauss 2001, S. 196, der Kontext des Eklats S. 190-197.

22 Brief von Quandt an Goethe vom 6.12.1828, in: Schmitz/Strobel 2001, S. 43: »Wenn Ew Excellenz uns über diesen Gegenstand belehren wollen, so würde dies ein unschätzbarer Beweiß Hoch Dero Wohlwollens seyn, doch bin ich nicht so kühn darum zu bitten und wage kaum es zu hoffen. "S. a. Schmidt-Funke 2006, S. 152-154.

23 Goethe an Quandt am 10.12.1828: „Was die Veranstaltung von Preisaufgaben betrifft, so bitte damit vorsichtig zu Werke zu gehen, und allenfalls das nächste Jahr damit noch inne zu halten.« Schmitz/ Strobel 2001, S. 44. Laut Schmidt-Funke 2006, S. 153 wusste Goethe zu diesem Zeitpunkt noch nicht, dass Böttiger hinter der Propagierung der Preisaufgaben stand.

24 Jahresbericht des Sächsischen Kunstvereins für das Jahr 1828, in: HStADD, 12509 Sächsischer Kunstverein, Nr. 1, 125r. S. a. Brief von Quandt an Goethe vom 2.3.1829, in: Schmitz/Strobel 2001, S. 49. 


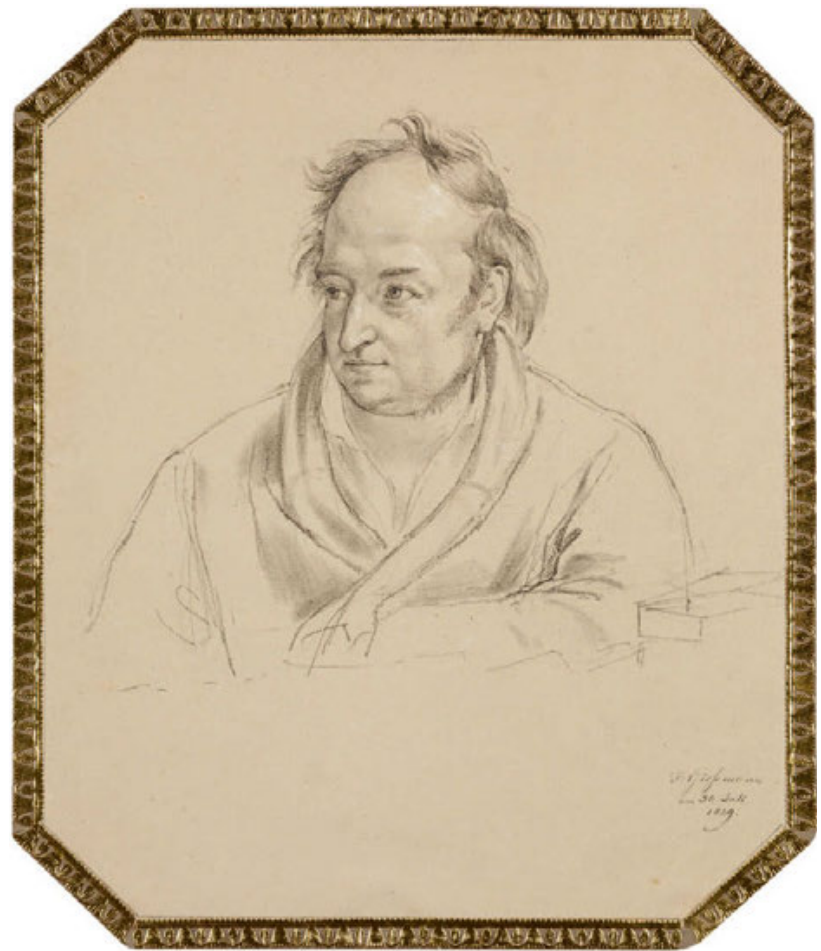

31 Friedrich Gießmann, Bildnis Johann Gottlob von Quandt, 30.7.1829, schwarze Kreide, weiß gehöht auf grau-ockerbräunlichem Tonpapier, $222 \times 188$ mm, München, Privatbesitz

dabei anleitend zur Seite stehen und nicht durch finanzielle Fördermittel unter die Arme greifen. Zudem wollte Quandt vermeiden, durch die Wettbewerbe falschen Ehrgeiz zu fördern statt wahres Streben nach Kunst. Er sah die Preisaufgaben demnach nicht als Chance, Historiengemälde zu fördern, sondern wollte durch Bildung Künstler und Publikum dazu bringen, die guten Gemälde schätzen zu lernen. ${ }^{25}$ Böttiger reagierte mit einer Gegenschrift im Artistischen Notizenblatt. Er glaubte, mit Preisaufgaben die vielfältigen Darstellungsmöglichkeiten gegebener Themen zu vermitteln, gegen die Unentschlossenheit der Künstler anzukämpfen und bei den Betrachtern die Arte di vedere, die Kunst des Sehens, zu fördern. ${ }^{26}$

Im Sommer 1829 erwähnte Quandt Goethe gegenüber, der Antikenforscher bestürme ihn immer noch mit Vorschlägen bezüglich Preisaufgaben (Abb. 31). Goethe antwortete knapp, Böttiger solle Themenvorschläge für die Ausschreibungen machen.
Grundsätzlich gälten ihm der Verweis auf die dreißig Jahre zuvor stattgefundenen Weimarer Preisaufgaben nichts: $\gg D a ß ~ m a n$ Preisaufgaben aufgestellt und daß sie zu ihrer Zeit genutzt, wird nicht geläugnet, das aber beweist noch nicht daß der Dresdner Verein 1829 Dergleichen aufgeben solle. $\ll^{27}$ Der Weimarer Dichter blieb aufgrund der durchwachsenen Erfahrungen der Idee gegenüber skeptisch.

Zum Ende des Jahres publizierte Quandt Ueber Preisaufgaben für bildende Künstler. In dem Bändchen ließ er seine Stellungnahme vom Anfang des Jahres, Böttigers Replik aus dem Artistischen Notizenblatt und eine erneute Antwort seinerseits abdrucken. Besonders die Arte di vedere, die Böttiger durch Preisaufgaben zu fördern glaubte, nahm er zum Anlass der Widerlegung. Die Kunst des Sehens sei nicht durch Experimente, wie sie Preisaufgaben darstellten, förderbar, sondern allein durch die Betrachtung »hoher Kunstwerke«. Nur an diesen würde sich der angeborene und nicht erlernbare Sinn für das Schöne, welcher die wahre Arte di vedere sei, entfalten. »Viele«, so Quandt, »würden über diese Concurrenzbilder [q.e. Wettbewerbsbilder - AR] schreiben, ohne die Arte di vedere zu besitzen, in den Salons würde man vielleicht ihrer [...] erwähnen, aber sie auch im Augenblicke wieder vergessen; in schöngeistrischen (sic!) Boudoirs höchstens ein Stündchen, sich selbst gern hörend, über diese Bilder und Aufgaben sprechen und auf Caffees darüber streiten. $\ll^{28}$ Quandt glaubte nicht an eine nachhaltige Kunstförderung durch Preisaufgaben.

Damit war das Thema vorerst abgewendet, jedenfalls war es kein Diskussionspunkt in der Generalversammlung im Dezember 1829. ${ }^{29}$ Allerdings wurde auch die Frage nicht geklärt, wie mit den Vereinsüberschüssen umzugehen sei. Böttiger selbst hatte daher in seinem Aufsatz vorgeschlagen, wenigstens den Versuch zu wagen, Künstler zu einem frei gewählten Bildgegenstand ihre Vorschläge einsenden zu lassen. Er berief sich auf einen Gedanken Quandts in einem Aufsatz über die Kunstakademien in Deutschland, den dieser in seiner Geschichte der Kupferstecherkunst von 1826 publiziert hatte. ${ }^{30}$ Quandt hatte vorgeschlagen, junge Künstler der Akademien sollten einem Komitee von drei Kunstkennern drei Vorschläge beliebiger Themen unterbreiten. Nach der Wahl des besten Bildthemas sollte der Künstler einen Karton entwerfen. Hierüber würde erneut diskutiert: „Die Comité muß diesen Entwurf prüfen und
25 Quandt 1829 (1), v. a. S. 10-13; Quandt 1826 (1), S. 288-289.

26 Böttiger, in: Quandt 1829 (1), S. 31-33: »Wenn Göthe jene [...] Aufgaben aufstellte, so war es ihm [...] darum zu thun, daß junge Künstler und feurige Köpfe daran lernten, was vortheilhafte, gleichgiltige und widerstrebende Gegenstände wären und wie mannigfaltig bei einem Gegebnen die Motive seyn könnten. [...] Und ist denn [...] die dadurch vielfach angeregte Aufmerksamkeit und Bildung in der arte di vedere für die Besuchenden gar nichts werth?«
27 Brief von Goethe an Quandt vom 11.7.1829, in: Schmitz/Strobel 2001, S. 59. S. a. Schmidt-Funke 2006, S. 153-154.

28 Quandt 1829 (1), S. 40-41. S. a. Schmitz 2001, S. 238.

29 Quandt, Einberufung der Generalversammlung am 21.12.1829, in: HStADD, 12509 Sächsischer Kunstverein, Nr. 1, fol. 183r-184V. 30 Böttiger, in: Quandt 1829 (1), S. 32-33. 
den Künstler auffordern, über das Rechenschaft zu geben, was sie an dem Entwurf etwa auszusetzen findet. Hat der Künstler Gründe anzuführen, durch welche er seine Composition gegen die aufgeworfenen Fragen und erregten Bedenklichkeiten vertheidigen kann, so haben die Beurtheiler sich damit zu befriedigen; nur das Grundlose ist als fehlerhaft in einer malerischen Composition zu betrachten. « $3^{1}$ Dadurch wollte Quandt die Künstler zu höheren Aufgaben anregen.

Für den Kunstverein hingegen erachtete er ein wie das von Böttiger vorgeschlagene Prozedere nicht als angebracht. Dennoch kam er nicht umhin, sich Gedanken über Aufträge durch das Komitee zu machen. In einem Brief an Julius Schnorr schrieb er daher im Juli 1829: »Ich hoffe immer, die Kunst sollte wie ein Baum, ohne Zwang, ohne künstliche Mittel aufwachsen, wodurch sie freyer $\mathrm{u}$ fröhlicher gedeihen würde. Allein es fehlt vielen Künstlern an innerm Triebe u Kraft u so haben sie einen Antrieb von außen nöthig. Daher werde ich mich wohl noch entschließen müßen, Bestellungen bey dem Kunstvereine einzuführen, so ungern ich auch darauf eingehe. $\aleph^{2}$ Sein Anliegen, Künstlern, die eigene Ideen hatten, als Kunstkenner zur Verfügung zu stehen, musste also andere Vorzeichen erhalten: es mussten die Kunstkenner sein, welche die Künstler zu eigenen Ideen anregten - dies aber in voller Freiheit.

Für die Generalversammlung 1829 wurde daher auf die Tagesordnung gesetzt, die bis anhin statuarisch nicht möglichen Aufträge nach dem Vorlegen von Entwurfsskizzen gutzuheißen. Quandt erhoffte sich dadurch großformatige, vielfigurige Historien: »Wir machten jedoch die Erfahrung, daß in Rücksicht der Künstler die genommene Maßregel nicht immer die

31 Quandt 1826 (1), S. 289-290. Böttiger nutzte Quandts Beispiel zugunsten seiner eigenen Argumentation für die Preisaufgaben. Dies wies Quandt in seiner Replik deutlich zurück: »Endlich muß ich noch feierlich dagegen protestiren, daß meine schon längst gemachten Vorschläge, welche Sie erwähnen, die aber keine Berücksichtigung erhalten haben, nicht in eine Classe mit Preisaufgaben gestellt, oder mit diesen verwechselt werden, denn sie unterscheiden sich in der Absicht, Verfahrungsweise und Wirkung ganz und gar von Preisaufgaben.« Quandt 1829 (1), S. 44.

32 Brief von Quandt an Schnorr vom 20.7.1829, in: SLUB Mscr. Dresd. n Inv. 15, Bd. 31, fol. 164. Zit. nach Schmitz/Strobel 2001, S. XXIV.

33 Quandt, Einberufung der Generalversammlung am 21.12.1829, in: HStADD, 12509 Sächsischer Kunstverein, Nr. 1, fol. 184r. Zum Marktcharakter der Kunstvereine siehe Schmitz 2001, S. 336-352.

34 Quandt, Notizen zur Rede an der Generalversammlung am 21.12.1829, in: HStADD, 12509 Sächsischer Kunstverein, Nr. 1, fol. 204V. »Indes aber scheint die Historienmalereÿ der Ermuthigung [zu bedür]fen, welche freÿlich von der Mehrzahl der Kunstliebhaber am wenigsten begünstigt worden war und wir [?] daher es uns besonders angelegen seÿn lassen, [wenn in?] diesem Fache sich nur einigermaßen Hoffnung [erwec]kendes zeigte, zu berücksichtigen.« Durch die schlechte Qualität des Mikrofilms waren die Wörter im Falz der Akte nicht mehr lesbar, weshalb sie aus dem Kontext, mit eckigen Klammern bezeichnet, ergänzt wurden

35 »Hiervon wären folgende gute Wirkungen zu hoffen: [...] Daß durch erwartete Wirkung haben konnte, weil viele zunächst für ihren Unterhalt sorgen und daher Brodarbeiten annehmen, größere Unternehmungen bei Seite legen und sich auf kleine Bilder, welche sichrer und leichter Absatz finden, beschränken müssen. Hieraus entsteht der Nachtheil, daß selbst Talentvolle ihre Kräfte nicht in vollem Maße entwickeln können und am Ende zurückgehen.«3 Das Ziel der Aufträge sollte es sein, weg von den gut verkäuflichen und beliebten kleinformatigen Genreund Landschaftsbildern hin zur aufwendigeren Historienmalerei zu gelangen. ${ }^{34}$ Zugleich wollte er mit den Künstlern in Kontakt treten und sie in Themenwahl und Ausführung beraten. ${ }^{35}$ Der Antrag auf Statutenänderung wurde mit großer Mehrheit angenommen und Aufträge des Sächsischen Kunstvereins damit ermöglicht. ${ }^{36}$

Die Statutenänderung war sehr dringend geworden, denn Quandt hatte seine Rollen als privater Kunstsammler und als Vorsitzender teilweise vermischt, auch wenn dies offiziell nicht der Grund für die Anpassung war. Unmittelbar nach der Ausstellung der Akademie in Dresden im August 1829, wo der Verein die Auswahl für die Ankäufe normalerweise traf, hatte Quandt das Historiengemälde Faust im Studierzimmer des Meißner Malers Georg Friedrich Kersting als Privatmann angekauft (vgl. Abb. 30). In einem Schreiben an den Kunstverein schlug er es zur Übernahme und Verlosung vor, was Ende des Jahres auch geschah. Quandt betonte, »der Künstler [habe] den Dichter glücklich benutzt u eine malerische Zusammenstellung, vieler im Gedichte erwähnter Gegenstände u Umstände, hervorgebracht. $\aleph^{37}$ Dieser private Ankauf durch den Vereinsvorsitzenden blieb nicht der einzige..$^{8}$ Quandt beabsichtigte mit diesen Vor-

Vorlegung von Modellen, Skizzen oder Cartons, welche die Künstler aus eignem, freien Antriebe entworfen haben, dem Comité Gelegenheit gegeben würde, mit den Künstlern in ein berathendes Verhältnis zu treten. Fände so mancher Künstler, der ohne Rathgeber oft nur auf sich selbst beschränkt ist, auf diese Weise Veranlassung, seine Ideen klarer zu entwickeln, wodurch seine Werke an Vollkommenheit gewinnen würden.« Quandt, Einberufung der Generalversammlung am 21.12.1829, in: HStADD, 12509 Sächsischer Kunstverein, Nr. 1, fol. 184r.

36 Annahme mit 56:19 Stimmen. Der neue Paragraph über die Aufträge unter $\$ 5$ der revidierten Statuten. Protokoll der Generalversammlung und Statuten, in: HStADD, 12509 Sächsischer Kunstverein, Nr. 1, vor fol. 229f. S. a. Jahresbericht für das Jahr 1829 vom 31.3.1830.

37 »Da mir jedoch dies Gemälde, für welches Achtzig Thaler gefordert wurden, des Beÿfalls werth zu seÿn schien, so habe ich mich dessen Besitzes versichert. Wenn die verehrten Comitemitglieder durch Abstimmung dieses Gemälde für würdig erklären, für den Preis gekauft zu werden, so trete ich dieses Bild an den Comite für $80 B$ wieder ab." Brief Quandts an die Komiteemitglieder vom 27.8.1829, in: HStADD, 12509 Sächsischer Kunstverein, Nr. 1, fol. 174r-v. Ebenso in der Einberufung der Generalversammlung vom 21.12.1829, ebd., fol. 184v: »[...] und ist erbötig, wenn diese Gemälde den Beifall des Comité verdienen, solche an den Verein für das den Künstlern bewilligte Honorar abzutreten.« S. a. Kovalevski 2010, S. 60, B-C 25.

38 Quandt an Goethe am 16.8.1829, in: Schmitz-Strobel 2001, S. 63-65. Weitere Privatankäufe: eine Madonna von Carl Gottlieb Peschel und 
käufen Gemälde, die er für gut befand, vorzeitig für den Verein zu sichern. Hierfür gab er auch Werke nach Entwürfen in Auftrag. Bei Annahme durch das Komitee trat er sie zum gleichen Preis ab. Statuarisch war dieses Vorgehen zwar korrekt, wie es gar in der Begründung für die Statutenänderung hieß: »Da aber bisher Bestellungen nicht statutarisch(sic!) zuläßig waren, jedoch von den Umständen fast dringend gefordert wurden, so hat der Vorstand des Vereins, v. Quandt, um nicht gegen die Statuten zu handeln, auf seine Gefahr bei einigen Künstlern, nach vorgelegten Zeichnungen, Gemälde bestellt, welche einen größern Aufwand von Zeit und Kraft verlangen, als ein Künstler an nicht bestellte Arbeiten wagen kann. $\ll^{39} \mathrm{Die} »$ dringlich geforderten Umstände« bezogen sich natürlich auf die Historienmalerei. Dieser Subtext deutet an, dass Quandt in einer Vermischung als privater Mäzen und offizieller Vertreter des Vereins seine eigenen Interessen verfolgen, durch die Ankäufe gewisse Vorentscheide treffen und mit geschickter Argumentation - wie im Fall der »Ermutigung« statuarisch begründet - die Ankaufsentscheide zu steuern vermochte. Dabei halfen ihm seine weitreichenden Künstler- und Kunstkennerkontakte, die er bei Bedarf aktivieren konnte.

Im Februar 1830 erfolgte die Ausschreibung eines ersten Auftrags ohne Themenvorgabe. Anders als bei der Preisaufgabe, die einen eng begrenzten Gegenstand zur Aufgabe gehabt hätte, sollten die Bewerber Entwürfe zu selbst gewählten Motiven einreichen. Ziel war demnach nicht das Gewinnen eines Wettbewerbes, sondern der Zuspruch des Auftrags. Die Künstler sollten eine größere Komposition mit Figuren, die idealerweise Zweidrittel der Lebensgröße maßen, entwerfen. Was Quandt darunter verstand, formulierte er in der Ausschreibung: Die Kunst könne »nur durch Anregung für historische Gegenstände $[. .$.$] wahrhaft gefördert und vom Gemeinen und Alltäg-$ lichen zum Edlen geführt werden [...]. Den üblichen Ausdruck: Geschichtsmalerei, wollen wir im weitern Sinne des Worts verstanden wissen und begreifen darunter die Darstellungen von bedeutenden Zuständen oder Handlungen, es mögen diese nun aus der Geschichte im engern Sinne, oder dem Bereiche der Poesie geschöpft seyn, sich eine tiefere Gemüthstimmung oder ein höherer sittlicher Grund ausspricht, als in den Bildern des alltäglichen Verkehres der Menschen, die dem Genremaler darzustellen überlassen bleiben. ${ }^{40}$ Wie wichtig Quandt die Förderung der Historienmalerei war, zeigt sich auch darin, dass er die Kosten für die Zu- und Rücksendung selber übernahm und nicht der Vereinskasse in Rechnung stellte.

eine Landschaft von Adrian Ludwig Richter, Rocca di mezzo. S. a. Briel 1987a, S. 23; Kovalevski 2010, S. 64-65, 70, Kat. Nr. B-C 27, 30.

39 Einberufung der Generalversammlung vom 21.12.1829, HStADD, 12509 Sächsischer Kunstverein, Nr. 1, fol. 184V.

40 Ausschreibung des Auftrags, in: Artistisches Notizenblatt, hrsg. v. Carl
Die Frage der Kunstkennerschaft bei Goethe und Quandt

Parallel zur Frage der Preisaufgaben und der Aufträge des Komitees entfaltete sich eine Diskussion mit Goethe, die ohne diesen Kontext nur unvollkommen einzuordnen bliebe. Quandt hatte den Vertreter der Weimarer Kunstfreunde über die Entscheidungen im Verein wie immer auf dem Laufenden gehalten. Dieser reagierte in vereinspolitischen Fragen jeweils nur knapp. Nach der Verlosung der Ankäufe von 1829 verlangte der Dichter aber zu den nach Weimar verlosten Gemälden genauere Erläuterungen. Dies führte zu einer sich über mehrere Briefe hinziehenden Diskussion über die Rolle des Kunstkenners bei Aufträgen.

Dabei ging es um drei Gemälde: ein Landschaftsbild des Norwegers und Dahl-Schülers Thomas Fearnley, um eine Ansicht des Kreuzgangs des Großmünsters Zürich des ehemaligen Dresdener Akademieschülers und in der Schweiz tätigen Malers Otto Wagner sowie um die Historie Tobias' Abschied von Carl Gottlieb Peschel. Die ersten beiden Lose gewann die Zarentochter Maria Pawlowna, Großherzogin von SachsenWeimar-Eisenach, das dritte die Mutter des Großherzogs, Luise von Hessen-Darmstadt. Quandt berichtete Goethe am 25. Januar 1830, er hoffe, dass die Bilder in Weimar Beifall erhalten würden, denn sie zeigten, dass die Dresdener Künstler »nach Vervollkommnung streben.«"

Tatsächlich schien Goethe nicht beglückt gewesen zu sein. Gelungene Arbeiten waren ihm auch deswegen umso wichtiger, als es sich bei den Gewinnerinnen um die höchsten Ehrenleute Weimars und Förderer der Künste handelte. So forderte er am 6. Februar bei Quandt genauere Angaben zu den Künstlern an, um ihre Bilder besser einordnen zu können. Die Auftragsfrage aufgreifend, schrieb er an Quandt: »Erlaubt sey mir nun auch zu sagen: daß bei den wirklich Verdienstlichen dieser Bilder, mir die von Denenselben vorgeschlagene Bestellung nur noch wünschenswerther erschienen; denn hätte man sich früher über diese Bilder, mit einsichtigen Kennern berathen, so wäre Verschiedenes, einen vollkommen guten Eindruck störende, leicht zu vermeiden gewesen. $\ll^{{ }^{2}}$ Goethe glaubte also, dass in einem Auftragsverhältnis die Kunstkenner - in diesem Fall natürlich Quandt und die Komiteemitglieder des Sächsischen Kunstvereins - den Künstler auf Probleme und Fehler hätten hinweisen können. Der Dichter führte aus, dass er sich das Verhältnis von Künstler und Kunstkenner als produktiv vorstelle, dass der

\footnotetext{
August Böttiger, 20.2.1830, in: HStADD, 12509 Sächsischer Kunstverein, Nr. 1, fol. 254r-v und KB 1830, Nr. 23, S. 92.

41 Brief von Quandt an Goethe vom 25.1.1830, in: Schmitz/Strobel 2001

S. 82. S. a. Kovalevski 2010, S. 48-53, Kat. Nr. B-C 17-19.

42 Goethe an Quandt am 6.2.1830, in: Schmitz/Strobel 2001, S. 84.
} 


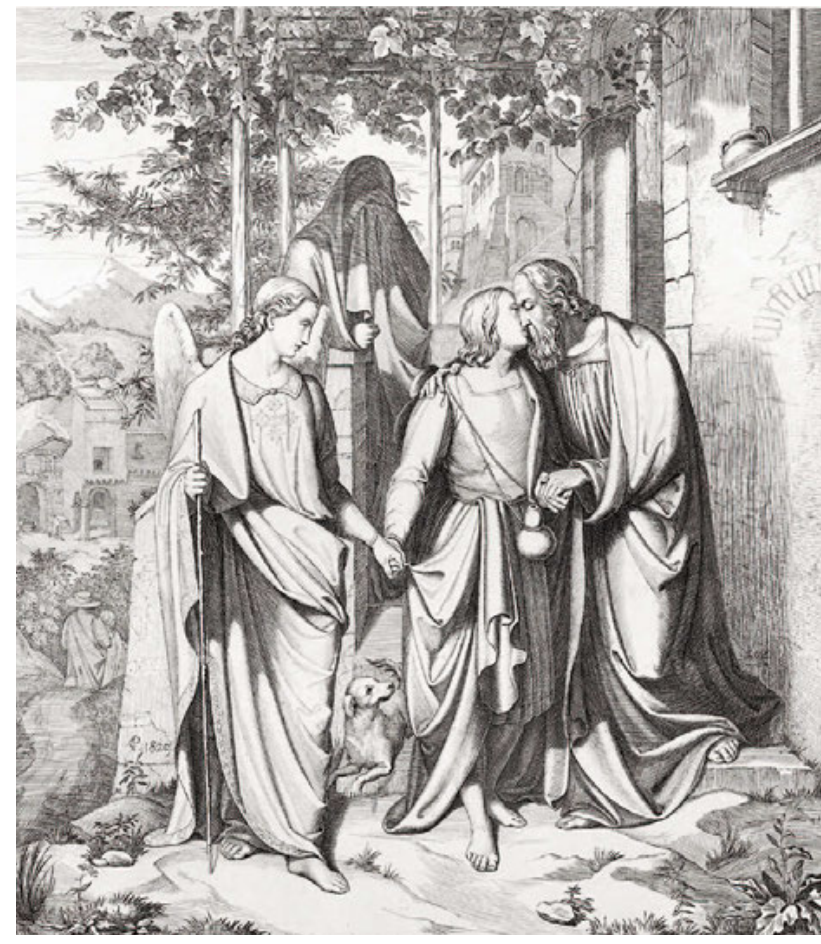

32 Ferdinand Anton Krüger nach Carl Gottlieb Peschel, Tobias' Abschied, 1829, Kupferstich, $199 \times 175$ mm (Bild), Frankfurt a/M, H. W. Fichter Kunsthandel

Kenner den Künstler unterstütze, dessen Idee bis ins Detail zur Ausführung zu bringen. Aus einer grundlegenden Skepsis heraus fragte er rhetorisch, ob für diese Tätigkeit der Kenner überhaupt dem Künstler gewachsen sei. ${ }^{43}$ Goethe suchte den regen Austausch zwischen Künstler und Kunstfreund, bei dem sich die beiden »in Rath und That zu steigern, ja zu überwinden suchen, bis sie zuletzt vollkommen einig geworden und ein völlig fertig congruirendes Bild entstanden ist. « ${ }^{4}$ Der Brief verdeutlicht, dass der Weimarer Dichter gerne bei den Ankaufsentscheidungen in Dresden mitgeredet hätte. ${ }^{45}$

Diese Skepsis provozierte Quandt zu einer ausführlichen Antwort. Er beschrieb wie verlangt die Biographien der drei Künstler und erklärte seine Vorstellung der Rolle von Kunstkennern. Am Wichtigsten sei die Erarbeitung einer guten Idee im Kunstwerk. Dort wo die Stringenz in der Durchführung fehle, solle der Kenner einhaken. Es sei seine Aufgabe, »auf so- kratische Weise« den Künstler zur Entwicklung seiner eigenen Ideen zu bringen. Dabei müsse der Ratgeber »indirekt « vorgehen, dem Künstler in der Entwicklung seines Bildmotivs also Freiheiten lassen. Er solle ihm nichts ein- oder ausreden, da »ein geheimer innerer Zusammenhang mit der Idee statt findet, denn das Bild entsteht immer, mit, in und durch die Idee. $\ll^{46}$ Der Kunstkenner sollte sich in erster Linie in den Künstler einfühlen und ihn nur sanft in eine andere Richtung führen. Im Zweifelsfall würde sich die Kunst schon selber ihren Weg bahnen. Der Kunstkenner müsse im Hintergrund agieren.

Da der Vereinsvorsitzende verstanden hatte, dass Goethe mit den verlosten Gemälden nicht zufrieden war, nahm er Peschels und Wagners Gemälde, heute nur noch als Kupferstiche überliefert, zum Beispiel. In Tobias' Abschied empfand er die verhüllte Mutter im Hintergrund als unlogisch (Abb. 32). In einer realen Szene hätte diese zu Tränen gerührt beim Jungen stehen sollen. Zwar verstand Quandt das verhüllte Gesicht als Topos des Schmerzes, doch schien ihm dies zu übertrieben: »Ist der Schmerz so groß, daß er sich verhüllen muß? Und wird beym Scheiden nicht die liebevolle Mutter den Anblick des Sohnes noch einmal recht tief ins thränenvolle Auge fassen? «77 Quandt ging also von seinen eigenen Vorstellungen einer realen Abschiedsszene aus und nicht von kunsthistorischen Topoi. Daher empfand er diese Partie in Peschels Historie als unentwickelt. Gleichzeitig wird hier Quandts idealistische und immer wieder erwähnte »Idee« etwas greifbarer.

Bei Wagner argumentierte er ähnlich. Er meinte, in einen Kreuzgang gehörten keine Spaziergänger (Abb.33). Diese wären eher in einer Markt- oder Straßenszene zu erwarten und stünden daher im Widerspruch »mit der Idee des Heiligthums $\ll_{.^{8}}$ Diese letztlich für Goethe kaum befriedigende Antwort zog nur noch eine lakonische Replik nach sich:»Ueber die Frage, inwiefern man bey Künstlern Werke bestellen und ihnen unter der Arbeit mit gutem Rath an Handen gehen solle, habe vielfach nachgedacht und finde große Schwierigkeit darin, daß Künstler und Kenner sich nicht leicht verstehen werden.« ${ }^{49}$

Die Ungereimtheiten zwischen Goethes und Quandts Vorstellungen von Kunstkennerschaft werden im diplomatischen Charakter der Vereinsbriefe nur bedingt wahrnehmbar. In gewissem Sinn manifestiert sich in der unterschiedlichen Wahr-
43 Ebd.: »Der Künstler hat oft einen sehr guten Gedanken, dessen Ausführung er auch gewachsen ist, aber er hat ihn nicht in allen einzelnen Theilen durchdrungen und da kommt ihm des einsichtigen Kenners Theilnahme wohl glücklich zu Hülfe; wie ich an meinem eigenen dichterischen Beyspiele weis und in einem langen Leben vielfach erfahren habe. Hiebey aber entsteht eine große und bedeutende Frage: Ist der Kenner und Kunstfreund der Sache gewachsen?«

44 Goethe an Quandt am 6.2.1830, in: Schmitz/Strobel 2001, S. 85. S. a. Grave 2005, S. 255-257.

$45 \gg \mathrm{Da}$ aus der Ferne hierin wenig oder nichts zu thun sey läßt sich vermuthen, ja sogar einsehen.« Goethe an Quandt am 6.2.1830, in: Schmitz/Strobel 2001, S. 85.

46 Brief von Quandt an Goethe vom 12.2.1830, in: Schmitz/Strobel 2001, S. 86-90.

47 Brief von Quandt an Goethe vom 12.2.1830, in: Schmitz/Strobel 2001, S. 89 .

48 Schmitz/Strobel 2001, S. 89. S. a. Brief von Quandt an Goethe vom 16.8.1829, in: ebd., S. 63-65.

49 Brief von Goethe an Quandt vom 27.5.1830, in: Schmitz/Strobel 2001, S. 92. 


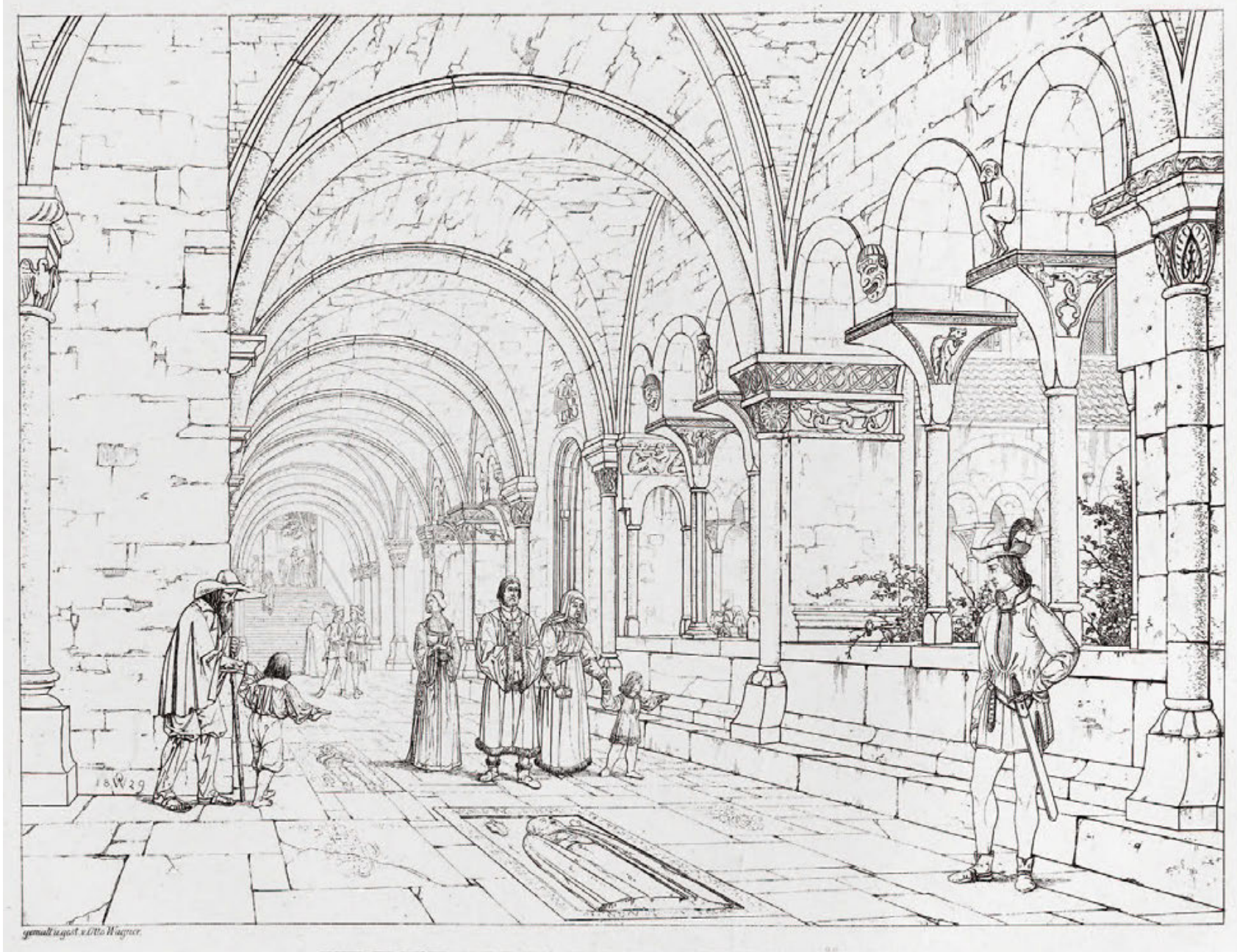

33 Otto Wagner nach dem eigenhändigen Gemälde, Kreuzgang am Dom in Zürich, 1829, Kupferstich, $182 \times 241$ mm (Bild), Frankfurt a/M, H. W. Fichter Kunsthandel

nehmung jedoch in Ansätzen bereits eine Entwicklung, die in die Richtung einer professionalisierten Kunstgeschichte deutet. Quandt als Kenner suchte weniger den direkten Umgang mit den Künstlern, sondern zog sich auf eine Position zurück, die es ihm erlaubte, aufgrund seiner Kenntnis der Kunstgeschichte sein Urteil zu fällen und den Künstler allenfalls durch sachliche Argumente umzustimmen. Während Goethe, selber Dichterkünstler, sich hier auf seine Kunstideale bezog, so traute Quandt der Kunst selber zu, sich ihren Weg zu bahnen. Diese Anschauung lässt sich nur dadurch erklären, dass der Dresdener Kunstkenner einen Überblick über die verschiedenartigen Entwicklungen in der Kunstgeschichte hatte.

Genau dies zeigt sich in Bezug auf den hier dargestellten Interessenskonflikt der beiden unterschiedlichen Briefpartner in
Dresden und Weimar erst, wenn man weitere Quellen zu Rate zieht. Besonders Goethes ausgeprägtes Antikenideal entpuppt sich hier als der Schlüssel zu den Differenzen. Quandts andersgeartetes Kunstverständnis, dessen Faszination für die Alten Meister, seine Förderung der Nazarener und sein fortwährendes Bemühen um einen Ausgleich der nördlichen und südlichen Kunstschulen hatte ein in Ansätzen wissenschaftliches Interesse an der Geschichte der bildenden Künste zur Folge..$^{50}$

Die erst im Zuge der umfassenden Goethe-Rezeption publizierten Briefentwürfe und Tagebuchnotizen zeigen, dass Goethe die Diskussion über Kunstkennerschaft mit Quandt eigentlich noch nicht hatte aufgeben wollen. So hat sich das Konzept einer nicht abgesandten Antwort auf dessen letzten Brief erhalten. Darin hatte der Weimarer skizziert, Historienmaler 
sollten zu vorgegebenen Themen aus der griechischen Mythologie oder dem Nibelungenlied mehrere Skizzen entwerfen. Dabei ergäbe sich mit Bestimmtheit Gutes, so dass der Kunstliebhaber »wegen des Einzelnen nicht zu mäkeln noch zu markten braucht«, da er das Thema in Auftrag gegeben habe. ${ }^{51}$ Auch äußert er sich, biblische Motive seien bereits zu oft durchgearbeitet worden und würden nichts Neues bringen. »Die hohe Kunst«, so schrieb er, »muß selbständig seyn, weder Frömmigkeit noch Patriotismus dienen hier zum Supplemente. « $\aleph^{2}$ Dies ist eine eindeutige Spitze gegen Quandt, der als Unterstützer der Nazarener galt, seit er auf seiner Romreise 1819/2O zahlreiche Bestellungen bei diesen Malern in Auftrag gegeben hatte. Gleichzeitig verdeutlicht die Aussage, dass Goethe mit Peschels Gemälde Tobias' Abschied unzufrieden war. Im selben Monat Mai 1830, in den die Diskussion mit Quandt fiel, äußerte er sich gegenüber dem Weimarer Staatskanzler Friedrich von Müller regelrecht frustriert: »Was für ein unseliger Kunstkenner ist Quandt! Lauter Tobiase zu akquirieren! Sind doch die Dresdner selbst blind und bedürften der Fischblase allerseits. Vielleicht wird in der Elbe einmal ein tüchtiger Hecht gefangen, mit dessen Leber man ihnen die Augen auswischen könne. «s3 Die Aussage bezog sich über das Weimarer Los hinaus auf zwei weitere Ansichten aus der Tobias-Geschichte, die der Kunstverein 1829 angekauft hatte..$^{54}$

Von alldem wusste Quandt nichts. Im Detail lag Goethe auch falsch. Wie der Vorsitzende des Sächsischen Kunstvereins nämlich im Jahresbericht auf das Jahr 1829 bis Ostern 1830 schrieb, wurde 1829 vor allem die Historienmalerei berücksichtigt. Dabei waren die Tobias-Motive bei weitem nicht die einzigen Ankäufe. Wenn auch keine Darstellungen nach antiken Mythologien, kamen nebst den drei Szenen aus der TobiasGeschichte aus dem apokryphen Buch Tobit in der Bibel zwei weitere biblische Motive und ein Gemälde nach Goethes Faust zur Verlosung.55 Dies geschah aus dem Grund, als sich der Verein im ersten Paragraphen der Statuten als Hauptzweck zur Unterstützung und Ermutigung der Künstler verpflichtet hatte.
Quandt betonte, dass Bildnisse, Landschaften und Genrebilder genügend verkauft würden, weswegen die Historienmalerei im Zentrum gestanden habe. »Von diesem Standpuncte aus wünschen wir, daß unsere Ankäufe betrachtet werden mögen. « ${ }^{56}$

In diesen unterschwelligen Differenzen entpuppt sich ein grundlegender Unterschied im Kunstverständnis von Goethe und Quandt. Dessen war sich der Dresdener Vereinsvorsitzende schon lange bewusst. Mit dem 1817 vom Schweizer Maler und Kunstberater Johann Heinrich Meyer verfassten Aufsatz Neu-deutsche religios-patriotische Kunst, der in Goethes Zeitschrift Über Kunst und Altertum in den Rhein- und MaynGegenden erschienen war, begann sich zu zeigen, dass Quandt und der Weimarer Dichter zwei verschiedenen Generationen und Sichtweisen angehörten. In dem Pamphlet verurteilte Meyer die Kunstrichtung der Nazarener in Rom als falschen Weg und erhob das Stilideal des antiken Griechenlands als einziges Vorbild für die Künstler. ${ }^{57}$ Der Aufsatz wurde im Namen der Weimarischen Kunstfreunde publiziert und Goethe beeinflusste ihn wesentlich. In vielen Briefen bereitete er das Erscheinen vor und sprach von einer Bombe, die »in den Kreis der Nazarenischen Künstler hinein plumpen« würde. Er bemitleidete, wie »ein herrlicher, seit langen Jahren unter deutscher Malerjugend nicht so angehäufter Fonds von Geist, Kraft, Liebe, Geschicklichkeit, Fleiß und Beharrlichkeit durch solche geistige Onanie fruchtlos vergeudet « würde. $5^{8}$

1818 griff Quandt in einem Brief an Schnorr mit einer gewissen Verwunderung Goethes Kunstansichten auf und verglich sie mit seinen Leitsätzen: »Der Mittel und Augenpunkt meiner Betrachtungen, ist der Mensch und alle Kunstgegenstände, ja ganze Epochen der Kunst betrachte ich als Äußerungen, des ewig fortschreitenden Menschengeistes, der niemals einen Rückschritt thut. [...] Unter diejenigen welche dem Gange des Menschengeistes ein gebieterisches Halt zurufen, gehört doch auch der große, verehrungswürdige Göthe. Er hält nun einmal den antiken Standpunkt für den einzig richtigen, ohne zu bedenken, daß dieser doch auch immer nur ein Punkt in der
51 Nicht abgesandtes Konzept zum Brief von Goethe an Quandt vom 27.5.1830, in: Schmitz/Strobel 2001, S. 95.

52 Schmitz/Strobel 2001, S. 95.

53 Müller/Goethe 1982, S. 193. S. a. Schmitz/Strobel 2001, S. 293; Eberlein 1928, S. 17; Bemmann 1925, S. 36.

54 Rudolph Julius Uschner, Abschied des Tobias und Gustav Adolph Hennig, Tobias' Heilung. Siehe Kovalevski 2010, S. 54-55, Kat. Nr. B-C 20-21.

55 Kovalevski 2010, S. 52-55, Kat. Nr. B-C 19-21, S. 58-61, Kat. Nr. B-C 23-25. S. a. den Bericht von Quandt an Goethe vom 30.12.1829, in: Schmitz/Strobel 2001, S. 76-78.

56 Jahresbericht des Sächsischen Kunstvereins von 1829 bis Ostern 1830 von Quandt, datiert 31.3.1830, fol. 231r: »Beim Ankauf dieser Kunstwerke behielt der Ausschuß immer den Hauptzweck des Vereins: Ermuthigung der Künstler, im Auge, und glaubte dabei vorzugsweise das Fach der Geschichtsmalerei berücksichtigen zu müssen, da die Bestellungen und Ankäufe aus eignen Mitteln der Kunstliebhaber sich fast auschließlich auf Bildnisse, Landschaften und etwa Genre=Gemälde beschränken.«

57 Meyer/Goethe 1817 [1999], S. 124-125. Der Aufsatz erschien in der zweiten Ausgabe der Zeitschrift Über Kunst und Altertum in den Rhein- und Mayn-Gegenden im April 1817, abgedruckt in: FA 1999, Bd. 20, S. 103-129. Zu Goethes Anteil am Artikel siehe Kommentar, ebd., S. 814-828. S. a. Thimann 2013, S. 301-305; Tauber 2011, S. 418420; Apel/Greif 1997, S. 619-639; Locher 2001, S. 156-163.

58 Die Zitate aus Briefen Goethes an Knebel (17.3.1817) und an Meyer (28.5.1817), in: MA 1994, Bd. 11.2, S. 987, 988. S. a. den Kommentar, in: ebd., S. 979-1006. Der Ausspruch der »geistigen Onanie« stammt von Friedrich Rochlitz, der am 22.5.1817 Goethe in einem Brief für den Aufsatz dankte, dazu der Kommentar von Hendrik Birus, in: FA 1999, Bd. 20, S. 828-831. S. a. Thimann 2013, S. 305-308. 
Sphäre ist, welche die Menschheit umkreisen soll.« ¿ $^{59}$ Die engagierte Stellungnahme des 31-jährigen geschah freilich bevor er in die Kreise des Weimarer Dichters vorstieß. Dennoch blieb ihm der Unterschied stets präsent.

Nachdem Quandt im April 1820 aus Rom zurückkehrte und ein paar Tage in Weimar verweilte, wurde er durch Meyer bei Goethe eingeführt: »Der alte Hofrath Mayer (sic!) gewann ein[e] Art Zärtlichkeit zu mir, obwohl er wußte, daß ich ein Freund $\mathrm{u}$ Anhänger der neuen Schule war. « ${ }^{60}$ Während des Besuchs erkundigte sich Goethe nach den deutschen Künstlern in Rom, darunter nach Overbeck. Quandt nahm sich vor, den Dichter mit beispielhaften Nachdrucken nazarenischer Künst-

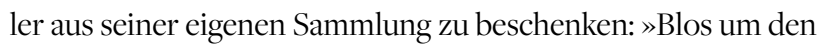
ehrwürdigen Greis [...] mit seinen Zeitgenoßen zu versöhnen, bin ich Willens, nach u nach ihm einige von meinen Bildern [... zur Ansicht zuzusenden. $\ll^{61}$

1826 griff er in seinem Aufsatz über die deutschen Kunstakademien Meyers Text über die neudeutsche Kunst noch einmal auf. Der zentrale Vorwurf des »mystischen Strebens«, den Meyer und mit ihm Goethe den jungen deutschen Künstlern in Rom gemacht hatte, deutete er zum Kompliment um. »Mir scheint es, als wenn dieses Beiwort, recht verstanden, vielmehr einen Lobspruch enthielte [...]. Denn ist nicht jedes erhabene Kunstwerk in dem edelsten Sinne mystisch zu nennen? inwiefern es dem Verstande unbegreiflich bleibt, wie dadurch eine Idee in ein Wirkliches sich verwandelt, ein Übersinnliches zu einem Wahrnehmbaren wird, und das Kunstwerk Symbol selbst des Göttlichen ist.« Auch das Patriotische wollte er positiv verstanden wissen, da es sich auf eine »Vorliebe für die Ei-

59 Brief von Quandt an Julius Schnorr von Carolsfeld vom 17.5.1818, in: SLUB, Mscr. Dresd. n Inv., Bd. 31, fol. 4 r-v. Quandt nahm auch in seinem Aufsatz Ueber das Altdeutsche in der Malerei gegen Goethe und Meyer Stellung; Quandt 1818 (1), S. 265-266.

60 Brief vom 23.12.1820, in: Schmitz/Strobel 2001, S. 17-19. Zu Meyers Entwicklung in Bezug auf die altdeutsche Kunst siehe Rössler 2013, S. 292-299.

61 Brief an Schnorr vom 7.1.1821, in: SLUB, Mscr. Dresd. n Inv. 15, Bd. 31, fol. 58 r-v; s. a. Schmitz/Strobel 2001, S. 21. Dies geschah allem Anschein nach erst 1830. Eine Liste der zugesandten Umrissstiche nach Quandts Gemälden im Brief an Goethe vom 23.6.1830, in: Schmitz/ Strobel 2001, S. 97. Es handelt sich um vier Figurengruppen aus Botticellis San Zenobio, einem Gemälde nach Rogier van der Weyden, Perugino und der Italienischen Landschaft Rhodens. Siehe Rüfenacht 2018, SQ-6, SQ-28, SQ-30, SQ-69. Kat. Quandt 1868, Nrn. 4, 26, 28, 67 . Louise Seidler berichtet, dass Goethe mit seinen Mittagsgästen gelegentlich unter anderem Abbildungen nach Werken aus Quandts Sammlung betrachtete; Seidler 2003, S. 64. S. a. Kovalevski 2006, S. 52

62 Quandt 1826 (1), S. 271-274. Meyers Gegenposition lautet: »Da aber jener National-Enthusiasmus [beim Aufstand gegen Frankreich - AR], nach erreichtem großen Zweck [...] ohne Zweifel wieder ablegen und in die Grenzen einer anständigen würdigen Selbstschätzung zurücktreten wird, so kann sich alsdann auch die Kunst verständig fassen lernen und die beengende Nachahmung der ältern Meister aufgeben, ohne doch denselben und ihren Werken die gebührende und auf wah- genthümlichkeit des deutschen Volks« beziehe. Sein Fazit aus der Umdeutung des Meyer-Goetheschen Manifestes gegen die neudeutsche Kunst mutet geradezu ironisch an und ist letztlich eine Kritik an den beiden Weimarer Gelehrten: »Wenn nun der Charakter der neusten Kunst im edeln Sinne mystischreligiöspatriotisch ist, das Kunstbestreben im Anfang des verflossenen Jahrhunderts aber >modischgriechelndfranzösirend oberflächlich genannt werden kann, so erheischt auch diese Verschiedenheit eine Verbesserung der Kunstschulen. $\ll^{62}$

Diese Differenz der Kunstanschauung bezog sich auf die Antike. Während sie für den Weimarer zentrales Vorbild und Höhepunkt war, war sie für Quandt ein Aspekt der Geschichte der Kunst und der Menschheit. Im Rückblick auf seine Bekanntschaft mit Goethe präzisierte der Dresdener Kunstfreund:»Wie Goethe, der seinen Sinn an dem in sich abgeschlossenen und wesentlich plastischen Charakter der Antike gebildet und an den Anblick von Werken einer zur Meisterschaft gereiften Kunstperiode gewöhnt hatte, über die Richtung der wiedererwachenden deutschen Kunst und junge Künstler, aus deren anfänglichen Leistungen man allerdings nicht ahnen konnte, zu welchen Blüthen die Knospen sich entfalten würden, dachte, ist hinreichend bekannt, und in Ekkermann's Gesprächen kommen Aeußerungen vor, welche, wie mir scheint, sich auf unsern Kunstverein beziehen. «33 Welche Passagen dies waren, soll hier nicht näher untersucht werden. Die Korrespondenz zwischen Quandt und Goethe zeigt die Differenzen auf, wie das Beispiel von Carl Gottlieb Peschels Tobias' Abschied gezeigt hat. Trotz Goethes Vorbehalten war es dieser Künstler, der den ersten, offiziellen Auftrag des Sächsischen Kunstvereins erhielt. ${ }^{64}$

re Erkenntnis gegründete Hochachtung zu entziehen. Ein gleiches gilt für die Religiosität, die [...] ihn [den Deutschen - AR] zur schlimmsten Zeit aufrecht erhalten [...]. [Möge] dagegen aber alle falsche Frömmelei aus Poesie, Prosa, und Leben bald möglichst verschwinden und kräftigen heiteren Aussichten Raum geben. MA 1994, Bd. 11.2, S. 341. S. a. Grave 2001, S. 87.

63 Quandt 2001 [1870], S. 238-239. Die Gespräche mit Eckermann, in: MA 1986, Bd. 19. S. a. Schmitz/Strobel 2001, S. XXXVII. Quandt lehnte das Antikenideal deutlich ab: Quandt 1819, Bd. 1, S. 69, 73.

64 Es handelt sich um das Gemälde Joseph wird von seinen Brüdern verkauft, heute in Würzburg, Martin von Wagner Museum. Es war eine von drei Einsendungen. Jahresbericht des Sächsischen Kunstvereins für das Jahr 1830, in: HStADD, 12509 Sächsischer Kunstverein, Nr. 2, fol. 73V (S. 4). In einem Brief an Goethe vom 4.2.1831 beschrieb es Quandt: »Der Maler, so scheint mir, hat glücklich ein neues Motiv aufgefunden, welches uns mit dieser Scene versöhnt u ihr etwas das Gemüth rührend u tröstlich Ansprechendes verleiht. Der Kaufmann welcher Joseph von dessen feindlichen Brüdern einhandelt, scheint dies mehr aus Mitleid gegen den Knaben als aus Gewinnsucht zu thun. Der Künstler hat dies auf eine würdige u einfache Weise ausgedrückt, indem der Kaufmann das Kind bey der Hand faßt, die Brüder des Josephs ernst anblickt u ihnen mit der andern Hand Gold darreicht. «Schmitz/Strobel 2001, S. 116. Goethes Antwort blieb aus. S. a. Kovalevski 2010, S. 146, Kat. Nr. B-C 69; Köhler 2002, S. 23-24; Köhler 1994, S. 11; Briel 1987a, S. 23. 


\section{Unterschiedliche Vorstellungen von Kunst in Dresden und Weimar}

Dass nicht nur Goethe mit den Dresdener Entscheidungen unzufrieden war, sondern auch Quandt durchaus eine andere Meinung hatte als der Weimarer, zeigt sich in einer kleinen Affäre um einen Auftrag an die Weimarer Malerin Louise Seidler im Jahr 1831. Der Sächsische Kunstverein ermöglichte es ihr, den eingereichten Karton Malerei und Dichtkunst als Gemälde auszuführen, das als Kupferstich überliefert ist (Abb.34). Goethe hatte das Motiv seiner seit Jahren protegierten Malerin angeregt und empfahl es zum Ankauf für den Verein. ${ }^{65}$ Der Dichter hatte sich bei seinem Beitritt in den Sächsischen Kunstverein versichern lassen, dass Künstler des Großherzogtums Sachsen-Weimar-Eisenach Arbeiten einreichen und die Aktionäre an den Verlosungen teilnehmen konnten. ${ }^{66}$ Der Auftrag an die Weimarer Künstlerin ist daher als Entgegenkommen seitens des Kunstvereins anzusehen, obschon er gegen die Statuten war. Eigentlich waren in diesem Jahr keine Überschüsse für Aufträge vorhanden. ${ }^{67}$

Das Resultat führte zu erneut intensiviertem Dialog zwischen Goethe und Quandt. Das ausgeführte Gemälde von Louise Seidler wurde vom Komitee des Kunstvereins zuerst abgelehnt, weil es Fehler in der Anatomie der Figuren aufwies. Quandt beschrieb Goethe in der Folge sein Dilemma: »Dies setzt mich in die höchste Verlegenheit, denn einerseits fühle ich den schönen Sinn in diesem Bilde, will der Künstlerin wohl und wünsche durch den Ankauf eines größern Werks als bisher, den Beschützern und Freunden der Kunst in Weimar einen Beweis unsrer dankbaren Gesinnungen zu geben und andrerseits erkenne ich die Fehler der Zeichnung, halte es für meine Pflicht, daß ich mich nicht in meinem Urtheile durch persönli-

65 Brief von Goethe an Quandt vom 6.5.1831, in: Schmitz/Strobel 2001, S. 125: »Zugleich empfehle ein von Fräulein Seidler nachzusendendes Bild, worauf die Künstlerin viel Fleiß u ihr ganzes Talent aufgewendet hat. « Brief von Seidler an Quandt vom 19.5.1831, in: Schmitz/Strobel 2001, S. 179. Siehe Kovalevski 2010, S. 136, B-C 64b; zu Goethes Förderung Louise Seidlers siehe Kovalevski 1999, S. 45-47.

66 Beilage zum Brief von Goethe und Quandt vom 9.11.1828, in: Schmitz/ Strobel 2001, S. 39. Offizielle Bestätigungen des Sächsischen Kunstvereins: ebd., S. 210-211.

67 Jahresbericht des Sächsischen Kunstvereins für das Jahr 1830, in: HStADD, 12509 Sächsischer Kunstverein, Nr. 2, fol. 74V (S. 6).

68 Brief von Quandt an Goethe vom 19.7.1831, in: Schmitz/Strobel 2001, S. 128-129: »Besonders scheint die schwebende Figur auffallend verzeichnet. [...] [S]o wollen die Arme sich nicht an die Schultern, die Beine nicht an den Leib fügen.«

69 Brief von Goethe an Quandt vom 23.7.1831: »Da man gedachter ihrer Arbeit unverkennbare Vorzüge einräumt und die Künstlerin selbst aufforde[rt] gewisse darin vorkommende Unrichtigkeiten zu verbesse[rn] so kann ich ihrem Wunsch nach Dresden zu gehen meine[n] Beyfall nicht versagen. "Goethe legte seinem Brief Seidlers Antwort vom 22.7.1831 bei. Die Malerin war etwas verzweifelt, da sie che Zuneigung bestimmen lasse und war selbst derjenige, welcher verfloßnes Jahr gegen alle Rücksichten lebhaft stritt und behauptete: nur die Berücksichtigung des entschiednen Verdienstes oder Talents ganz allein und keine Hinsicht auf Gönner und Empfehlungen, sollte den Comite bey der Wahl von Kunstwerken leiten. $\ll^{68}$ Mit der Bitte, Goethe möge ihn unterstützen, schlug er daher vor, die Künstlerin solle in Dresden Korrekturen vornehmen. Der Dichter stimmte zu, ebenso die Malerin. ${ }^{69}$ Quandt organisierte Gutachter in der Kunstakademie. ${ }^{7 \circ}$

In der Folge erhöhte Goethe den Druck, weil er einem guten Ende für seine Malerin nicht zu trauen schien: »Was Sie Liebes und Gutes unserer Künstlerin erzeigen können, wird unserm hiesigen mit dem Ihren verbundenen Verein zu Gut kommen; da man, wie ich nicht verbergen will, hie und da zu wanken anfängt $[\ldots] . \ll^{71}$ Als Seidler anfangs September 1831 bereits für die Korrekturen in Dresden weilte, verwies er auf die rückläufigen Mitgliederzahlen und gab beiläufig zu erkennen, er beabsichtige die Vereinsgeschäfte abzugeben. ${ }^{72}$ Quandt verstand und antwortete, man habe Seidler inzwischen einen Ankaufspreis für ihr korrigiertes Gemälde vorgeschlagen. Lakonisch reagierte er auf die implizite Rücktrittsdrohung: »Nur eine Frage erlauben mir Ew Excellenz noch an Dieselben zu richten: An wen sollen wir uns in Zukunft wenden? Ich zweifle nicht, daß mehrere Freunde der Kunst und der guten Sache bereitwillig seyn würden $[. .$.$] «73 Man hätte von dem glühenden$ Goethe-Verehrer eher Bedauern und Umstimmungsversuche als derartige Dreistigkeit erwartet. Doch hierin zeigt sich Quandts Eigenständigkeit und Abgeklärtheit. Er stellte die Vereinstätigkeit über die persönlichen Präferenzen. Goethes Antwort war ebenfalls kurz: er dankte für das »erwünschte Ende« der Seidler-Angelegenheit, legte die Namen neu beigetretener Weimarer Vereinsmitglieder bei und beschloss die

ihren Karton mehreren Künstlern, darunter dem Berliner Maler Karl Wilhelm Wach, vorgelegt hatte. Diese hätten die von Quandt angesprochenen Fehler nicht gesehen. Daher wünschte sie in Dresden eine Begutachtung durch Künstler. Die beiden Briefe in Schmitz/Strobel 2001, S. 131-132, 182-183. S. a. Kovalevski 2010, S. 11-12.

70 Naeke, Matthäi und Vogel. Brief von Quandt an Goethe vom 3.8.1831, in: Schmitz/Strobel 2001, S. 134.

71 Brief von Goethe an Quandt vom 1.8.1831, in: Schmitz/Strobel 2001, S. 133-134. Noch druckvoller am 13.9.1831: »Erlauben Sie mir zu sagen daß es politisch seyn wird unsern Künstlern etwas zu Gute zu thun«. Ebd., S. 135 .

72 Brief von Goethe an Quandt vom 13.9.1831, in: Schmitz/Strobel 2001, S. 136: »Vorstehendes würde ich nicht aussprechen, die Angelegenheit unsrer guten Seidlerin Ihnen nicht nochmals empfehlen, wenn ich nicht, zu Ende dieses Jahres, diese Angelegenheit, mit mehrern mir obliegenden, in andere Hände zu geben mich genöthigt sähe.« S. a. Kovalevski 2010, S. 136.

73 Brief von Quandt an Goethe vom 19.9.1831, in: Schmitz/Strobel 2001, S. 139. Zum Ankauf siehe auch den Brief von Quandt an Seidler vom 17.9.1831, in: ebd., S. 185-186. 


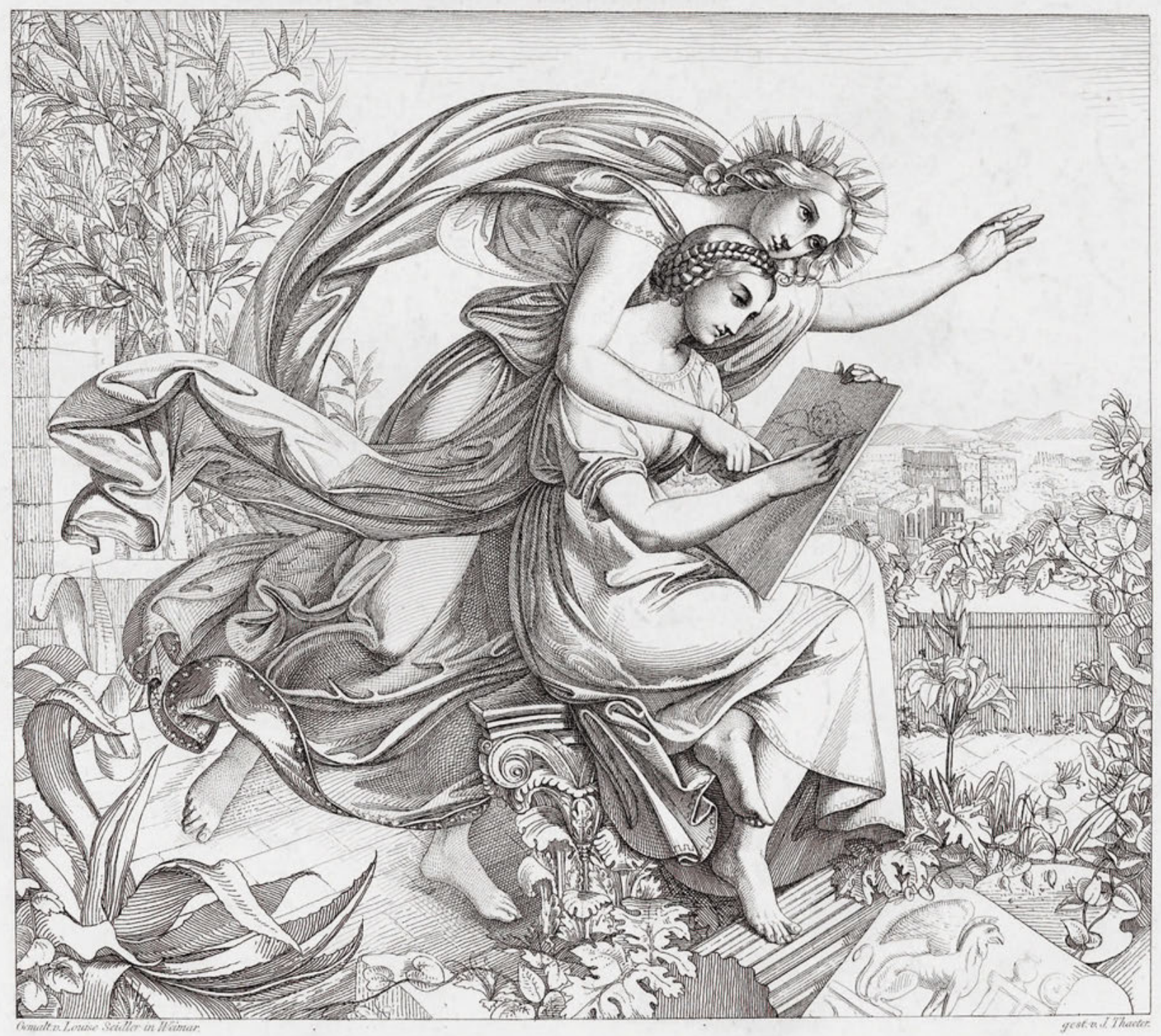

34 Julius Caesar Thaeter nach Louise Seidler, Malerei und Dichtkunst, 1831, Kupferstich, $178 \times 202$ mm (Bild), Frankfurt a/M, H. W. Fichter Kunsthandel

Geschichte, indem er meinte, er wolle sich von Dingen, die ihm wichtig seien, nicht trennen. ${ }^{74}$

Die Affäre um Seidlers Gemälde ist trotz ihrer diplomatischen Lösung ein weiteres Beispiel, das die unterschiedlichen Ansichten der beiden Korrespondenten nachzeichnet. Im offiziellen Jahresbericht auf das Jahr 1831 lobte Quandt zwar kurz das Bild. Immerhin stand Goethe dahinter.75 Mit verhaltener

74 Brief von Goethe an Quandt vom 10.10.1831, in: Schmitz/Strobel 2001, S. 140-141.

75 »Fräulein Seidler hatte eine Idee, die ihr Göthe gegeben, in einem allegorischen Gemälde dargestellt. Die Malerin hatte in die Züge der allegorischen Figuren schon im Entwurfe so viel Anmuth und Schönheit gelegt und den Rath der Künstler unsers Comités bei der Ausführung des Gemäldes so treulich befolgt, daß dieses Bild, wegen
Skepsis formulierte er hingegen seinen persönlichen Brief an den Dichter: »Das Gemälde meiner werthen Freundin, der Seidler, hat viel Anziehendes durch eine zartsinnige Darstellung eines bedeutenden Gedankens. Es mag schwierig seyn, in der Erscheinung selbst, den Unterschied und doch auch die Verwandschaft der bildenden Kunst und der Poesie auszudrücken $\lceil\ldots .$.$] und doch ist es der Künstlerin wohl gelungen. \aleph^{76}$ Man

des Gedankens, des Fleißes und der Darstellung, belohnenswerth geachtet wurde. " Jahresbericht des Sächsischen Kunstvereins von 1831 bis Ostern 1832, in: HStADD, 12509 Sächsischer Kunstverein, Nr. 2, fol. 232 (S. 6); s. a. Kovalevski 2010, S. 126.

76 Brief von Quandt an Goethe vom 19.7.1831, in: Schmitz/Strobel 2001, S. 128-129. 
wird hier den Eindruck nicht los, Quandt habe sich aus vereinspolitischen Gründen auf einen Ankauf eingelassen. Wenn er gegenüber Goethe die Schwierigkeit des Bildgegenstandes betonte und das gute Gelingen hervorhob, drückte er eher sein Wohlwollen gegenüber dem Ideengeber aus, dem die Künstlerin nicht ganz gewachsen war. Ob dessen Idee gut war, muss dennoch angezweifelt werden, auch wenn Quandt dies nie offen formuliert hätte.

Verständlicher wird dies, wenn man sich vor Augen führt, was er mit »Erscheinung« meinte. Dieser Begriff bezieht sich auf sein Diktum, dass Kunst ein Gedanke in anschaulicher Form sei. Das Kunstwerk ist demnach die visuell wahrnehmbare Erscheinung einer guten Idee. Doch diese Idee soll nicht abstrakt umgesetzt werden, sondern sich nach der Natur richten. In den Briefen aus Italien, die ein Jahr vor dem Ankauf des Gemäldes von Louise Seidler erschienen waren, schrieb er: »Allein, da die Kunst kein abstractes, sondern ein concretes Denken ist, ein Denken des Begriffs in einer Erscheinung, so bedarf der Künstler nothwendig der Kenntnis einer Erscheinungswelt, einer positiven Kenntnis [...] Er bedarf ein Reales, was er blos durch Wahrnehmung in Besitz nehmen kann. «77 Hierzu steht Seidlers Allegorie in einem Widerspruch. Sie stellt abstrakte Begriffe dar, die sich nicht in ein »reales« Motiv übersetzen lassen. Während ein Begriff wie die Mutterliebe sich in einer Madonnendarstellung, der Begriff der Weiblichkeit sich in der Venus von $\mathrm{Ca}^{-}$ pua manifestieren könne, so sei das Verhältnis von Dichtkunst und Malerei eben schwierig zur »Erscheinung « zu bringen. ${ }^{78}$

Louise Seidler schrieb an Quandt, Goethe habe ihr vorgeschlagen, das Flüchtige und Bleibende der beiden allegorischen Figuren auszudrücken..$^{79}$ Die Poesie ist demnach in ihrem aufwallenden Gestus als die Flüchtige, die ruhige Zeichnerin als die Bleibende zu interpretieren. Dieser Aussage liegt Gotthold Ephraim Lessings erfolgreiches Buch Laokoon: oder über die Grenzen der Mahlerey und Poesie von 1766 zugrunde. Lessing beabsichtigte mit der Schrift Malerei und Poesie voneinander abzugrenzen. Der Unterschied der beiden Künste liege in der unterschiedlichen Darstellung von Zuständen und Handlungen. Zustände müsse die Poesie durch ihre Abhängigkeit von der fortschreitenden Zeit nacheinander beschreiben. Umgekehrt könne die Malerei Handlungen nur in einem bestimmten Moment vermitteln..$^{80}$ Dieser »fruchtbarste Augenblick « sei unmittelbar vor dem Höhepunkt einer Handlung. Damit würde die Phantasie des Betrachters angeregt, sich die Fortsetzung selber vorzustellen. ${ }^{81}$

Quandt war mit dieser Argumentation nur bedingt einverstanden. Er befürwortete zwar die Unterscheidung der Möglichkeiten und Grenzen der beiden Künste und die Forderung nach der Darstellung des richtigen Moments in der Malerei. Doch dass dieser Moment ein unentschiedener Zustand sei, glaubte er nicht. ${ }^{82}$ Genau dies hatte Goethe in seinem Artikel Ueber Laokoon in den Propyläen von 1798 als wichtigen Leitsatz für die Malerei aufgestellt: »Der höchste pathetische Ausdruck, den [die bildende Kunst] darstellen kann, schwebt auf dem Uebergange eines Zustandes in den andern. $\kappa^{83}$ Das wiederum ist in Seidlers Bild als Allegorie dargestellt. Die Poesie weist in einem Akt der Bewegung die sitzende Malerei auf den rechten Moment hin, den es darzustellen gilt. Die Malerei soll das Flüchtige festhalten und zum Bleibenden erklären. Seidlers Allegorie nach Goethes Idee ließe sich im Einzelnen nach diesem Prinzip durchdeklinieren. Doch Quandt ging es um Grundlegenderes.

In den Briefen aus Italien hatte er bereits eine Kritik der Allegorie formuliert. Diese zeige nicht eine Idee im Kunstwerk, sondern deute nur darauf hin. Idee und Erscheinung bildeten keine Einheit und daher seien Allegorien keine echten Kunstwerke. Der Kunstschriftsteller sagte dies zwar nicht explizit in Bezug auf Seidlers Allegorie der Poesie und der Malerei, aber er schrieb es doch ziemlich deutlich: »Nun sollen wir aber durch eine Darstellung nicht blos auf eine Idee schließen, sondern sie selbst darin anschauen; und deshalb sind Allegorien keine reinen Kunstdarstellungen, sondern gewöhnliche Nothbehelfe der Künstler, wenn sie unvermögend waren, die Idee in einem Bilde zu vergegenwärtigen. $\aleph^{84}$ Interessanterweise richtete sich
77 Quandt 1830 (1), S. 298-299.

78 Zur Venus von Capua, heute im Museo Archeologico Nazionale Napoli, siehe Quandt 1830 (1), S. 74: »Meine Vernunft erkannte im Bilde, was sie von dem Begriff der Weiblichkeit forderte, und doch war es kein abstracter Begriff, sondern ein Concretes, ein mit der Erscheinung ganz verwachsenes Eins geworden."

79 Brief von Seidler an Quandt vom 19.5.1831, in: Schmitz/Strobel 2001, S. 179.

80 Lessing 1766, S. 150-189, hier S. 153-154: »Gegenstände, die neben einander oder deren Theile neben einander existiren, heissen Körper. Folglich sind Körper mit ihren sichtbaren Eigenschaften, die eigentlichen Gegenstände der Mahlerey. Gegenstände, die auf einander, oder deren Theile auf einander folgen, heissen überhaupt Handlungen. Folglich sind Handlungen der eigentliche Gegenstand der Poesie. Doch alle Körper existiren nicht allein in dem Raume, sondern auch in der Zeit. [...] Folglich kann die Mahlerey auch Handlungen nachahmen, aber nur andeutungsweise durch Körper [...], schildert die Poesie auch Körper, aber nur andeutungsweise durch Handlungen."

81 Lessing 1766, S. 23-28, hier S. 24: "So ist gewiß, daß jener einzige Augenblick [...] nicht fruchtbar genug gewählet werden kann. Dasjenige aber nur allein ist fruchtbar, was der Einbildungskraft freies Spiel läßt [...]. In dem ganzen Verfolge eines Affects ist aber kein Augenblick, der diesen Vortheil weniger hat, als die höchste Staffel desselben.»

82 Quandt 1844 (1), S. 91-94, hier S. 93: „Das Wahre ist, daß der Moment nicht fruchtbar genug gewählt werden kann, daß Irrige aber, daß der unentschiedene Zustand der fruchtbarste Moment sey, den der Künstler wählen könne.« S. a. Quandt 1830 (1), S.73-82.

83 Goethe 1798, S. 7-14, hier S. 12.

84 Quandt 1830 (1), S. 311-312: »Auch sucht die Allegorie durch Ideenas sociation sich zu helfen und ist blos hindeutend. So z. B. ist eine be- 
schon Lessings Schrift gegen die »Allegoristerei« in der bildenden Kunst. ${ }^{85}$ Noch erstaunlicher ist, dass Quandt in seiner Kritik an der Allegorie auf eine Unterscheidung Goethes zurückgreift. Der Weimarer hielt fest, dass ein Symbol fruchtbar für die Kunst sei, weil es das Ganze im Einzelnen zeige, wohingegen die Allegorie immer nur ein Beispiel eines Ganzen, und daher der Kunst unwürdig sei. ${ }^{86}$ Umso bemerkenswerter erscheint dann Goethes Anregung zu einer Allegorie.

Quandts Vorstellungen von förderungswürdiger Kunst entsprach Seidlers Gemälde kaum. In seiner Ansprache zur Generalversammlung im Dezember 1831 erwähnte er es nicht und im Jahresbericht auf das Jahr 1831 behandelte er es nur knapp, obschon es der offizielle Auftrag des Kunstvereins war. Deutlich mehr schrieb er dagegen über die neuen Historien von Carl Gottlieb Peschel und August Richter. ${ }^{87}$ Dadurch wird augenscheinlich, dass Quandt mit der Allegorie Seidlers nicht glücklich war.

So wie Goethe mit Peschels Tobias-Motiv wenig anfangen konnte, so fern lag es Quandt, Seidlers Bild zu rühmen. Die Werke dieser beiden Künstler wurden dabei Schauplätze der unterschiedlichen Ansichten ihrer Förderer. ${ }^{88}$ Die beiden Bilder dienten der impliziten Kritik des jeweils anderen. Goethe und Quandt sprachen dies natürlich nie offen aus, sondern wussten ihre Meinungen in geschickter Sprache und Diplomatie zu verklausulieren. Dennoch ist die Förderung der Künste der größte gemeinsame Nenner. Ihr unterstellten sie beide auch ihre Ungereimtheiten. Damit ist wohl auch die andauernde Korrespondenz zwischen Quandt und Goethe bis zum Tod des Dichters im März 1832 zu erklären.

\section{Neue Fördermaßnahmen}

Diese Förderung nach seiner ganz eigenen Überzeugung beschäftigte Quandt als Vorstand des Sächsischen Kunstvereins nach Goethes Tod weiter: »Da unsere Künstler nicht so geist-

kannte Allegorie auf den Frieden eine Taube, welche in einem Helme nistet [...]. Allerdings muß Friede im Lande seyn, wenn eine Taube Zeit hatte, ihr Nestchen in einem Helme zu bauen [...]. Aber dies sind nicht Darstellungen des Friedens selbst, sondern Handlungen, welche auf Frieden schließen lassen."

85 Lessing 1766, Vorrede, [s. p.]: »Völlig aber, als ob sich gar keine solche Verschiedenheit fände, haben viele der neuesten Kunstrichten aus jener Uebereinstimmung der Mahlerey und Poesie die crudesten Dinge von der Welt geschlossen. [...] Sie hat in der Poesie die Schilderungssucht, und in der Mahlerey die Allegoristerey erzeuget; indem man jene zu einem redenden Gemählde machen wollen, ohne eigentlich zu wissen, was sie mahlen könne und solle, und diese zu einem stummen Gedichte, ohne überlegt zu haben, in welchem Maasse sie allgemeine Begriffe ausdrücken könne, ohne sich von ihrer Bestimmung zu entfernen, und zu einer willkührlichen Schriftart zu werden.« Zu Lessings Kritik siehe ÄGB 2010, Bd. 1, S. 652-653. S. a. Scholl 2007, S. 233-239, 248. reich u thätig sind, wie ich hoffte, so können Preisaufgaben als Anregungsmittel für solche, welche ohne äußern Antrieb nichts hervorbringen würden, von einigem Erfolg seyn u ich habe daher selbst Preisaufgaben in Vorschlag gebracht, vorausgesetzt, daß zugleich auch Aufforderungen an Künstler ergehen, welche sie zur Ausführung selbst gewählter Gegenstände ermuthigen, wodurch dann auch erfindsameren Künstlern eine freÿe Geistesthätigkeit vergönnt wird. ${ }^{89}$ Die unterschiedlichen Vorstellungen über die Kunstankäufe, die fehlenden Historien und eine gewisse Enttäuschung über seine ins Leere laufenden Fördermaßnahmen führten Quandt 1832 doch noch einmal auf die Preisaufgaben zurück. Er, der noch drei Jahre davor vehement gegen Böttigers Vorstöße angekämpft hatte, griff nun selber das Thema auf. Ein ausführliches Manuskript von Anfang 1832 in den Kunstvereinsakten des Sächsischen Hauptstaatsarchives verdeutlicht dabei die Bedingungen und Begründungen, die er sich zurechtgelegt hatte. Die Preisaufgaben sollten den Fleißfördern und dazu anregen, sich mit komplexen Bildgegenständen zu beschäftigen. Die gestellten Themen sollten klar formuliert und bildlich umsetzbar sein, da sich Künstler allzu oft nicht darstellbare Gegenstände zur Aufgabe machen würden. Schließlich sollten die Maler gezwungen sein, menschliche Figuren in mannigfaltigen Bewegungen zu zeigen, damit sie ihre anatomischen Kenntnisse verbessern könnten. Gerade dies war ihm sehr wichtig, »weil sie allein dem Künstler eine freÿe Thätigkeit verleiht und seine Sphäre erweitert, so daß er darstellen kann was er will, nicht blos will, was er, nach seiner beschränkten Fähigkeit, kann. $\ll^{90}$ Es ging ihm also nicht einfach um einen technischen Aspekt der Kunst, sondern darum, dass die Figurenmalerei den Maler überhaupt erst zum freien Künstler mache. Von den Aufgabenstellern im Vereinskomitee erwartete er eine anregende Aufgabe, die den Geist beschäftige und das Auge erfreue und die nicht spitzfindig, sondern leicht lösbar sei.

In der Folge unterbreiteten die Komiteemitglieder Themenvorschläge für eine Preisaufgabe: Außer Carl Gustav Carus,

86 Dazu Grewe 2015, S. 134-136.

87 Manuskript von Quandts Rede zur Generalversammlung vom 19.12.1831, in: HStADD, 12509 Sächsischer Kunstverein, Nr. 2, fol. 152r153V. Jahresbericht des Sächsischen Kunstvereins von 1831 bis Ostern 1832, in: HStADD, 12509 Sächsischer Kunstverein, Nr. 2, fol. 232r-v (S. 5-6). S. a. Kovalevski 2010, S. 136, Kat. Nr. B-C 64b. August Richter, Rebekka am Brunnen und Carl Gottlieb Peschel, Joseph wird von seinen Brüdern verkauft, in: ebd., S. 132, 146, Kat. Nr. B-C 63, 69.

88 Zu Seidler siehe Kovalevski 2006, S. 259-264; Schmitz/Strobel 2001, S. 219-220; Kovalevski 1999, S. 45-47.

89 Undatiertes Manuskript von Quandt, in: HstADD, 12509 Sächsischer Kunstverein, Nr. 2, fol. 18or.

90 Undatiertes Manuskript von Quandt, Jan. 1832, in: HstADD, 12509 Sächsischer Kunstverein, Nr. 2, fol. 180v-181r. 
der Szenen aus einer Schlacht zwischen römischen Legionen und den germanischen Truppen unter Arminius nach dem Historiographen Tacitus zur Diskussion stellte, schlugen allesamt Themen aus der griechischen Antike, hauptsächlich aus Homers Ilias und Odyssee, vor.91 Dies ist vor dem Hintergrund von Quandts skeptischer Haltung gegenüber Goethes Griechenland-Affinität erstaunlich. Man schien auf dieselben Mittel zurückzugreifen, wie die Weimarischen Kunstfreunde in ihren Preisaufgaben um die Jahrhundertwende. Selbst Böttiger, der noch drei Jahre zuvor ganz allgemeine Themen wie »Mutterliebe« oder »Abschied« vorgeschlagen hatte, wich nun auf die antike Mythologie aus. ${ }^{92}$ Zwar wird in Quandts Begründung seiner eigenen Vorschläge deutlich, warum er Szenen aus der Ilias und der Odyssee wählte. Er argumentierte mit Lessing, der in einem der Briefe antiquarischen Inhalts geschrieben hatte, Künstler sollten nicht Gemälde nach Homer malen, sondern homerische Gemälde. ${ }^{93}$ Damit meinte Quandt, es seien nicht gelehrte und archäologische Bilder gefordert, sondern Bilder »in homerischem Geist«, also mit Frische und Wahrheit gemalt. Das Interessante an Historiengemälden sei nicht die »genaue Darstellung wirklicher Begebenheiten «, sondern Phantasie und tiefer liegende Sinnzusammenhänge. ${ }^{94}$

Freilich hatte dieses Argument wenig mit Lessing zu tun. Der schrieb nämlich im Laokoon, auf den sich die von Quandt zitierte Passage der Briefe antiquarischen Inhalts bezieht: »Ich finde, Homer mahlet nichts als fortschreitende Handlungen [...]. Was Wunder also, daß der Mahler, da wo Homer mahlet, wenig oder nichts für sich zu thun siehet, und daß seine Erndte nur da ist, wo die Geschichte eine Menge schöner Kör- per, in schönen Stellungen, in einem der Kunst vortheilhaften Raume zusammenbringt, der Dichter selbst mag diese Körper, diese Stellungen, diesem Raum so wenig mahlen, als er will? «95 In der Abgrenzung von Poesie und Malerei wollte Lessing verdeutlichen, dass Homer gewisse Handlungen ausführlich behandeln konnte, während er Ansammlungen von Menschen nicht genauer beschrieb. Da jedoch die Malerei, wie sein Hauptargument lautete, der Zeitlichkeit unterworfene Handlungen nicht wirklich verdeutlichen konnte, musste sie auf andere Bildgegenstände ausweichen. Dies waren eben »schöne Körper in schönen Stellungen $\ll{ }^{96}$ Dieser mit Ironie formulierte Abschnitt, in dem der Dichter und Literat Lessing die bildenden Künste in ihre Schranken weisen wollte, formuliert genau das, was Quandt mit den Preisaufgaben ernsthaft befördern wollte: die Darstellung des menschlichen Körpers anhand einer dem Dichter ähnlichen, aber eben eigenständigen Kunst.

In den Diskussionen der Vorschläge im Komitee wurde vor allem abgewogen, inwieweit die Preisaufgaben eine vielfältige Figurenzeichnung fördern und das Gemüt ansprechen würden, wie Quandt zusammenfasste. Die Aufgabe von Carus nach dem römischen Historiographen Tacitus wurde als zu »geschichtlich« empfunden. ${ }^{97}$ Die Künstler sollten nicht archäologische, sondern anatomische Studien betreiben. Eines von Quandts eigenen Themen wurde verworfen, weil es zu akademischer, also lehrbuchmäßiger, Aktzeichnung veranlassen würde und der letzten, sehr kontrovers diskutierten Weimarer Preisaufgabe rund dreißig Jahre zuvor zu nahe sei.98 Schließlich entschied man sich für den Vorschlag von Carl August Böttiger. Er lautete:»Hermes übergibt den neugeborenen Bachus (sic!) den
91 Alle Vorschläge der Komiteemitglieder, in: HStADD, 12509 Sächsischer Kunstverein, Nr. 2, fol. 183r-189r sowie in Quandts Zusammenfassung der Diskussion vom 12.1.1832, in: ebd., fol. 199v.

92 Böttiger in: Quandt 1829 (1), S. 30. Sein Vorschlag in: HStADD, 12509 Sächsischer Kunstverein, Nr. 2, fol. 187r.

93 Quandt bezieht sich hier auf Lessing 1808, S. 13: »Hingegen die Gemälde, welche Caylus vorschlägt, sind mehr Gemälde zum Homer, als Homerische Gemälde, als Gemälde in dem Geiste des Homers und so angegeben, wie sie Homer selbst würde ausgeführt haben, wenn er, anstatt mit Worten, mit dem Pinsel gemalt hätte.« Lessings Text ist eine Reaktion auf eine Kritik an seinem Laokoon. Lessing kritisiert dort die Forderungen des französischen Kunstgelehrten Anne-Claude Philippe Comte de Caylus, der Homer aus der Sicht eines Malers lese und zahlreiche Passagen vorschlage, die exakt so gemalt werden könnten. Siehe Lessing 1766, S. 224-226: »Handlungen aber aus dem Homer zu mahlen, blos weil sie eine reiche Composition, vorzügliche Contraste, künstliche Beleuchtungen darbieten, schien der alten Alten ihr Geschmack nicht zu seyn [...].«

94 »Es dürfte hier wohl auch nicht überflüßig seÿn, daran zu erinnern, was der scharfsinnige Lessing verlangt, daß die Künstler wohl homerische Gegenstände wählen, aber nicht, wie Caÿlus vorschlägt, Gemälde zum Homer, malen sollen (Lessings Schriften Berlin: 1808. Thl: II. S. 13). Es werden also hiermit nicht archäologische, nicht gelehrte Bilder verlangt, sondern solche, welche in homerischem Geist gedacht sind, mit der ganzen Frische u Wahrheit alter Kunst, denn es sind ja nicht geschichtliche Bilder, welche eine genaue Darstellung wirklicher Begebenheiten, wo also die Phantasie durch gegebene Umstände beschränkt ist, seÿn solle.« Undatiertes Manuskript von Quandt, Jan. 1832, in: HstADD, 12509 Sächsischer Kunstverein, Nr. 2, fol. 182 r.

95 Lessing 1766 , S. $155-156$.

96 Zu dieser Kernthese des Laokoons siehe Lessing 1766, S. 150-189. S. a. ÄGB 2010, Bd. 1, S. 655-656.

97 Johann Gottlob von Quandt, Manuskript »Warum Kunstfreunde Preisaufgaben ertheilen sollen« vom 12.1.1832, in: HStADD, 12509 Sächsischer Kunstverein, Nr. 2, fol. 199v: »Hinsichtlich der Aufgabe 1 [Varusschlacht-Thema von Carus], wurde erinnert, daß dieser Gegenstand, gewandete Figuren erfordern, welche den Künstler mehr zu archäologischen Forschungen über Bekleidung u Gewandung der Römer u Deutschen u geschichtliche Genauigkeit als zum Studium des Menschenkörpers veranlassen würde."

98 Ebd., fol. 200r-v. Quandt schlug Achills Verfolgung der Troer in den Fluss Skamandros aus der Ilias vor. Der Bezug auf die Weimarer Preisaufgaben war aber ungenau: Die letzte Preisaufgabe von 1805 war Herkules' Taten gewidmet. Das Thema »Achills Kampf mit den Flüssen« wurde in der dritten Preisaufgabe von 1801 gestellt. Eine Kontroverse der Gelehrten brach hingegen 1802 bei der vierten Ausgabe zum Thema »Perseus befreit Andromeda« aus. Klauss 2001, S. 190-191, 198. 
Nymphen auf dem Berge Nysa.« Die gestellte Aufgabe, so die Experten des Kunstvereins, verlange kenntnisreiche Zeichner, stimme den Betrachter positiv, weil Anmut und Freude zum Ausdruck komme, ein Mann, Frauen und ein Kind darstellbar seien und weil die Aufgabe für die Maler leicht zu fassen sei.99

Anfang Februar erfolgte die Ausschreibung. Sie verlangte von den Künstlern einen Karton mit großen Figuren in mindestens Zweidritteln der Lebensgröße sowie eine Farbenskizze. Zudem wurde eingeschränkt, dass keine Gespräche zwischen den Figuren dargestellt werden dürften. ${ }^{100}$ Auf die Ausschreibung gingen weniger als drei Entwürfe ein, so dass die Preisvergabe erst gar nicht stattfand.

Glücklicherweise hatte man noch eine weitere Preisaufgabe mit freier Themenwahl ausgeschrieben. Hier konnte tatsächlich ein Auftrag vergeben werden, der allerdings schon vor der offiziellen Preisausschreibung im Komitee diskutiert worden war. Es handelte sich um die neutestamentliche Geschichte Die Speisung der Fünftausend des Dessauer Malers Franz August Schubert. Das ausgeführte Gemälde wurde nach Quandts Austritt als Vorstand 1833 durch den Verein angekauft. ${ }^{101}$ Chancenlos blieb hingegen Louise Seidlers Entwurf einer Darstellung von Hagar und Ismael in der Wüste, denen ein Engel mit Proviant erscheint. ${ }^{102}$ Trotz hehrer Ziele musste der Versuch mit Preisaufgaben im Sächsischen Kunstverein als gescheitert angesehen werden. Mögliche Gründe scheinen in der Themenwahl zu liegen.

99 Johann Gottlob von Quandt, Manuskript »Warum Kunstfreunde Preisaufgaben ertheilen sollen« vom 12.1.1832, in: HStADD, 12509 Sächsischer Kunstverein, Nr. 2, fol. 20ov: »Erstens weil sie zu mannigfaltigen Gestalten Veranlassung gäben und also geübte $u$ kenntnißreiche Zeichner verlangen. Zweÿtens, weil beide das Gemüth ansprechen u zwar [...] durch die anmuthige u natürliche Freude der Nÿmphen, über das ihrer Pflege anvertraute Kind [...]. Drittens, fand man diese beiden Aufgaben, als leicht faßlich u darstellbar, folglich empfehlenswerth." S. a. Briel 1987b, S. 25

100 Ausschreibung der Preisaufgabe des Sächsischen Kunstvereins am 6.2.1832, in: HStADD, 12509 Sächsischer Kunstverein, Nr. 2, fol. 216v. Zur Begründung der Einschränkung: »(...) weil oft Künstler durch den Gehalt der Gedanken in einer Rede zu dem Fehlgriffe verleitet werden, Sprechende darzustellen, und den Inhalt eines Gesprächs zur sichtlichen Wahrnehmung zu bringen glauben, welcher bildlich undarstellbar ist; denn nur was sichtlich deutbar, kann bildlich darstellbar seyn. Im Bilde aber sieht man sprechen, allein man hört die Worte nicht."

101 Franz August Schubert, Die Speisung der Fünftausend, 1833, Lwd., $149 \times 216 \mathrm{~cm}$, Berlin, Gronert Kunsthandel siehe https://gronert-kunsthandel.berlin/katalog/gemaelde/die-speisung-der-fuenftausenddurch-christus-franz-august-schubert-1833 (letzter Zugriff: 5.6.2018). Schubert hatte seinen Entwurf schon vor der Veröffentlichung der Preisaufgabe an den Kunstverein geschickt. Quandt erklärte ihm daher, er solle inn zum Wettbewerb einreichen. Dabei brachte er zahlreiche Korrekturvorschläge an. Brief von Quandt an Schubert vom 3.1.1832, in: HStADD, 12509 Sächsischer Kunstverein, Nr. 2, fol. 196r-197v. Auch nach dem Auftrag wurden zahlreiche Anpassungen gewünscht. Brief von Quandt an Schubert vom 14.1.1833, in: ebd., Nr. 3, fol. $7 r-8 v$. Da der Maler 1834 für einen Romaufenthalt abreiste, schien er das Gemälde relativ schnell vollendet zu haben. Der Verein
Historische oder mythologische Aufgaben

Dass zum gestellten Thema »Hermes übergibt den neugeborenen Bachus den Nymphen auf dem Berge Nysa zu wenige Eingaben gemacht wurden, erstaunt kaum. Es entstammte der Bibliotheke des Apollodorus. Zwar ist diese Überlieferung eine wichtige Quelle zur griechischen Mythologie, die 1828 in einer neuen deutschen Übersetzung erschienen war. Doch ist kaum davon auszugehen, dass sie einer breiten Künstlerschaft bekannt war, zumal die Ausschreibung nicht näher definierte, woher sie stammte. Darüber hinaus waren die bekannten $\mathrm{Ge}$ schichten aus der Bacchus-Mythologie diejenigen, in denen es um den Indieneroberer, um den Befreier und Bräutigam von Ariadne ging und nicht um dessen Adoption als Kleinkind. ${ }^{103}$

Der eigenwillige Gegenstand war vom Antikenspezialisten Böttiger eingebracht worden. Er hatte schon früher über den Ariadne-Mythos in der antiken Kunst gearbeitet, aus dem die Geschichte der gestellten Preisaufgabe stammte und kannte Darstellungen auf antiken Denkmälern. ${ }^{104}$ Seine Idee ging womöglich auf eine eigene, sehr gelehrte Auslegung eines römischen Sarkophagreliefs mit der Vermählung von Bacchus und Ariadne zurück, die er 1801 im ersten Heft seines Archäologischen Museums publiziert hatte. ${ }^{105}$ Doch gerade diese Gelehrtheit steht in großem Widerspruch zum Anliegen des Kunstvereins, die Maler durch klar formulierte Preisaufgaben zu

verlangte in der Folge erneut Anpassungen und wollte das Preisgeld reduzieren, wogegen Schubert erfolgreich opponierte. Kovalevski 2010 S. 278 , Kat. Nr. B-C 135b.

102 Brief von Quandt an Friedrich von Müller vom 11.1.1833: „Der Carton unsrer Freundin Louise Seidler, ist glücklich hier angekommen. Sie verlangte mein aufrichtiges Urtheil u ich glaubte ihr nicht vorenthalten zu dürfen, daß es mir scheint; als wenn sie sich in den Charakter und die Lage Hagars nicht denken konnte. In einem Augenblicke wo die Lebensrettung eines geliebten Kindes entschieden wird [...], ergreift das geängstete, natürliche, Weib, gewiß mit ungestümer Hast, das Rettungsmittel. In diesem Bilde aber, greift Hagar, nach der Schale die der Engel darreicht, mit so viel Anstand, wie eine Dame, die eine Tasse empfängt, die ihr jemand aus der Gesellschaft am Teetisch darreicht. Hagar ist schön, sogar sehr schön, aber keine leidenschaftliche Hagar u keine Dulderinn [...], wie überhaupt mehr der Verstand, als Phantasie u Gefühl, an diesem Bilde Theil hat.«Schmitz/Strobel 2001, S. 226.

103 Apollodor 2005, Buch III, 29. Die entsprechende Passage in der Übersetzung von Christian Gottlob Moser, Apollodor's Mythologische Bibliothek, Stuttgart: Metzler, 1828, III.4.3, S. 139: »Den Dionysus verwandelte Zeus in einen jungen Ziegenbock und entzog ihn auf diese Art der Rachsucht der Here. Hermes nahm ihn und brachte ihn zu Nymphen, welche zu Nysa in Asien wohnten [...].« Die Stelle auch bei Ovid, Metamorphosen, Buch III, 310-315, was aber nicht die direkte Quelle sein kann, da Zeus das Kind hier den Nymphen direkt übergibt und nicht der Götterbote Hermes.

104 Böttiger 1801, S. 97, Anm. 19.

105 Böttiger 1801, S. 75-89. Ebd., S. 83-84 schildert er die Adoption des Bacchus. Der Sarkophag stammt aus der Caracalla-Zeit, zu Böttigers Zeit in Rom, Villa Casali, heute in Kopenhagen, Glyptothek Ny 
Historiengemälden anzuregen. Böttiger selber hatte beabsichtigt, mit der Publikation des Archäologischen Museum einem gemeinen Publikum und Kunstschülern eben gerade nicht seltene, sondern bekannte Mythen in antiken Kunstwerken vorzustellen. ${ }^{106}$ Auch war ihm aufgrund seiner Erfahrungen mit den Weimarer Preisaufgaben bewusst, dass eingeschränkte Gegenstände kaum Erfolg haben würden: »Vielleicht waren selbst die doch sehr klug erwogenen Wahlen aus Homer's Heroenwelt bei den in den Jahren 1799-1801(sic!) von den Weimar'schen Kunstfreunden bestimmten Aufgaben [...] noch zu eng begrenzt und vielleicht bewirkte auch dieser Umstand (..) das damals allgemein beklagte Aufhören jener Aufgaben. $\ll^{107}$ Dass sich auch der grundsätzlich skeptische Quandt hatte überzeugen lassen, ja selbst zwei homerische Themen zur Auswahl gebracht hatte, ist erstaunlich. Man schien sich, um nichts zu riskieren, zu stark auf die akademische Forderung nach guter Figurenmalerei eingeschränkt und dabei den fehlenden Gegenwartsbezug des Themas übersehen zu haben. Das mythologische Motiv konnte kaum künstlerisches Interesse hervorrufen und scheint vielmehr den theoretischen Diskussionen zu entstammen, dievon Quandt protokollarisch festgehalten - in den Akten des Vereins überliefert sind. ${ }^{108}$

Natürlich war es dem Vereinsvorstand ein Anliegen, dass sich die Künstler an neue und unbekannte Themen wagten. Doch in dieser Hinsicht wäre der Vorschlag von Carl Gustav Carus, eine Passage aus Tacitus' Beschreibung der Varusschlacht gegen Arminius, deutsch Hermann, zur Aufgabe zu bringen, viel aktueller gewesen. Tacitus' Annalen lagen seit 1830 in einer ganz neuen Übersetzung von Wilhelm Bötticher vor. ${ }^{109}$ Im Zuge der napoleonischen Eroberungen und der Befreiungskriege setzte eine vermehrte Rezeption der Hermannsschlacht ein. Besonders die verheerende Niederlage des römischen Feldherrn Varus 9 n. Chr. im Teutoburger Wald war für die Glorifizierung des Cheruskerführers zum deutschen Helden sehr bedeutsam. Heinrich von Kleist hatte 1808 das Drama Die Hermanns-

Carlsberg Inv.-Nr. 778. Siehe Die Dionysischen Sarkophage. 2. Teil: Die Denkmäler 72-171 (Die antiken Sarkophagreliefs, Bd. 4), hrsg. v. Friedrich Matz, Berlin: Gebr. Mann Verlag, 1968, Nr.75, S. 183-186.

106 Der genaue Titel der Hefte lautete Archäologisches Museum zur Erläuterung der Abbildungen aus dem classischen Alterthume für Studirende und Kunstfreunde. In der Einführung schreibt Böttiger: »Das Studium der Antike ist zu einer neuen Wissenschaft, zur Archäologie aufgewachsen. Die Anwendung davon auf architectonische Verzierungen in unsern Wohnungen und Gärten [...] ist täglich vor unsern Augen und also auch in unsern Gesprächen, in unsern gangbaren Lesereien und noch mehr in unsern Geistesproducten von höhern Ansprüchen. [...] So ist es keineswegs gleichgültig, welche Gegenstände und mit welcher Auswahl und Behandlung ihnen auf die angenehmste Weise in die Hände gespielt werden. Böttiger 1801, S. IV-V.

107 Carl August Böttiger, in: Quandt 1829 (1), S. 30. Zur Begründung der Aufgabe der Weimarer Preisaufgaben s. a. Klauss 2001, S. 199-202 mit weiterführender Literatur. schlacht geschrieben, das 1821 publiziert worden war. Caspar David Friedrich hatte 1812 das Grab des Arminius gemalt. Im Zuge der nationalstaatlichen Entwicklungen im 19. Jahrhundert wurde Hermann patriotisch vereinnahmt. Es entstanden Denkmäler und Opern für den germanischen Heroen. ${ }^{110}$ In diesem Kontext hätte Carus' Vorschlag höchste Aktualität gehabt und es wäre vorstellbar gewesen, dass ein solches Thema als Preisaufgabe für die Künstler interessanter gewesen wäre. Die thematische Beschränkung auf den Kampf um den römischen Adler, das Feldzeichen auf der Standarte der Legion, hätte auch ein Motiv vorgegeben, für das die Kunstgeschichte mit Leonardo da Vincis Kampf um die Fahne in der Anghiarischlacht anregend gewirkt hätte. Genau dies war Quandts Argument gegen Carus' Vorschlag: »Auch wird beÿ dieser Aufgabe der Künstler unwillkührlich gezwungen, an den ähnlichen Gegenstand, welchen L. da Vinci behandelt hat, zu denken u die Erinnerung an dieses Meisterwerk, durch welches die Aufgabe gelöst zu seÿn scheint, müßte ihn nothwendig befangen machen. ${ }^{111}$ Der Vereinsvorsitzende dachte also vielmehr kunsthistorisch als dass er sich die Frage gestellt hätte, welche Themen für die Künstler von Interesse sein würden.

Das Problem der historisch-archäologischen Motive in der Historienmalerei sollte sich ein Jahrzehnt später in einem Gelehrtenstreit um zwei großformatige Bilder belgischer Künstler zu nationalen Themen erst richtig stellen. Die Gemälde lösten eine weitreichende Diskussion aus, wie eine neue deutsche Historienmalerei wirken solle. Mit Carus' Thema hätte der Sächsische Kunstverein in dieser Frage voranschreiten können. Doch vielleicht war die Zeit zwei Jahre nach den Umsturzversuchen der 183oer Revolutionen und den neuen Verfassungen in den deutschen Ländern noch zu früh, um sich gesamtdeutschen Geschichtsthemen zuzuwenden. Die Preisaufgaben im Sächsischen Kunstverein unter Quandts Vorstand wurden jedenfalls nicht mehr weiterverfolgt und Versuche gab es danach, auch unter Quandts Nachfolger Carus, keine mehr.

108 Quandt, Manuskript »Warum Kunstfreunde Preisaufgaben ertheilen sollen« vom 12.1.1832, in: HStADD, 12509 Sächsischer Kunstverein, Nr. 2, fol. 199r-200v.

109 Tacitus, Annalen, Buch I, 55-69, zur Varus-Schlacht Buch I, 61. Die Übersetzung von Wilhelm Bötticher, Des Cajus Cornelius Tacitus sämmtliche Werke. Erster Band: Der Annalen erstes bis sechstes Buch, Berlin: Verlag von Theodor Christian Friedrich Enslin, 1831. Carus' Vorschlag in: HStADD, 12509 Sächsischer Kunstverein, Nr. 2, fol. 18gr.

110 Varusschlacht und Hermannsmythos wurden 2009 zum 2000-jährigen Jubiläum der Schlacht in Ausstellungen, Büchern und Artikeln thematisiert. Siehe Tillman Bendikowski, »Mythos einer Schlacht«, in: Die Zeit, 4.11.2008 [Internetressource: www.zeit.de/2008/45/DOSvarus-schlacht, letzter Zugriff: 17.9.2018].

111 Johann Gottlob von Quandt, Manuskript »Warum Kunstfreunde Preisaufgaben ertheilen sollen« vom 12.1.1832, in: HStADD, 12509 Sächsischer Kunstverein, Nr. 2, fol. 199v. 


\section{Enttäuschte Reaktionen und autoritäre Gesten}

Quandts Engagement für die Förderung der Kunst und vor allem der Historienmalerei in Dresden verlief letztlich enttäuschend. Der Rückblick im Jahresbericht auf die erste vierjährige Amtsperiode nach seiner Wiederwahl anlässlich der Generalversammlung vom 19. Dezember 1831 verdeutlicht dies: »Vor nunmehr vier Jahren fand der neu gebildete Verein Werke vor, welche fast ohne Hoffnung, Kunstfreunde dazu zu finden, von den Künstlern hervorgebracht worden waren [...]. «112 Nach Fortschritten der ersten zwei Jahre seien vor allem Landschaften und Genrebilder gemalt worden, die gut abgesetzt werden konnten. »Wir dürfen es uns aber nicht verbergen, daß nicht blos eine geistig=productive, sondern fast mehr noch eine industriöse Thätigkeit unter den Künstlern erwachte und im dritten Jahre sich zeigte.« An großen Werken fehlte es jedoch, weshalb auf die erste Ausschreibung für ein Historiengemälde nur drei Vorschläge eingegangen seien. So analysierte er: »Hinsichtlich der Classe von Bildern, welche man im Allgemeinen die historische nennen kann, muß angeführt werden, daß es diejenige ist, welche von der kleinern Zahl Kunstfreunde gefördert zu werden pflegt und die von dem großen, bloß schaulustigen Haufen am lieblosesten und unverständigsten beurtheilt wird; daher denn immer auch nur eine kleine Zahl von Künstlern den muthigen Entschluß zu fassen vermag, sich diesem Fache zu widmen, zumal da Werke dieser Art sehr mühevolle Vorstudien, glückliche Naturanlagen und eine ausdauernde Kraft bei der Ausführung erfordern.« Als zentrale Aufgabe des Vereins unterstrich Quandt, die Künstler müssten weiterhin zu grö-

112 Nachfolgende Zitate alle nach dem Jahresbericht des Sächsischen Kunstvereins von 1831 bis Ostern 1832, in: HStADD, 12509 Sächsischer Kunstverein, Nr. 2, S. 231r-232r (S. 3-5).

113 »Diese Thatsachen, in denen wir uns und Andern klar und offen darlegen, was wir erreichet oder auch verfehlt haben, müssen uns zugleich erkennen lassen, was ferner zu thun nöthig ist. Dieß ist denn vor allem, 1) das durch vereinte Kräfte zu fördern, was der einzelne Kunstfreund nicht oder doch nur selten vermag: umfassendere größere Werke der Kunst zu veranlassen und zu unterstützen. [...] Sodann 2) ist nöthig, durch die Wahl der Werke den Sinn auf das Würdige und Gehaltvolle hinzulenken und deßhalb wenigstens eben so sehr, ja fast noch mehr, auf den geistigen Gehalt, als auf die Technik zu sehen; denn nur hierdurch kann der Kunstsinn gebildet und die Kunst gehoben werden. «ahresbericht des Sächsischen Kunstvereins von 1831 bis Ostern 1832, in: HStADD, 12509 Sächsischer Kunstverein, Nr. 2, S. 232V (S.6).

114 Brief von Quandt an Schnorr vom 1.1.1833, in: SLUB, Mscr. Dresd. n Inv. 15, Bd. 31, fol. 184r, zit. nach Schmitz/Strobel 2001, S. XXII: »[Das Publikum will] kleine Bilder u unbedeutende Gegenstände haben, um viel Gewinne bei der Verloosung zu bekommen u diese Gegenstände sollen so gemalt u vorgestellt seyn, wie sie gewöhnt sind in Bildern es zu sehen. Ich beklage daß die Künstler mich wenig unterstützen, denn wenn nur etwas recht Bedeutendes hervorträte, so würde es doch durchdringen u sich Beyfall erzwingen. Die Nichtigkeit der kleinlichen, manierirten Leistungen würde erst einigen, dann mehrern in ßeren Werken aufgefordert werden, die würdig und gehaltvoll seien. Dabei sei primär auf den »geistigen Gehalt« und sekundär auf die technische Qualität zu achten. ${ }^{113}$ Nur durch den Inhalt und nicht durch die Technik sei der Kunstsinn des Publikums zu verbessern.

Innerhalb des Vereins stieß dieser Schwerpunkt des Vorsitzenden immer häufiger auf Widerstand. Quandt warf dem Komitee vor, »kleinliche, manierirte Leistungen« aus Rücksicht auf die Mitglieder und aus eigenen Interessen anzukaufen. ${ }^{114}$ Seinem Freund Schnorr von Carolsfeld schrieb er: »Ich habe mich über meine Collegen sehr zu beklagen, denn was die Classe der Kunstfreunde im Comite betrifft, so sind dies Leute, denen die Kunst doch blos ein Spaß, oder eine Gelegenheit ist, Günstlinge zu befördern u die Künstler im Comite, sind gewinnsüchtig u eitel. «115 Wegen solcher Anklagen war es bereits im August 1830 zu einem ersten Eklat gekommen. In einer ausnehmend emotionalen Reaktion hatte Quandt seinen Rücktritt als Vorstand eingereicht. Grund war der Ankauf von Gemälden August Anton Tischbeins, Friedrich August Moritz Retzschs und Thomas Fearnleys. Sie waren ihm Beweis dafür, keinen Einfluss auf den Kunstsinn und das Urteil des Vereins zu haben. ${ }^{116}$ Das zugrunde liegende Problem lag in der protektionistischen Unterstützung von Retzsch. Als stellvertretendes Komiteemitglied und Professor für Malerei an der Kunstakademie durfte er eigentlich keine Gemälde an den Verein verkaufen. Doch Heinrich Vitzthum von Eckstätt, Direktor ebendieser Bildungsanstalt, hatte sich für den Ankauf von Retzschs Bild eingesetzt, dem das Komitee gegen den Willen seines Vorsitzenden zustimmte. ${ }^{117}$ Diese Art der Unterstützung konnte Quandt nicht

die Augen fallen und das Publicum an das Bessere gewöhnt u diesem zugewendet werden. « Zur Problematik des Verhältnisses von Vorstand und Vereinsmitgliedern siehe Schmitz 2001, S. 57-64. Zur Frage des Gewinns siehe ebd., S. 336-352.

115 Brief von Quandt an Schnorr vom 3.1.1831, in: Schmitz/Strobel 2001, S. 208 (SLUB, Mscr. Dresd. n Inv. 15, Bd. 31, fol. 176r): Der Vorwurf richtete sich gegen Vogel von Vogelstein, den er als »kleinlich, neidisch, eigennützig, knechtisch u hinterlistig« bezichtigte und gegen Dahl, der »ganz eitel u ganz einseitig in seinem Urtheil« sei, der auch »erbärmliche Stümper « begünstige, sofern sie ihm schmeichelten. Von diesen Vorwürfen nahm er Naeke und Matthäi aus.

116 Brief von Quandt an Vitzthum von Eckstätt vom 1.8.1830, in: HStADD, 12509 Sächsischer Kunstverein, Nr. 1, fol. 273r: »Beÿ der gestrigen Conferenz habe ich meinen Irrthum, daß ich glaubte dem Verein zu nützen, deutlich erkannt und einsehn gelernt, wie ganz und gar ich keinen Einfluß auf das Urtheil und den Kunstsinn des Vereins habe, denn sonst wäre es unmöglich gewesen, daß Bilder wie die, von Retzsch u Tischbein und Farnleÿ gekauft worden sind. « Kovalevski 2010, S 76-77, 96-99, Kat. Nr. B-C 33: Tischbein, Sterbender Krieger; Nr. 45: Retzsch, Der Becher; Nr. 46b: Fearnley, Mondschein.

117 Brief von Quandt an Vitzthum vom 3.8.1830 über Retzschs Bild, »welches fehlerhaft gezeichnet, schlecht gemalt $u$ in der schwächlichsten Manier gedacht ist. Wie wenig Beÿfall dieses Bild erworben hat, kann man schon darin erschließen, daß es selbst des Künstlers Gönner nicht gekauft haben u seit vielen Jahren in des Malers Atelier stehen 
gutheißen. In seinem Rücktrittszirkular an das Kollegium betonte Quandt: »[...] wenn ich auch meine Meinungen u Absichten nicht für unfehlbar halte, so bin ich mir doch am wenigsten dessen bewusst, daß weder eine persönliche $\mathrm{Zu}=$ noch Abneigung oder irgend andrer Rücksichten es bedürfen, das Gute zu fördern, den Sinn für das Wahre und Schöne in der Kunst zu wecken und talentirte Künstler zu Thätigkeit anzuregen $[. ..] . \ll^{118}$ In seinen Augen diente der Kunstverein weder als Zeitvertreib noch als Unterstützungsinstitution für bedürftige Künstler, sondern als Förderinstrument für Talente. Er hielt es für seine Pflicht, gerecht zu urteilen und nicht alles und jeden zu loben, zu ernst seien diese »Angelegenheiten des menschlichen Geistes u der Bildung. «19

Das Komitee bemühte sich in der Folge sehr darum, Quandt zum Bleiben umzustimmen. Doch dieser stellte weitreichende Bedingungen. Er verlangte eine Zweidrittelmehrheit für Kunstankäufe, eine Begründung für oder gegen Ankäufe von jedem einzelnen Vorstandsmitglied und ein Vetorecht für den Vorsitzenden: »Sollte ein Kunstwerk in Vorschlag für den Ankauf gebracht werden, welches nach der Überzeugung des Vorstands, eine der Kunst verderbliche und verführende Manier charakterisiert, so ist es die Pflicht des Vorstandes und er soll dazu autorisiert seyn, dessen Ankauf und die Abstimmung darüber nicht zuzulassen. $\ll^{120}$ Diese autoritäre Forderung trug erpresserhafte Züge. Freilich sah Quandt dies nicht so. Das Veto des Vorsitzenden sei keine Begünstigung, sondern eine Bürde. Es sei für das ästhetische Gewissen des Vereinsvorstands unabdingbar,

blieb.« Ebenso Quandts persönlicher Brief an Retzsch vom 30.8.1830, beide in: HStADD, 12509 Sächsischer Kunstverein, Nr. 1, fol. 279 r und fol. 346r-347r. S. a. Kovalevski 2010, S. 96; Hildebrand-Schat 2004, S. 321; Altner 1990, S. 106; Briel 1987b, S. 19.

118 Zirkular von Quandt an die Komiteemitglieder vom 1.8.1830, in: HStADD, 12509 Sächsischer Kunstverein, Nr. 1, fol. 274r-v.

119 Vitzthum hatte Quandts Zirkular zurückgehalten und versuchte inn noch umzustimmen. Quandts Antwort vom 3.8.1830 zählte Gründe für den Rücktritt auf: »[...] betreffen die meisten Comitemitglieder die Zwecke des Vereins, ihre Pflichten u die Kunst selbst, aus einem dem meinen ganz verschiedenen Gesichtspunkte. Einige glauben aus menschenfreundlichen Gesinnungen, daß der Zweck des Vereins seÿ, hülfsbedürftige Künstler zu unterstützten, indeß ich dafürhalte, der wahre Zweck ist: Talentvolle zu ermuthigen u zu belohnen. Andere glauben alles loben zu müssen, indeß ich es für Pflicht halte, gerecht im Urtheil zu seÿn. Noch andere betrachten die Künste, als einen hübschen Zeitvertreib u ich dagegen, als sehr ernste Angelegenheiten des menschlichen Geistes u der Bildung." HStADD, 12509 Sächsischer Kunstverein, Nr. 1, fol. 279r-v. S. a. Schmitz 2001, S. 62, 329-333.

120 Brief von Quandt an das Komitee vom 11.8.1830: HStADD, 12509 Sächsischer Kunstverein, Nr. 1, fol. 291r-292v.

121 »Dennoch ist es für das ästhetische Gewissen des Vorstandes unerläßlich, den Ankauf von Kunstwerken verhindern zu können, welche eine Entwertung der Kunst bezeichnen, denn durch den Ankauf von Kunstwerken legen wir ja ein öffentliches Zeugniß ab, das wir für recht halten und welcher Richtung der Künstler folgen soll. « Brief von Quandt an das Komitee vom 11.8.1830: HStADD, 12509 Sächsischer Kunstverein, Nr. 1, fol. 292r-292v. S. a. Schmitz 2001, S. 62. wenn die Kunst nicht entwertet werden solle. Jeder Ankauf sei ein öffentliches Zeugnis über die Ausrichtung des Kunstvereins. Für Quandt war es eine Vertrauensfrage: »Es folgt hieraus disjunctis zweÿerleÿ. Entweder verdient der Vorstand ein solches Vertraun $\mathrm{u}$ also auch einen solchen Einfluß beÿ Entscheidung über Kunstwerke, oder er verdient ein solches Vertraun in seine Einsichten u Unpartheilichkeit nicht $\mathrm{u}$ also auch nicht Vorstand des Vereins zu seÿn, denn nur diese Eigenschaften machen ihn fähig Vorstand zu seÿn. « ${ }^{121}$

Das Komitee reagierte mit einer Verzögerungstaktik. Bis Ende des Jahres gestand man ihm die Forderungen zu, verlangte aber, dass die Vorschläge durch die Generalversammlung gutgeheißen würden, da sie Statutenänderungen erzwingen würden. ${ }^{122}$ Die Ankäufe waren größtenteils mit der Akademieausstellung Ende Juli und Anfang August 1830 getätigt worden und Quandt nahm in der Folge gar nicht mehr an den wenigen verbleibenden Vorstandssitzungen teil. ${ }^{123} \mathrm{Am}$ 1. Dezember verschickte er auf eigene Kosten allen Mitgliedern seinen offiziellen Rücktritt. ${ }^{124}$ Danach nahm die Affäre eine Wende: zahlreiche Mitglieder des Vereins in Dresden und in den auswärtigen Orten baten Quandt zu bleiben. Darunter befanden sich auch Goethe und andere bedeutende Persönlichkeiten. Sie vermochten ihn umzustimmen. ${ }^{125}$ Die Generalversammlung am 20. Dezember wählte ihn mit überwältigender Mehrheit wieder. Vitzthum von Eckstätt schied aus dem Komitee aus, wohl weniger wegen seiner Schwerhörigkeit, wie die offizielle Begründung lautete, sondern eher wegen seiner Unterstützung für Retzsch. ${ }^{126}$ Über

122 Vorstandssitzung vom 15.8.1830, Beschlussprotokoll, in: HStADD, 12509 Sächsischer Kunstverein, Nr. 1, fol. 294r-296v.

123 Kovalevski 2010, S. 70-120. Über die meisten Bilder war am 31. Juli, also einen Tag vor Quandts Rücktrittsdrohung abgestimmt worden. Siehe Protokolle und Briefe, in denen Quandt nie als anwesend vermerkt wird oder unterzeichnet. HStADD, 12509 Sächsischer Kunstverein, Nr. 1, fol. 307r-318v.

124 Gedruckter Rücktritt Quandts vom 1.12.1830, in: HStADD, 12509 Sächsischer Kunstverein, Nr. 1, fol. 320r.

125 Brief von Goethe an Quandt vom 28.8.1830: »/hre reinen Gesinnungen, theurer Mann, auf einen festen Charakter gegründet, werden gewiß auch zu Beruhigung aller Theilnehmer in diesem Falle wie in andern das wahrhaft Nützliche und Gehörige geltend zu machen wissen. "Quandts Bericht an Goethe vom 25.12.1830: »Von Ew Excellenz selbst und später von dem Herrn Geheime Rath und Kanzler von Müller, erhielt ich die mir werthen Versicherungen; daß mein Austritt als Vorstand des Kunstvereins, ganz gegen den Wunsch vieler Mitglieder in Weimar, seyn würde.« Schmitz/Strobel 2001, S. 101, 108. Aus Leipzig erhielt er 45, aus Dresden 102 Unterstützungsbekundungen. Siehe dazu Quandts gedruckte Dankesnachricht an die Mitglieder, ca. um den Jahreswechsel 1830/31, in: HStADD, 12509 Sächsischer Kunstverein, Nr. 1, fol. 340r.

126 Quandt erhielt 137 Stimmen, Vitzthum als einziger Gegenkandidat nur 11. Protokoll und Wahlauszählung der Generalversammlung, in: HStADD, 12509 Sächsischer Kunstverein, Nr. 1, fol. 326r-330v. Hierzu auch der Brief von Quandt an Goethe vom 25.12.1830, in: Schmitz/ Strobel 2001, S. 108-109. S. a. Briel 1987b, S. 19. 
Quandts Forderungen nach einer Stärkung der Macht des Vorsitzenden wurde nicht diskutiert. Das Wohlwollen der zahlreichen Mitglieder schien dem frisch Wiedergewählten genügt zu haben. Statuarische Änderungen gab es jedenfalls keine. ${ }^{127}$

\section{Richtungsstreitigkeiten: Hohe Kunst oder arme Künstler}

Doch nicht nur innerhalb des Vorstands gab es Unstimmigkeiten bezüglich der Politik des Kunstvereins. Im Herbst 1831 wurde im Dresdener Anzeiger ein anonymer Artikel publiziert, der die Gründung eines neuen Aktienvereins für Kunstankäufe aus der jährlichen Akademieausstellung verlangte. ${ }^{128}$ Die Quellen dieser erfolglos versuchten Gründung eines weniger elitären Kunstvereins werden hier erstmals untersucht. ${ }^{129}$ Dieser sollte finanziell günstigere Bedingungen für die Mitglieder schaffen. Anstatt der fünf Taler des Kunstvereins sollten nur 16 Groschen pro Aktie verlangt werden, was der Hälfte eines Talers entsprach. Der Initiant erhoffte sich dadurch eine viel größere Anzahl an »unbemittelten Kunstfreunden« und damit ein höheres Vereinskapital. Mit diesem sollten bedürftige Künstler gefördert werden, deren Bilder vom Sächsischen Kunstverein nicht angekauft wurden. ${ }^{130}$ Das Anliegen stieß vorab in den Medien, später auch bei dem Direktor der Kunstakademie, Heinrich Vitzthum von Eckstätt, auf fruchtbaren Boden. ${ }^{131}$ Der einflussreiche Buchhändler Johann Christoph Arnold gehörte ebenfalls zu den Befürwortern und schrieb an Vitzthum, bereits

127 Neue Statuten, die auf Quandts autoritäre Forderungen eingegangen wären, existieren in den Akten des Kunstvereins nicht. Einzig die Zweidrittelmehrheit wurde eingeführt, wie Quandt an Schnorr am 3.1.1831 berichtet: »Da so viel werthlose Bilder aus Partheilichkeit gekauft worden waren, so machte ich es zur Bedingung, daß ein anderer Modus in der Abstimmung eingeführt werde. Der Comite besteht aus 9 Personen u wenn 5 Stimmen, sich für einen Ankauf erklärten, so wurde das Gemälde gekauft. Leicht aber waren 5 Stimmen zu gewinnen u so kamen wir oft zu schlechten Werken. Gegenwärtig sind 6 Stimmen zu einem Ankaufe erforderlich. Das hat nun zwar wieder den Nachtheil; daß manches wohlgefällige Bild nicht gekauft wird, allein doch den weit größern Vortheil; daß nicht so leicht ein unwürdiges Product begünstigt werden kann.«Abgedruckt in: Schmitz/Strobel 2001, S. 208 (SLUB, Mscr. Dresd. n Inv. 15, Bd. 31, fol. 176r). Die oft zitierte Forderung nach einem Vetorecht kam demnach nicht. Vgl. Kovalevski 2010, S. 10; Schmitz 2001, S. 62; Schmitz/Strobel 2001, S. 302, 305; Briel 1987b, S. 18

128 Dresdener Anzeiger, 25.9.1831, Nr. 268, S. 4, in: HStADD 11126 Kunstakademie, Nr. 94, fol. 2v. Wahrscheinlich handelt es sich beim Initianten um den Archivar des Kriegsratsarchivs Karl August Engelhardt. Er korrespondierte in dieser Zeit gelegentlich mit Heinrich Vitzthum von Eckstätt.

129 Siehe dazu die Dokumentensammlung mit dem Titel »Acta Academ: Die Gründung eines Actien=Vereines zum Ankauf und folgender Verloosung von Kunstwerken aus der Zahl der zu den öffentlichen Ausstellungen der Academie der bildenden Künste gelangenden dergl: betrf:«, in: HStADD 11126 Kunstakademie, Nr. 94. hätten sich hunderte Leute nach Losen des neuen Vereins erkundigt, weil sie mit den Ankäufen des Sächsischen Kunstvereins unzufrieden seien..$^{132}$ Ein weiterer anonymer Schreiber im Dresdener Anzeiger äußerte den Wunsch, »daß einst, wenn die Sache ins Leben tritt, bei einer Wahl der zur Verloosung zu erkaufenden Stücke, das Publikum nicht durch Autorität, oder auf diese einflößenden, vielleicht durch mannichfache Rücksichten geleiteten guten Rath bevormundet werde. $\ll^{133}$

Der zu gründende Verein war also explizit ein Gegenentwurf zum Sächsischen Kunstverein. Die Akademiedirektion übernahm im Dezember 1831 die Federführung. Sie kam zum Schluss, dass der Aktienbeitrag auf einen Taler festgelegt werden müsse, da sonst zu wenig Kapital zusammenkomme. Der Verein sollte unter anderem diejenigen, positiv rezensierten Gemälde der Akademieausstellung verlosen, die nicht an den Sächsischen Kunstverein oder anderweitig verkauft worden waren. Die Rechnungsführung übernahm Karl Theodor Winkler, der gleichzeitig Sekretär der Akademie und Kassier des Sächsischen Kunstvereins war. ${ }^{134}$ Quandt nahm den Gründungsversuch missbilligend zur Kenntnis: »Der GehRth [Geheimrat] Graf Vitzthum, errichtet jetzt einen academischen Kunstverein, der ganz auf die Schwächen der Menschen berechnet ist u es wird ihm daher nicht an Theilnehmern fehlen. Die Actie wird nur $1 \mathrm{~T}$ kosten u die Absicht ist viele u kleine Bilder zu kaufen, damit viel Gewinne gemacht werden können u weil kleine Genrebilder mehr gefallen als größre Werke.«35

Wider Erwarten war die Nachfrage nach Mitgliedschaften gering. Obschon im Spätsommer 1832 nur sechzig Lose ver-

130 Dresdener Anzeiger, 25.9.1831, Nr. 268, S. 4, in: HStADD 11126 Kunstakademie, Nr. 94, fol. 2v: »Nun fehlt es zwar nicht an einem Actien=Verein für die Kunst, welcher unter einsichtvoller Leitung des Hrn. v. Quandt einer sehr lebhaften Theilnahme, sogar des Auslandes, sich erfreut. Aber - die Actie kostet fünf Thaler - wer kann diese leicht entbehren? Wie, wenn man nun auch mit der jährlichen Kunstausstellung einen solchen Verkauf von Actien à 16gl [Groschen], wie bei der Gewerbeausstellung, verbände und davon zur Verloosung meist solche Gemälde kaufte, welche der größere Actien=Verein nicht berücksichtigen konnte? *) Wie gern würde so mancher unbemittelte Kunstfreund so eine Actie kaufen! welche Freude und Aufmunterung, auch, wenigstens augenblickliche, Hilfe so manchem unbemittelten Künstler dadurch zu Theil werden!«

131 Verschiedene Artikel im Dresdener Anzeiger, September/Oktober 1831, Nr. 263, 268, 282, in: HStADD 11126 Kunstakademie, Nr. 94, fol. 5V, $6 \mathrm{v}, 10 \mathrm{r}$.

132 Brief von Arnold an Vitzthum vom 3.10.1831, in: HStADD 11126 Kunstakademie, Nr. 94, fol. 3.10.1831.

133 Dresdener Anzeiger, 16.10.1831, Nr. 289, S. 4, in: HStADD 11126 Kunstakademie, Nr. 94, fol. 12v.

134 Bekanntmachung der Akademiedirektion im Dresdener Anzeiger, 28.12.1831, Nr. 362, S. 1-2, in: HStADD 11126 Kunstakademie, Nr. 94 , fol. $22 r-v$.

135 Brief von Quandt an Johann Georg Keil vom 26.12.1831, in: Schmitz/ Strobel 2001 S. 208-209: S. a. Bertsch 2009, S. 571; Schmitz 2001, S. $239-333$. 
kauft worden waren, schritt man im September zur Wahl eines Vorstands. Erstaunlicherweise war Quandt als Kandidat aufgestellt worden - ob mit oder ohne seine Zustimmung, lässt sich den Akten nicht entnehmen. Er wurde gar als Vorsitzender gewählt. ${ }^{136}$ Hierauf folgte eine klare Absage seinerseits: »Als Vorstand des sächsischen Kunstvereins, welcher danach strebt, die Kunst zu einem höhern Ziele hinzuführen, indem er die Hand denen biethet, die von der Natur befähigt zu seÿn scheinen, eine höhere Stufe der Kunstausbildung zu erreichen oder auch solchen sich zu erhalten, kann ich nicht füglich die Vorsteherschaft eines andern Vereins übernehmen, dessen hauptsächlichster Zweck es ist, den Absatz von Werken der bildenden Künste beÿ den öffentlichen Ausstellungen zu befördern, um so wohlgemeint auch diese Absicht seÿn mag, so führt sie doch unvermeidlich dazu, daß die geistige Kunstthätigkeit zurück tritt und die gemeine Erwerbsthätigkeit hervorgelenkt wird, was also den Zwecken des ersteren Vereins ganz entgegen gesetzt ist. $\ll^{137}$ Er bedauerte, dass sich die Kunstfreunde nicht einigen würden.

Dass Quandt überhaupt in den Vorstand des neuen Vereins gewählt wurde, ist erstaunlich. Die Akten der Kunstakademie, die beteiligten Personen und Quandts Reaktion deuten eigentlich in eine ganz andere Richtung. Im Sächsischen Kunstverein hatten sich zwei Parteien gebildet. Sie teilten sich auf in eine Gruppe idealistischer Kunstförderer, die um der Kunst willen vor allem Historien und andeutungsreiche Landschaften und Genrebilder einforderten sowie in eine Gruppe realistischer Künstlerförderer, die sich eher um die Künstler und deren Absatznöte kümmerten. Letztere waren die Initiatoren des neuen Kunstvereins, der bedürftige Künstler durch Ankäufe unterstützen wollte. Dies konnte der Vorsitzende des Sächsischen Kunstvereins nicht gutheißen, wie er mehrfach betont hatte.

In seiner Absage zeigen sich auch zwischenmenschliche Probleme. Quandt hob hervor, dass er nur für einen freien Verein arbeiten und sich nicht einem neuen unter der Kontrolle der Direktion der Kunstakademie unterwerfen wollte. ${ }^{13^{8}}$ Hier schwingt noch die Aversion gegen Heinrich Vitzthum von Eck-

136 Brief von Quandt an Winkler vom 22.9.1832, in: HStADD 11126 Kunstakademie, Nr. 94, fol. 69r; Auszählungsprotokoll und Wahlzettel, in: ebd., fol. 37r-68r; Information zu den Vorstandswahlen an die Gründungsmitglieder des Vereins vom 3.9.1832, in: ebd., fol. 35; Artikel über den schlechten Start: Dresdener Anzeiger, 7.8.1832, Nr. 220, S. 1, in: ebd., fol. $26 r$ r.

137 »Ferner muß ich bedauern, daß nicht alle wackern[?] Kunstfreunde sich zu gleichen Zwecken vereinen, denn nur durch ein einiges Zusammenhalten und Verfolgen eines Zweckes, kann ein schönes Ziel vollkommen erreicht werden.« Antwortschreiben Quandts an die Initianten des zu gründenden Vereins vom 24.9.1832, in: HStADD 11126 Kunstakademie, Nr. 94, fol. 70r-71r. Ein zweites Exemplar dieses Briefes aus der SLUB Dresden ist publiziert in: Schmitz/Strobel 2001, S. 217, wobei sie den Brief nicht einordnen können. stätt mit, der knapp zwei Jahre zuvor mit der Retzsch-Affäre aus dem Sächsischen Kunstverein ausgeschieden war. In einem Brief an Johann Georg Keil in Leipzig schrieb Quandt: »Dieser Vitzthumsche Kunstverein wird zur Folge haben daß viele Künstler, statt nach dem Höhren zu streben, nur sich auf das Leichte u Gefällige legen. Ob dies Unternehmen eines Directors der Academie würdig ist, mögen andere beurtheilen. Solche Menschen sind unsere vornehmen Leute! Doch sind sie diese, welche Ehren u Gunstbezeugungen erhalten, in deß der nicht Hochgebohrne für das Allgemeine, für einen edlen Zweck thun mag was er kann, ohne daß man es zu bemerken kaum für werth hält. Ja es wird ihm wohl gar noch für eine Manie ausgelegt. «138 Der Bürger Quandt fühlte sich also als Einzelkämpfer.

Interessant für die Parteienbildung unter den Kunstfreunden sind auch die in der Akte überlieferten Wahlzettel. Während beispielsweise sein alter Freund, der sächsische Kabinettsminister Bernhard August von Lindenau, Quandt wählte, schrieben ihn Vitzthum von Eckstätt und der Kassier des Kunstvereins Karl Theodor Winkler überhaupt nicht auf die Wahlzettel für das Komitee des neuen Vereins. ${ }^{100}$ Nach Quandts Absage sind keinerlei Dokumente zum Verein für den Ankauf und die Verlosung von Kunstwerken der Akademieausstellungen vorhanden. Das geringe Interesse auf der einen, Quandts ungewollter Wahlerfolg auf der anderen Seite dürfte den Initianten um den Direktor der Kunstakademie, Vitzthum von Eckstätt, gezeigt haben, dass der Vorsitzende des Kunstvereins noch fest im Sattel saß. Die internen Unstimmigkeiten schienen jedoch Überhand zu nehmen, wenn nicht einmal der Kunstvereinskassier Winkler Quandt wählen wollte.

\section{Interne Querelen und Resignation}

Wenige Monate später brachen diese internen Querelen im Komitee des Sächsischen Kunstvereins endgültig hervor. Obschon Quandt erst an der Generalversammlung vom Dezember 1831 für weitere vier Jahre in den Vorsitz gewählt worden war, zog

138 »Schließlich aber bekenne ich, daß ich nur einem freÿen Verein von Kunstfreunden meine Dienste zu widmen vermag, aber nicht einem solchen, über welchen die General=Direction der königl. Academie der bildenden Künste sich die oberste Leitung vorbehalten hat." Antwortschreiben Quandts an die Initianten des zu gründenden Vereins, in: HStADD 11126 Kunstakademie, Nr. 94, fol. 70v-71r.

139 Brief von Quandt an Keil vom 26.12.1831, in: Schmitz/Strobel 2001, S. 209.

140 Auszählungsprotokoll und Wahlzettel, in: HStADD 11126 Kunstakademie, Nr. 94, fol. 37r-68r. Quandt erhielt mit 11 Stimmen doppelt so viele wie seine Gegner, der Buchhändler Arnold (5 Stimmen), Vitzthum von Eckstätt (6 Stimmen) oder Winkler (4 Stimmen), die die Gründung des Vereins vorangetrieben hatten. 
er sich anfangs Februar 1833 aus den Geschäften zurück.141 Der Grund lag in der Uneinigkeit zwischen ihm und den Komiteemitgliedern über die Aufgaben des Vereinsvorstands sowie Unstimmigkeiten über eine neu einzurichtende Geschäftsordnung. ${ }^{1.2}$ Der Hauptpunkt, der ihn irritierte, betraf die Rückmeldungspflicht des Vorsitzenden. Alle Jahresberichte, Bestellungen von Kunstwerken, Bekanntmachungen, Einladungen zu Generalversammlungen, Behördeneingaben und Antwortschreiben sollten im Namen des gesamten Vorstands und nicht nur des Präsidenten gemacht werden. Dass dieser Punkt überhaupt eingebracht wurde, verdeutlicht die bisher steile Hierarchie im Kunstverein. Quandt hielt die Zügel eng und handelte oft eigenmächtig. Er indessen sah dies als seine gewissenhafte Pflicht an: »Da ich nun aber bey Gründung des Vereins die Vorsteherschaft nicht unter solchen Bedingungen übernahm, wie der Comite hier vorschreibt und nicht gemeint war, durch eine blos mechanische Thätigkeit dem Kunstvereine, der mir sein Vertraun schenkte, zu nützen, so bin ich meiner Verpflichtung als Vorstand überhoben. Nachtheiliges abzuwehren, jeden Unbill, woher er auch komme, abzuweisen, was dem Verein zum Nutzen gereichen könne herbeyzuführen, die Beschlüße des Comite gewissenhaft aufrechtzuhalten und zu vollziehen, hielt ich für meine Schuldigkeit, zumal da meine Unabhängigkeit mich dazu eignete; aber die Ausführung der Comitebeschlüße war wie billig mir überlaßen, da ich der Beurtheilung der Welt allein ausgesetzt war und der Tadel nie den Comite, sondern den Vorstand trift. Eben so hielt ich mich für berechtigt in den Jahresberichten, welche dazu mir allein Gelegenheit gaben, meine Ansichten von dem gesammten Vereine offen auszusprechen. Meine Gesinnungen aber nun der Prüfung des Comite zu unterwerfen u mir vorschreiben zu laßen, was ich denken, sprechen u schreiben soll, ist mir ganz unmöglich. $\ll^{143}$

Quandt hielt sich also in gewissem Sinn für unverzichtbar. Seine Gewissenhaftigkeit, die seiner Vorstellung von Kunst und ihrer Rolle für die Gesellschaft entsprang, war ihm zeit sei- nes Lebens ein Leitfaden und ließ ihn sicherlich immer wieder andere Meinungen überhören. Seine Ansichten standen über alläglichen Handlungen, wie sie im Kunstverein erforderlich wurden. Jedenfalls glaubte er dies, da seine Richtlinien in seinen Augen allgemeingültig waren. Deren höchstes Gebot war, dass die Kunst allein um ihrer selbst willen gefördert werden sollte. Als reicher, geadelter Bürger war er zudem unabhängig und brauchte sich nicht Erwartungen anderer zu unterwerfen. An Goethes Nachfolger in Weimar, Friedrich von Müller, schrieb er dementsprechend im April 1833: $\gg$ Daß man sich in meinem Vaterlande durch den Drang nützlich zu werden, keine Gunst und keine Freunde erwirbt, zumal wenn man mit Ernst das Gute will, keine Rücksichten auf Protectionen nimmt, noch selbst solche sucht und Kunst $\mathrm{u}$ Wissenschaft nicht blos als eine Dilettantenunterhandlung betreibt, das wußte ich wohl, daß man aber in so hohem Grade Neid und Feinde sich durch redlichen Willen und Festigkeit zuzieht, das mußte ich erst erleben, um es zu glauben. Wie ein ganzer Comité, auf die eine Waagschale einen Begünstigten des Hofs, auf die andere einen redlichen Mann der das Wohl einer Anstalt will und nach Kräften fördert legen und diesen jenem aufopfern kann, begreife ich zwar nicht, allein ich habe es erfahren.« Quandt sah sich also als Opfer von Interessen und Protektionismus. Der Vorwurf richtete sich in diesem Fall gegen den königlichen Leibarzt Carl Gustav Carus, den er hier mit dem »Begünstigten des Hofs« meint. Der Mediziner und Maler war seit 1831 stellvertretender Vorstand und Quandt schien sich mit ihm sehr schnell überworfen zu haben. Seine Aversion hing damit zusammen, dass Carus zu denjenigen Mitgliedern gehörte, die seinen Fokus auf die Historienmalerei missbilligten und mit weniger hohen Ansprüchen mehr Kunstwerke ankaufen und verlosen wollten.144

Doch Quandt verstand sich geradezu als Personifikation des Vereins. Seine problematische Selbstsicht, unabhängig im Urteil zu sein und nur das Beste für die Kunst zu wollen, stand über allen anderen Meinungen. Seinen autoritären Führungsstil zu hin-
141 Das Komitee gab sich am 13.2.1833 überrascht: „Der Comité des Sächs. Kunstvereins ist so vollkommen von den Verdiensten überzeugt, welche Sie sich seit fast 5. Jahren durch geistvolle Leitung [...] erworben haben, daß er nur mit wahrem Bedauern aus dem an ihn gerichteten Schreiben vom 7. d.M. ersehen hat, wie Sie die Geschäfte dieser Stellung plötzlich niederzulegen sich veranlaßt gefunden haben." Schmitz/Strobel 2001, S. 222 (HStADD, 12509 Sächsischer Kunstverein, Nr. 3, fol. 44r). S. a. Schmitz 2001, S. 62.

142 Entwürfe und definitive Geschäftsordnung, in: HStADD, 12509 Sächsischer Kunstverein, Nr. 3, fol. 29r-v, 66r-70v, 104r-108v. Quandt fühlte sich abgesetzt, was so wohl nicht ganz korrekt ist; siehe Brief von Quandt an Karl August Förster vom 16.5.1833, in: ebd., fol. 136r-v: »[...] Was jedoch alle Geschäffte betrifft, welche vormal[s] dem Vorstande des Kunstvereins oblagen, so kann ich solche von dem Tage an, an welchem mich der Comite absetzte und durch die neue Geschäfftsordnung mir diese Besorgungen abnahm, nicht mehr besorgen.«Die wichtigen Briefe zum Rücktritt sind publiziert in: Schmitz/Strobel 2001, S. 221-228. S. a. Briel 1987b, S. 25-26.

143 Brief von Quandt an das Komitee des Sächsischen Kunstvereins vom 26.3.1833, in: Schmitz/Strobel 2001, S. 224-225 (HStADD, 12509 Sächsischer Kunstverein, Nr. 3, fol. 71r-72v).

144 In einem Brief an Eduard Bendemann schrieb Quandt am 10.3.1837: »Als mich der Comite des Kunstvereins, auf Antrieb des Hofrath und Leibartzt Carus, absetzte, [...].« Leipzig, Universitätsbibliothek, 232, Quandt, Johann Gottlob von, fol. 1V-2r. S. a. Briel 1987b, S. 25; Briel 1984, S. 47-48. Die sechs überlieferten Briefe in Vereinssachen von Quandt an Carus zwischen dem 20.4.1830 und 24.8.1832 zeigen noch keine Irritation ihres Verhältnisses. SLUB, Mscr. Dresd. App. 204, Nr. 97h-n. S. a. Schmitz 2001, S. 47-48. Auch seine Rezension der Neun Briefe über Landschaftsmalerei war äußerst wohlwollend und interessiert; Quandt 1831 (4), Sp. 97-102. 
terfragen, schien ihm nicht in den Sinn zu kommen. Die Sache ist indessen zweischneidig. Einerseits hatte Quandt, wenn sein Schwerpunkt auch auf der Förderung großformatiger Historiengemälde lag, ohne weiteres auch Genre- und Landschaftsbilder unterstützt, so lange diese seinen Ansprüchen genügten. ${ }^{145}$ Zudem unterhielt er mit viel Ehrgeiz ein großes Netzwerk, wie die zahlreichen eigenhändigen Briefe an Künstler und Kunstinteressierte in halb Deutschland beweisen. Damit war er auch erfolgreich. Immerhin traten dem Sächsischen Kunstverein Ortsvereine wie Weimar, Leipzig, Breslau oder Oldenburg bei. In regelmäßigem Kontakt stand er mit dem Münchner, Nürnberger und Berliner Kunstverein. Besonders diese Breitenwirkung betonte Quandt durchaus selbstbewusst, war er sich doch seiner eigenen Bekanntheit als Kunstschriftsteller im Klaren. ${ }^{146}$ Andererseits schloss er immer wieder seine Kollegen aus, setzte sie unter Druck oder stellte sie vor vollendete Tatsachen, indem er Künstler direkt betreute, die dem Verein etwas verkaufen wollten, Kunstwerke für den Verein ankaufte oder Meinungen zu vereinspolitischen Fragen durch seine eigenmächtig geführte Korrespondenz vorzeichnete. ${ }^{147}$ Dass er die Archivalien des Vereins eigenhändig in einem Verzeichnis zusammenfasste, deutet auch auf das Steuerungspotenzial hin, dass er den Akten zuschrieb. Sie enthielten alle seine persönlichen Verhandlungen. ${ }^{148}$ Gleichzeitig hatte er die finanziellen Möglichkeiten, seine Gedanken und Meinungen immer wieder flugblattartig zu veröffentlichen, so wie er es im Kunstverein mit seinen Stellungnahmen zu den Preisaufgaben 1829 oder mit der Rücktrittsdrohung Ende 1830 getan hatte. Damit fehlte ihm wohl gelegentlich die Bodenhaftung, was zum Bruch mit den anderen Mitgliedern des Komitees führte. Diese Künstler und Akademielehrer wie Hartmann, Vogel und Dahl oder Hofangestellte wie der Leibarzt des Königs, Carus, mussten vielleicht eher andere Interessen berücksichti-

145 Kovalevski 2010 hat im Katalog jeweils die Stimmenverhältnisse der Bildankäufe angegeben. Sie sind oftmals einstimmig.

146 Im Kontext der Retzsch-Affäre wird dies deutlich: »Erlauben Ew Excellenz mir noch ein Bekenntniß: Ich bin nehmlich auf nichts eitel $u$ habe es auch nicht Ursache zu seÿn, als einzig und allein auf den Namen, welchen ich mir unter den Künstlern und Kunstkennern des Auslandes erworben habe [...]. Der Vorstand trägt in solchen Fällen immer die Schuld, wenn er auch der Unschuldige ist u der in der literarischen Welt bekannte Mann, ist daher derjenige, gegen welchen zuerst die Critik gerichtet wird. «Brief von Quandt an Vitzthum vom 3.8.1830, in: HStADD, 12509 Sächsischer Kunstverein, Nr. 1, fol. 28or.

147 Ein bezeichnendes Beispiel hierfür war im Frühjahr 1829 die umstrittene Frage, ob Künstler des Komitees eigene Bilder zur Verlosung geben könnten. Dies war bis dahin nicht möglich. Quandt war vehement dagegen und zog vor der entscheidenden Generalversammlung Goethe und diverse auswärtige Ortsvereine auf seine Seite. Mit dieser Strategie konnte er die Dresdener Mitglieder, die sich als Mehrheit für die Änderung ausgesprochen hatten, überstimmen. Siehe Korrespondenz zwischen Quandt und Goethe zwischen dem 28.3. und 29.4.1829, in: Schmitz/Strobel 1829, S. 51-56. Quandts eigenhändi- gen. Wahrscheinlich aber hatten sie zumindest mehr Erfahrung in alltäglicher Teamarbeit, als der komplett unabhängige, freiberuflich arbeitende Quandt.

Mit dem Rücktritt als Vorstand des Sächsischen Kunstvereins schien auch seine Tätigkeit im Sächsischen Altertumsverein zu Ende gegangen zu sein. Während die Gründe im Kunstverein in zwischenmenschlichen Schwierigkeiten und Enttäuschungen über das verfehlte Ziel einer Förderung der Historienmalerei zu suchen sind, entziehen sie sich im Fall des Altertumsvereins unserer Kenntnis. Womöglich war es aber genau die zermürbende Tätigkeit im Kunstverein und die jahrelange Trägheit des Altertumsvereins, die ihn der Vereinsarbeit überdrüssig machten. ${ }^{149}$ Er mochte wohl entgegen anfänglicher Hoffnungen nicht mehr an die fördernden und bildenden Maßnahmen dieser Institutionen glauben. Letztlich haben genau diese Schwierigkeiten ihm den Rücktritt aus dem Kunstverein anfangs 1833 erleichtert: »So habe ich denn eine Erfahrung mehr gewonnen, bin um eine große Bürde, welche ich zwar gern übernommen hatte, freyer und auch das Gefühl erlittnen Undanks hat etwas Erhebendes. ${ }^{150}$ Von neuem konnte er sich, seinem Gewissen entsprechend, anderen, eigenen Dingen zuwenden.

Als Quandt 1835 schließlich auch seine Mitgliedschaft im Kunstverein formal zurückzog, begründete er dies mit den Ankäufen von »Frucht u Dornenstück[en] «. Dieses niedere Genre wollte er nicht weiter mit Beiträgen unterstützen und zog alle seine Aktien und diejenigen seiner Frau zurück. ${ }^{51}$ Für die erhoffte Förderung der Historienmalerei und höherer Aufgaben in den Künsten blieb ihm die Publikationstätigkeit. Wie er seine Kunstansichten in Bezug auf die Bildgattungen verbreitete, wird im nachfolgenden Kapitel behandelt. Es soll aufzeigen, wie die gescheiterte Förderung guter Kunst im Sächsischen Kunstverein dennoch weiterhin eines seiner wichtigsten Anliegen blieb.

ges Verzeichnis der Akten 1828-1830, in: HStADD, 12509 Sächsischer Kunstverein, Nr. 1, fol. 350r-354V.

148 Brief von Quandt an das Komitee vom 7.2.1833: »[...] Die Vereinsacten, welche in Concepten einen Theil der weitläufigen Correspondenz und schriftlichen Verhandlungen enthalten, die ich als Vorstand führte, [...] zeigen, welche Obliegenheiten mir übertragen, welcher Modus bisher dabey beobachtet worden und herkömmlich ist, da hierüber die Statuten nichts Näheres bestimmen.« Schmitz/Strobel 2001, S. 221.

149 Brief von Quandt an Keil am 26.12.1831, kurz nach seiner Wiederwahl als Vorsitzender für weitere vier Jahre: »Man hat mich wieder zum Vorstand des Kunstvereins erwählt u dies ist eben so gütig als grausam. Nicht nur daß die Geschäffte selbst sehr viel Zeit rauben, sie sind eine Quelle des Verdrußes, wenn man dem Eigennutze u dem dummen Hochmuthe sich widersetzt, was die Pflicht des Vorstands erfordert. In der That kann man bey diesem Amte zum Menschenfeinde werden."

150 Brief von Quandt an Müller vom 18.4.1833, in: Schmitz/Strobel 2001, S. $227-228$.

151 Brief von Quandt an das Komitee des Sächsischen Kunstvereins, in: Schmitz/Strobel 2001, S. 229 (HStADD, 12509 Sächsischer Kunstverein, Nr. 3, fol. 290). S. a. Schmitz 2001, S. 325-333. 


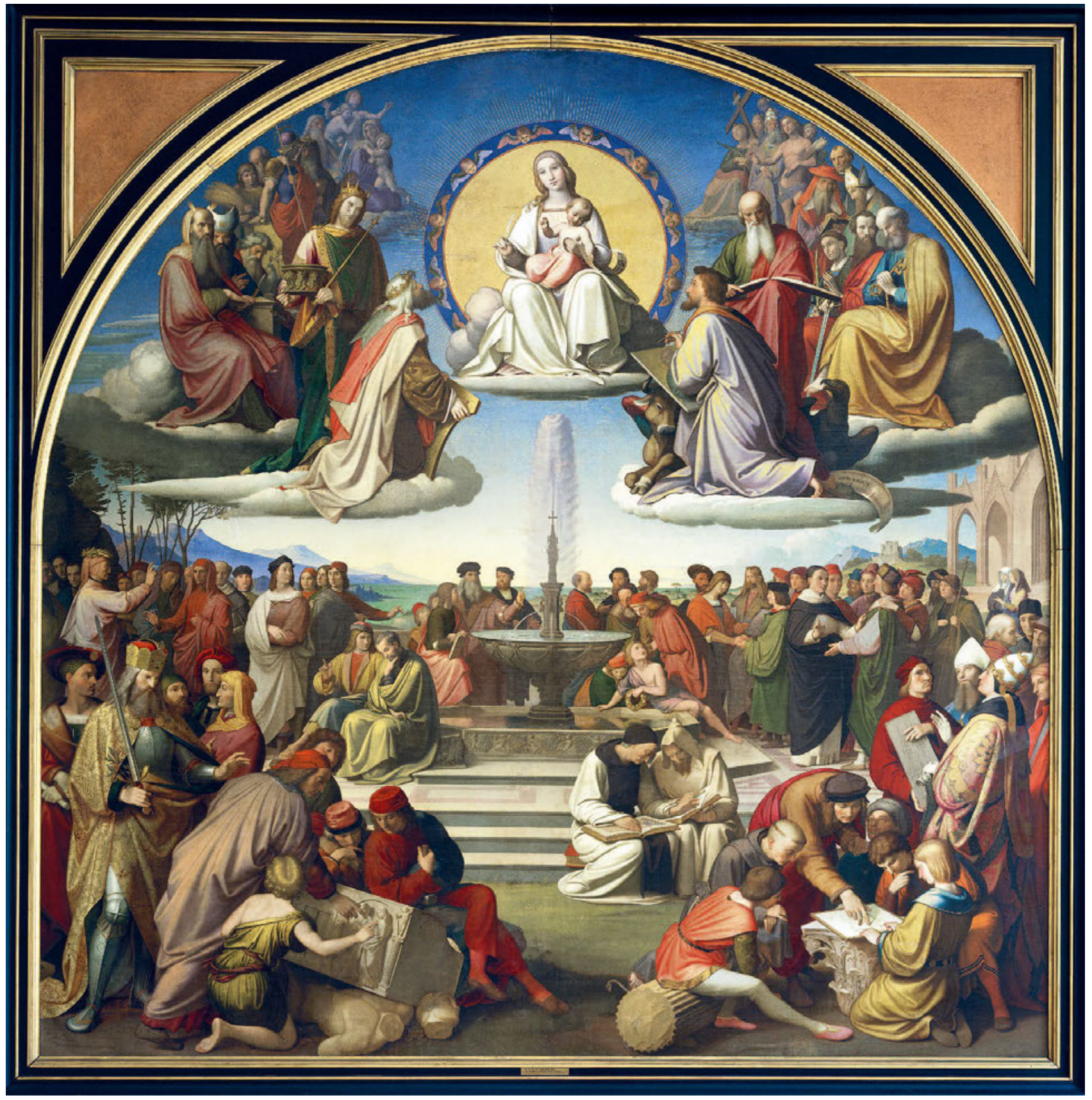

35 Johann Friedrich Overbeck, Der Triumph der Religion in den Künsten, 1831-1840, Öl auf Leinwand, $392 \times 392$ cm, Frankfurt a/M, Städel Museum, Inv.-Nr. 892 


\section{POESIE IN DER KUNST: Historienmalerei und andere Bildgattungen}

Quandts Schwerpunkt der Förderung im Kunstverein lag auf der Historienmalerei. Besonders beispielhaft erschien ihm dabei der Gründer der Lukasbrüder und Nazarener Künstler Friedrich Overbeck. Dessen unter den Zeitgenossen viel diskutiertes Frankfurter Gemälde Der Triumph der Religion in den Künsten war ihm eine »stumme Hymne « von paradiesischer Erscheinung (Abb. 35). ' Gerade dieser Anspruch einer poetischen Kunst ließ Quandt tendenziell Historien begünstigen. Eine theoretische Abhandlung über die einzelnen Bildgattungen hat er jedoch nie geschrieben. Dies rührt von seiner grundlegenden Einstellung her, dass Kunst Ausdruck des menschlichen Geistes sei. Deshalb spielte es für ihn grundsätzlich keine Rolle, welcher Gattung ein Kunstwerk angehört. ${ }^{2}$ Werke der unterschiedlichen Bildgattungen können bei Quandt positiv bewertet sein, wenn er darin eine Manifestation der menschlichen Vernunft erkennen kann. Dennoch ist der Kunstschriftsteller der klassischen Gattungshierarchie verhaftet geblieben. Entsprechende Tendenzen lassen sich an vielen Stellen erkennen. Den klassischen Bildgattungen der Malerei folgend, werden in diesem Kapitel seine Aussagen zur Historie und Landschaft, zum Genre, Porträt und Stillleben untersucht. ${ }^{3}$

\section{Gegenstand und Aufgabe der Kunst}

»Der zoologische Maler sieht freilich weiter nichts als das Fell, indeß ein [Paulus] Potter die Naturidee bildlich in den einzel-

1 Quandt 1846 (2), S. 374-375, hier S. 375: »Die seelenvollste und man darf sagen, seligste bildliche Dichtung ist das große Bild, welches das Städelsche Museum besitzt. Es wird der Triumph der christlichen Religion benannt, doch scheint mir die Benennung >Paradiesı treffender. Wer es nicht gesehen, dem können wir nur rathen, es anzuschauen, aber beschreiben läßt sich so etwas nicht. « S. a. Grewe 2015, S. 211-213; Thimann 2015, S. 35-36; Grewe 2005, S. 80-83.

2 "Diesem Endlichen setzten sie nun das Unendliche, die von keinem Raume und keiner Zeit begränzte Idee entgegen. Allein der Begriff von einem Dinge an und für sich, wie Sie Sich erinnern werden, liegt in dem Umfange der Idee, deren höheres und allgemeineres Merkmal der Inhalt jeder Gattung in sich trägt und einschließt." Quandt 1844 (1), S. 132. »Ein Bild ist nicht mehr eine Luxussache, sondern ein Kunstwerk, welches das Auge nicht blos reizen, sondern den Geist befriedigen, und indem es ihn beschäftigt, erfreuen soll. Daher muß das Geistige, die Idee, darin, in alle Theile desselben übergegangen, das Bild ein ausgesprochener Gedanke, eine zur sinnlichen Wahrnehmung zurück- nen lebenden Thieren, der Genremaler in jedem Individuum die Menschheit erkennt, dem Landschafter aber die gesammte Natur eine göttliche Offenbarung, und seine Kunst ein Pantheismus ist. So wird denn jeder äußere sinnliche Gegenstand durch die Spontaneität des Geistes zu einem inneren Gegenstande und jeder innere durch die Darstellung zu einem äußeren. $\aleph^{4}$ Diese Passage entstammt dem Aufsatz Ueber Gegenstände und Aufgaben der bildenden Kunst, den Quandt 1847 veröffentlicht hat. Darin unterscheidet er den »Gegenstand « eines Kunstwerks von seiner »Aufgabe «. Der Gegenstand sei das sinnlich wahrnehmbare Thema oder Motiv des Kunstwerks. Die Aufgabe wiederum sei das Thema, das dem Künstler aufgetragen werde und solle immer eine Idee, also einen Vernunftbegriff, bezeichnen, die sinnlich wahrnehmbar gemacht werde. Diese Idee werde damit zugleich Gegenstand und Aufgabe seines Bildes.

Indem Quandt seine Kunstbetrachtungen immerzu auf die gedankliche Ebene der philosophischen Ästhetik übertrug, eröffnete sich ihm zumindest eine theoretische Offenheit gegenüber jeder Art von Kunst, also auch allen Spielarten der Gattungen. So stellte er fest, dass Gegenstände und Aufgaben der Kunst immer zeitlich bedingt seien: »Diese Forderungen [an die Kunst - AR], welche aus den politischen, religiösen oder häuslichen Lebensverhältnissen hervorgehen, haben immer einen speciellen Zweck und sind daher durch die Denkungsweise der Menschen in einer bestimmten Zeit bedingt. Wenn nun jemand sagte: Was gehen mich die Götter der Griechen an, oder Legenden, die ich nicht glaube, und was kümmert mich die Ge-

geführte, aus der Natur abstrahirte, geistige Anschauung seyn. Es ist das Kunstwerk nichts anders als eine Idee, welche mit solcher Deutlichkeit gedacht ist, daß sie, vermittelst des Scheins, als Erscheinung eines Wirklichen uns entgegen tritt."Quandt 1821, S. 117. S. a. Thimann 2014, S. 137-142.

3 Bei dem hier diskutierten Gattungsbegriff geht es um die Kunstwerke, die durch ihren Gegenstand bestimmt sind. Siehe hierzu die Unterscheidung von Kunstgattungen (Malerei, Skulptur, Architektur) und Bildgattungen (Historie, Landschaft, Genre, Porträt, Stillleben) in: Bätschmann 2005, S. 34.

4 Quandt 1847, S. 67. Paulus Potter ist einer der wenigen niederländischen Maler des 17. Jahrhunderts, den Quandt schätzte. Siehe Briefe an Rudolph Weigel vom 7.11.1857, in: SLUB, Mscr. Dresd., App. 0204, Nr. $97 \mathrm{~V}$ und an Sibylle Mertens-Schaaffhausen, nicht datiert [1835], in: Bonn, Universitäts- und Landesbibliothek, Dezernat 5 / Abt. Handschriften und Rara, Autographensammlung, Kiste 86. S. a. Fernow 1806-1808, S. 310-314. 
schichte, da sie der Vergangenheit angehört, ich mag also nichts von der Art dargestellt sehen, so würde man auf keine Weise ein Recht haben, ihm Bilder, welche solche Aufgaben behandeln, aufzuzwingen.«

In der Tat zwang Quandt niemandem Themen auf. Oft überließ er beauftragten Künstlern die Wahl des Themas. Dennoch zeigt sich in zahlreichen Beurteilungen von Kunstwerken und in der Art und Weise, wie er Künstler förderte, dass er der Historie zur Erreichung seines Kunstideals tendenziell mehr zutraute als der Landschaftsmalerei oder den Genrebildern. Die Historie war die Bildgattung, die er mit erhöhter Aufmerksamkeit behandelte, und die Künstler, die sich mit ihr beschäftigten, unterstützte er ganz besonders.

Die Begünstigung der Historienmalerei vor allen anderen Gattungen hat ihre traditionelle Grundlage in der Kunsttheorie des 18. Jahrhunderts und widerspiegelt im Detail die Diskussionen seiner Zeit. Diese hatte Johann Georg Sulzer in seiner Enzyklopädie Allgemeine Theorie der Schönen Künste, die 1771 bis 1774 in zwei Bänden publiziert worden war, festgehalten und die begrifflichen Grundlagen für viele Jahre bestimmt. ${ }^{6}$ Basierend auf der französischen Kunsttheorie erklärte Sulzer die Historie als Gemälde, auf dem handelnde Personen den Hauptgegenstand darstellen. Die Absicht solcher Bilder sei die Vermittlung von Leidenschaften, äußerlichem Verhalten und innerlichen Empfindungen: »Der Historienmahler ist der Mahler des menschlichen Gemüthes, seiner Empfindungen und seiner Leidenschaften. [...] Soll es, als Historie, gut seyn, so muß es nicht blos das Aug, sondern den Geist und die Empfindung reitzen; es muß dem empfindsamen Menschen Gedanken und Empfindungen erweken, die in ihm würksam werden. « Wie Quandt einige Jahrzehnte später stellte der Schweizer Gelehrte ein Fehlen guter Historien fest und empfahl den Künstlern »Nachdenken und Überlegung«, da zu vieles ohne Verstand gemalt würde. Der
Historienmaler aber müsse Philosoph und Dichter sein und die Charaktere der Menschen erforschen können. Ebenso müsse er empfindsam sein, um die Gemütszustände großer Figuren darstellen zu können. ${ }^{8}$ Ähnliches liest man auch bei Quandt immer wieder. Dennoch nahm der Dresdener Kunstschriftsteller nicht an den grundsätzlichen Gattungsdiskussionen seiner Zeit teil. Genaue Differenzierungen von Untergattungen der Historie, wie sie sich beispielsweise im Aufsatz Über die Gegenstände der bildenden Kunst von Johann Heinrich Meyer und Johann Wolfgang von Goethe, erschienen 1798 in den Propyläen, oder in August Wilhelm Schlegels Vorlesungen über schöne Literatur und Kunst der Jahre 1801 bis 1804 manifestierten, fehlen bei ihm. ${ }^{9}$ Wohl waren sie auch nicht nötig: So meinte Schlegel, es sei allgemein anerkannte Definition, dass ein historisches Gemälde mehrere Personen in unterschiedlichen Beziehungen und Handlungen mit Ernst und Würde zeige. ${ }^{10}$

Dennoch formulierte Quandt in seinem Aufsatz von 1847, warum bestimmte Gegenstände für die Kunst bedeutsam seien: »[Das] ewig Schöne ist die im Kunstwerke dargestellte gegenwärtige Idee. Wer aber nur an dem Historischen oder Mythischen klebt, und nicht bis zur Idee eindringt, das Bild sieht, ohne den Gedanken zu erkennen, dem wird Alles, was Künstler des Alterthums und der neueren Zeit geschaffen, nicht zeitgemäß scheinen, dahingegen selbst dem Ungläubigen ein Madonnenbild, als bildliches Dasein der Mutterliebe, heilig sein wird, wenn er in das Innere der Darstellung einzudringen vermag, und folglich werden die Götter der Griechen, als bildliche Ideen des Schönen, Guten und Wahren, wie die Heiligen, als bildliche Ideen von Tugenden, immerdar würdige, und da das Denken unendlich ist, unerschöpfliche Gegenstände für die Kunst bleiben. $\ll^{11}$ In diesem Satz zeigt sich eine Unterscheidung, die für die Beurteilung der Historienmalerei wichtig bleiben sollte. Quandt missfiel eine wortwörtliche Darstellung mythologi-
5 Quandt 1847, S. 69. Die Feststellung, dass Kunstwerke in ihre Zeit eingeordnet werden müssen, kommt in diesem Aufsatz stärker zum Ausdruck als in den früheren Schriften. Wahrscheinlich reagiert hier Quandt auf Hegels Ästhetik oder Philosophie der Kunst, die seit 1835 basierend auf Vorlesungsnotizen seiner Schüler von Heinrich Gustav Hotho herausgegeben wurde. Siehe Gethmann-Siefert 1995, S. 202-203, 213-214.

6 Eintrag »Historie«, in: Sulzer 1771, S. 540-545. S. a. Gaehtgens 1996, S. 52-53.

7 Sulzer 1771, S. 540-541.

8 Sulzer 1771, S. 541: „Die erste Sorge des Mahlers geht auf die Wahl der Materie, wobey es um so viel mehr nöthig ist, ihm Nachdenken und Ueberlegung zu empfehlen, da der große Haufen der Mahler so gar unüberlegt und so gar ohne Verstand handelt, daß bald nichts selteners ist, als historische Gemählde, die sich durch ihren Inhalt empfehlen." Ebd., S. 544: „Wir erwarten Sachen von ihm, die unsren Verstandes und Gemüthskräften einen stärkern Schwung geben. Er soll uns mit Menschen bekannt machen, die wir ihres Charakters halber bewundern, oder die uns wenigstens sehr intressant sind. Darum muß er, so wie der Dichter, ein Mann von großem Verstand, und von vorzüglichen
Gemüthskräften seyn. Denn, was er selbst nicht zu fühlen im Stand ist, wird er gewiß uns nicht empfinden machen. Er muß ein Philosoph seyn, der gewohnt ist, das Genie und die Charaktere des Menschen zu erforschen, ihre Urtheile, Gesinnungen und Leidenschaften gegen einander abzuwiegen."

9 Schlegels Einteilung der Historienmalerei in eine symbolische Historie und eine Historie nach Tatsachen richtet sich gegen das fünfteilige System von Goethe und Meyer. Dieses umfasst die rein menschliche und historische Darstellung, das Charakterbild, die erfundene, mythische oder allegorische sowie die symbolische Darstellung. Schlegel 1801/02, fol.31r-42r; Meyer/Goethe 1798, Bd. 1, S. 20-54. S. a. Rössler 2011, S. 346-347; Gaehtgens 1996, S. 55-57.

10 »Ein historisches Gemählde ist anerkannter Maßen ein solches, auf welchen mehre Personen in Lagen, Verhältnissen, Handlungen gegen und mit einander dargestellt sind. Und zwar wird dabey noch ein gewisser Grad von Ernst und Würde sowohl im Charakter der Einzelnen, als in dem was alle zusammen vornehmen, erfodert." Schlegel 1801/02, fol. 31r; s. a. Gaehtgens/Fleckner 1996, S. 299.

11 Quandt 1847, S.71. S. a. Grewe 2015, S. 228. 
scher oder historischer Textquellen in der Malerei. Vielmehr solle auf die Idee zwischen den Zeilen fokussiert werden. Seine Beispiele, um dies zu erläutern, basieren auf historischen Gegenständen: eine Maria stellt die Mutterliebe dar, Motive aus der griechischen Mythologie das Schöne, Gute und Wahre. »Geistiger Bildstoff « war das, was Quandt in der Kunst suchte. ${ }^{12}$ Die Geschichte der Menschheit bot ihm zufolge unendlich viele Anlässe hierzu.

\section{Poetische Historien und allgemein menschliche Begriffe}

In einem Bericht über die Ausstellung der Dresdener Kunstakademie des Jahres 1818 hatte Quandt geschrieben: »Auf die Historienmalerei in höherem Sinne äußert die Richtung der Poesie am entschiedensten ihren mächtigen Einfluss.« Diese Art der Historienmalerei würde nicht das »geschichtliche Factum«, also ein Motiv, das auf einer historischen Quelle beruhe, abbilden, sondern stelle »vielmehr einen Moment der ewig neu sich entfaltenden Menschheit, in Raum und Zeit, dar.«133 Der Historienmaler löse sich dabei von der sinnlichen Erscheinung der Malerei und bilde eine Idee ab. Diese würde im Betrachter Gedanken über das Gesehene auslösen.

Mit diesen Überlegungen begann Quandt seine Analyse des Gemäldes Der Raub des Hylas von Ferdinand Hartmann, Professor der Historienmalerei an der Dresdener Akademie (Abb.36). Hylas, Freund und Waffenträger des Herakles, wurde von Nymphen in eine Quelle gezogen und verschwand darin. Quandt rühmte Hartmanns Darstellung der Nymphen, weil in ihnen die Idee der mythologischen Geschichte vorzüglich aufgefasst sei. Eine Figur zeige Liebe, eine andere Sehnsucht und eine weitere Leidenschaft. Damit werde die Bedeutung der Sage fassbar: es gehe um ein Bündnis zwischen der Natur und dem Menschen. Hylas hingegen hätte nicht abwehrend, sondern sich hingebend dargestellt werden müssen. Dies wäre in Quandts Augen angemessen gewesen, denn Begriffe wie Liebe, Sehnsucht und Leidenschaft seien »Momente des Gemüths« und somit unabwendbare Charakteristika des Menschen und seiner Natur. ${ }^{14}$

12 »Unzählige Momente aus der Geschichte, ja dem Leben der Individuen [...], Entwickelungsmomente der Menschheit, [können] Stoff und Träger für Gedanken, als Motive zu Kunstwerken, überhaupt geistiger Bildstoff werden.«Quandt 1847, S. 71.

13 Quandt 1818 (1), Sp. 1919.

14 Ebd., Sp. 1920: »Warum widerstrebt aber Hylas den Nymphen, und folgt nicht willig der freundlichen Lockung? Ist Hylas das Bild des Menschen, der durch Liebesmacht und Zauber angezogen, in den Bronnen der Natur hineinsinkt, so wäre ein sich Hingeben in die Arme der Nymphen, der Idee welche in der Fabel ausgesprochen wird, wohl noch angemessener gewesen, und der große deutsche Dichter [Goe-

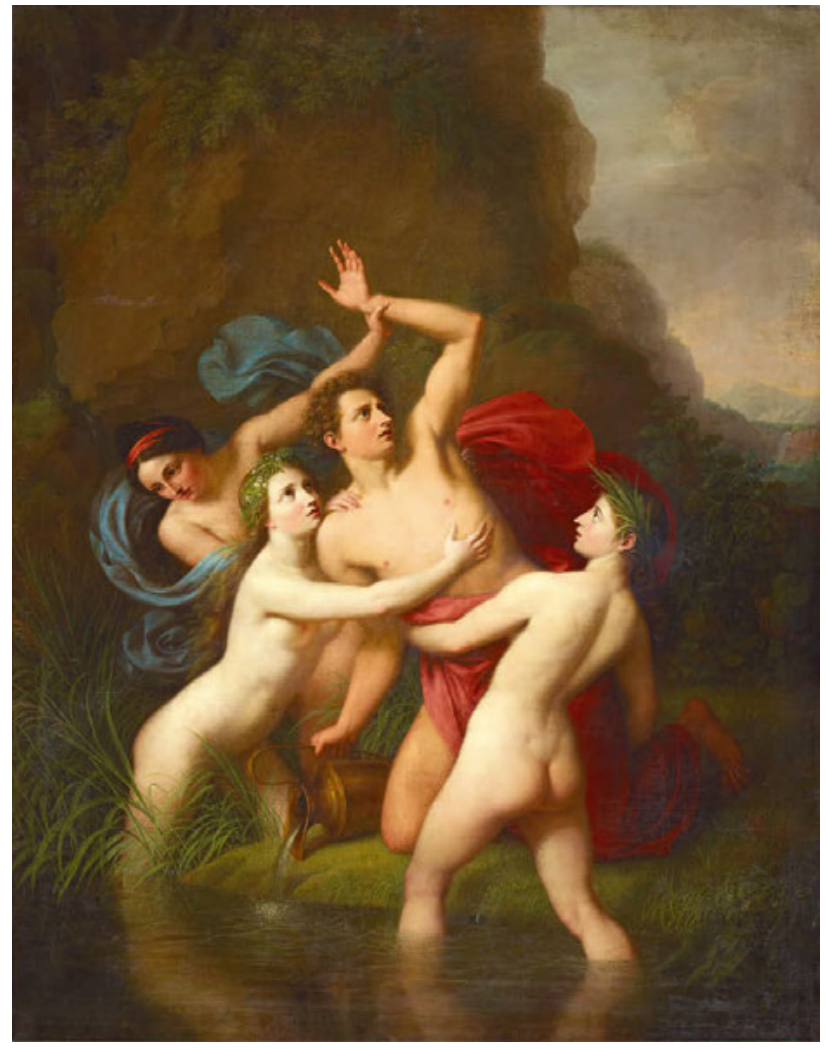

36 Ferdinand Hartmann, Der Raub des Hylas, um 1818, Öl auf Leinwand, $255 \times 197,5$ cm, Leipzig, Museum der bildenden Künste, Inv.-Nr. G 102

Derartige Begriffe sollten sich laut Quandt in Historiengemälden manifestieren und gedankenanregend wirken. Nicht die Darstellung der mythologischen Geschichte interessierte ihn, sondern ihre Interpretationsfähigkeit. Für Quandt war ein Gemälde eine Metapher für allgemeine Begriffe. Damit stehe die Historie der Poesie näher als der historiographisch fundierten Geschichtserzählung. Dieser Einsicht blieb er zeit seines Lebens treu, wie weitere Stellungnahmen zur Historienmalerei noch verdeutlichen werden. Dabei rezipierte er einen auf Hegel zurückgehenden Gedanken, gemäß dem die Poesie die Lehrerin der Menschheit sei. ${ }^{15}$ Schelling, der für Quandt, wie er selber immer wieder schrieb, sehr wichtig war, spitzte dies in der Rede Ueber das Verhältnis der bildenden Künste zu der Natur von

the] sagt in seinem Fischer: Halb zog sie ihn, halb sank er hin - Selbst wenn die Mythe von Hylas weiter nichts, als eine verschönernde, heitere Einkleidung einer traurigen Begebenheit wäre, so sollte doch auch in der bildlichen Darstellung alles vermieden seyn, was uns daran erinnert, daß Hylas ertrank; aber eben diese Vorstellung wird durch das bange Sträuben des Mannes nur zu sehr in uns angeregt."

15 Georg Wilhelm Friedrich Hegel, [Das älteste Systemprogramm des deutschen Idealismus], 1797 [Internetressource: http://www.zeno.org/ nid/20009176381, letzter Zugriff: 17.9.2018]: »Der Philosoph muß ebensoviel ästhetische Kraft besitzen als der Dichter. [...] Die Poesie bekommt dadurch eine höhere Würde, sie wird am Ende wieder, was sie 


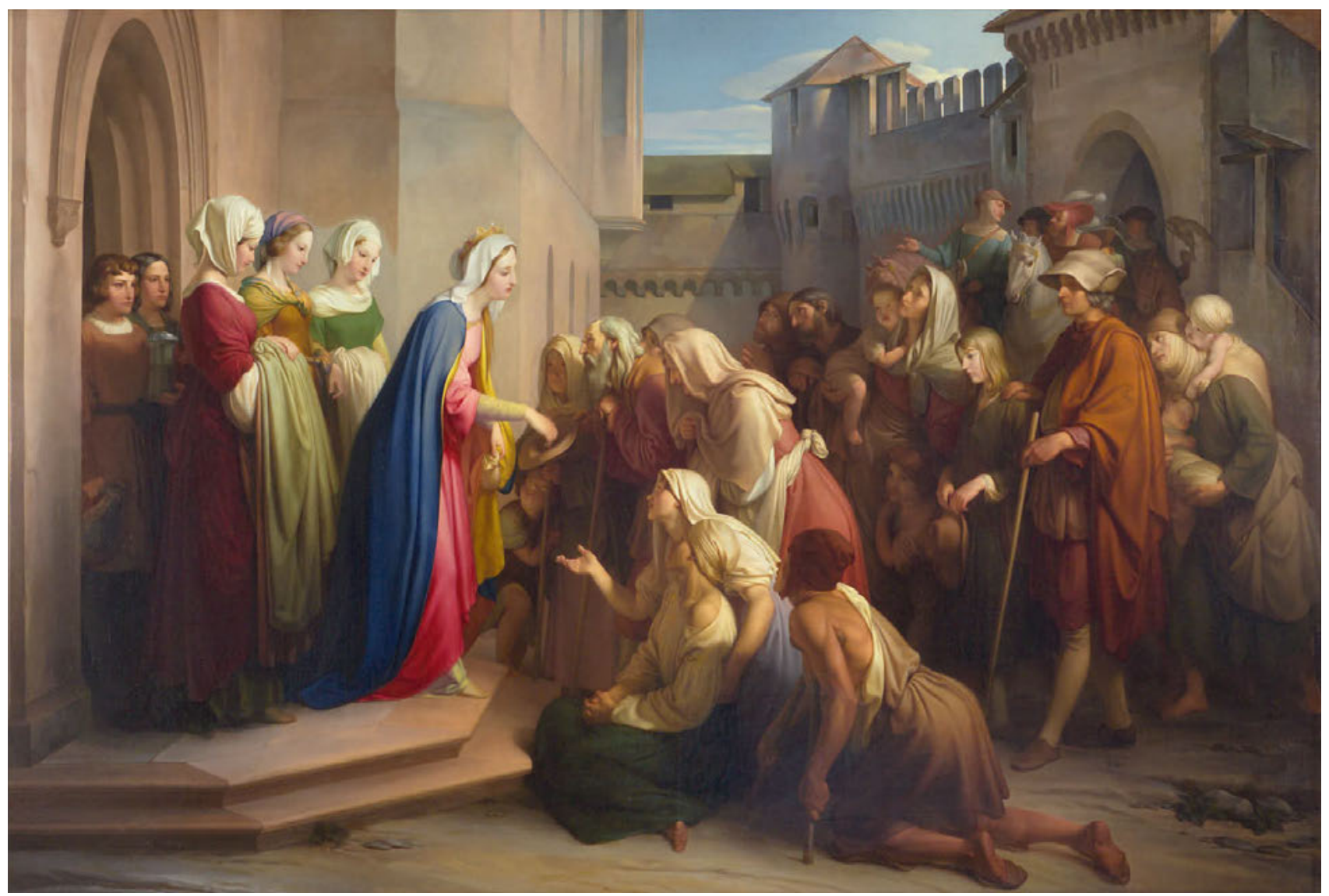

37 Gustav Heinrich Naeke, Die Heilige Elisabeth verteilt Almosen auf der Wartburg, 1820-1827, Öl auf Leinwand, $235 \times 158$ cm, Frankfurt a/M, H. W. Fichter Kunsthandel

1807 zu: »Denn es soll die bildende Kunst, nach dem ältesten Ausdruck, eine stumme Dichtkunst sein. $\ll^{16}$

Mit dem Gemälde Die Heilige Elisabeth verteilt Almosen auf der Wartburg von Gustav Heinrich Naeke besaß Quandt eine großformatige Historie, die für sein Verständnis von Geschichtsmalerei sehr wichtig war (Abb. 37). Er hatte das Bild noch während seines Romaufenthalts 1820 in Auftrag gegeben und dem Künstler für die Wahl des Motivs freie Hand gelassen. ${ }^{17} 1828$ vollendete Naeke, seit 1824 Lehrer und Professor an der Dresdener Kunstakademie, das Gemälde. Quandt lobte das Bild, das ganz im Sinne seiner Kunstauffassung war: »Es ist so glücklich in den Grenzen des Wirklichen gehalten, daß es durch seine Naturwahrheit weder das Edle herabzieht noch das Auge durch den Anblick von Gebrechen beleidigt. Dahingegen blickt die ewig u in allen Verhältnissen göttliche innere Menschennatur aus ihrer körperlichen Verdunklung u weltlichen Gebrechlichkeit hindurch, so daß der Geist freudig, selbst in Dürftigkeit u Roheit das gleiche Wesen erkennt, ohne daß der Künstler die Wahrheit verfälscht o[der $]$ verputzt hätte. $\aleph^{18}$ Begeistert schrieb er, sogar die Bettler und Krüppel seien mit derartiger Wahrheit und Würde gemalt, dass jeder »vom Schicksal Begünstigte« ihm verwandte Wesen erkennen würde..$^{9}$ Quandt suchte in der am Anfang war - Lehrerin der Menschheit; denn es gibt keine Philosophie, keine Geschichte mehr, die Dichtkunst allein wird alle übrigen Wissenschaften und Künste überleben.«S. a. Gethmann-Siefert 1995, S. $189-190$.

16 Schelling 2004, S. 54. Quandt kommentiert die Rede in seinen Vorlesungen über Ästhetik; Quandt 1844 (1), S. 121-127, die entsprechende Stelle S. 121. S. a. Scholl 2005, S. 239-250; Schmitz/Strobel 2001, S. XXIII.

17 Brief von Quandt an Veit Schnorr vom 25.3.1820, in: SLUB, Mscr. Dresd. n Inv. 8, Bd. 2, fol. 194r-v; Schnorr 1886, S. 178, 430, 451, 455. Förster 1846, S. 315-316 mit einer ausführlichen Würdigung. S.a. Rüfenacht 2018, SQ-95; Kat. Wartburg-Eisenach 2007, S. 526-528; Ko- valevski 2010, S. 304; Neidhardt 1988, S. 157-164; Maaz 1986, S. 42-44; Bemmann 1925, S. 17-18; Raczyński 1836-1841, Bd. 3, S. 216-217, 225.

18 Brief an Schnorr vom 1.3.1825, in: SLUB, Mscr. Dresd. n Inv. 15, Bd. 31, fol. 121v. S. a. Brief von Rudolf Schadow an Johann Gottfried Schadow vom 17.1.1821, in: Berlin, SMB, Nachlass Johann Gottfried Schadow, NL Sw 182: »N[a]eke hat einen Carton gemahlt vorstellend die h. Elisabeth welche Allmosen vertheilt, es ist ein nobler Sinn und viel Wahrheit verbunden in diesem Werk, er wird dies Bild für H. v. Quan[d]t mahlen, er selbst ist ein sehr stiller zurückgezogener Mensch.« S. a. KB 1828, Jg. 9, Nr. 21, S. 83.

19 Brief an Schnorr vom 1.3.1825, in: Ebd, fol. 124V. 
Kunst den philanthropischen Ausdruck einer allgemeingültigen Menschlichkeit, die sich in Naekes Gemälde ganz besonders zu zeigen schien und sowohl hinter Krankheit und Armut, als auch hinter Erfolg und Ehre aufzublitzen vermochte und vom Künstler bloß eingefangen werden musste.

Dementsprechend bestand Quandts eigene Sammlung mehrheitlich aus Historienbildern Alter und Neuer Meister. 1824 besaß er sechzehn altmeisterliche Historien und fünf Neue Meister. Nach seinem Tod verzeichnete der Auktionskatalog von 1868 neunundzwanzig Historien Alter und nur acht Neuer Meister. ${ }^{20}$ Das Verhältnis ist bezeichnend. Dass Quandt als Sammler keine größere Zahl zeitgenössischer Historien erreichte, mag an einer Problematik liegen, die auch seine Arbeit im Kunstverein betroffen hatte. Einerseits kosteten sie relativ viel und waren somit für Privatpersonen oft nicht erschwinglich. Dies war zwar für den wohlhabenden Quandt nicht der springende Punkt, zumal Alte Meister damals bereits rar und teuer waren - aber die meisten Künstler mussten notgedrungen marktkonform produzieren, was Quandt als Vorstand des Kunstvereins bekanntlich bemäkelt hatte. Andererseits war die Historie in seiner Auffassung diejenige Gattung, die eine Rolle für die Gesellschaft und somit auch für die Öffentlichkeit spielte. Dies stand in einem gewissen Widerspruch zur privat präsentierten Historie.

Doch Quandts Ziel war eine größere Breitenwirkung für die Historiengemälde. In Dresden war der Markt dafür eher schlecht. Akademie-Professoren wie Ferdinand Hartmann oder Friedrich Matthäi, die sich gelegentlich historischen Themen zuwandten, dabei aber den klassizistischen Formen treu blieben, waren für Quandt weniger interessant. ${ }^{21}$ Er legte seine Hoffnungen eher in die Berufung der jüngeren Professoren Carl Vogel von Vogelstein im Jahr 1820 und Gustav Heinrich Naeke 1828. Der königliche Auftrag an Vogel, im neu erbauten Festsaal und in der Kapelle des Neuen Palais von Schloss Pillnitz Fresken zu malen, fiel in die Zeit nach Quandts Umzug nach Dresden. Der Künstler hatte in den Lünetten des Kuppelsaals des Palais Allegorien der bildenden Künste, der Poesie,

20 Angaben gemäß Kat. Quandt 1824 und 1868. Alle Werke aufgeführt in Rüfenacht 2018, S. 6-41.

21 Altner 1990, S. 106-110; Neidhardt 1976, S. 29-32.

22 Richter 2002, S. 30; Welich 1996, S. 112-114; Briel 1987 (1), S. 21-22; Quandt 1823, S. 21.

23 Quandt 1823, S. 21-22; KB 1822, Nr. 98, S. 389-391, Nr. 99, S. 393-396. S. a. Welich 1996, S. 112-113.

24 Quandt 1846 (2), S. 381: »Es traf dies edle Unternehmen [die Ausmalung des Casino Massimo in Rom] in die ersten Regierungsjahre des Königs Ludwig, der die deutschen Künstler um sich versammelte und den gereiften Talenten ein weites Feld würdiger Thätigkeit eröffnete.« S. a. ebd., S. 388. Schnorr informierte Quandt über die Aufträge des bayerischen Königs. Kuhlmann-Hodick 2000, S. 35-36, 43; Büttner 1990, S. 77-91. der Liebe und der Philosophie ausgeführt und in der Kapelle ein Bildprogramm aus der Mariengeschichte gemalt. ${ }^{22}$ Die neuen Fresken stießen auf viel Zustimmung, wohl auch, weil es seit längerer Zeit die ersten in Dresden waren. Auch Quandt äußerte sich positiv darüber. ${ }^{23}$ Dennoch vermochten sie nicht mit den königlichen Aufträgen an Peter Cornelius und Schnorr von Carolsfeld für biblische und mythologische Geschichtszyklen in der Münchner Residenz mithalten. ${ }^{24}$ Bis es in Dresden zu einem größeren Freskenauftrag an Eduard Bendemann kam, sollte es noch viele Jahre dauern. So stellte Quandt immer wieder Historien wie Naekes Heilige Elisabeth in den Akademieausstellungen aus. ${ }^{25}$ Mit seinem Freskenauftrag zu Balladen Goethes an Carl Gottlieb Peschel im Belvedere-Turm in Dittersbach anfangs der 183 oer Jahre konnte er schließlich selber einen Künstler, den er während seiner Zeit als Vorsitzender des Sächsischen Kunstvereins stark gefördert hatte (vgl. Abb. 111-116), mit einem großen Auftrag beschäftigen. ${ }^{26}$ In diesem Verein wiederum war sein Anliegen einer breitenwirksamen Förderung der Historienmalerei, wie gezeigt wurde, grandios gescheitert.

\section{Förderung durch Kunstschriftstellerei}

Andere Fördermöglichkeiten boten Publikationen. Im Jahr 1843, ein Jahrzehnt nach seinem Austritt aus dem Sächsischen Kunstverein, erläuterte Quandt die Entwicklung der Historienmalerei an der Wende vom 18. zum 19. Jahrhundert in seinem Reisebericht Beobachtungen und Phantasien über Menschen, Natur und Kunst auf einer Reise in's mittägige Frankreich. Er befand sich auf der Rückreise nach Dresden und stand im Frankfurter Städel Museum vor den monumentalen Historienbildern Der Triumph der Religion in den Künsten von Friedrich Overbeck (Abb.35), Einfuihrung der Künste in Deutschland durch das Christentum von Philipp Veit (Abb. 38) und Carl Friedrich Lessings Jan Hus zu Konstanz (Abb. 43). ${ }^{27}$ Angeregt durch diese Bilder, die unter den Kunstkennern Deutschlands zu zahlreichen

25 Rezension in KB 1828, Jg. 9, Nr. 21, S. 83. S. a. Neidhardt 1993, S. 37-40, 45, Ders. 1976, S. 238-239.

26 Ausführlich hierzu Kap. Der ideale Mensch: Goethe-Inszenierungen in Dresden und Dittersbach.

27 Zur Entwicklung der neueren deutschen Kunst siehe Quandt 1846 (2), S. 368-388. Zu den Werken Kat. Frankfurt 1977, S. 270-271; Kat. Düsseldorf 2011, Nr. 66, 225, 234, S. 96-97, 266-268, 279-280. Lessings Hus war von Athanasius Graf Raczyński in Auftrag gegeben worden, der es wegen des hohen Preises aber nicht übernehmen wollte. Siehe die Korrespondenz zwischen Raczyński, Lessing und Vermittlern in Kaiser 2017, S. 486-504. 

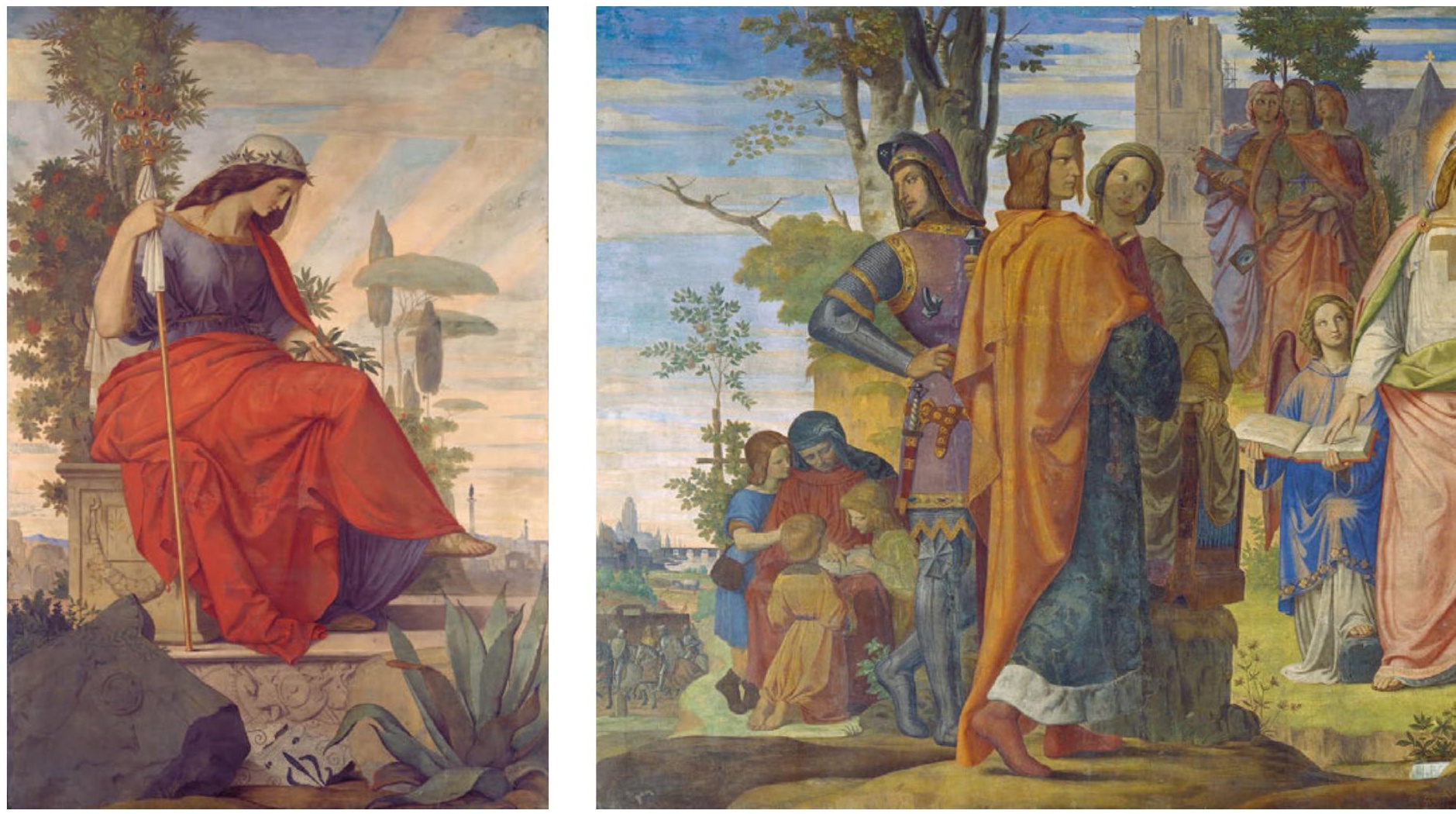

38 Philipp Veit, Dreiteiliges Wandbild. Links: Italia; Mitte: Die Einführung der Künste in Deutschland durch das Christentum; Rechts: Germania, 1834-1836, Fresko auf Leinwand übertragen, 285 × 191 / 612 / 192 cm, Frankfurt a/M, Städel Museum, Inv.-Nr. 1114-1116

Diskussionen geführt hatten, äußerte er sich zur Entwicklung der neuen deutschen Kunst. ${ }^{28}$

Quandt beschrieb die Künstler Eberhart von Wächter, Asmus Jacob Carstens und Christian Gottlieb Schick als Vorboten einer Malerei, in der die Poesie der Gedanken zur bildlichen Darstellung gekommen sei. ${ }^{29}$ Mit Friedrich Overbeck habe sich die deutsche Malerei dann ihre Bahn gebrochen. Dieser sei ein seelenvoller Maler, dessen tiefgreifende Gefühle in die Bilder einflössen. Philipp Veits Die Einführung der Künste in Deutschland durch das Christentum empfand der Freund historischer Gemälde zwar als etwas allegorisch, dennoch überzeugte ihn die bildgewordene These, dass die Göttlichkeit der Kunst das menschliche Dasein belebe. Er deutete die offensichtlich missionarische Christlich-

28 Insbesondere Overbecks Triumph wurde kontrovers diskutiert; zusammenfassend Assel//äger 2005 [2010], Kap. 2, 4-6. S. a. Thimann 2014, S. 195-201.

29 Quandt 1846 (2), S. 370-374, hier S. 374: »[...] denn Carstens, Wächter und Schick gingen nur wie Propheten einer neuen Zeit voraus, in der die Kunst sich in allen Richtungen entfaltete, und diese lassen sich mit den Gattungen der Poesie vergleichen, da, wie wir dargethan, beide einen Urquell haben, und die Malerei ein bildliches Denken und Dichten ist.« S. a. Grewe 2015, S. 124-127; Grewe 2007, S. 93-96; Locher 2005, S. 31-32.

30 Quandt 1846 (2), S. 378-379: »Veit ist nicht überhaupt ein Künstler, keit des Nazarener Malers in seinem Sinne und erkannte darin vielmehr die Göttlichkeit einer allgemeinen Idee. ${ }^{30}$

Auch im Nazarener der zweiten Generation, Julius Schnorr von Carolsfeld, entdeckte Quandt hohe Qualitäten. So bezeichnete er ihn als einen »episch bildenden Dichter«. Schnorr stelle in seinem Freskenzyklus zum Nibelungenlied in der Münchner Residenz historische Persönlichkeiten als Heroen dar. Er zeige Geschichte als »Weltbegebenheit«, wodurch der betrachtende Mensch den Menschen an sich erkenne, der sowohl der Gegenwart wie der Vergangenheit und Zukunft angehöre. Schnorr sei befähigt, dem Betrachter gewissermaßen eine höhere Bedeutung zu vermitteln und also darüber hinaus zu gehen als das, was eigentlich dargestellt würde..$^{3}$ 

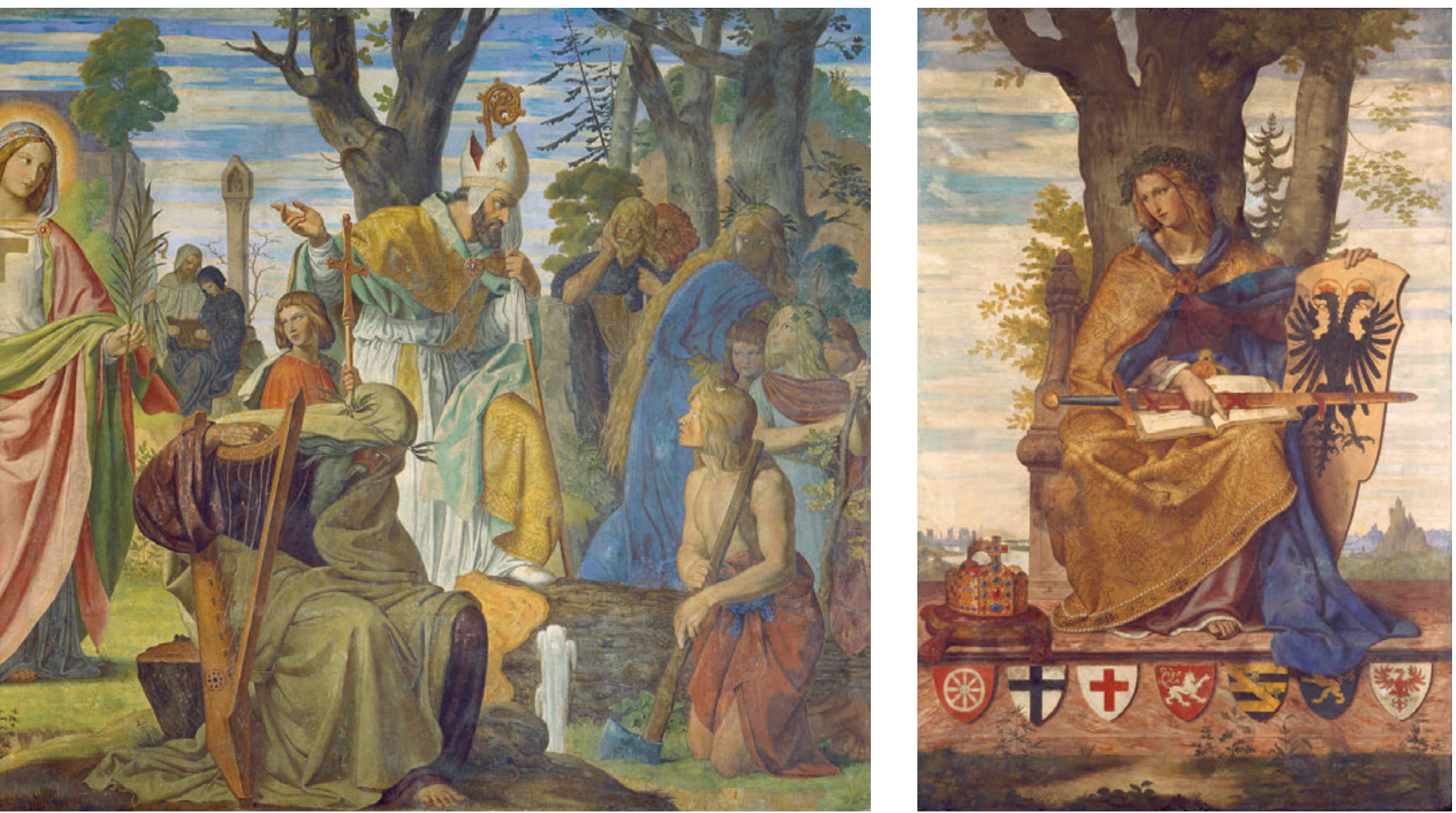

Solches attestierte Quandt noch dem etwas älteren Peter von Cornelius, der zwischen 1819 und 1824 als Direktor der Düsseldorfer Kunstakademie amtete und danach die Münchner Akademie leitete. Er vermöge über das Wirkliche hinauszugehen und Ideales darzustellen..$^{32}$ In jenen Jahren wurde Cornelius vom bayerischen König Ludwig mit Freskenprojekten beauftragt. Damit bot sich dem Maler die Möglichkeit, öffentlich sichtbare Kunstwerke auszuführen, wie er sie schon seit seiner Zeit in Rom propagiert hatte. Der Maler erhoffte sich zudem eine Wiederbelebung der italienischen, monumentalen Freskenmalerei - Anliegen also, die Quandt teilte. ${ }^{33}$

Darstellungen zur Weltbegebenheit, in der sich die Idee der Menschheit darthut, und das Schicksal des gesammten Geschlechts entscheidet und also eine höhere Bedeutung hat, als die blos factische. Das Individuum wird aber durch diese Auffassungsweise aus seiner engen historischen Persönlichkeit herausgehoben und zum Heros, in welchem der Mensch den Menschen erkennt, der sowohl der Gegenwart wie der Vergangenheit und Zukunft angehört, und der Moment ist dann auch kein Punkt in der Zeit, sondern in der Ewigkeit; die Geschichte selbst aber, sonach nicht mehr armselige Aufzählung des Geschehenen und Vergangenen, sondern ein Epos, das eine höhere Sicherheit hat, als die Historie.« Zum Kontext siehe Locher 2005 , S. 58-62. S. a. Quandt 1840 (3), Sp. 403

32 Quandt 1846 (2), S. 374-375: »[...] Keiner beherrscht den geistigen Stoff wie er, vor dessen Genius sich jeder Gedanke gleichsam krystallisiren, gestalten, Bild werden muß. Dabei aber empfangen diese
Im gleichen Atemzug mit Cornelius nannte Quandt den um eine Generation jüngeren Wilhelm von Kaulbach, ebenfalls Maler monumentaler Freskenzyklen in München und Berlin. Auch er agiere besonders überzeugend in der stringenten Überführung weitreichender Gedankengerüste in die Malerei. Gemälde wie die Zerstörung Jerusalems, welches Kaulbach für das Treppenhaus des Neuen Museums in Berlin ausgeführt hatte, würden den Betrachter über das Innerste des Menschen belehren und zum Nachdenken anregen. ${ }^{34}$ Im Jahr des Besuchs in Frankfurt 1843 entschied sich Quandt gegen einen Auftrag für seine eigene Sammlung, weil er glaubte, dass jedes neue Gemälde

Bilder das hohe Gepräge des Geistes, aus dem sie hervorgehen, und dieses specifische Merkmal ist das, was wir den Styl des Meisters nennen, der in der Schülernachahmung zur leeren, eingelehrten, todten Form wird und aufhört, das Merkmal einer großen Individualität zu sein. Wir können den Styl des Cornelius, das heißt seine Auffassungsweise, nicht anders als romantisch nennen.« S. a. Büttner 1980/99, Bd. 2, S. 20-25. Eine frühe Rezension und damit Rezeption des Künstlers von Cornelius' Blättern nach Goethes Faust in Quandt 1817, S. 143-147.

33 Büttner 1980/99, Bd. 1, S. 70-76. S. a. Grewe 2017, S. 35-36; Grewe 2015, S. 83-87; Mai 2011, S. 52-53; Locher 2005, S. 52-57.

34 Quandt 1846 (2), S. 382-383. Das Fresko wurde im Zweiten Weltkrieg zerstört. Vgl. Die Zerstörung Jerusalems, 1841-46, Leinwand, $585 \times 705 \mathrm{~cm}$, München, Bayerische Staatsgemäldesammlungen, Neue Pinakothek. S. a. Quandt 1840 (3), Sp. 405-406; Locher 2005, S. 62-67. 


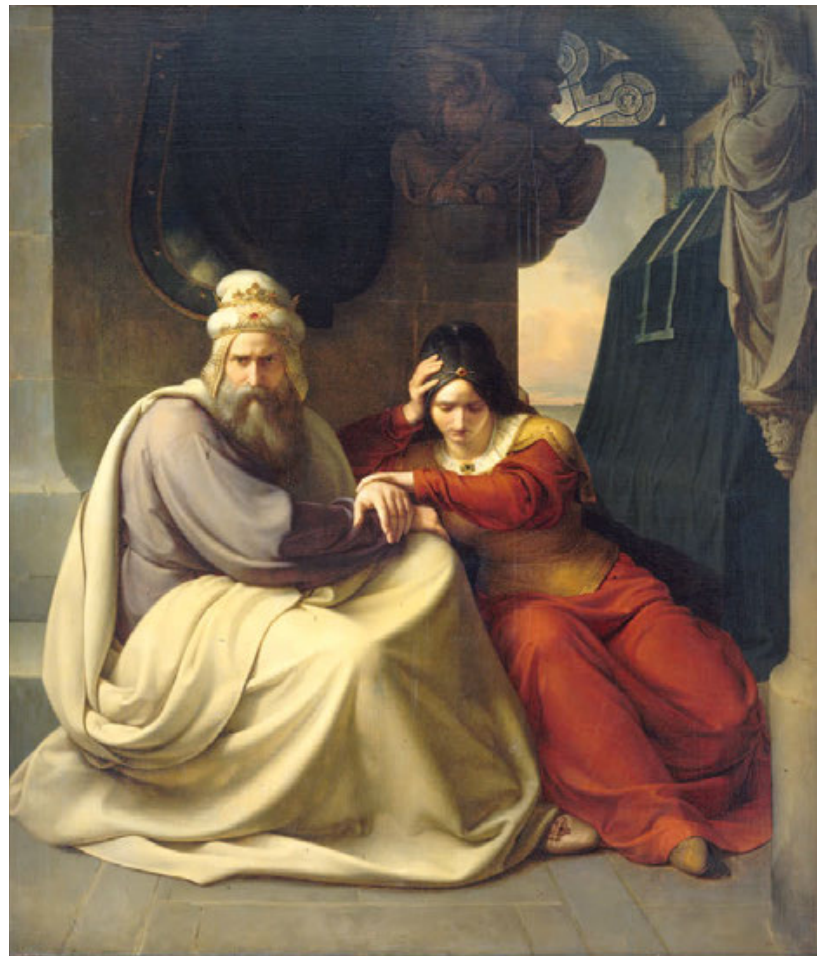

39 Carl Friedrich Lessing, Das trauernde Königspaar, 1830, Öl auf Leinwand, $215 \times 193 \mathrm{~cm}$, St. Petersburg, The State Hermitage Museum, Inv.-Nr. 「Э-4778

Kaulbachs nach dessen Zerstörung Jerusalems nur ein Abklang auf dieses große Wandbild wäre. ${ }^{35}$

Auf Cornelius folgte Wilhelm von Schadow als Direktor der Düsseldorfer Malerschule. Seine Berufung lag in einer Neuorientierung hin zum privaten Ölbild. ${ }^{36}$ In Schadow glaubte Quandt eine besondere Begabung für das Kolorit entdeckt zu haben. Der Berliner Künstler verfolge eine Malerei der »Lichtpoesie«. Die Düsseldorfer Kunstakademie unter Schadow habe bedeutende Anteile an der positiven Entwicklung der deutschen Kunst gewonnen. ${ }^{37}$ Ihren Studenten würde eine gute Technik vermittelt, wodurch sie in der Lage seien, handwerkli- che Probleme hinter sich zu lassen und sich auf die Inhalte ihrer Gemälde zu konzentrieren..$^{8}$

Dennoch bedurften gerade diese Inhalte weiterer Fortschritte. Die romantisch-elegische Seelenmalerei der frühen Düsseldorfer Maler um Carl Friedrich Lessing und Eduard Bendemann behagte Quandt nicht richtig. So kritisierte er an Lessings Das trauernde Königspaar den Jammer im Ausdruck der Dargestellten - gerade das, was die zeitgenössische Kritik als tiefgründige Ernsthaftigkeit schätzte (Abb. 39). ${ }^{39}$ Auch das höchst erfolgreiche und mehrfach wiederholte Gemälde von Bendemann, Gefangene Juden in Babylon, empfand er als »von dieser Influenza nicht ganz frei « (Abb. 4O).$^{40} \mathrm{Im}$ ersten Moment mag diese Kritik erstaunen, wo doch Quandt immerzu von der Wichtigkeit der Wirkung eines Gemäldes auf das Gemüt sprach. Doch das Problem dieser Trauerbilder lag für ihn im Fehlen eines dramatischen Moments. Die Figuren empfangen widerstandslos ihr Schicksal, sie nehmen es nicht aktiv in die Hand, kämpfen nicht um Veränderung. Quandt schrieb dementsprechend, in der Malerei müsse die dramatische Poesie ausgebildet werden. Die Künstler sollten, ausgehend von einer historischen Tat oder einer Katastrophe, ein Motiv darstellen, das die Handlungen von Menschen nach einem Ereignis zusammenfasste..$^{4}$

Bendemann entwickelte diese Dramatik in einer neuen Historie erfolgreich weiter. Dabei handelt es sich um das Gemälde Jeremias auf den Trümmern Jerusalems, entstanden 1835 (Abb. 41). ${ }^{42}$ Darstellung und Komposition stehen in engem Zusammenhang mit den Gefangenen Juden. Doch was Quandt überzeugte, war die Einbindung des Motivs und seiner Figuren in den Kontext der dramatischen Geschichte um den Verlust Jerusalems an die Babylonier. Dies war bei den Gefangenen Juden weniger der Fall. Hier steht die passive Emotion im Mittelpunkt. Nur die Ruinen im Hintergrund lassen den geschichtlichen Kontext erahnen. Im Jeremias jedoch sitzt der Prophet inmitten Klagender, Sterbender und Toter auf den rauchenden Trümmern des zerstörten Tempels. Der Gram des Juden
35 Brief von Quandt an Schnorr vom 21.1.1843, in: SLUB, Mscr. Dresd. n Inv. 15, Bd. 31, fol. 225V: „Sie fragten, ob ich noch nach einem Gemälde von Kaulbach ein Verlangen hegte, allein ich habe mir diesen Wunsch aus dem Sinn geschlagen, weil er mir unerreichbar scheint. Kaulbach ist durch den König so beschäfftigt, daß das, was man etwa noch von dem Künstler verlangen könnte, nur Späne seÿn würden, welche von seiner größten Arbeit, der Zerstörung von Jerusalem, abflögen.«

36 Mai 2011, S. 53-56; Locher 2005, S. 68-70.

37 Quandt 1846 (2), S. 376-377: »[...] und er ward recht eigentlich Vater seiner eignen Schule, wozu ihn ein höchst wohlwollendes Gemüth, ein klarer, gebildeter Verstand, die große technische Erfahrung und ein geläuterter Kunstsinn vollkommen befähigten.« Zu Schadows Errungenschaften in Düsseldorf aktuell Grewe 2017, S. 14-17.

38 Quandt 1846 (2), S. 383: »Es erwies sich [...] der große Vortheil einer zweckmäßigen Technik der Malerei und eines Unterrichts, der beleh- rend und anregend zugleich ist, wodurch der junge Künstler alsbald in den Stand gesetzt wird, mit Geistesfreiheit zu Tage zu fördern, was in inm liegt.«

39 Rezension in: KB 1830, Nr. 82, S. 328 und KB 1831, Nr. 4, S. 15. S. a. Grewe 2015, S. 266-267; Kat. Düsseldorf 2011, Nr. 124, S. 160.

40 Quandt 1846 (2), S. 384. S. a. Grewe 2015, S. 267-271, 285-287; Kat. Düsseldorf 2011, Nrn. 125-128, S. 162-167.

41 Quandt 1846 (2), S. 385: »Die dramatische Poesie entwickelt die Idee in einer Folge von Handlungen, die in einer That, der Katastrophe, ihren Gipfel und Ausgangspunkt erreichen. Dem dramatischen Maler stellt sich nun die Idee bildlich in einer solchen That vor die Seele [...]."

42 Eduard Bendemann, Jeremias auf den Trümmern Jerusalems, 1835, Lwd., Hannover, Leineschloss (Kriegsverlust). Kat. Düsseldorf 2011, Bd. 1, S. 91-92. 


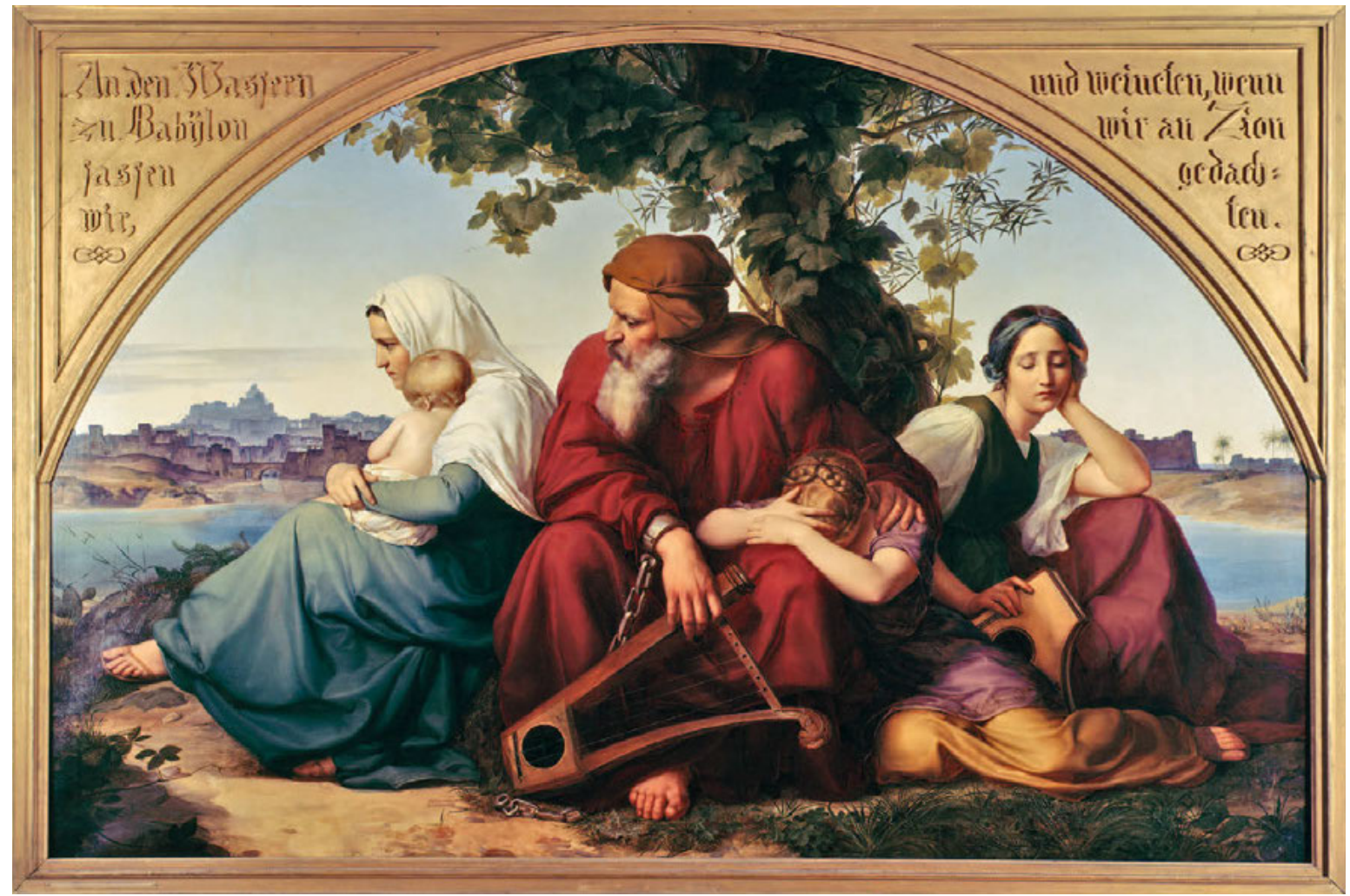

40 Eduard Bendemann, Gefangene Juden in Babylon, 1832, Öl auf Leinwand, $183 \times 280 \mathrm{~cm}$, Köln, Wallraff-Richartz-Museum \& Fondation Corboud, Inv.-Nr. WRM 1939

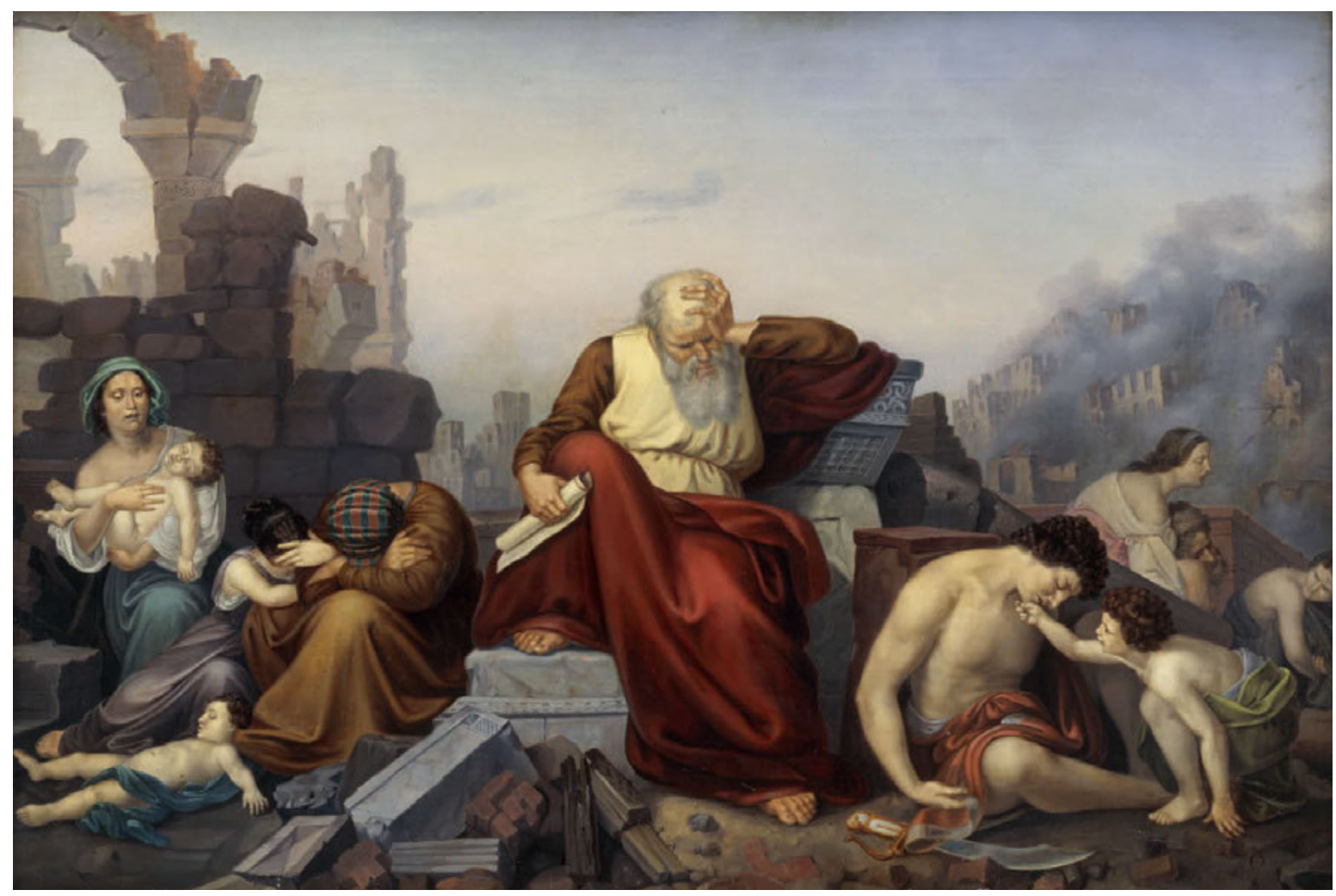

41 Eduard Bendemann, Jeremias auf den Trümmern Jerusalems (eigenhändige, verkleinerte Kopie nach dem verloren gegangenen Original im Leineschloss, Hannover), nach 1836, Öl auf Leinwand auf Holz aufgezogen, $41 \times 61$ cm, Berlin, Jüdisches Museum, Inv.-Nr. 2000/64/O 


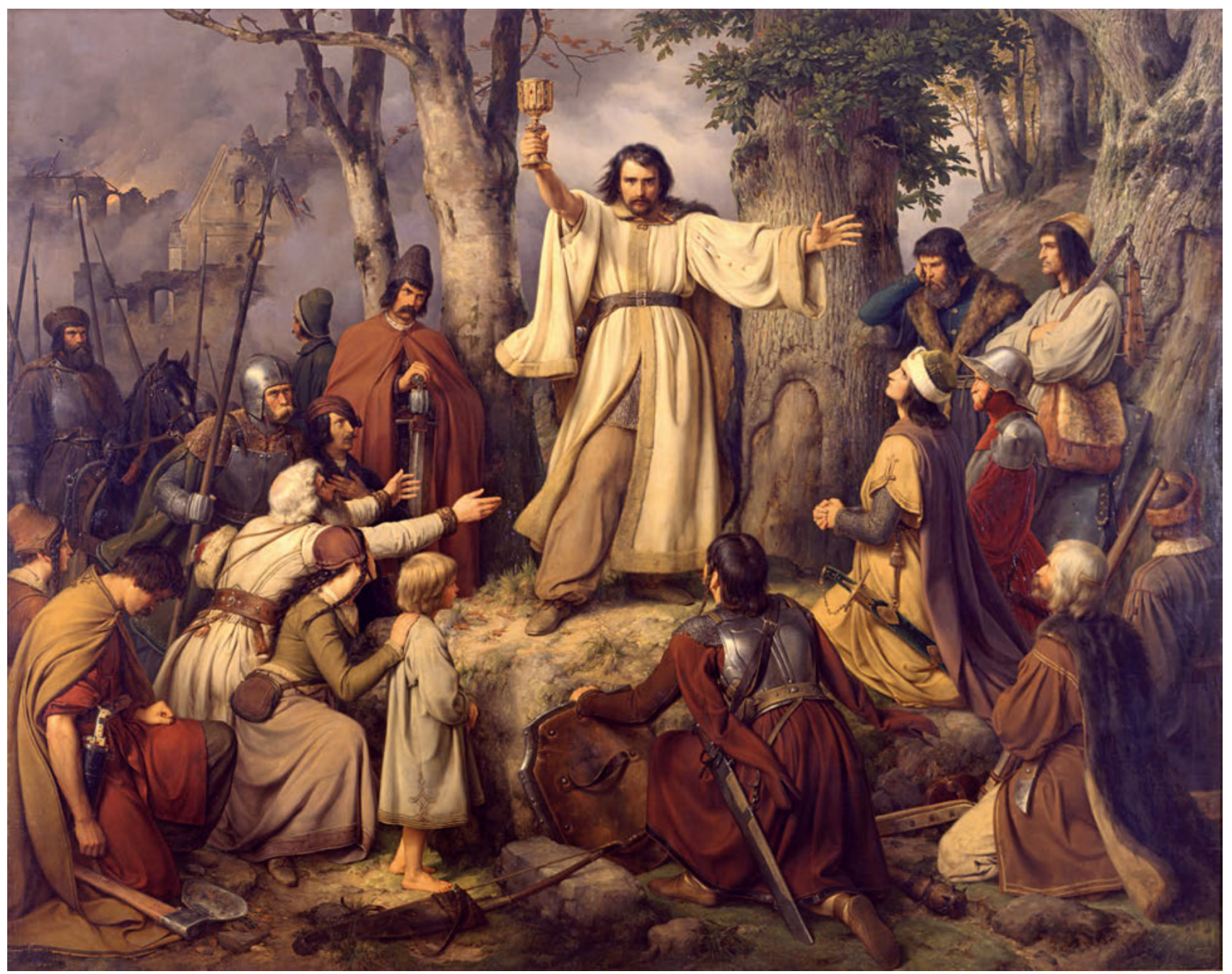

42 Carl Friedrich Lessing, Hussitenpredigt, 1836, Öl auf Leinwand, $223 \times 293$ cm, Berlin, SMB, Alte Nationalgalerie, Inv.-Nr. A II 829

über den Verlust des kulturellen Mittelpunkts seines Volkes ist das Motiv der Momentaufnahme, deren Ursprung in der Zerstörung Jerusalems liegt. Solche dramatischen Höhepunkte schätzten Quandt und die Zeitgenossen, die das Bild 1836 in Berlin gesehen hatten. ${ }^{43}$ Quandt notierte: »Was Jeremias mit prophetischem Sinne in der Zukunft sieht und beklagt, die Vernichtung der höchsten irdischen Größe und Schönheit, geht in des Künstlers Darstellung als ein Gegenwärtiges vor sich.«Es sei nicht eine in sich gekehrte Klage, die im Bild zum Selbstzweck werde, sondern die Klage entspränge der Zerstörung und trage, so Quandt, die Ahnung einer schweren Zukunft in sich. Diese Klage sei handelnd. Quandt las Bendemanns Je-

43 Rezension in: KB 1836, Nr. 45, S. 190-191. S. a. Brief von Quandt an Bendemann vom 10.3.1837, in: Leipzig, Universitätsbibliothek, Sondersammlungen, Mappe 232, Quandt, Johann Gottlob von, fol. 1v.

44 Die Zitate in: Quandt 1846 (2), S. 385-386.

45 Kat. Düsseldorf 2011, Nrn. 225, 234, S. 266, 279. Die Hussitenpredigt, remias als Metapher der »Vernichtung in ihrer furchtbaren Größe $\ll \cdot 4$

Auch Lessing habe sich durch die Beschäftigung mit der Natur in einer Reihe von Landschaftsgemälden erfolgreich von der empfindsam-rührenden Malerei befreit. Doch erst mit zwei Historien, der Hussitenpredigt und Jan Hus zu Konstanz, habe er wahre Meisterschaft erlangt (Abb. 42-43). ${ }^{45}$ Wie sich Lessings Können in Quandts Augen zeigte, lässt sich im Kontext zweier Historien der belgischen Künstler Louis Gallait und Edouard de Bièfve aufzeigen. Ihre beiden Monumentalbilder waren auf einer Deutschlandtournee anfangs der 1840er Jahre mehrfach gezeigt worden und hatten zu intensiven Diskussionen geführt. ${ }^{46}$

1836, Lwd., $228 \times 290$ cm, Berlin, SMB, Alte Nationalgalerie, Inv.-Nr. 208.

46 Gallait: Die Abdankung Karls V. in Brüssel; de Bièfve: Der Kompromiss des niederländischen Adels, beide Bilder heute in Brüssel, Koninklijke Musea voor Schone Kunsten van België. Fastert 2000, 


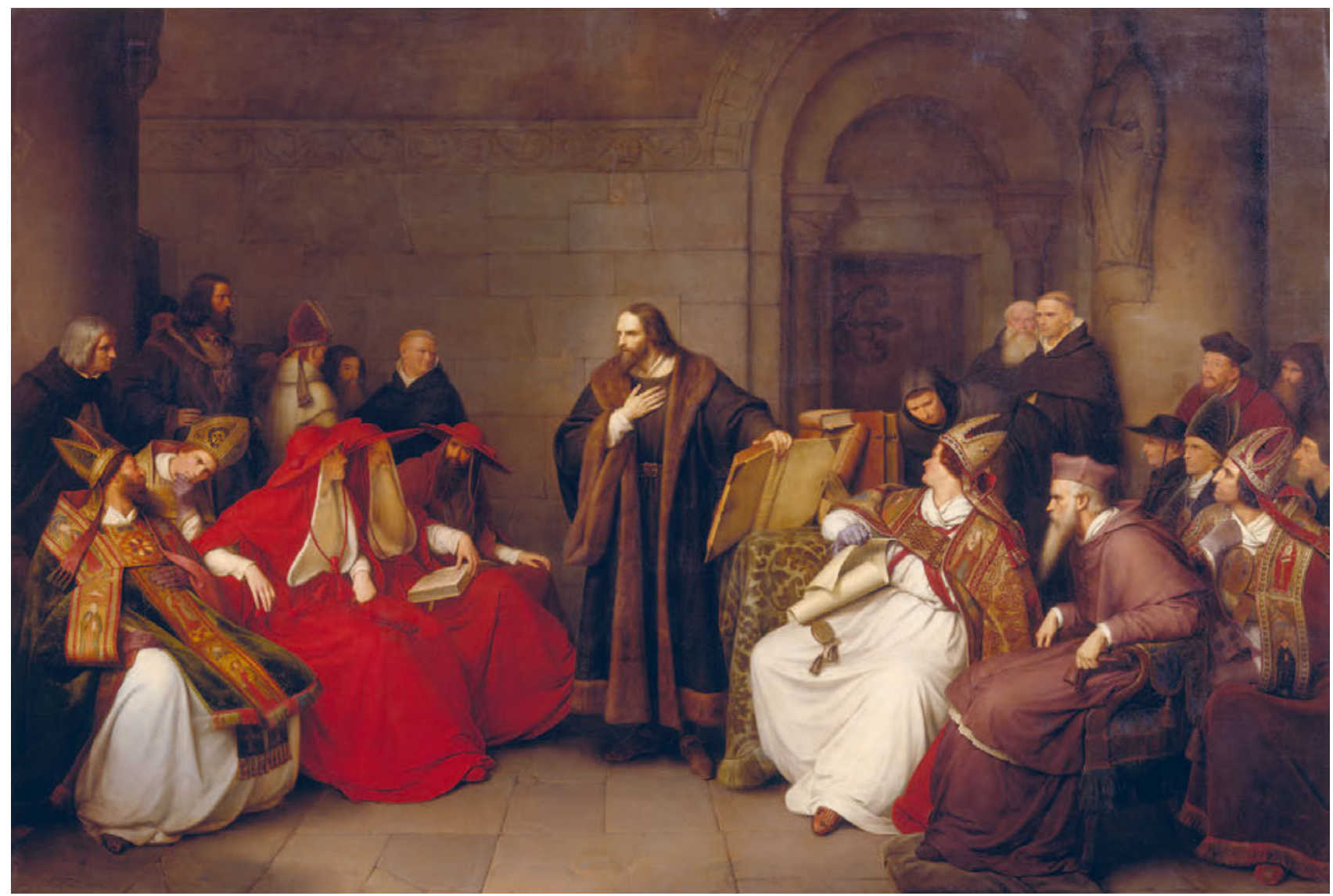

43 Carl Friedrich Lessing, Jan Hus zu Konstanz, 1842, Öl auf Leinwand, $308 \times 455$ cm, Frankfurt a/M, Städel Museum, Inv.-Nr. 901

\section{Eine neue Historienmalerei? Diskussionen um zwei belgische Bilder}

Anlässlich der Berliner Kunstausstellung im Herbst 1842 diente Lessings Jan Hus zu Konstanz als Vergleichsbild im Kunstgelehrten-Streit um die Historien von Gallait und de Bièfve, die dort ebenfalls gezeigt wurden (Abb. 44-45). In pastosem Pinselstrich gemalt, stellten die belgischen Gemälde Szenen aus der flämischen Geschichte dar. Im Kunst-Blatt bezogen die wichtigen Kunstschriftsteller Stellung: Ernst Förster und Johann Gottlob von Quandt äußerten sich 1843 negativ, Friedrich Theodor Vischer, Franz Kugler und Jakob Burckhardt reagierten mit befür-

S. 312; Kat. Düsseldorf 2011, Bd. 2, S. 270-271, Kat. Nr. 227 (Frankfurter Replik der Abdankung Karls V. von Gallait). Die Bilder wurden 1842 in Düsseldorf, Köln und Berlin, 1843 in Dresden, Wien, München und Stuttgart sowie 1844 in Karlsruhe, Darmstadt und Frankfurt am Main gezeigt. S. a. Gaehtgens 1996, S. 58-60; Kat. Wien 1996, Bd. 1, S. 61-65.

47 Förster 1843, S. 109-113, 118-119; Quandt 1843 (2), S. 165-166, 170-171; Burckhardt 1843, S. 14-15; Kugler 1843, S. 241-243, 246-248; Vischer 1844, S. 46-54. S. a. Büttner 2011, S. 108-109; Koschnik 2010, S. 6-7; Prange 2004, S. 155; Karge 1998, S. 140.

48 Passavant 1844, S. 274-275, 279-280, 282-283, 286-287, 291. Passavants wortenden Aufsätzen. ${ }^{47} 1844$ schrieb Johann David Passavant einen Text, der die aufwogenden Meinungen zu einer Synthese brachte und die belgischen Bilder kunsthistorisch verortete. $4^{8}$

In den divergenten Meinungen über die Bilder von Gallait und de Bièfve manifestierte sich die Suche nach einer gemeinsamen Bildsprache und kollektiven Themen der sich langsam konsolidierenden deutschen Nation. Die Historienmalerei schien ein geeignetes Experimentierfeld zu sein. Über den Modus wurde man sich jedoch nicht einig. Der Philosoph Friedrich Theodor Vischer betonte, die belgischen Bilder würden die »geschichtliche Wirklichkeit« darstellen. In seinem Aufsatz schränkte er jedoch ein, dass Deutschland in seiner Geschichte

Text kann als Vermittlung zwischen den Fronten angesehen werden. Er bezeichnet den Charakter der belgischen Malerei als auf realer Grundlage basierend, die deutsche Historie dagegen als ideale und poetische Malerei und begründet dies anhand einer kunsthistorischen Einordnung. Über die Bilder von Gallait und de Bièfve urteilt Passavant, »daß dieselben in den herrschenden Geist der Zeit eingehend, sich die Aufgabe gestellt [haben], bedeutende vaterländische Begebenheiten zu versinnlichen, die das allgemeine volksthümliche Interesse erregen und daher höchst national sind.» Ebd., S. 283. 


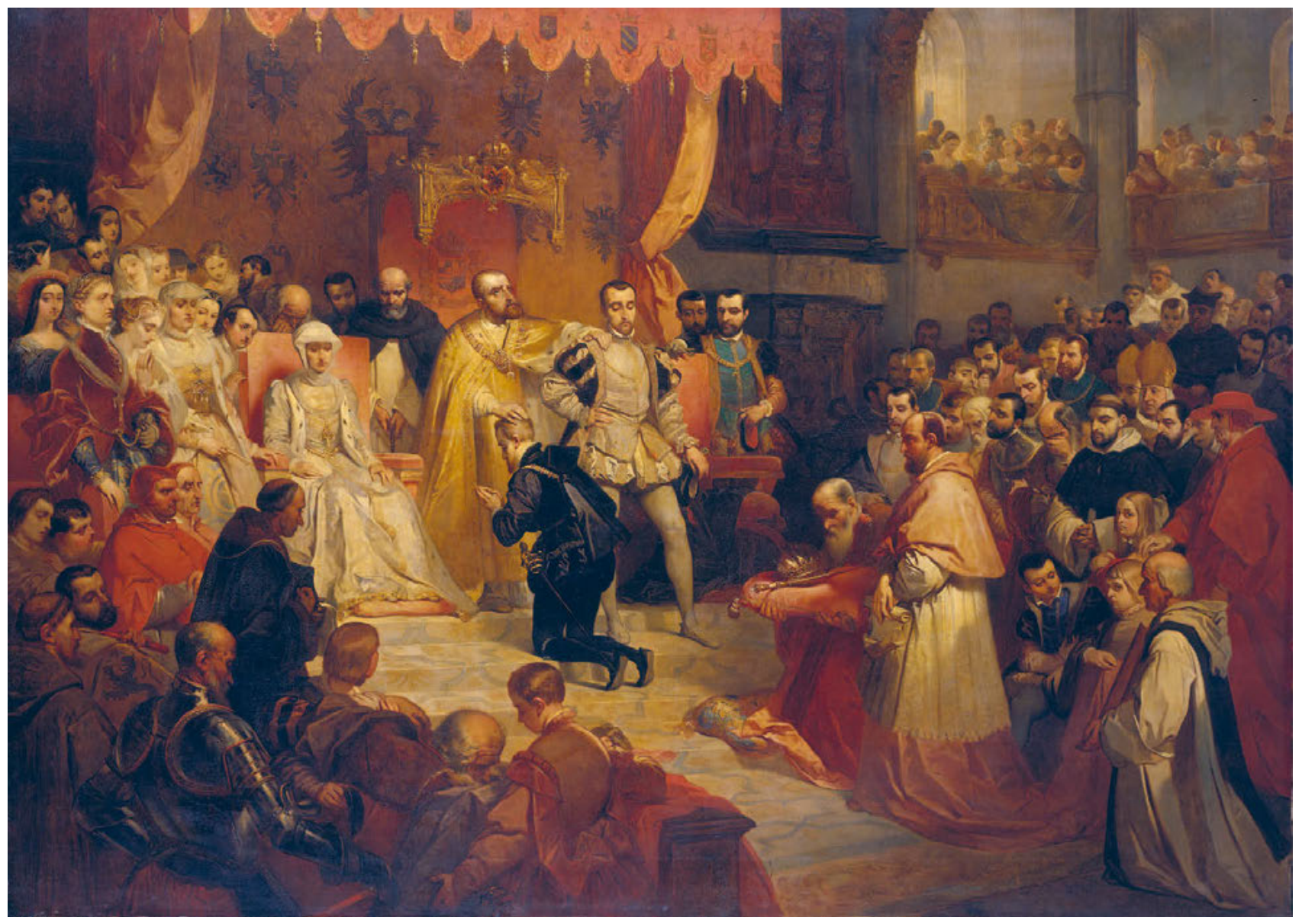

44 Louis Gallait, Die Abdankung Kaiser Karls V. zu Gunsten seines Sohnes Philipp II. zu Brüssel am 25. Oktober 1555 (eigenhändige, verkleinerte Kopie des Originals in Brüssel, Koninklijke Musea voor Schone Kunsten van België), 1842, Öl auf Leinwand, $122 \times 170$ cm, Frankfurt a/M, Städel Museum, Inv.-Nr. 947

keinen »nationalen Stoff, der so populär, so wahrhaft national, im Politischen so malerisch wäre, wie die großen Scenen, welche die Befreiung der Niederlande vom spanischen Joche mit sich brachte.« Die deutsche Geschichte sei monarchisch und unpopulär, die Reformation einseitig kirchlich und unmalerisch, »ein Drama im Kirchenrock und Chorhemd«, und der Bauernkrieg durch sein trauriges Ende eine peinvolle Erinnerung. Vischer schlug keine konkreten Maßnahmen vor, verlangte einzig, dass sich die Malerei der Wirklichkeit stelle.49

Jacob Burckhardt sah in den belgischen Historien ein Beispiel nationaler Kunst, da bedeutende historische Individuen und ihre Geschichten dargestellt seien. Diese durch Quellen überlieferten und historisch fundierten Themen stellten einen Bezug zur Nation der Gegenwart her. So wirkten die Bilder in der jungen belgischen Nation, die erst seit 1831 unabhängig war, einend. Eine solche Malerei benötige auch Deutschland..$^{50}$ Mit Lessings Jan Hus zu Konstanz sei ein qualitativ hochstehender Weg zwar vorgegeben, so Burckhardt. Das Problem liege darin, dass es nur ein Situationsbild sei. Es fokussiere zu stark auf die Charaktere der einzelnen Figuren. Für eine Versammlung von Menschen sei das Format zu groß und das Motiv sei »ein rein psychologisches Problem«. Die Charakterköpfe zeigten zwar
49 Vischer 1844, S. 49. In einer bösen Kritik an Friedrich Overbecks Triumph der Religionen deutet er seine Vorstellungen an: »Unser Gott ist ein immanenter Gott; seine Wohnung ist überall und nirgends; sein Leib ist nur die ganze Welt, seine wahre Gegenwart der Menschengeist. Diesen Gott zu verherrlichen ist die höchste Aufgabe der neuen Kunst. Die Geschichte, die Welt als Schauplatz des Herrn, die naturgemäße Wirklichkeit in scharfen, nicht romantisch schwankenden, festen Umrissen als eine Bewegung, worin sittliche Mächte Gottes Gegenwart verkündigen [...], das ist das Feld des modernen Künstlers. Wir kennen keine Wunder mehr, als die Wunder des Geistes, diese innere Romantik bringe der Künstler in gediegenen, plastisch geläuterten Formen zur Erscheinung." Vischer 1844 [1841], S. 192-193. S.a Thimann 2014, S. 195-197.

50 Burckhardt 1843, S. 14-15: »Hier sehen wir endlich einen geschichtlichen Styl vor uns; wir erkennen in beiden Werken ein Gemeinsames, den Geist einer gewaltigen Schule, die ihren höchsten Entwickelungen erst entgegengeht. Großartige Momente von hohem nationalem Interesse fassen hier eine endlose Menge bedeutender Individualitäten zu einem ganzen zusammen.« S. a. Locher 2005, S. 62; Prange 2004, S. 155. 


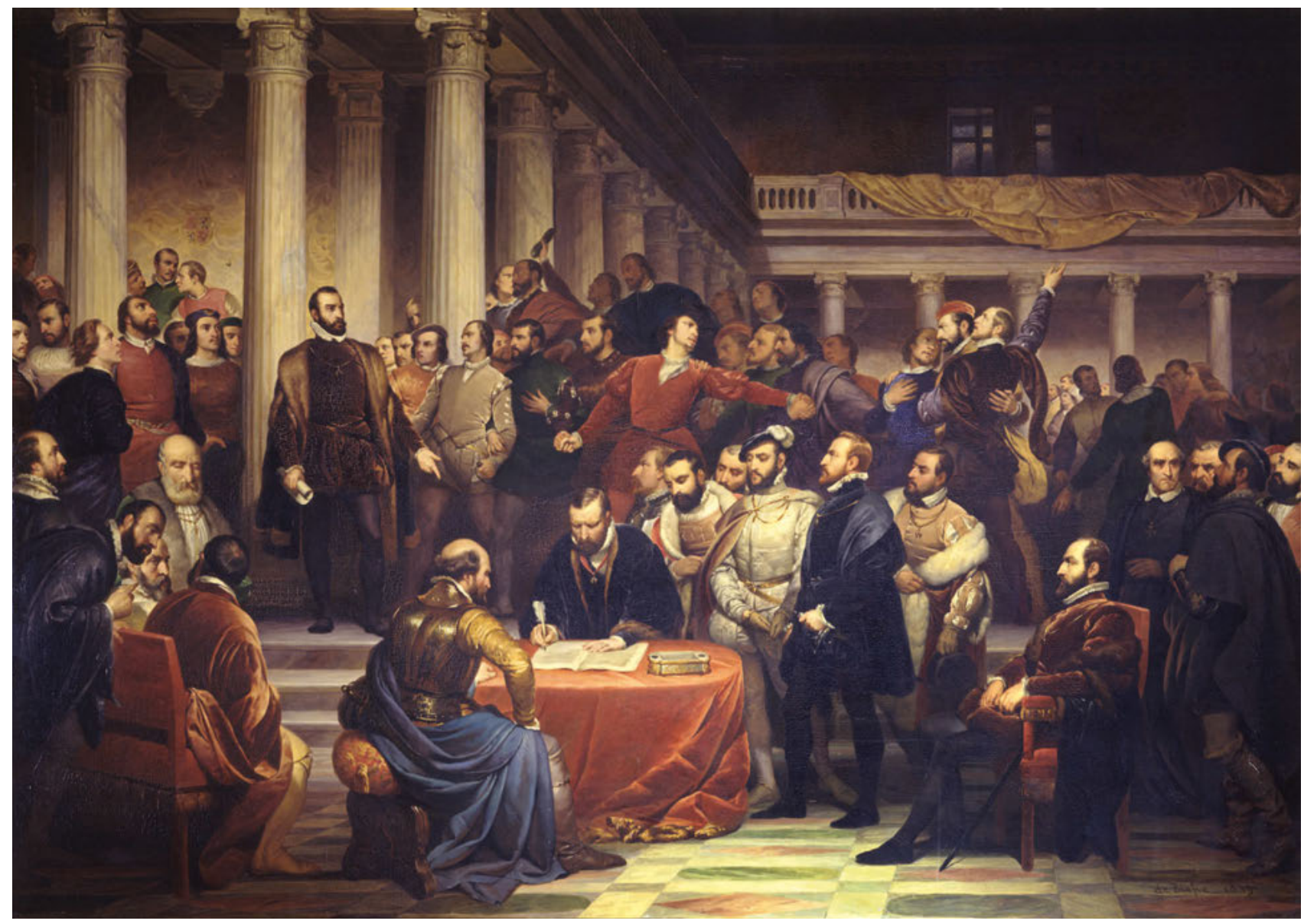

45 Édouard de Bièfve, Der Kompromiss des niederländischen Adels im Jahre 1566 (eigenhändige, verkleinerte Kopie des Originals in Brüssel, Koninklijke Musea voor Schone Kunsten van België), 1849, Öl auf Leinwand, $161 \times 226$ cm, Berlin, SMB, Alte Nationalgalerie, Inv.-Nr. W.S. 15

alle Glaubensrichtungen ihrer Zeit auf, doch die eigentliche Geschichte werde nicht dargestellt. ${ }^{51}$

Franz Kugler ging noch einen Schritt weiter. Die deutsche Historienmalerei müsse den belgischen Bildern in ihrer Volksnähe folgen, Einheit und Existenz der Nation unterstützen und demokratisch werden: »Unsere Kunst muß jenem aristokratischen Element [...] als nothwendiges Gegengewicht ein demokratisches hinzugesellen.« Was die deutsche Historienmalerei

51 Burckhardt 1843, S. 10: »Diese wundersamen Köpfe, vom begeisterten Reformator bis zum plumpsten Mönche, vergegenwärtigen uns alle Tendenzen, die sich in jener Zeit kreuzten, und in sofern ist das Bild allerdings ein historisches, aber eben nur in demselben einseitigen Sinne, in welchem etwa eine Culturgeschichte Weltgeschichte heißen könnte. Der dargestellte Moment ist das Untergeordnete, und tritt vor der mächtigen Charakteristik völlig zurück. Wir begrüßen das Bild als eines der größten Werke deutscher Kunst, aber es ist und bleibt ein bloßes Situationsbild. Nicht als ob dieser Gattung die Anerkennung versagt würde! aber eine wahrhafte Historienmalerei hat doch ohne Zweifel ein höheres Prinzip.« Ähnlich etwas früher, aber nur im Privaten, äußert sich Athanasius Graf Raczyński; siehe Kaiser 2017, S. 277-280.

52 Kugler 1843, S. 247: »Nur wo ein kräftiges Gemeingefühl im Volke waltet, wo dasselbe eine nationale Existenz hat, da gewinnen auch die benötige, sei Leben..$^{52}$ Der etwas ältere Passavant pflichtete in den Grundzügen dieser Argumentation bei, unterstrich aber die spezifisch belgische Eigenheit der Gemälde, die nicht auf Deutschland übertragbar sei. Er lobte die technische Ausführung und die quellennahe Interpretation des Geschehens, wollte dies aber als »von nur untergeordnetem Kunstwerth « verstanden wissen. .3

Die Gegner äußerten sich mit Argumenten, wie sie bei Quandt zum Vorschein kommen. Er kritisierte, dass den bel-

künstlerischen Darstellungen jene sieghafte Existenz, der wir unsern Sinn nicht verschließen können. Und weil seit der jüngsten Zeit auch in Deutschland das Gemeingefühl des Volkes, das nationale Bewußtseyn in aller Freudigkeit erwacht ist, so mußten jene beiden Bilder, in denen man die verwandte Stimmung erkannte, auch bei uns mit so entschiedenem Beifall aufgenommen werden [...].»

53 Passavant 1844, S. 275. S. a. ebd., S. 283: „Sie [die Belgier - AR] werden daher bei dem einmal nach Außen gewandten Blick, bei ihren praktischen Lebensansichten nicht auf allgemein poetische und religiöse Richtungen zurückkommen können. [...] Bei der durch sie eingeschlagenen Bahn ist höchstens zu erwarten, daß die nationale Geschichtsmalerei sich mehr und mehr zu einer selbstständigen Darstellungsund Behandlungsweise ausbilden werde, und so als eine wahrhaft originelle, neubelgische Malerschule zu begrüßen ist.« 
gischen Künstlern »mehr an geschichtlich-wahrem Detail, als einer das Ganze durchdringenden und gestaltenden Idee gelegen« sei. Thre Gemälde seien zu stark an historischen Quellen orientiert. Historienmalerei habe nicht den Zweck historischkorrekter, sondern poetisch-wahrer Darstellung. Sie zeige die »Wahrheit des Gedankens«. Die Historien sollten einen »geschichtlich gegebenen Charakter oder Begriff« zeigen, nicht historische Einzelereignisse. Quandt suchte also nach dem universalgeschichtlichen Kontext. »Eigentlich ist es doch nur die von poetischen und religiösen Ideen belebte Kunst, die zu der höchsten Wahrheit, der wahrhaft ästhetischen und der wahren Freiheit des Geistes emporsteigt, $[. .].[$ die $]$ ihre Wesen sogleich in verklärten Leibern erschafft. [...] In dieser Kunst ist gar keine Schranke und Trennung zwischen Wirklichkeit und Geist. $\ll^{54}$

Damit steht die Historie in Quandts Verständnis der Poesie näher als der Historiographie. Die poetische Kunst manifestiere sich in einer spezifisch deutschen Historienmalerei wie sie in Lessings Jan Hus zu Konstanz zu erkennen sei: »Was sich in alter Zeit zugetragen, steht lebendig vor uns [...]. Wie dem Historiker die Gewißheit, daß sich etwas auf bestimmte Weise zugetragen hat, das Wichtigste an der Geschichte ist, so hat auch hier der Geschichtsmaler sein ganzes Talent und seine außerordentliche technische Erfahrung und Uebung aufgeboten, dem geschichtlichen Bilde den Schein von materieller Wirklichkeit zu geben, wodurch das historische Gemälde, statt die pragmatische Auffassung einer Begebenheit zu sein, zu deren Abbildung $[. .$.$] wird.« Es geht nicht um die unvollständig bleibende$ Rekonstruktion einer Vergangenheit durch die Quellen, sondern um die Charakterisierung einer vergangenen Gegenwart. Diese soll real wirken und den Schein vermitteln, wie es gewesen sein könnte. Die durch Quellen bekannten Fakten würden eine solche künstlerische Vergegenwärtigung nur noch bekräftigen: »Der Clerus [auf dem Bild Jan Hus zu Konstanz - AR] der damaligen Zeit ist so physiognomisch charakterisirt, daß man mit Hülfe der Geschichte die Personen, die man vor sich sieht, mit Namen nennen könnte. «55 In gewissem Sinn erschafft

54 Alle Zitate nach Quandt 1843 (2), S. 165-166, 170-171. S. a. Quandt 1831 (3), S. 65. Ebenso Förster 1843, S. 111: »Und doch fehlt für eine historische Auffassung nichts weniger, als Alles. So wenig ein Stück Erdrinde mit Allem was an Steinen, Pflanzen und Thieren darauf wächst, Naturgeschichte ist; so wenig, als Reden und Gespräche, wie sie das Leben unmittelbar hervorbringt, Poesie sind; so wenig als die Wiederholung der Töne in der Natur Musik ist: so wenig giebt eine Abspiegelung des wirklichen Momentes ein historisches Bild, und folglich ist eine auf dieses Prinzip gegründete Auffassung keine historische.« S. a. Fastert 2000, S. 313-314; Maaz 1986, S. 15; Richter 1909, S. 572-573. Zum Begriff der Universalgeschichte siehe Zwenger 2003, [s. p.]; Nipperdey 1976, S. 45 .

55 Alle Zitate in: Quandt 1846 (2), S. 384-385. Ausführlich über Lessings Jan Hus auch Quandt 1844 (1), S. 45-47; Brief an Julius Schnorr vom
Quandts idealer Historienmaler eher Historienromane als historische Studien. Seine Bilder sind Geschichten, die auf wahren Begebenheiten basieren. Während Burckhardt in Lessings Malerei das dramatische Moment vermisste, erachtete Quandt gerade die Figurendarstellung als den Höhepunkt des Dramas und den Jan Hus zu Konstanz als ein bedeutendes Charakterbild deutscher Historienmalerei..$^{5}$

\section{Geistvolle Poesie oder historische Kontexte}

Die Poetisierung der Historienmalerei war jedoch nicht weiterführend. ${ }^{57}$ Die Düsseldorfer Malerschule wandte sich vermehrt realistischen Darstellungsmethoden zu und wurde vor allem im Landschafts- und Genrebild erfolgreich. Quandts Verständnis der Historie wirkte zunehmend antiquiert. Man kann dies mit Passavant verdeutlichen: während der Städel-Inspektor zwar wie Quandt die deutsche Historienmalerei ähnlich subjektiv charakterisierte und ihr historische Tiefe und idealen Geist zuschrieb, so wies doch die Art und Weise seiner Argumentation für die methodische Klarheit der Kunstgeschichte wegweisende Aspekte auf, die bei Quandt fehlten..$^{58} \mathrm{Er}$ verglich die belgischen Historien von Gallait und de Bièfve mit den flandrischen Künstlern der frühen Neuzeit und des Barocks, stellte sie in den Kontext neuster historisch-politischer Entwicklungen und stellte Bezüge zu nationalen Besonderheiten her. Auch in seiner Beschreibung dreier Entwicklungsstufen der neueren deutschen Kunst ortete er historische Zusammenhänge wie die napoleonische Besatzung, interkonfessionelle Konflikte und die Rolle der Kunst für die sich konsolidierende deutsche Nation. ${ }^{59}$ Diese Art der Kontextualisierung findet sich auch bei Burckhardt und Kugler wieder, die wie Passavant als frühe Vertreter einer wissenschaftlichen Kunstgeschichte gelten. ${ }^{60}$

Beispielhaft hierfür ist Lessings Jan Hus zu Konstanz (Abb. 43). Ursprünglich ein Auftrag der Vorstandskommission des Städelschen Kunstinstituts im Jahr 1837, bemühten sich nach seiner erfolgreichen Aufnahme durch die deutsche Kunstszene

21.1.1843, in: SLUB, Mscr. Dresd. n Inv. 15, Bd. 31, fol. 225V-226r. S. a. Prange 2004, S. 97-98.

56 Quandt 1850 (2), S. 252: »[...] Geschichte und Dichtung [haben] verschiedne Aufgaben [...], jene [strebt] nach materieller, diese nach innerer Wahrheit [...].«S. a. Passavant 1844, S. 287. Zum Charakterbild siehe Büttner 2011, S. 107-108.

57 Locher 2005, S. 62; Gaehtgens 1996, S. 58-60.

58 »Die deutsche [Historienmalerei beruht] [...] auf idealer oder poetischer Grundlage, und gefällt sich daher besonders in tiefen geistigen Combinationen und in der Darstellung des innern Seelenlebens [...]. Wenn der nationale Geist sich weiter mit Kraft ausbildet, [liegt] noch die ganze Entwickelung einer vollendeten Kunst vor [...]. «Passavant 1844, S. 291.

59 Passavant 1844, S. 286-287, 291.

60 Prange/Locher 2007, S. 13-14, 155-156. 
mehrere Institutionen um einen Ankauf. Zu diesen gehörte der Leipziger Kunstverein. Quandt sagte dem Sammlungskonservator Carl Lampe ein zinsloses Darlehen über einen Viertel des hohen Kaufbetrags von 8000 Talern zu, weil er es in seiner Vaterstadt zu sehen wünschte. ${ }^{61}$ Schließlich kam es gegen den Willen des Städel-Direktors und Nazarener Malers Philipp Veit doch nach Frankfurt. Johann David Passavants Cousin Philipp Jacob Passavant spielte dabei eine zentrale Rolle. Lessings Gemälde wurde im gleichen Saal wie Overbecks Der Triumph der Religion in den Künsten (Abb. 35) gezeigt und Veits Einführung der Künste in Deutschland durch das Christentum (Abb. 38) gegenübergestellt. Damit hingen drei Bilder beieinander, die zwei Richtungen der neusten deutschen Kunst zeigten: zum einen die religiös-idealistische Monumentalmalerei der Nazarener, zum anderen die realistisch-historische, genreartig und mit psychologisierenden Elementen durchdrungene Düsseldorfer Historienmalerei. ${ }^{62}$

Für das Städelsche Kunstinstitut hatte dies weitreichende Folgen. Veit quittierte im Januar 1843 empört seinen Dienst, da er, der katholische Nazarener, es als Affront empfand, seine Einführung der Künste in Deutschland direkt gegenüber Lessings Prä-Protestanten Jan Hus hängen zu sehen. ${ }^{63}$ Damit blieb zwar mit Johann David Passavant während der folgenden, mehrjährigen Sedisvakanz des Direktorenpostens ein ehemaliges Mitglied der Nazarener als Inspektor übrig. Doch dessen kunsthistorisch in die Breite schauende Sammlungspolitik, die er seit seinem Antritt 1840 verfolgte, und die vermehrt aus Düsseldorf ankommenden jungen Künstler und Kunstlehrer hatten das Ende der nazarenischen Prägung von Städel-Museum und Akademie zur Folge. ${ }^{64}$

Passavant beobachtete, dass Lessing sich in seinen Historien vor allem für den Streit zwischen weltlichen und kirchlichen Potentaten des Spätmittelalters interessierte, womit eine Interpretation mit aktuellem Bezug möglich wurde. Realpolitisch bezog sich die Jan-Hus-Thematik auf das so genannte »Kölner Ereignis«: In den Jahren 1837/38 eskalierte im Kölner Erzbistum

61 Hommel 2000, S. 227.

62 Grosskinsky 2011, S. 151-153; Locher 2005, S. 76-78.

63 Kat. Düsseldorf 2011, Nr. 235, S. 279; Suhr 1991, S. 86-87.

64 Grosskinsky 2011, S. 153-157; Gallwitz 1977, S. 13-17. Zu Passavants Sammlungspolitik siehe Passavant 1849, S. 6-16, bes. S. 8: »Dessen [des Städel'schen Instituts - AR] Plan in dieser Beziehung kann einzig im Festhalten des Grundsatzes bestehen, günstige Gelegenheiten abzuwarten und zu benutzen, um aus allen Zeiten und Schulen der Malerei nur ausgezeichnete Werke zu erwerben, welche einestheils, wenn auch vorerst nur in beschränkter Weise, einen anschaulichen Begriff der verschiedenen Kunstentwickelungen geben, und zugleich je nach der Eigenthümlichkeit der Zeiten und Schulen erhebend auf das Gemüth, belebend auf den Geist, oder erfreulich durch meisterliche Ausführung, aufs mannigfachste den Beschauer zu fesseln vermögen.« ein seit Mitte der $1830 e r$ Jahre schwelender Streit, in dem es um die Zuständigkeit der Kindererziehung in gemischt-konfessionellen Familien ging. Dem zugrunde lagen Fragen um kirchliche Freiheiten und gesetzgeberische Vollmachten im Rechtsstaat Preußen, auf dessen Territorium das Kölner Erzbistum lag. Der Konflikt erfasste in der Folge das ganze preußische Rheinland und Ostpreußen und zog sich bis zur Thronbesteigung Königs Friedrich Wilhelm IV. 1840 hin. ${ }^{65}$

Lessing hatte mit der Hussitenpredigt schon 1836 ein entsprechendes historisches Thema aufgegriffen, in dem es um Deutungshoheiten in theologischen Fragen ging. Der Auftrag der Städelschen Vorstandskommission erging exakt im Jahr der konfessionellen Eskalation in Köln 1837 und der Düsseldorfer Maler wählte wieder Jan Hus als Thema. Das Bild des Künstlers aus dem katholischen Düsseldorf wurde im protestantischen Frankfurt und in der preußischen Hauptstadt Berlin zum Programmbild des interkonfessionellen Konflikts. Weniger als protestantisches Manifest denn als antiklerikale Stellungnahme ist Lessings Bild heute zu interpretieren. ${ }^{66}$ Johann David Passavant stellte lapidar fest: »Da nun diese Verhältnisse noch mächtig in die Gegenwart eingreifen, so erklärt sich leicht die Aufregung, die besonders für und gegen letzteres Bild entstanden ist. ${ }^{67}$ Der Städel-Inspektor erkannte damit die gesellschaftspolitische Relevanz von Lessings Jan Hus zu Konstanz.

Als Quandt zusammen mit Passavant 1843 durch die Säle des Städels ging, war Lessings Gemälde bereits zusammen mit Veits und Overbecks Monumentalbildern ausgestellt. ${ }^{68}$ Es ist umso erstaunlicher, dass er trotz der Führung des Städel-Inspektors nicht auf die kunsthistorisch spektakuläre und in ihrer aktuellen Brisanz provokative Hängung Bezug nahm. Mit keinem Wort erwähnte er den Abgang Veits, er verschwieg die divergenten Richtungen der drei Gemälde und betrachtete sie nicht aus aktueller Perspektive.

Der Dresdener Kunstfreund interessierte sich freilich wenig für die realpolitische, sondern vielmehr für die ästhetische Wirkungsweise von Kunst. Er suchte gar nicht in erster Linie

65 Hahn/Berding 2010, S. 400-403; Nipperdey 1998, S. 418-420. S. a. Grewe 2017, S. 19.

66 Grosskinsky 2011, S. 151-152; Büttner 2011, S. 107-108; Kat. Düsseldorf 2011, Nr. 235, S. 279; Locher 2005, S. 77; Nipperdey 1998, S. 561. Eine lesenswerte Einordnung des preußischen Konfessionskonflikts aus Sicht des katholischen Polen Athanasius Graf Raczyński bei Kaiser 2017, S. 277-282.

67 Passavant 1844, S. 287.

68 Quandt 1846 (2), S. 384: »Wir sehen in dem Städelschen Museum dieses bewunderte und bewunderungswürdige Bild vor uns und sehen es oft und immer mit erneutem Interesse. « Zur gemeinsamen Besichtigung des Museums siehe den Hinweis bei Quandt 1846 (2), S. 366: »Die Betrachtung des Museums in dem Städelschen Akademiegebäude wurde mir um so lehrreicher, da mein wackerer Freund Passavant mich auf das Wichtigste der reichen Sammlung aufmerksam machte.« 
nach den augenscheinlichen Unterschieden der drei Gemälde, sondern fragte nach ihren Gemeinsamkeiten. Und diese lagen im poetischen Element. Quandt fahndete nach der idealen, vernunftgeborenen Idee. Damit waren die Kontexte, in denen die Kunstwerke entstanden waren, weniger bedeutsam. Doch genau in jenen zeigte sich die Suche nach einer neuen, deutschen Historienmalerei, wie sie im Gelehrtenstreit um die belgischen Bilder offenkundig wurde. Vischer, Burckhardt, Kugler und Passavant - wenn auch mit unterschiedlichen Argumenten - verstanden die Historienmalerei vor dem Hintergrund der sich konsolidierenden deutschen Nation. Es ging primär darum, wie die deutsche Vergangenheit charakteristisch umgesetzt werden konnte und sekundär um quellenkonforme Geschichtsdarstellung. Zentral war die Frage, welche Historienmalerei den »Volksgeist« in seiner Einheit am besten befördern konnte. Man verlangte von Künstlern und Auftraggebern $\gg$ Zeitbewusstsein« ${ }^{69}$ Wenn die Autoren hierbei in ihrer Definition des Deutschen als dem Tiefgründigen und Geistvollen Quandt immer noch nahekamen, gingen sie doch in ihren Forderungen weiter. Die poetisierend-ideale Freskokunst der Nazarener hatte die Erwartungen nicht erfüllt. Die realistisch-psychologisierenden Charakterbilder der Düsseldorfer schienen einen besseren Weg aufzuzeigen. ${ }^{7 \circ}$

\section{Neue Richtungen: Düsseldorfer Malerei}

Doch Quandts Problem lag weniger in einem fehlenden Verständnis für neue Kunstrichtungen. Im Gegenteil zeigte er eine Offenheit für Neuerungen und nahm begeistert Anteil an den Entwicklungen in Düsseldorf, wie auch seine Stellungnahme für Lessings Jan Hus gezeigt hat. Zudem hatte sich Quandt mehrfach bemüht, von mehreren Düsseldorfer Malern Gemälde für seine Sammlung zu erhalten. In einem Brief an Edu-

69 Die zitierten Worte nach Büttner 2011, S. 108: „Volksgeist« nach Georg Herwegh, »Zeitbewusstsein« nach Anton Springer, beide 1845. S. a. Prange/Locher 2007, S. 86.

70 Büttner 2011, S. 105-112.

71 Brief von Quandt an Bendemann vom 10.3.1837, in: Leipzig, Universitätsbibliothek, Sondersammlungen, Mappe 232, Quandt, Johann Gottlob von, fol. 1r-v: »Ew. Wohlgebohren habe ich eine Bitte vorzutragen, [...] nicht ohne Besorgniß einer abschläglichen Antwort, spreche ich sie aus, da mehrere Düsseldorfer Künstler gleiche Gesuche, rund zurückgewiesen, oder die Hoffnung einer dermaleinstigen Erfüllung, auf eine entmuthigend ferne Zeit, hinausgestellt haben. Meine Bitte, oder Anfrage, ist diese; ob Sie wohl für mich ein Gemälde, so groß oder klein, als Sie es den Umständen angemessen finden, von einem einfachen Gegenstande, dessen Wahl ich Ihnen ebenfalls ganz überlasse, für ein Honorar von Ein Tausend Thaler, machen wollten. Darf ich zweÿ Wünsche in dieser Beziehung aussprechen, so wäre der Eine; daß Sie mehr einen heroischen, als idÿllischen Gegenstand wählen möchten u der zweÿte Wunsch der, daß die Erfüllung meiner Bitte, ard Bendemann, von dem er sich vergeblich ein Kunstwerk erhoffte, äußerte er sich wohlwollend über die Historienmalerei der Rheinländer Malerschule und rühmte dessen Jeremias auf den Trümmern Jerusalems (vgl. Abb. 41). Er konnte sich in einer Ausstellung in Dresden um die Jahreswende 1836/1837 davon überzeugen, an der nebst diesem und Lessings Hussitenpredigt zahlreiche weitere Historien zu sehen waren. Diese Gemälde waren seiner Meinung nach höheren Zielen gewidmet. Sie vermochten tragische Ereignisse wie den Untergang Jerusalems präzise und assoziationsreich darzustellen. ${ }^{7}$

Die Dresdener Schau der Düsseldorfer Bilder war von Quandts Nachfolger im Kunstverein, Carl Gustav Carus, angeregt worden und stieß auf ein überwältigendes Echo. Hierauf wies auch Quandt hin und schrieb an Bendemann, das Dresdener Ausstellungspublikum sei sehr erregt gewesen. Dabei erwähnte er einen Generationenkonflikt, der für die jungen Akademieschüler der Stadt an der Elbe heilsam sei:»Die Ausstellung der Düsseldorfer Gemälde in Dresden hat gut gewirkt; das Publicum sehr aufgeregt, die ältern Künstler zu einer heilsamen Resignation gestimmt $\mathrm{u}$ die kräftigern unter den jüngern Leuten ermuthigt, nach einem höhern Ziel zu streben, wovon sie früher glaubten, daß es in unsrer Zeit unerreichbar seÿ. Viele Talente mögen im Keime, durch die ehemals geisttödende Dresdner Academie erstickt worden seÿn u andern fehlte es ganz u gar an Aufmunterung, so sehr sie es verdient hätten, in dem eine Schneelandschaft ein Prospect u ein Portrait die höchsten Aufforderungen waren, deren sich ein sächß: Künstler zu erfreun hatte. $\ll^{22}$ In diesem spöttischen Seitenhieb gegen die Dresdener Akademie der bildenden Künste unter Heinrich Vitzthum von Eckstätt, gegen den er seit der gescheiterten Zusammenarbeit im Kunstverein gelegentlich polemisierte, klingt die Reorganisation der Kunstakademie an, die in diesen Monaten zu einem Ende kam. Ein Resultat davon war der neu eingeführte akademische Rat, der dem Direktor zur Seite gestellt wurde. Diesem nicht zu fern läge, denn jemand, der wie ich, ein halbes Jahrhundert hinter sich liegen sieht, hat nur wenig Jahre mehr zu hoffen, in welchen er nicht ganzer Frische u Kraft des Gemüths sich zu freun u zu genießen vermag [...]. Mit neuer Stärke, ist in mir der Wunsch erwacht, ein Gemälde von Ihnen zu besitzen, als ich die Düsseldorfer Bilder in Dresden wiedersah. Immer kehrte ich zu dem Jeremias zurück, in welchem mit tragischer Größe, der Untergang eines ganzen Volkes, in ein Bild zusammengefaßt ist [...]." Der Auftrag kam wohl wegen Bendemanns Tätigkeit für den König und als Professor der Akademie nicht zur Ausführung. Zur Düsseldorfer Ausstellung in Dresden siehe Spitzer 2011, S. 141-142.

72 Brief von Quandt an Bendemann vom 10.3.1837, in: Leipzig, Universitätsbibliothek, Sondersammlungen, Mappe 232, Quandt, Johann Gottlob von, fol. 1v. S. a. Spitzer 2011, S. 141-142. Angeblich war Quandt zusammen mit Bendemann und Hübner beauftragt, die Ausstellung zu organisieren, was im Rahmen seines Amtes als Akademischer Rat im Bereich des Möglichen liegt. Die Angabe konnte nicht überprüft werden. Vgl. Hommel 2000, S. 225-226. 
gehörte Quandt seit 1836 selber an. ${ }^{73}$ Hier vertrat er mit Verve seine Überzeugungen, wozu auch die Gründung von Ateliers gehörte. Tatsächlich wurden solche mit dem Ende der Reform 1837 gebildet.74 Für diese Ateliers versuchte man Düsseldorfer Maler zu gewinnen. ${ }^{75}$ Quandt setzte seine Hoffnungen in Eduard Bendemann, der 1838 tatsächlich als leitender Professor des Malerateliers an die Akademie berufen wurde. Der Kunstfreund war hierüber hoch erfreut und glaubte, dass nun ein genialer Meister gemeinschaftlich mit seinen Schülern anregend und fördernd zusammenarbeiten könne. ${ }^{76}$

Zeitgleich erging ein königlicher Auftrag an Bendemann. Er sollte den Thronsaal des Residenzschlosses mit Fresken bemalen. Quandt fungierte als Überbringer der Nachricht: »Verehrtester Herr und Freund, Se Maj: der König hat den Entschluß gefaßt, Ihnen in den Sälen des hiesigen Schloßes eine Frescoarbeit aufzutragen. Die Eile mit der ich Ihnen dies melde, wird Ihnen ein Merkmal der Freude seÿn, welche ich über diese Nachricht fühle, denn es reihen sich daran noch mehrere Hoff-

73 Zur Ernennung siehe den Brief von Quandt an Schnorr vom 3./6.1.1837, in: SLUB, Msr. Dresd. n Inv. 15, Bd. 31, fol. 196-204. S. a. Wilmowsky 2017, S. 766; Altner 1990, S. 130.

74 Zur Reform der königlichen Kunstakademie siehe Altner 1990, S. 127130. Quandt 1847, S. 68 über Ateliers.

$75 »[. .$.$] Unser kunstliebender König selbst war durch diese Ausstellung$ eigenthümlich bewegt worden, und, ohne daß er darüber irgend weitere Mittheilungen vorläufig gemacht hatte, veranlaßte er jetzt in der Stille durch Minister von Lindenau, daß Unterhandlungen eröffnet würden, ob es wol möglich sei, einige der bedeutenderen Kräfte dieser neurheinischen Schule auf hiesigen Boden zu verpflanzen."Carl Gustav Carus, zitiert nach Spitzer 2011, S. 142.

76 »Bei der neuen Organisirung der Akademie in Dresden erkannte man an, dass die Kunst nicht wie eine Kenntniss gelehrt, sondern als Naturanlage entwickelt und als Geschicklichkeit geübt werden müsse und dies nur durch einen genialen, productiven Meister möglich sei, der in unmittelbarere Beziehung und in ein näheres Verhältniss zu Schülern tritt, als bei einem akademischen Classenunterricht statfinden kann. Es wurden daher bei der Akademie für Architektur, Sculptur, Malerei und Kupferstecherei Ateliers eingerichtet, in welchen Meister und Schüler gemeinschaftlich arbeiten und in eine anregende und fördernde Berührung kamen und Bendemann 1838 zum Vorstand des Maleratelier der Akademie nach Dresden berufen." Quandt 1846 (4), S. 15. S. a. Brief von Quandt an Winkler vom 5.10.1837, in: SLUB, Mscr. Dresd. App. 204, Nr. 98e. Auf Bendemann folgte bereits 1839 mit Julius Hübner noch ein weiterer, in Düsseldorf ausgebildeter Maler. Spitzer 2011, S. 142.

77 Brief von Quandt an Bendemann vom 4.10.1837, in: Leipzig, Universitätsbibliothek, Sondersammlungen, Mappe 232, Quandt, Johann Gottlob von, fol. $1 r-v$. Quandt bezieht sich hier indirekt auf einen ersten Berufungsversuch von 1836, den Bendemann noch abgelehnt hatte, weil ihm über die Professorentätigkeit hinaus Aufträge fehlten. Mit dem königlichen Auftrag im Schloss war der Anreiz größer.

78 In diesem Zusammenhang skizzierte Quandt ein spöttisches Charakterbild der alten Hofleute, die über königliche Entscheidungen wie den Auftrag an Bendemann überrascht waren: »Dieser Graf Loos [Johann Adolph Graf von Loß - AR], Haus Marschall des Königs, ist ein langer, dünner Mann. In allen seinen Bewegungen ist etwas Rückendes u Zuckendes. Beÿ jedem Worte verzerrt sich sein Mund in Geburtsschmerzen u wenn man ihm fest ins Gesicht schaut, kann er nungen und zwar diese; daß Sie der Unsere werden und auf unsre jungen Künstler wirken. [...] Niemand hat wohl größre Freude darüber als ich! - Sie sagten, könnte ich hier eine Arbeit in Farbe unternehmen, so bliebe ich wohl-u ich glaube dies war Ihnen Ernst. «77 Der Künstler nahm den königlichen Auftrag an, worauf ihm Quandt in einem erneuten Brief seine Freude darüber ausdrückte und zu den Maßen der zu bemalenden Säle verhalf. ${ }^{78}$ Bis 1842 waren die Fresken vollendet. Die Hauptgemälde zeigten Ereignisse aus der Vita Kaiser Heinrichs I. und Figurendarstellungen verschiedener Gesetzgeber. Um den ganzen Saal herum verlief ein Fries mit dem Lauf des Lebens von der unschuldigen Geburt über die verschiedenen Lebensalter und menschlichen Tätigkeiten bis hin zur Erlösung im Tod. ${ }^{79}$

Doch selbst wenn Quandt die Düsseldorfer Malerei unterstützte, war es auch hier eine idealisierte poetische Kunst, die ihn interessierte. Der Richtungsstreit der Realisten und Idealisten, der die Rheinländer Akademie vor große Herausforderungen stellte und gerade im Landschaftsfach zu ganz eigenen

gar nicht sprechen, er spückelt[?] wie ein Kätzchen. Das Erstaunlichste aber ist, die Weise, auf welche er seine gefastelte[?] Zunge lößt. Wenn seine Verlegenheit den höchsten Grad erreicht hat, er mag nun stehen oder sitzen, so hebt er mit größter Schnelligkeit das linke Bein in die Höhe u kneipt sich mit der rechten Hand, in die große Fußzehe. Dies ist alles buchstäblich wahr. [...] Dabeÿ ist der Graf Loos von einer unglaublichen Hartnäckigkeit u die alten Gewohnheiten des Hofs Friedrich Augusts, haben ihn u viele andere Hofleute statisch gemacht. Es war niemand im ganzen Lande abhängiger, als der König Friedrich August, der von Gewohnheiten, seinen Hofleuten, einer nach der Uhr abgemessnen Lebensordnung, so gebunden war, daß er nicht thun konnte was er wollte, sondern was seine Höflinge ihm sagten, daß eben nach der Uhr zuthun seÿ. Der König Anton, ein heitrer u wohlwollender Charakter, streifte diesen Zwang ab u zog sich nach seinem Schloße Weesenstein zurück. Die Hofleute waren das beÿ seinem Vorgänger, was die Strelitzen [Palastgarde] in Rußland u die Janitscharen in der Türkei waren. Der jetzige König hat als junger Prinz, lange genug in dieser Abhängigkeit gestanden, um sich dieser zu unterwerfen. Die alten Herren des Hofs können aber nun nicht begreifen, wie ein König sich selbst zu etwas entschließen kann, u so weiß sich Graf Loos nicht darein zu finden, wie der König sich entschließen konnte, Säle im Schloße in Fresco malen zu laßen, ohne daß er, der Haus Marschall, dem König es vorgeschlagen hat. Wolframsdorf, dem ich darüber Vorwürfe machte, daß er die Maase nicht sogleich geschickt, entschuldigte sich damit, daß er es nicht [habe] wagen dürfen, ohne vorher den Graf Loos um Erlaubniß zubefragen. Diese Menschen sind in der That mehr zu beklagen, als daß man ihnen bös seÿn kann, denn sie sind innerlich u äußerlich verdorrt und verschrumpft. Wer würde wohl glauben, daß dieser Graf Loos, ein wissenschaftlich gebildeter $u$ liebenswürdig junger Mann war, wie Alle versichern welche ihn früher kannten. Zum Glück sind diese Art Leute jetzt unschädlich gemacht, da der König mehr Zutraun zu sich selbst faßt u selbständiger in seinem Handeln wird. « Brief von Quandt an Bendemann vom 8.1.1838, in: Leipzig, Universitätsbibliothek, Sondersammlungen, Mappe 232, Quandt, Johann Gottlob von, fol. 1r-2r. Bendemanns Antwort vom 23.2.1838, in: SLUB, Mscr. Dresd. App. 278, Nr. 18. S. a. Spitzer 2011, S. 142-143.

79 Der Auftrag zog noch einen weiteren nach sich. Bendemann bemalte den anschließenden Ballsaal bis 1855 mit hellenischen Motiven. Quandt 1846 (4), S. 15; Bendemann 1847, S. 3-8. 
Produkten führen sollte, spielte für Quandt keine Rolle mehr. ${ }^{80}$ Er blieb seiner Überzeugung von der Historienmalerei als wichtigster Bildgattung treu, selbst wenn er den anderen Gattungen theoretisch die Möglichkeit zumaß, ebenfalls gute Kunst hervorzubringen. Politisch-gesellschaftliche Zeitereignisse, wie sie in der Historienmalerei oder, wie in Düsseldorf, in einer sozialkritischen Genremalerei verarbeitet werden konnten, spielten für ihn eine untergeordnete Rolle. Vielmehr stand Quandts Kunsturteil unter der Prämisse, dass Kunst Ausdruck der Vernunft und Emanation des menschlichen Wirkens sei: »Alle Künste sind da überhaupt nur Emanationen eines Urquells, welcher das Gemüth des Menschen ist, da aber die Poesie selbst als ein ganz geistiges Wesen unmittelbar aus dem Gemüthe hervorströmt, so wird sie allen andern Künsten voraus gehen und sich am ersten entfalten, indeß die bildende Kunst einer geraumen Frist zu ihrer selbstständigen Entwicklung bedarf $[\ldots] . \ll^{81}$ Die Historienmalerei war laut Quandt hierfür besonders prädestiniert. Denn in der Geschichte der Menschheit konnte er die menschliche Vernunft festmachen und der Künstler als vernünftiger Mensch vermochte dies im Bild darzustellen.

Diese Vernunftgeschichte konnte Quandt grundsätzlich auch in anderen Bildgattungen finden. Wie er Gemälde anderer Gattungen beurteilte, sei nachfolgend anhand einiger Beispiele skizziert. Dabei bleiben die Kriterien, wie sie in Bezug auf die Historienmalerei ausführlich beschrieben worden sind, weitgehend gleich.

\section{Landschaftsmalerei als Metapher der menschlichen Vernunft}

Besonders in der Landschaftsmalerei waren die Voraussetzungen für hochstehende Kunst gegeben, da ihr Gegenstand die Natur war. ${ }^{82}$ Der Künstler als Mensch war Teil der Natur und konnte so durch seine Vernunft das Schöne darin entdecken und darstellen: »Die Natur ist freilich allmächtig, aber nur im Ganzen und im Einzelnen bedingt, dahingegen ist die Kunst im Schaffen des Einzelnen frei, jede Individualität bei ihr eine To-

80 Baumgärtel 2011, S. 42-45; Mai 2011, S. 53-57; Locher 2005, S. 71-81.

81 Quandt 1846 (2), S. 372.

82 Zu Quandt und die Landschaftsmalerei siehe Rüfenacht 2017, S. 152-179.

83 Quandt 1846 (2), S. 299

84 »Es muß Natur sein, oder von uns dafür gehalten werden, damit wir an dem Schönen als einem solchen ein unmittelbares Interesse nehmen können.« Kant 1790 [2009], S.650. Das Naturschöne führt jedoch zu einem Riss »zwischen Erkenntnissubjekt und Natur«, den Kant in der Kritik der Urteilskraft dadurch zu kitten versucht, als er einen inneren Bauplan der Natur postuliert, der allem zugrunde liegt. Durch den Künstler bzw. das Genie wirke die Natur in die Kunst, so dass das Kunstwerk als Produkt der Natur erscheine. Siehe dazu Hartmut Böhme, talität und eine absolute Form des Daseins der Idee und folglich auch schön, indeß die Schönheit in der Natur etwas zwar Mögliches, aber immer Zufälliges ist und meistens durch äußere specifische Merkmale getrübt erscheint. Aber wie das Auge des Astronomen durch den Dunst hindurch den leuchtenden Kometenkern entdeckt, muß das Künstlerauge die verborgene Schönheit in der Naturbildung überall erkennen und nicht blos den äußern Schein nachahmen. $\ll^{83}$ Die Kantschen Ursprünge dieses umständlichen Votums bedürften hinsichtlich des Begriffs der Schönheit in der Natur und der Kunst einer genaueren Untersuchung genauso wie die Herkunft von Quandts Naturbegriff generell. Dieser nährt sich aus der Vorstellungstradition einer gesetzmäßigen Natur, die für den Menschen nicht restlos nachvollziehbar ist. ${ }^{84}$

An dieser Stelle sei nur festgehalten, dass Quandt wie andere Autoren den Landschaftskünstler als Vermittler zwischen der allmächtigen Natur und dem vernünftigen Menschen bezeichnet. Dieser lenke die Wahrnehmung des Betrachters auf die natürliche Schönheit. In einem Brief an Goethe schrieb er: »Die Natur ist so folgerecht, ein Theil in ihr aus dem andern hervorgegangen, einer durch den andern bedingt, daß alles einen Guß ausmacht. Wäre die Natur nicht so folgerecht, so hätte gar keine Welt Daseyn. [...] Deshalb machen Landschaften auf mich, in welchen kein folgerechter Zusammenhang ist, immer einen widrigen Eindruck, denn in solchen Bildern erscheint die Natur als ein unmöglicher und unvernünftiger Zufall oder Werk launenhafter Allmacht. $\ll^{85}$ Die rhetorische Leitfrage zu dieser Vermittlungsarbeit des Künstlers stellte sinngemäß Schelling:»Wie können wir jene scheinbar harte Form [der geregelten Natur - AR $]$ geistig gleichsam schmelzen, daß die lautere Kraft der Dinge mit der Kraft unseres Geistes zusammenfließt, und aus beiden nur Ein Guß wird? ${ }^{86}$ Carl Ludwig Fernow, dessen Römische Studien in Quandts Bibliothek standen, meinte in seinem Aufsatz Ueber die Landschaftmalerei im zweiten Band seines Werks: »Denn alle Gegenstände einer Landschaft stehen durch die Idee, deren Ausdruck das Ganze seyn sol, in gegenseitiger Abhängigkeit. Nur in Beziehung auf das Ganze wird jedes Einzelne bedeutend [...] und das Zufälligscheinende erhält innere Zwekmäßigkeit.« ${ }^{87}$

»Natürlich/Natur«, in: ÄGB, Bd. 4, S. 486-488. Zur naturwissenschaftlich basierten Erkenntnis eines allgemeingültigen Regelwerks der Natur bzw. zur Vorstellung einer durch und durch mechanisierten Natur seit dem 16. Jahrhundert ebd., S. 474-485. S. a. Dietzsch 2016, S. 47-48.

85 Brief an Goethe vom 11.4.1831, in: Schmitz/Strobel 2001, S. 121. S. a. Quandt 1830 (1), S. 54-65.

86 Schelling 2004, S. 62-64. Quandt rezipierte Schellings Rede Über das Verhältnis der bildenden Künste zur Natur (1807) unter anderem in Quandt 1844 (1), S. 121-127. S. a. Fernow 1806-1808, S. 310-314.

87 Fernow 1806, S. 14. S. a. ebd., S. 24: »Und wenn auch Inhalt und Karakter einer Landschaft durch besondere Naturerscheinungen oder durch bedeutende Staffirungen näher bestimmt werden, so sind solche Bestimmungen doch nur als etwas Zufälliges anzusehen [...].« 
Gerade Fernow dürfte für Quandt wenn auch nicht nachweisbares, so doch ideelles Vorbild gewesen sein, weil er mit seinem 1806 erschienen Aufsatz einen Mittelweg zwischen klassizistischer und romantischer Kunstauffassung eingeschlagen hatte. ${ }^{88}$ Wie Quandt stellte er eine Verbindung von Landschaftskunst und Dichtung her: »Jede Darstellung der landschaftlichen Natur, wenn sie nicht Abbildung einer wirklichen Aussicht ist, sol eine Dichtung seyn; denn auch der Maler ist nur in sofern ein wahrer Künstler, als er dichtet [...]. Denn die Landschaftmalerei kann ihre ideali $[\mathrm{s}$ chen Scenen nie anders als im Karakter und Stil der wirklichen Natur dichten, da weder das Einzelne noch das Ganze in ihr ein Ideal, d. h. eine solche Erhebung über das Wirkliche zuläst, wo die Natur mit der Volkommenheit ihrer Erzeugnisse nicht hinan reicht. $\ll^{89}$

Stärker als Quandt betonte Fernow zwar, die Natur sei »kein Erzeugnis einer dichterisch gestimmten Einbildungskraft, kein echtes Kunstwerk«. In dieser Aussage verbirgt sich noch die ältere Vorstellung eines Prinzips der vom Menschen gestalteten Natur, wie es sich im Landschaftsgarten ab der zweiten Hälfte des 18. Jahrhunderts niederzuschlagen begonnen hatte. ${ }^{90}$ Dennoch zeigt sich sowohl bei Fernow wie auch bei Quandt ein Staunen über die Vollkommenheit und Allmacht der Natur, der gegenüber der Landschaftsmaler als klein erscheint. Denker der Frühromantik wie die Gebrüder Schlegel hoben diesen Gegensatz der allmächtig waltenden Natur und des schaffenden Menschen noch stärker heraus und forderten eine neue Landschaftsmalerei. So legten die beiden Autoren in ihrem fiktiven Galeriegespräch Die Gemählde der Figur des Reinholds die Aussage in den Mund, die Kunst müsse »als bloße Abschrift der Natur gegen das ewige Regen und Weben derselben unendlich zurückstehen [...]. Der Künstler kann die landschaftliche Natur nur durch Wahl und Zusammenstellung verbessern, nicht an sich erhöhen. $\ll^{91}$ Diese Auswahl und Zusammenstellung von Motiven aus der Natur war freilich nichts Neues, wie Oskar Bätschmann es für die Landschaftsmalerei des 18. Jahrhunderts als »Kombinatorik « von Einzelelementen aus Naturstudien und der »Erfindung« der Landschaftskomposition im Atelier charakterisiert hat. ${ }^{92}$ In der älteren Theorie diente die

88 Busch 1997, S. 247-249

89 Fernow 1806, S. 34-35. »Die Natur ist unerschöpflich an Motiven aller Art; aber sie fodert, dass ihr eine dichterische Fantasie begegne; ein geübter Kunstsin, der sie lebendig auffasse; ein Geist, der den rohen dürftigen Stof zu einer reichen idealischen Schöpfung ausbilde.« Ebd., S. 64 .

90 Fernow 1806, S. 35. Zum Ideal der gestalteten Natur siehe Wolf 2002, S. 15-16; Bätschmann 1989, S. 23.

91 Schlegel 1996, S. 31. Zu Fernow in Quandts Bibliothek siehe oben Kap. Bildnis eines Kunstgelehrten sowie Abb. 1. S. a. Wolf 2002, S. 30.

92 Bätschmann 1989, S. 27-37.

93 Schlegel 1996, S. 31. Siehe hierzu auch Busch 1997, S. 242-244 über Philipp Otto Runge. Bätschmann 1989, S. 65-66 zu Carus' Erdlebenbild.
Kombinatorik jedoch der Überwindung natürlicher Unwägbarkeiten, während die romantische Theorie die Natur und ihre Gesetzmäßigkeiten, ihr ewiges und damit unfassbares »Regen und Weben« über den Menschen stellte. Deshalb meint Schlegels Reinhold, die Landschaftsmalerei müsse genau dies »durch etwas von wesentlich verschiedner Art ersetzen « - was in unterschiedlichster Ausprägung auch geschah, wie die Arabesken von Philipp Otto Runge oder Carl Gustav Carus' literarische Forderung eines »Erdlebenbildes« beispielhaft darlegen. ${ }^{93}$

Mit Carus lässt sich zeigen, dass Quandt durchaus auch der neusten Literatur zugewandt war. Die Neun Briefe über Landschaftsmalerei des Dresdener Arztes und Malers hatte der Kunstkenner 1831 rezensiert.94 Neu an dessen Werk war die Verknüpfung von Naturwissenschaft und Landschaftsmalerei. Carus schrieb vom Inneren der Natur, deren Geheimnisse besonders Geologen und Meteorologen aufdecken und die Maler darstellen konnten.95 Zwar sollte Quandt erst später diese Verknüpfung in sein Denken aufnehmen. Doch ganz im Sinn frühromantischer Gattungstheorie sollte auch bei ihm ein Künstler das Schöne aus dem Verborgenen, aus dem Verdeckten und Inneren der Natur herausschälen.

Für Quandt zentral blieb dabei, dass der Landschaftsmaler die Natur nicht nachahmte, da er sie nie als Ganzes, sondern nur in ihren Einzelaspekten festhalten konnte. Eindrücke direkt nach der Natur würden nur selten ein vernunftmäßiges Ideal von Schönheit hervorbringen. Vielmehr sollte der Künstler sich die Naturgesetze und Naturformen im Studium aneignen und verstehen lernen. Erst dann würde er eine von seiner Vernunft durchdrungene und in sich folgerichtige Kunst erschaffen. ${ }^{96}{ }^{\circ}$ Das Werk eines Künstlers wird in allen Theilen zusammenhängend und ganz in sich übereinstimmend seyn, weil der Künstler alle Theile in naturgemäßen Formen gedacht, diese aber nach einer Idee bestimmt hat. Die Natur kann die Idee des Künstlers nicht bestimmen. Das wahre Ideal ist die vom Menschengeist durchdrungene Wirklichkeit.« ${ }^{97}$ Diese Durchdringung beschrieb er als Poetisierung des dargestellten Naturgegenstandes, der wie die literarische Poesie vom vernünftigen Geist des Künstlers gestaltet werden sollte.

94 Quandt 1831 (4), S. 97-102.

95 »Was bildet den Landschaftsmalerei, als die große irdische, uns umgebende Natur? - und was ist erhabener als die Erfassung des geheimnisvollen Lebens dieser Natur? « Zit. nach Bätschmann 1989, S. 57. S. a. ebd., S. 6o-61.

96 Quandt 1817, S. 147; Quandt 1819, Bd. 1, S. 71-72; Quandt 1830 (1), S. 55-56, 298-300; Quandt 1831 (4), Sp. 99-101.

97 Quandt 1830 (1), S. 64; Quandt 1839 (1), S. 5 über die Mimesis: »Die Darstellung des Wirklichen an sich [...] leitete auf Abwege, und zwar zu einer Natürlichkeit, die in Niedrigkeit ausartete.« Quandts Mimesiskritik lautet ähnlich wie bei Schelling: »Wenn wir die Dinge nicht auf das Wesen in ihnen ansehen, sondern auf die leere, abgezogene Form, so sagen sie auch unserm Innern nichts. « Schelling 2004, S. 57-59. 


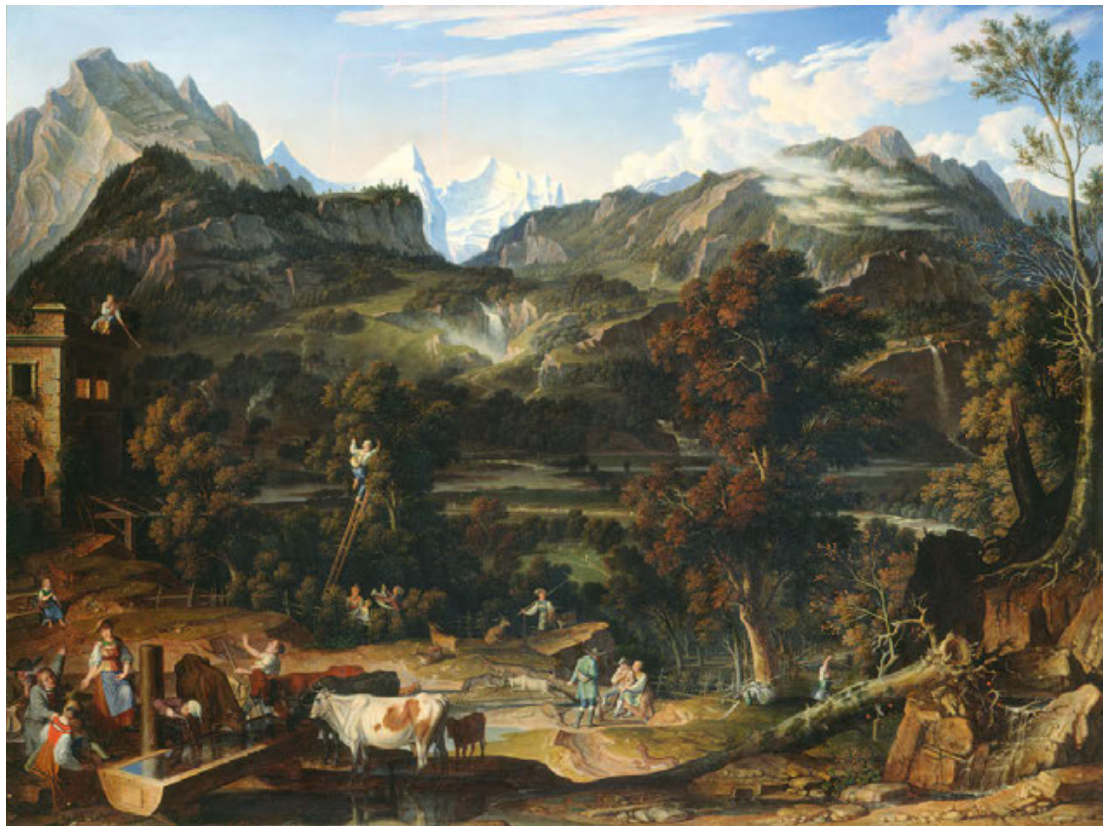

46 Joseph Anton Koch, Berner Oberland (Blick von der Burgruine Resti auf Meiringen, Reichenbachfälle und Wetterhorn), 1816, Öl auf Leinwand, $73 \times 99 \mathrm{~cm}$, Dresden, SKD, Albertinum | Galerie Neue Meister, Gal.-Nr. 2465
Quandt kam angesichts der Forderung nach einer Durchdringung der Kunst durch die Vernunft zum Schluss: »Das Landschaftsfach ist als kein besonderes zu betrachten, denn der Historienmaler bedarf der Landschaft, und der Landschafter kann der menschlichen Figuren nicht entbehren. $\otimes^{98}$ Trotz aller Unterschiede der Gattungen hob er einen Ausgleich in ihrem Modus hervor. Darin gleicht er Reinhold in Schlegels Galeriegespräch, der »nichts von solchen Rangstreitigkeiten« in den Bildgattungen hielt.99 Entsprechend besaß Quandt in seiner eigenen Sammlung ähnlich viele Landschaften wie Historien, und von jenen ähnlich viele mit wie ohne Staffagefiguren. Seine Kunstansichten sah er erfüllt in den Gemälden von Adrian Ludwig Richter und Ernst Ferdinand Oehme, die er persönlich kannte und förderte. Darüber hinaus sammelte er Gemälde älterer Landschaftsmaler wie Joseph Anton Koch, Caspar David Friedrich oder Johann Martin von Rohden, die er ebenfalls schätzte. ${ }^{100}$

Quandt 1826 (1), S. 279. S. a. Thimann 2014, S. 139-140.

Schlegel 1996, S. 34: »Waller. Und machen die Landschaftsmahlerey zur höchsten Gattung, weil in ihr das bloße Phänomen eine so wichtige Rolle spielt? Reinhold. Vielleicht. Indessen halte ich nichts überhaupt nichts von solchen Rangstreitigkeiten."

100 Quandt besaß 182420 Landschaften, davon 18 von Zeitgenossen, 11 mit Staffagefiguren. 1868 wurden 34 Landschaften versteigert, davon 31 von Zeitgenossen, 19 mit Figuren. Kat. Quandt 1824; Kat. Quandt 1868. Alle Landschaftsgemälde in Quandts Sammlung aufgeführt in Rüfenacht 2018, S. 16-40.

101 Hierzu ausführlich Kap. Kunsttheorie mittels Präsentation: Assoziationsreiche Pendants.

102 Kat. Quandt 1868, S. 23-24, Nrn. 81-82; Rüfenacht 2018, SQ-83, SQ84. S. a. Quandt 1853, S. 169: »In früherer Zeit zeichnete Karstens, dann Thorwaldsen und auch Cornelius die Figuren in Kochs Land-
Einige dieser Landschaften präsentierte Quandt als Bildpaare. ${ }^{101}$ Exemplarisch sei Joseph Anton Kochs Berner Oberland und die Ideale Landschaft mit der Heimkehr Jakobs genannt (Abb. 46-47). Letzteres vereinigt Quandts Sammlungsschwerpunkt in den Gattungen der Landschaft und der Historie nicht nur durch das Motiv der Figurengruppe, das aus der alttestamentarischen Jakobsgeschichte stammt, sondern auch durch den Maler der Figuren. Diese wurden nämlich vom berühmten Münchner Künstler und Erneuerer der Freskenmalerei Peter Cornelius entworfen. ${ }^{102}$ Das Pendant hatte Quandt gekauft, als er 1819 für ein knappes Jahr in Italien weilte. Der Standort des Malers ist genau lokalisierbar. Er blickt von der Burgruine Resti oberhalb von Meiringen auf die Reichenbachfälle und tief in das Reichenbachtal in Richtung des Passes Große Scheidegg, über dem sich die berühmten und oft dargestellten Wetterhörner erheben. ${ }^{103}$

Ein anderes Bildpaar hatte Adrian Ludwig Richter geschaffen. Auf dem einen ist das morgendliche Wasserholen vor der nahe bei

schaften. [...] Koch gerieth dadurch, dass er die Staffage seiner Landschaften ausmalte, welche andere Künstler gezeichnet hatten, in die Selbsttäuschung, dass er ein großes Talent für die Historienmalerei habe.«

103 In der besitzenden Institution, der Galerie Neue Meister in Dresden (Gal. Nr. 2465) wird das Berner Oberland betitelte Werk auf 1816 datiert. Wahrscheinlicher ist eine Entstehung im Jahr 1821. Siehe den Brief von Rudolf an Johann Gottfried Schadow vom 17.1.1821, in: Berlin, Staatliche Museen preußischer Kulturbesitz (SMB), Zentralarchiv, Nachlass Johann Gottfried Schadow, NL Sw 182: »[...] Koch mahlt eine große Landschaft aus der Gegend des Staubbach in der Schweiz, Bestellung v. H. v. Quan[d]t [...].«In der Koch-Literatur findet sich zwar kein »Staubbach«, doch sind Reichenbach- und Staubbachfall nicht allzu weit voneinander entfernt, was aus der Berliner Perspektive zu Konfusionen geführt haben mag. S. a. Rüfenacht 2018, SQ-83. 
47 Joseph Anton Koch, Ideale Landschaft mit der Heimkehr Jakobs, 1816, Öl auf Leinwand, $74,5 \times 98 \mathrm{~cm}$, Leipzig, Museum der bildenden Künste, Inv.-Nr. G 120

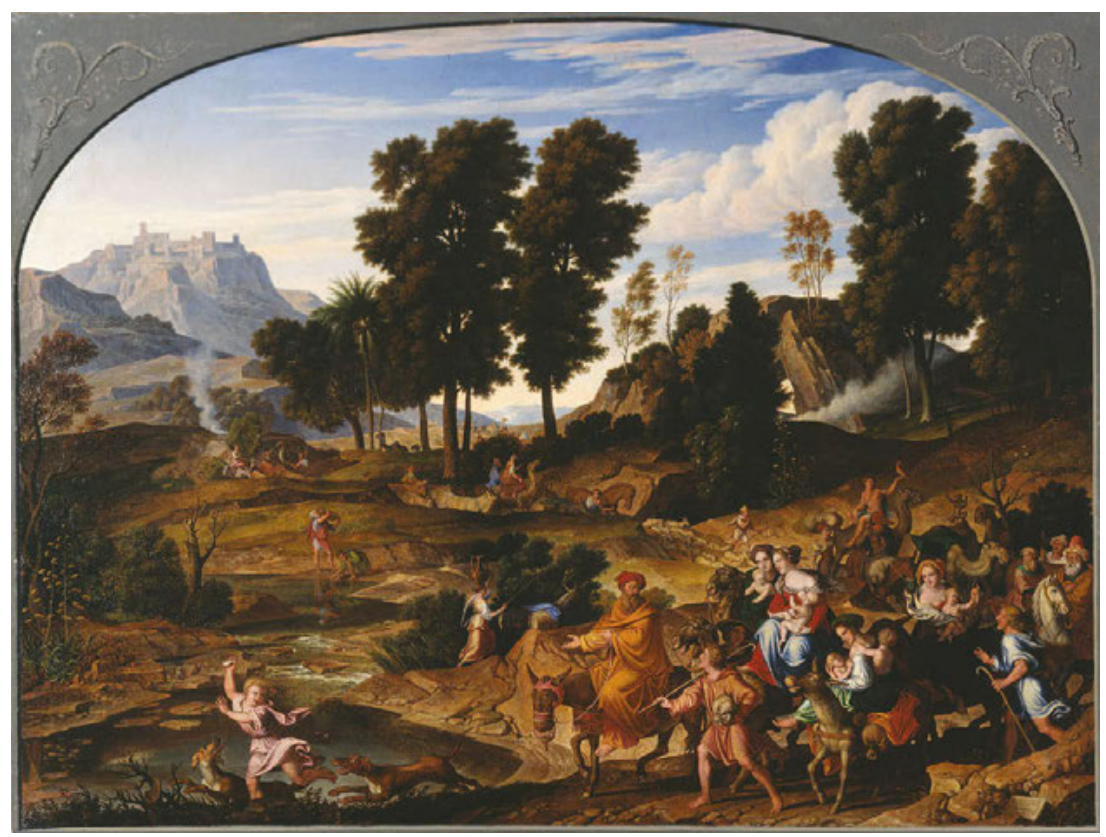

Rom gelegenen Stadt Ariccia dargestellt. Das andere Motiv zeigt das Städtchen Civitella in den Abruzzen bei Abendlicht mit vom Feld zurückkehrenden Bauern (vgl. Abb. 56-57). ${ }^{104}$ Der innere Zusammenhang der beiden Gemälde liegt im Motiv des Schöpfens an der Quelle zu Beginn des Tages und des Einbringens der Ernte am Abend. Der gemeinsame Gedanke zeigt sich im Gedeihen, das Leben ermöglicht. Wasser und Ernte, Morgen und Abend deuten einen idyllischen Lebenskreis an. Über das Abend-Bild schrieb Quandt: »Das eine ist die Ansicht von Civitella in Abendbeleuchtung; wirklich ein bewundrungswürdiges Bild in Hinsicht der Farbe in welcher sich das Hinschmelzen des Lichts u die allmähliche Dämmrung in den Thälern, trefflich darstellt. Eine Familie welche mit Früchten des Feldes u Gartens heimkehrt, ist die Staffage. Es sind Frauen welche in einem historischen Bilde zu stehn würdig wären. $\ll^{105}$ Richter war sehr bemüht um diese Figuren und ließ sie sogar von Schnorr in Rom überarbeiten. ${ }^{106}$ In Quandts Verständnis hatte der Maler damit die künstlerisch-poetische Durchdringung seiner Landschaft erreicht. ${ }^{107}$

Die Verbindung lebensnaher Figuren und genrehafter Szenerien in einer Landschaft findet sich in einem weiteren berühmten Bild Richters, das sich in der Sammlung von Quandt befand: die Überfahrt über die Elbe am Schreckenstein (vgl. Abb. 10). ${ }^{108}$ Die Einbindung markanter und verschiedenartiger Figuren prägte die Rezeption dieses Werks besonders. Man kann es nicht eindeutig den traditionellen Gattungen der Landschaft oder des Genres zuordnen. Wie in den Abend- und Morgen-Gemälden wird auch dieses Motiv in der Forschung dem Lebenskreis zugeordnet. Die Lebensalter widerspiegeln sich in den nachdenklichen Figuren im schaukelnden Lebensboot. Kinder, Jugendliche, das junge Pärchen und die Alten ziehen wie der auf den Stock gestützte Wanderer, von flüchtigen Harfenklängen umgeben und von der Burgruine an verblichene Zeiten erinnert, auf ihren Lebenswegen dahin. Auch dieses Bild war für Quandt, durch die anschaulich-menschlichen Charaktere, in seiner Art ein Historiengemälde - und damit vom vernünftigen Geist des Künstlers durchdrungen. ${ }^{109}$

Analysiert man die weiteren Landschaften in Quandts Sammlung, so wird deutlich, dass die durchkomponierten, insbesondere auch südlichen Landschaften mit Staffagefiguren in der Tradition Claude Lorrains einen Kontrapunkt zu den nördlichen Landschaften der Romantik bilden. ${ }^{110}$ Doch gerade die Präsenz von Figuren in Quandts Landschaftsgemälden
104 Rüfenacht 2018, SQ-67, SQ-68; Kat. Bad Muskau 2016, S. 43-44; Kat. Dresden/München 2003, S. 141-147, Kat. Nrn. 6, 7.

105 Brief an Schnorr vom 20.9.1828, in: SLUB, Mscr. Dresd. n Inv. 15, Bd. 31, fol. 159r. Quandt 1848, S. 239-240 charakterisiert Richters Figuren als »integrirende Theile der Natur «. Selbst Schinkel sei davon begeistert gewesen. Richter schrieb während seines Aufenthaltes in Civitella über die Bildgenese in sein Tagebuch: »Fürs erste will ich mich in das romantische Gebiet wagen, wo Natur und Mensch zu gleichen Theilen herrschen, eines dem andren Bedeutung und Interesse giebt [...].« Zitiert nach Kat. Dresden/München 2003, S. 19.
106 Kat. Dresden/München 2003, S. 18, 141.

107 In einem Tagebucheintrag von 1830 äußerte Richter seine Gedanken über die Landschaftsmalerei und fragte, ganz im Sinne Quandts: »Könnte man nicht ein historisches Gemälde, ein Gedicht, ja eine Musik auch in eine Landschaft übersetzen? « Richter 1909, S. 573. 108 Rüfenacht 2018, SQ-78.

109 Kat. Dresden/München 2003, S. 28-29.

110 Biedermann 2017, S. 26-28; Bätschmann 1989, S. 29-32. Siehe auch Fernow 1806, S. 113-118. Eine Zusammenstellung dieser Landschaften bei Rüfenacht 2018, SQ-63 (Steinkopf), SQ-69 (Rohden), SQ-83, SQ-84 
wirkt auch verbindend. Es mögen sich darin Forderungen des 18. Jahrhunderts zeigen, wie sie bereits Sulzer in seinem Artikel zur Landschaftsmalerei formuliert hat und wie sie noch bei Fernow erkennbar sind: »Die Darstellung einer idealischen Naturscene wird ästhetisch interessanter, wenn sie, wie die wirkliche Natur, als ein Aufenthalt lebender Wesen erscheint [...]; denn sie ist nicht nur der Natur gemäs, sondern die Landschaft erhält dadurch ihren bestimmten poetischen Karakter, mehr Bedeutung und höheres Interesse. ${ }^{111}$ Dennoch steht diesen traditionellen Landschaften eine beachtliche Anzahl figurenloser Naturlandschaften gegenüber, die Quandt in seinen Sammlungshängungen auch bewusst gemeinsam präsentierte, wie detailliert noch zu zeigen sein wird. In der programmatischen Gegenüberstellung der Gemälde Bewaldetes Tal des holländischen Alten Meisters, Jacob van Ruisdael, und Dittersbacher Grund des jungen sächsischen Künstlers Ernst Ferdinand Oehme thematisierte er seine Gefühle bei der Naturbetrachtung. ${ }^{112}$ Die emotionalen Seelenlandschaften Caspar David Friedrichs fügte er in seinen Hängungen in den Kontext schöner Landschaften in Lorrain'scher Tradition ein. Es lässt sich darin erkennen, dass der Kunstsammler die ästhetischen Kategorien des Schönen und Erhabenen durch Ergänzung weiterer Zuordnungen wie dem Tragischen und Rührenden und durch deren virtuelle Durchmischung auszugleichen versuchte. Die »Kombinatorik« nachahmender Naturstudien und die harmonisierende »Erfindung« von Landschaften, zum Beispiel in den Gemälden von Koch oder Rohden, verbinden sich in Quandts Sammlung mit dem »visuellen Schrecken« und der »seelenvollen Wirkung« romantischer Gemälde eines Friedrich oder Oehme. ${ }^{133}$ Im vollen Bewusstsein der historischen Tragweite der Gattungsdebatten der näheren Vergangenheit und Gegenwart kombinierte Quandt diese Bilder in teilweise sehr gelehrten Gegenüberstellungen in den Räumen seiner Sammlung. ${ }^{114}$

Typisch für seine ausgleichende Kunsttheorie verband der Sammler Tradition und neue Errungenschaften. In den Bildern Richters mag sich dieser Ausgleich künstlerisch manifestieren. Gerade sie vereinen Ideen der Historien-, Landschafts- und Genremalerei gekonnt miteinander und erweitern das emotionale Spektrum des Betrachters, indem sie allgemeine Themen des Alltags und des Lebens aufgreifen. Besonders die assoziationsreiche Kombination verschiedener Landschaftsgemälde in

(Koch), SQ-103 (Wagner), SQ-106 (Helmsdorf), SQ-108 (de la RiveGodefroy), SQ-113, SQ-114 (C. A. Graff), SQ-115, SQ-116 (Klotz).

111 Fernow 1806, S. 31-33, ausführlich zur Staffage und ihrer Aufgabe in der Geschichte der Kunst ebd., S. 75-100. Sulzer 1774, S. 654: »Durch eine wolausgesuchte Handlung aus dem sittlichen leben, die der Mahler in seine Landschaft sezet, kann er ihr einen Werth geben, der sie mit den besten historischen Gemähld in einem Rang sezet."

112 Siehe unten Kap. Erlebnis und Dichtung. Rüfenacht 2018, SQ-36 (Oehme); SQ-39 (Ruisdael). der Sammlungspräsentation verdeutlicht, dass Kunst über die Gattungsgrenzen hinweg die menschliche Vernunft darstellen müsse. Weil der Mensch Teil der Natur sei, seien Naturdarstellungen ein geeignetes Medium der Vermittlung: »Die Natur ist eine Autokratie die keine andern Gesetze hat, als die, welche ihre eigne Vernunft $[. .$.$] gab. Diese Gesetze sind äußerst einfach$ $\mathrm{u}$ allgemein, so daß ihre Anwendung eine fast unendliche Mannichfaltigkeit u eine beinahe unbeschränkte Möglichkeit zuläßt u darum der beschränkte menschliche Verstand nicht bestimmen kann, was möglich oder unmöglich së̈. [...] Wer kann aber sagen, daß ein Berg, eine Wolke, eine Welle gerade die oder jene Form haben solle? Hegel hat wohl Recht zu sagen: Was ist, ist vernünftig.- Nur muß dieser Satz in Beziehung auf Landschaftsmalerei, welche eben nichts Wirkliches, sondern blos den Schein einer Wirklichkeit hervorbringt, so modificirt werden, daß der Landschafter, um die Vernunft nicht zu beleidigen, nur das darstellen darf, dessen Möglichkeit sich durch Naturformen, also erfahrungsmäßig, darlegen läßt. [...] In dem Landschaftsbilde herrschen dieselben Naturgesetze wie im Cosmos u die Phantasie des Künstlers, in welchem die Allkraft des Lebens, wie im Weltall, von dem er ein Theilchen ist, waltet, gestaltet, ohne der Naturgesetze sich bewusst zu werden, das Kunstwerk eben so gesetzmäßig, wie die Natur ihre Erzeugnisse. $\ll^{115}$

Diese späte Aussage ist gleichsam die Essenz von Quandts Gattungstheorie. Das Zitat relativiert seine frühere Haltung, als er noch schrieb, die künstlerische Vernunft würde nicht von der Natur bestimmt. Die Weiterentwicklung dieses Gedankens scheint in der Rezeption von Carl Gustav Carus' Neun Briefe über Landschaftsmalerei begründet zu sein. In seiner Rezension von 1831 schrieb Quandt: »Diese Uebereinstimmung des Natur- und Gemüthslebens beruht aber auf der Einheit des Menschen mit der Natur [...]. Die Materie muss aber nicht bloß belebt, sondern selbst lebendig, geistig, des Bewusstseyns fähig seyn, wenn wir die Landschaft ein Erdenlebenbild nennen sollen [...]. Nicht bloß die Landschaft, alle Kunst ist, um uns der treffenden Worte des Vfs zu bedienen, mystisch und orphisch. Sie schließt in sich, wie die Natur, ein geheimes Selenleben, welches nur der Geweihte schaut. ${ }^{116}$ Die Anteilnahme an der zeitgenössischen Debatte ermöglichte es ihm offensichtlich, seinem Prinzip der Ausgleichung treu zu bleiben und die Landschaftsmalerei noch stärker als in der menschlichen Vernunft geborene Bildgattung darzulegen.

113 Bätschmann 1989, S. 27-56, hier die Zwischentitel S. 27, 45, 50. Zu den Bildern Friedrichs siehe Rüfenacht 2018, SQ-52, SQ-66, SQ-92.

114 Siehe Kap. Assoziationsreiche Pendants.

115 Brief von Quandt an den Leipziger Verleger Rudolph Weigel vom 26.3.1859, in: SLUB, Mscr. Dresd. App. 204, Nr. $97 y$.

116 Quandt 1831 (4), Sp. 98-100. S. a. Kat. Quandt 1860 (1), S. 192. Zu Carus' Briefen siehe Bätschmann 2002, S. 36-39; Bätschmann 1989, S. 57-61. 


\section{Gute Kunst in anderen Bildgattungen}

Das Prinzip der geistigen Durchdringung zieht sich als roter Faden durch Quandts geschriebenes Werk. Es betrifft letztlich alle Bildgattungen in gleicher Weise. Ganz besonders kommt dies im Jahresbericht des Sächsischen Kunstvereins von 1831 zum Vorschein. Als dessen Vorsitzender hatte er sich mit den unterschiedlichen Problemen, die mit den Gattungen einhergingen, zu beschäftigen: »Wir dürfen es uns aber nicht verbergen, daß nicht blos eine geistig=productive, sondern fast mehr noch eine industriöse Thätigkeit unter den Künstlern erwachte [...]. Die Zahl leicht entworfener Landschaften [hat sich] ungemein vermehrt; denn sehr viele junge Maler eignen sich in diesem Fache rasch die nöthigste Geschicklichkeit an, um ein Bild auf die Leinwand hinzuwerfen, das der Natur ungefähr ähnlich sieht und wohl auch Bewunderer gewisser Art findet, die selbst die Natur nie genau angesehen haben, bedenken aber nicht, daß, was sie liefern, darum, weil es Luft und Erde vorstellt, noch keine Landschaft, viel weniger ein Kunstwerk ist; denn zu ersterer wird Kenntniß der Perspective, so wie eine genaue Beobachtung der charakteristischen Formen der in der Natur vorkommenden Gegenstände erfordert, und um ein Kunstwerk hervorzubringen, bedarf es weit mehr der geistigen Auffassung des innern Lebens der Natur in ihren äußeren Erscheinungen, als technischer Handgriffe. [...] Die Genremaler, anstatt den Begebenheiten des Alltagslebens eine Seite abzugewinnen, welche Blicke in das Innere des Herzens vergönnt, und solche Gegenstände also durch Gefühl und Humor zu heben, zogen höhere aus Poesie und Geschichte entlehnte Aufgaben in einen niedern Kreis dadurch herab, daß sie solche auf eine Weise behandelten, welche jede Spur geistiger Bedeutsamkeit verlöschte, gerade so, als wären es Ereignisse, denen man nur durch eine geschickte technische Behandlung von Nebensachen ein Interesse beilegen könnte. «117 Quandt sprach also vielen Malern von Landschaftsgemälden, besonders aber von Genrebildern eine geistig anspruchsvolle Arbeit ab und unterstellte ihnen geradezu serielle Produktionsweisen, um die Moden der Zeit zu treffen und Bilder zu verkaufen.

Gerade in Bezug auf die Genremalerei dachte Quandt wohl an Vereinsankäufe wie denjenigen einer Margarethe von Johann Friedrich Jakob Rentsch. Es stellte Gretchen am Spinnrad dareine Szene aus Goethes Faust (Abb. 48). In einem Brief an Louise Seidler schrieb der Kunstfreund, das Bild sei auf der Akademieaus-

117 Jahresbericht des Sächsischen Kunstvereins von 1831 bis Ostern 1832, in: HStADD, 12509 Sächsischer Kunstverein, Nr. 2, fol. 231r-231V (S. 3-4). S. a. Kovalevski 2010, S. 12; Schmitz 2001, S. 336-352.

118 Brief von Quandt an Seidler vom 26.11.1829, in: Schmitz/Strobel 2001, S. 175 .

119 »Der Moment des Bildes ist der, als sie singt: Meine Ruh ist hin, mein Herz ist schwer. Zarte u geschmakvolle Ausführung geben diesem

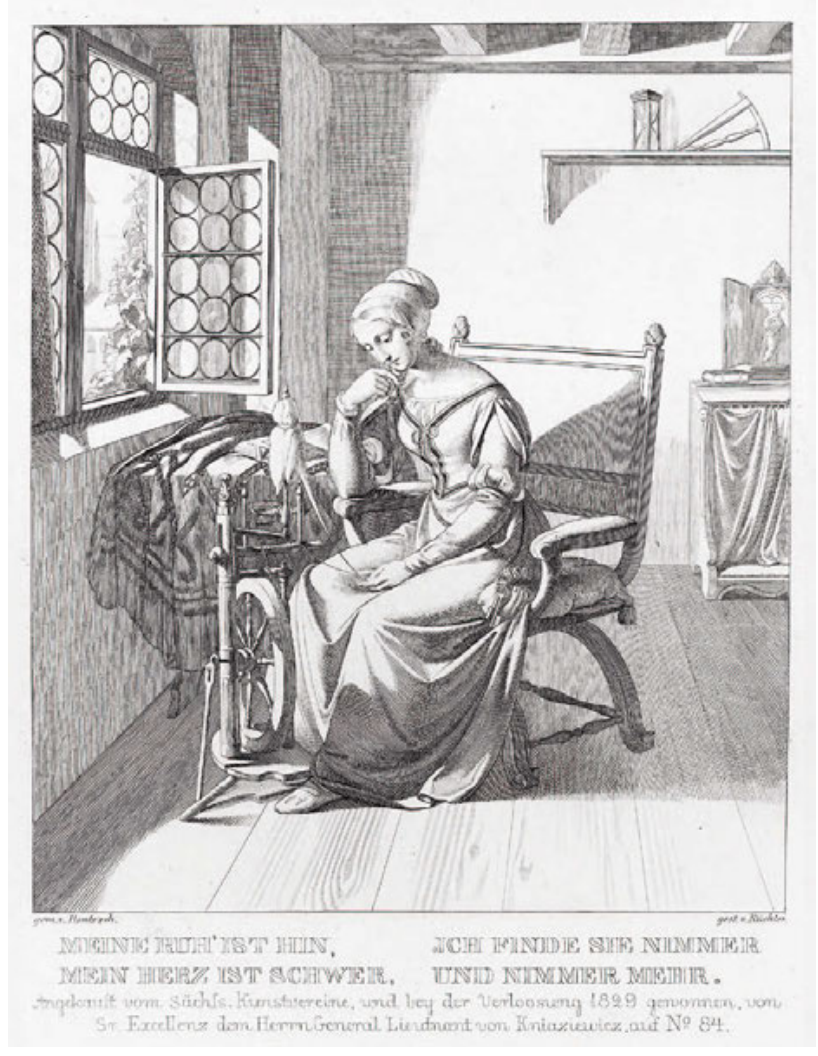

48 Carl Gotthelf Küchler nach Johann Friedrich Jakob Rentsch, Margarethe, 1829, Kupferstich, $206 \times 174$ mm (Bild), Frankfurt a/M, H. W. Fichter Kunsthandel

stellung von zahlreichen Liebhabern betrachtet worden, weswegen es der Kunstverein gekauft habe. Es müsse bei so viel Gefallen ja etwas Anziehendes haben. Quandt selber konnte ihm nicht viel abgewinnen, weil er das Gretchen-Motiv mit anderen Vorstellungen verband. ${ }^{118}$ Sein Missfallen beschrieb er in einem Brief an Goethe. Zwar sei das Gemälde durch eine zarte und geschmackvolle Ausführung wertvoll, nur wollte ihm der Bildtitel »Margarethe« nicht gefallen. Er als Betrachter trage durch die Lektüre des Faust »ein Bild ungeschmückter Natur in sich«, also eine Vorstellung, die nicht bildhaft werden könne. Überhaupt mache sich jeder Leser ein anderes Bild dieser Figur, weswegen solche konkreten literarischen Motive nicht benannt werden dürften. ${ }^{119}$

Es ist bemerkenswert, dass Quandt hier den »historischen« Aspekt des Bildes nicht anerkennt. Dies hängt wohl damit zusammen, dass der Maler gleichsam eine quellennahe Deutung des Gegenstands wählte. Es ist also nicht unbedingt ein Bild,

Gemälde Werth. Ich wollte nur daß der Künstler dies Bild nicht Margarethe genannt hätte, weil es als solche keinem genügt, der ein Bild ungeschmückter Natur in sich trägt. Überhaupt wird jedes einzelne Bild Gretchens, immer Widerspruch finden, denn jeder trägt u hegt wohl ein andres Bild für Gretchen im Herzen und ich möchte wie Mephistopheles sagen: >Denn Jedem kommt sie wie sein Liebchen vorı. Quandt an Goethe, 30.7.1829, in: Schmitz-Strobel 2001, S. 63. 
das zum Nachdenken über allgemeine Begriffe anregt. Vielmehr schränkt die bildgewordene literarische Vorlage die Bildwelt des Faust-Lesers ein. Aus diesem Grund ließ Quandt beim Kupferstich für die Vereinsmitglieder den Beginn der entsprechenden Passage aus dem Faust, »Meine Ruh ist hin,/mein Herz ist schwer,/ich finde sie nimmer/und nimmer mehr«, beifügen, um die Bedeutung der Darstellung zu öffnen. ${ }^{120} \mathrm{Da}-$ mit versuchte er das aufzuwerten, was er selber als Herunterziehen höherer Poesie in niedere Sphären verstand. Durch das Zitat aus dem Faust wurde die simple Genreszene erst wieder als Szene aus dem Faust und nicht als schlichtes Mädchen am Spinnrad charakterisiert. In gewissem Sinn versuchte Quandt durch den Text das Bild zu historisieren, was dem Maler seiner Meinung nach nicht gelungen war. Es zeigt sich hier, dass die Offenheit zur Interpretation durch den Betrachter das ist, was Quandt an Kunst schätzte.

Quandts grundsätzliches Problem mit der Genremalerei lag im Pauschalverdacht, dass sie geistlos die Natur nachahmte, was generell der Haltung seiner gelehrten Zeitgenossen entsprach, wie beispielsweise Aussagen August Wilhelm Schlegels darzulegen vermögen. ${ }^{121}$ Damit widersetzte er sich aktuellen Entwicklungen hin zu einer realistischen Malerei, wie sie sich im Erfolg der sozialkritischen Genremalerei in Düsseldorf nach und nach niederschlug und deren er sich sehr wohl bewusst war. ${ }^{122}$ Er hoffte, dass es sich dabei um eine vorübergehende Mode handeln würde: »Man sollte hoffen, daß durch die unbefangne Nachbildung des Wirklichen, der Sinn für das Schöne, was der Natur tief eingebohren ist, sich rein entwickeln und läutern müße. [...] Sollte dieses sich Hinneigen unsrer Zeit zur Genremalerey, also einem Realismus in der Kunst, nicht eine Durchgangsperiode u Krisis seÿn, aus welcher sie völlig von einem falschen Ideal gereinigt, in neuer Naturschönheit, Wahr-

120 Brief von Quandt an Seidler vom 26.11.1829, in: Schmitz/Strobel 2001, S. 175; Kovalevski 2010, S. 34, Kat. Nr. B-C 10.

121 »Alle Kunst ist ein Streben nach Wahrheit, jedoch beruht die des Genrebildes auf der Uebereinstimmung mit dem Scheine [...]." Quandt 1843 (2), S. 165. Zu Schlegel siehe Gaehtgens 2002, S. 347.

122 Quandt 1844 (3), Sp. 697: »Auch hierin verräth sich die Gesinnung der Düsseldorfer Schule, welche die Stimmung des Gemüths, das Gefühl, über die Idee setzt, obwohl das Gefühl erst durch die bildliche Idee geweckt wird und so gleichsam nur eine Begleiterin jener ist. [...] Anstatt den trefflichen Talenten, welche der Director von Schadow so väterlich sorgfältig und liebevoll gepflegt hat, eine höhere Richtung auf die Idee zu geben, ließ er sich selbst in die Weichheit des Gefühls einwiegen.«S. a. Grewe 2017, S. 17; Gaehtgens 2002, S. 37-40.

123 Brief von Quandt an Ludwig Schorn, 12.11.1835, in: Weimar, GSA 85/24,11. Die Hoffnung währte nicht lange, den 1850 glaubte er festzustellen, dass die historischen Darstellungen eine Tendenz zum genrehaften hätten: »Aber wir sehen dies nicht blos an Goethe's Denkmale, sondern an vielen neuern Kunstwerken, daß unsere Landsleute an Persönlichkeiten, an das, was der Geschichte angehört, erinnert sein wollen, und ihnen eine genremäßige Aehnlichkeit wichtiger ist, als ein Charakterbild.» Quandt 1850 (2), S. 62. heit u Schlichtheit hervorginge u zugleich wieder zur Darstellung des Edelsten, durch wieder erworbene Technik, befähigt würde, denn nur wenn der Künstler kann, was er will, vermag er seine Ideen darzustellen. $\ll^{123}$ Der Nachahmung des Gegenständlichen konnte er also nur abgewinnen, dass sie ein Durchgangsstadium zu höheren Aufgaben sei.

Interessanterweise äußerte sich Quandt auch kaum über Porträts, obschon er selber eine Anzahl Alter und Neuer Meister besaß. Die Porträtkunst war seiner Meinung nach nur »ein Zweig [...] der Kunst und nicht der höchste. $\ll^{124} \mathrm{Ihr}$ Grundproblem entsprach demjenigen der Genremalerei. Die Nachahmung des Äußeren lasse kein speziell interessantes geistiges Vorgehen des Malers erwarten, sondern verlange in erster Linie Geschicklichkeit. Eine der wenigen aussagekräftigen Passagen über Porträts lässt sich einem späten Brief an Arthur Schopenhauer entnehmen und zeigt, dass es ihm auch bei dieser Gattung darum ging, als Betrachter geistig angeregt zu werden: »[...] Die Portraits sollten eigentlich nicht nach der Natur, sondern von genialen Künstlern nach dem Eindruck gemalt werden den eine Person auf sie machte, es sollten Charakterbilder seÿn, die den Menschen auf seinem Culminationspunkte darstellten. Man sagt von gelungenen Bildnissen, daß solche jemand vorstellen `wie er leibt u lebt $<$, ich wollte die Bildnisse stellten mir Freunde mehr dar, wie sie leben, als wie sie leiben. Dies ist eine Anforderung die man nicht an jeden Künstler machen kann, denn wenige haben eine solche Reproductivität u noch weniger die Fähigkeit, das Geistige eines anderen zu verstehn u bildlich zu denken [...]. «125 Demnach sollten Porträtisten nicht nur das Äußere des Menschen, die Physiognomie, darstellen, sondern auch seinen Charakter als vernunftbestimmtes Wesen. In der Fähigkeit, das Innere eines Menschen sichtbar zu machen, lag für Quandt das Potential der Porträtkunst, eine bedeutsame Bild-

124 Quandt 1846 (2), S. 322. Zu den Porträts in Quandts Sammlung siehe Rüfenacht 2018, SQ-1 (Rauch), SQ-31 (Umkreis Bruyn), SQ-32 (Scorel), SQ-33 (Venezianisch), SQ-38 (Amberger), SQ-88 (Schnorr), SQ-120, SQ-121 (Graff), SQ-122 (Matthäi).

125 »Mein theurer, alter Freund. So eben habe ich Ihr Bildnis erhalten u streite mich mit dem mir unbekannten Künstler, der Sie nicht so aufgefaßt hat, wie ich mir Sie denke, aber freilich ist sehn u jemand denken, etwas ganz anderes. Das bildliche Denken idealisirt, alles Zufällige bleibt weg u die Zeit hat keinen Einfluß auf das Bild des Freundes in unserer Erinnerung. Die Portraits sollten eigentlich nicht nach der Natur, sondern von genialen Künstlern nach dem Eindruck gemalt werden den eine Person auf sie machte, es sollten Charakterbilder seÿn, die den Menschen auf seinem Culminationspunkte darstellten. Man sagt von gelungenen Bildnissen, daß solche jemand vorstellen swie er leibt u lebtr, ich wollte die Bildnisse stellten mir Freunde mehr dar, wie sie leben, als wie sie leiben. Dies ist eine Anforderung die man nicht an jeden Künstler machen kann, denn wenige haben eine solche Reproductivität u noch weniger die Fähigkeit, das Geistige eines anderen zu verstehn u bildlich zu denken. Jedes Bild ist ein Begriff u darum auch ein Urtheil u wie oft sind die Urtheile über Charaktere, unrichtig! - So scheint mir Lunteschütz hinsichtlich Ihrer Augen fehl- 
gattung zu sein. Auch wenn diese in seinem Kunstverständnis nur eine untergeordnete Rolle spielte, zeigt sich in den Äußerungen zum Porträt doch eine interessante Überführung seiner wiederholten Forderung nach dem Geistigen in der Kunst.

In seiner eigenen Sammlung befand sich ein Bildnis, das seine Erwartungen erfüllte. Es handelte sich um eine Goethe-Büste von Christian Daniel Rauch. Gerade weil Quandt Goethe kannte, suchte er nach einem Abbild, das seiner Vorstellung entsprach (vgl. Abb. 102). In seinen Vorträgen über Ästhetik für bildende Künstler an der Kunstakademie zeigte er die Büste zusammen mit einem Gipsabguss von Goethes Gesicht. Mit Abguss und Büste erklärte er den Unterschied zwischen Naturnachahmung durch Kopien oder Abgüsse und wahrer Kunst. Während der Gesichtsabguss das Vergängliche und Augenblickliche von Goethe zeige, stelle der Bildhauer »den Ausdruck seines Geistes, seines Wesens, die Idee von ihm, das Ewige in ihm « dar. Quandt konstatierte daher in Bezug auf die Büste: $\gg$ Dies ist der wahre Göthe! «26 Wo Porträtkunst also den Charakter des Dargestellten zum Ausdruck brachte, war sie ihm durchaus förderungswürdig.

Stillleben bekämpfte Quandt in seiner Zeit als Vorstand des Sächsischen Kunstvereins vehement, wo sie statuarisch anfänglich ausgeschlossen waren. Gelegentliche Ankäufe hatten schließlich sogar zu seinem Austritt als Vereinsmitglied geführt. ${ }^{127}$

geschossen zu haben, denn es liegt in dem Blick nicht das forschende des Philosophen, sondern das Mistraun eines Beobachters, weshalb ich jedoch den Künstler völlig entschuldige, weil kein Mensch unbefangen ist, der sich portraitiren läßt, wozu noch kommt, daß bei den meisten Bildnissen das Gesicht etwas seitwärts gewandt wird u die Augen gerade auf den Maler gerichtet sind, weil das Bild den Beschauer ansehn soll, woraus ein lauernder Ausdruck entsteht. Daher haben die Profile u die en face Ansichten große Vorzüge, denn bei diesen findet der wenigste Zwang statt. Die 3/4 Wendung ist herkömmlich u bietet dem Künstler auch große Vortheile dar, aber dann sollten die Augen auch gerader in derselben Richtung wie das Gesicht u nicht nach dem Beschauer blicken, was wieder eine Observanz ist, welche füglich unterlassen werden könnte, da doch der Ausdruck bei historischen Bildern nichts verliert, unerachtet die handelnden Personen den Zuschauer nicht ansehn. Die volle Wirkung des Blicks zu malen, übersteigt freilich das Vermögen der Kunst, denn es fehlt den gemalten Augen die Magie. Was die Kunst vermag, hat Lunteschütz geleistet, er zeigt uns den weitgewölbten gedankenvollen Schädel u wer die Hieroglyphen der Physiognomik versteht, kann in der Zeichnung vieles lesen. Meine Frau welche freundlich grüßt, sagt, daß sie Ihr Bild ohne Namensunterschrift nicht erkannt hätte, denn Sie stehn 38 Jahre jünger in ihrer Erinnerung. Ich sah Sie, als ich aus Spanien kam u finde nicht daß Sie um zehn Jahre älter aussehn. Was dem Bilde einen Schein von zeitigem Alter giebt, ist die Gewohnheit der etwas gesenkten Haltung des Kopfs, welche Sie mit allen Denkern gemein haben u ich bin gewiß, daß selbst Göthe, der um die impertinente Welt zurückzuweisen, sich sehr à plomb hielt, dennoch, wenn er in seinem Zimmer oder Garten einsam u sinnend auf u abging, das Haupt senkte. Anstatt Ihnen viel von mir zu schreiben, übersende ich mein Bildniß, es mag Ihnen das Übrige sagen.« Brief von Quandt an Schopenhauer vom 8.4.1857, Frankfurt a/M, Universitätsbibliothek J. C. Senckenberg, Nachlass Arthur Schopenhauer, Na 50, Sign. 195 [Internetressource: Jochen Stollberg, Die Schopenhauers und Johann
Diese Gattung lag im besonderen Verdacht der geistlosen Naturnachahmung. Die Plinius-Anekdote des Wettstreits zwischen Zeuxis, dessen gemalte Trauben die Vögel herbeilockten, und Parrhasios, dessen Vorhang gar den Maler täuschte, galt Quandt als ein Beispiel für Kunst ohne Wahrheit: »[...] der, welcher die menschlichen Sinne zu betrügen vermöchte, [sei] ein größerer Künstler, ist von keiner ästhetischen Bedeutung. Es könnte blos daraus folgen daß der eine ein geschickterer Techniker, aber kein größrer Künstler war. « ${ }^{128}$ Dementsprechend waren Stillleben in seiner Sammlung nicht präsent. ${ }^{129}$ Doch selbst dieser niederen Gattung attestierte Quandt grundsätzlich die Möglichkeit, geistigen Gehalt zu haben und dadurch gute Kunst zu sein, solange sie beim Betrachter eine geistige Wirkung hervorrufe. ${ }^{30}$

Wo ihm Kunst wahr erschien und den Betrachter zu Gedanken anregte, spielten Gattungen bei Quandt theoretisch keine Rolle. Für den Kunstfreund war es entscheidend, seine Erwartungen erfüllt zu sehen. Ob dies nun das Werk eines Alten oder Neuen Meisters war oder dieser oder jener Bildgattung entsprach, war dabei weniger wichtig. Quandts Förderung der Künste manifestierte sich in verschiedensten Bereichen. Als Käufer, Mäzen, Vereinsmitglied, Kunstkenner und Kunstschriftsteller hat er sich dadurch einen in seiner Zeit weithin bekannten Namen in der Kunstszene gemacht.

Gottlob von Quandt, http://apps.webable.de/cms/fileadmin/doc/ Quandt_Schopenhauer.pdf, letzter Zugriff: 17.9.2018].

126 Quandt 1844 (1), S. 34-35: »Der Unterschied des Stoffs, daß die eine Büste von Gyps, die andere von Marmor ist, kann keine so höchst verschiedene Wirkung verursachen, als beide auf den Beschauer hervorbringen. Es liegt dieser Unterschied darin, daß die eine uns aufs Genaueste das Zeitliche, Vergängliche, darum nur Scheinbare, Unwesentliche, nur augenblicklich und materiell Wirkliche angiebt, die andere Büste aber uns den wahren Göthe, den Ausdruck seines Geistes, seines Wesens, die Idee von ihm, das Ewige in ihm darstellt. Wenn ein Beschauer nicht wüßte, daß beide Büsten Göthe darstellten, und man fragte ihn, welcher von beiden ist Göthe? so würde gewiß die Entscheidung auf die Marmorbüste fallen, und jeder wird sagen: dies ist der wahre Göthe! « S. a. Quandt 1850 (2), S. 61-63; Rüfenacht 2018, SQ-1.

127 Erst ab 1829 konnte der Verein Stillleben ankaufen: Statuten von 1829, in: HStADD, 12509 Sächsischer Kunstverein, Nr. 1, vor fol. 230r. Brief von Quandt an das Komitee des Sächsischen Kunstvereins, in: Schmitz/Strobel 2001, S. 229.

128 Quandt 1830 (1), S. 290. Die Anekdote in Plinius Secundus, Naturalis Historiae, Liber XXXV, Cap. XXXVI, 65.

129 Ein einziges Stück verzeichnet in Kat. Quandt 1868, Nr. 52, S. 16. Zwei Gouachen in Kat. Quandt 1824, S. 9. Siehe Rüfenacht 2018, SQ-54, SQ-127, SQ-128. S. a. Briel 1987 (1), S. 18; Maaz 1986, S. 18.

130 Quandt 1819, Bd. 1, S. 68-69: »Der Blumenmahler kann sagen: Auch ich bin ein Künstler, da uns durch jeden dieser Gegenstände ein vollständiger Begriff gegeben, indem jedes Wahrnehmbare Symbol von etwas Geistigem ist; jeder sinnliche Eindruck eine geistige Wirkung hervorbringt [...].« Quandt schränkte im Nachsatz aber sogleich wieder ein, »daß wir den Künstler und sein Werk, der uns erhabnere Anschauungen gibt, höher würdigen als einen andern, der gemeinere uns darbiethet, daß also Rafael höher steht, als etwa Huysum, so vortrefflich auch dieser in seiner Art ist [...].« 
